\title{
A study of the relationship between the leadership styles of principals in smaller learning communities, the number of structures and strategic configurations and the rates of student success of 9 th graders
}

Sara Jane Lewis-Stankus

West Virginia University

Follow this and additional works at: https://researchrepository.wvu.edu/etd

\section{Recommended Citation}

Lewis-Stankus, Sara Jane, "A study of the relationship between the leadership styles of principals in smaller learning communities, the number of structures and strategic configurations and the rates of student success of 9th graders" (2007). Graduate Theses, Dissertations, and Problem Reports. 4315. https://researchrepository.wvu.edu/etd/4315

This Dissertation is protected by copyright and/or related rights. It has been brought to you by the The Research Repository @ WVU with permission from the rights-holder(s). You are free to use this Dissertation in any way that is permitted by the copyright and related rights legislation that applies to your use. For other uses you must obtain permission from the rights-holder(s) directly, unless additional rights are indicated by a Creative Commons license in the record and/ or on the work itself. This Dissertation has been accepted for inclusion in WVU Graduate Theses, Dissertations, and Problem Reports collection by an authorized administrator of The Research Repository @ WVU. For more information, please contact researchrepository@mail.wvu.edu. 
A Study of the Relationship between the Leadership Styles of Principals in Smaller Learning Communities, the Number of Structures and Strategic Configurations and the Rates of Student Success of $9^{\text {th }}$ Graders

Sara Jane Lewis-Stankus

\author{
Dissertation submitted to the \\ College of Human Resources and Education \\ at West Virginia University \\ in partial fulfillment of the requirements \\ for the degree of
}

Doctor of Education

in

Educational Leadership Studies

\author{
Richard Hartnett, Ed.D., Chair \\ Mildred Beer, Ed.D. \\ Paul Chapman, Ph.D. \\ Ernest Goeres, Ph.D. \\ Robert Rubenstein, Ed.D. \\ Department of Advanced Educational Studies \\ Morgantown, West Virginia \\ 2007
}

Keywords: Principals, Leadership Styles, Ninth Grade, Student Achievement, Smaller Learning Communities, School Size, High School Reform.

Copyright 2007 Sara Jane Lewis-Stankus 


\begin{abstract}
A Study of the Relationship between the Leadership Styles of Principals in Smaller Learning Communities, the Number of Structures and Strategic Configurations and the Rates of Student Success of 9th Graders
\end{abstract}

Sara Jane Lewis-Stankus

This study examines the relationship between the leadership styles of principals in smaller learning communities and rates of ninth grade students' success. To examine this relationship, the Leadership Behavior Description Questionnaire was used to collect data from ninth grade teachers regarding the principal's leadership style. This survey was used along with a demographic questionnaire given to the principals that collected information regarding the age, gender, number of years experience, highest degree earned, certification, and ninth grade student achievement data. These surveys were sent to 302 public high schools that qualified for a Smaller Learning Communities (SLC) Grant in 2003. The schools include Cohort A (204 schools) and Cohort B (98 schools). The principals delivered the surveys to their ninth grade teachers, and the teachers completed them and returned them in a self-addressed stamped envelope. Responses were received from 456 teachers and 124 high school administrators. Descriptive statistics, Chi-square test, ANOVA, MANOVA, including normality, homogeneity of variance/covariance were assessed. Pearson's correlation coefficients and cross-tabulations were used to examine patterns in the data.

Major research findings indicate a large percentage (48.5 percent) of principals did not use a particular style of leadership, and their leadership did not significantly impact student achievement. With respect to leadership styles, it was found that principals from high schools in Smaller Learning Communities (Cohort 3), used a multiframe approach (31.1 percent), followed by the single-frame (11.1 percent), and finally the paired-frame (9 percent) approaches. Another significant finding was that learning achievement in algebra of students from smaller schools was significantly higher than that of students from larger schools.

Recommendations from this study include implementation of professional development activities for principals from large high schools that includes an increased awareness of their personal leadership orientation, as well as development of multi-frame leadership practices in order to improve their leadership effectiveness. 


\section{DEDICATION}

I dedicate this effort to my family, the source of my inspiration, strength, and perseverance - to Hannah, Leah, Isaac, and Steve; also to my sister Barb, who encouraged my love of learning. Thanks be unto to God for the encouragement of Psalm 32:8 ("I will instruct thee and teach thee in the way which thou shalt go; I will guide thee with mine eye. KJV) 


\section{ACKNOWLEDGEMENTS}

Completion of this doctoral program would not have been possible without the support, understanding, and encouragement of many persons. I would first like to thank my committee chair, Dr. Richard Hartnett for adopting me into "the family" and provoking thought throughout this research project. Without his patience, guidance and continued counsel, I would not have been successful at completing this most challenging task. My sincerest appreciation is extended to the members of my doctoral committee: Mildred Beer, Ed.D; Paul Chapman, Ph.D.; Ernest Goeres, Ph.D.; and Robert Rubenstein, Ed.D, who have provided thoughtful and constructive feedback while providing the guidance and support I needed, at times when I needed it the most. Dr. Hartnett, Dr. Beer, Dr. Goeres, Dr. Chapman, and Dr. Rubenstein, I now have a greater appreciation when I call you "Doctor," you have been true mentors and advisors during this entire process.

Many people have made this possible, my colleagues, Teresa Knight and Eddie Vincent for cheering and supporting me even in my absence and to Robin Lewis for helping me set deadlines. Thanks to my mom for your unconditional love and spiritual guidance. I extend my utmost gratitude to Tongshan Chang, my virtual advisor, without your statistical wisdom, and your knowledge of research methodology, this would have never been possible. Thank you for your patience and persistence. Only God and Dr. Hartnett could have found Dr. Chang and sent him my way!

Finally, I would like to thank my family, especially my husband Steve, who has been there by my side throughout this long journey, and has never complained about the long hours of study and writing, or the financial burden during the past few years. 


\section{TABLE OF CONTENTS}

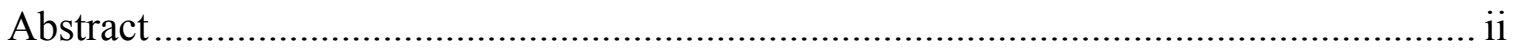

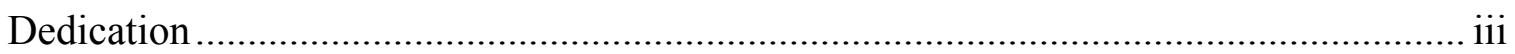

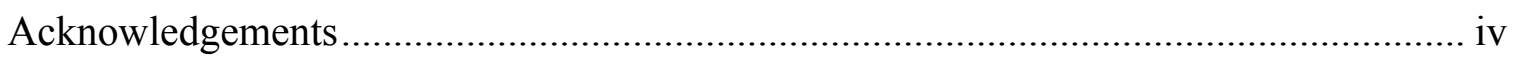

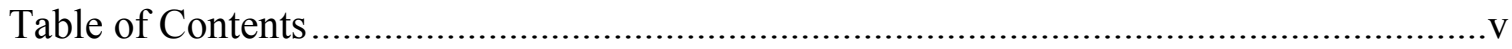

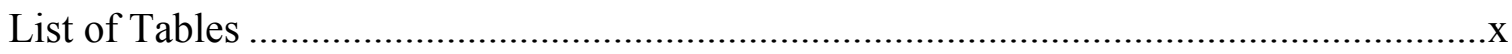

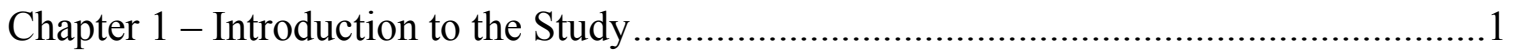

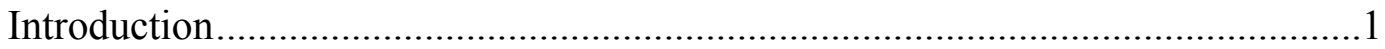

Statement of the Problem and Research Questions ...........................................5

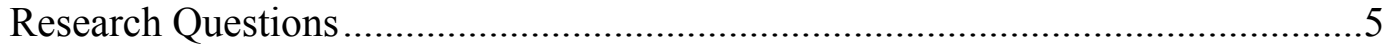

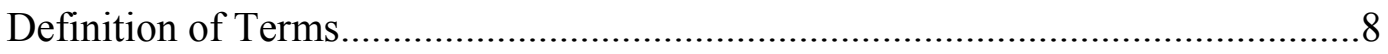

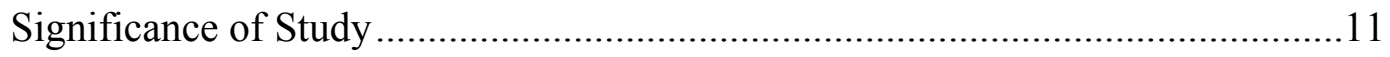

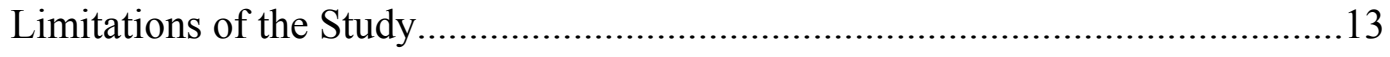

Summary of the Chapter ......................................................................... 13

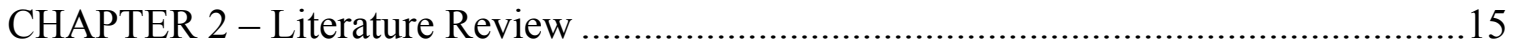

Bolman and Deal's Four-Frame Model ....................................................... 15

Research Using Bolman and Deal's Four-Frame Model.................................23

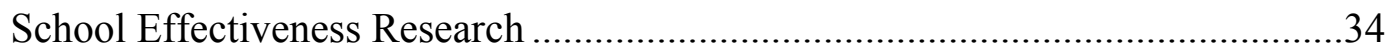

The Principal as the Instructional Leader ....................................................44

Research Relating to Smaller Learning Communities......................................50

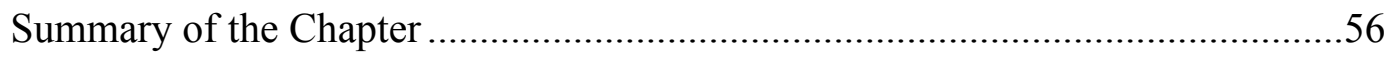

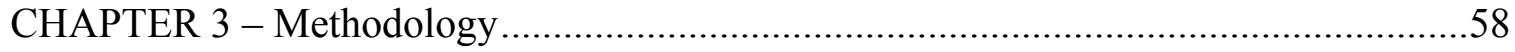




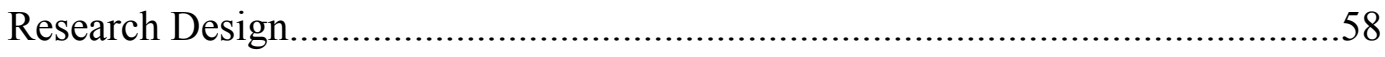

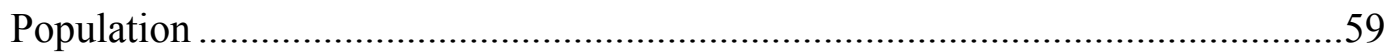

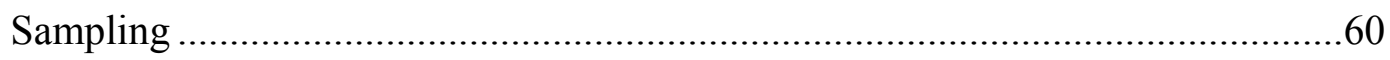

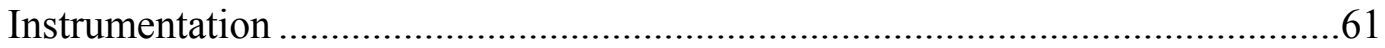

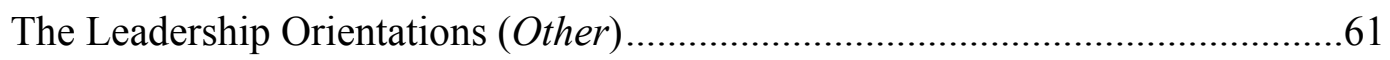

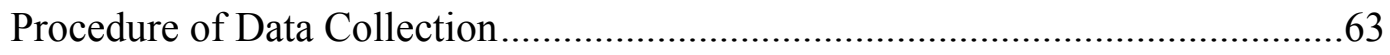

Data Analysis ..............................................................................................64

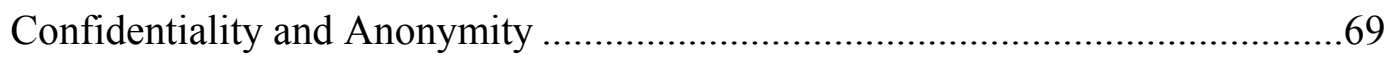

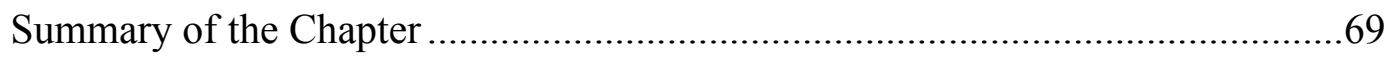

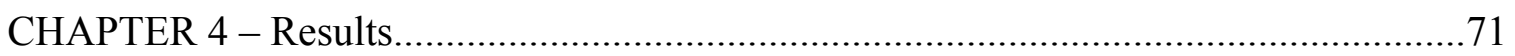

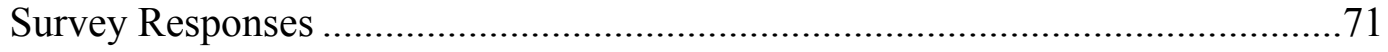

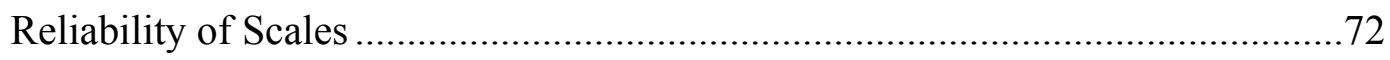

Leadership Orientation (Others) ………………….........................................73

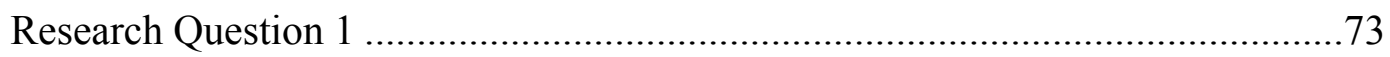

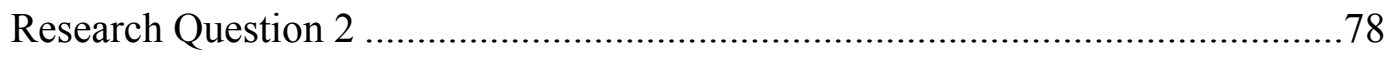

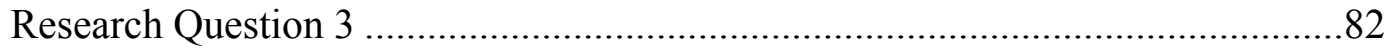

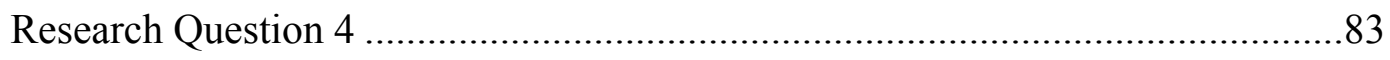

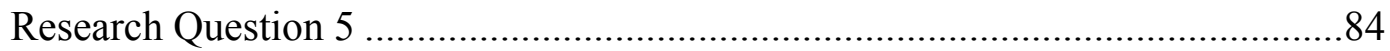

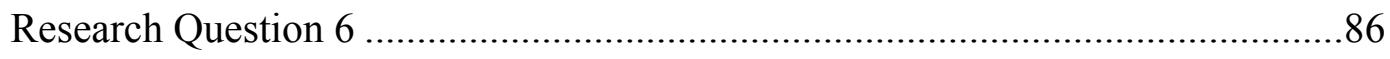

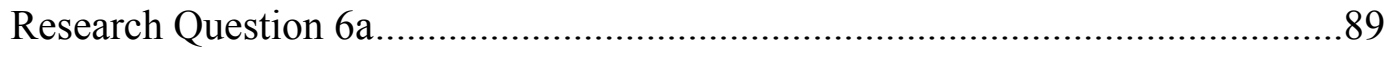

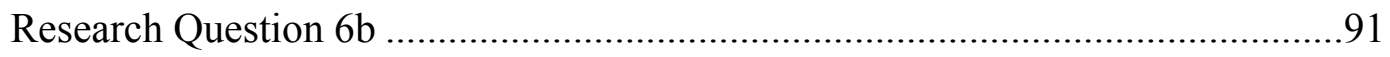

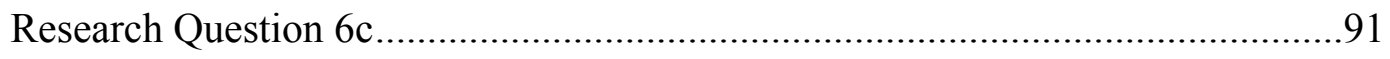

Research Question 6d ................................................................................92 


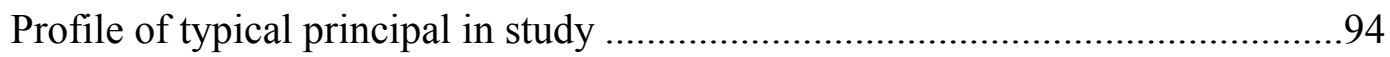

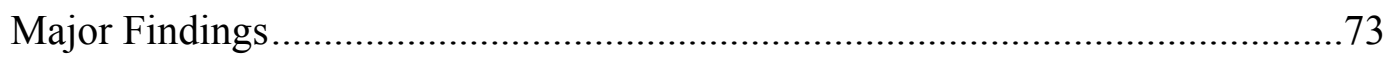

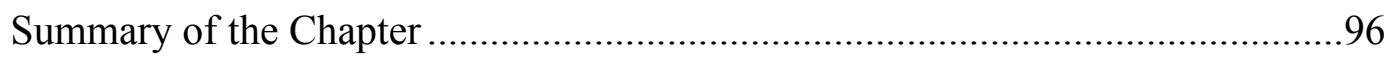

CHAPTER 5 - Conclusions and Recommendations ..................................................98

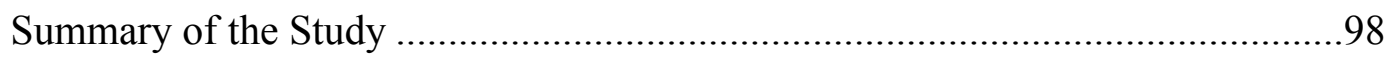

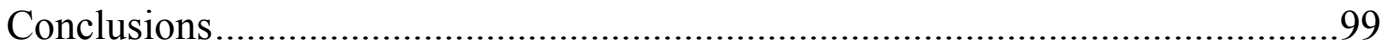

General Pattern of Principals’ Leadership Styles .............................................99

Demographic Effect on Leadership Styles ..................................................103

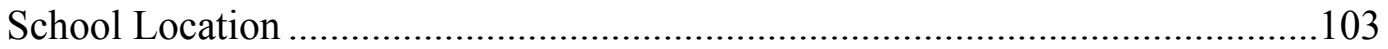

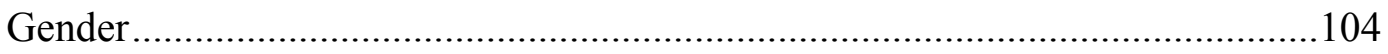

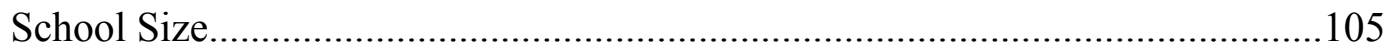

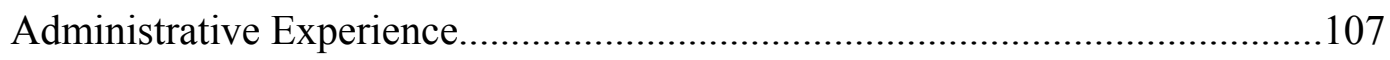

Relationship of Individual Leadership Frames and Student Academic

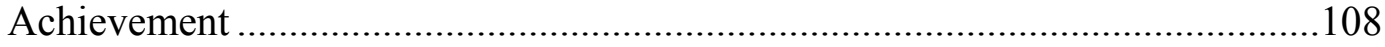

Relationship of Individual Leadership Frames \& Use of

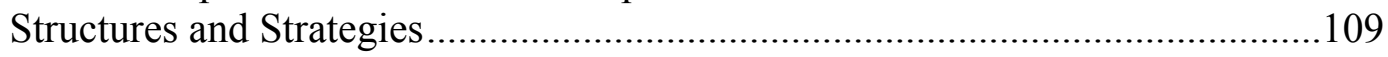

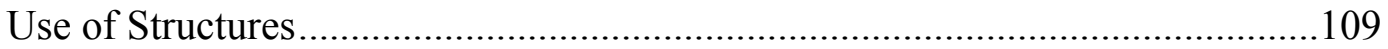

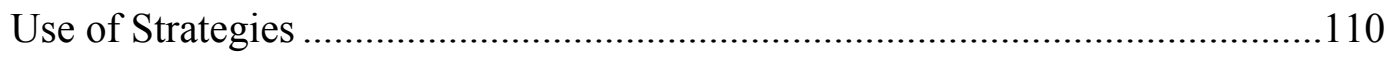

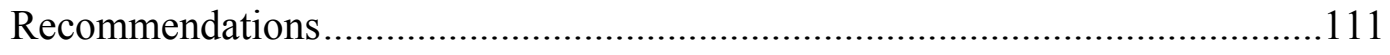

Recommendations for Practice ................................................................ 111

Recommendations for Further Studies................................................. 114

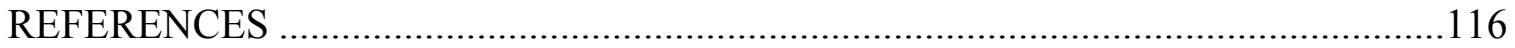


A. The Survey Instrument

B. Permission to Use Survey Instrument

C. The Principal Survey.

D. Cover Letter to Principals, First Mailing

E. Cover Letter to Principals, Second Mailing.

F. Cover Letter to Principals, Third Mailing

G. Cover Letter to Ninth Grade Teachers.

H. Approval by the West Virginia University Institutional Review Board Documentation

Certificate of Human Participant Protections Training

I. Cohort 2003 A - 204 Schools

J. Cohort 2003 B - 98 Schools

K. Cohort 2003 A/B Database (School Name, Principal, Address, Phone Number and E-mail Address)

L. Smaller Learning Communities Structures and Strategies Defined

M. Smaller Learning Communities Structures- 89 used in Cohort $2003 \mathrm{~A} / \mathrm{B}$ with frequencies

Cohort A Structures

Cohort B Structures.

N. Smaller Learning Communities Strategies- 36 used by Cohort $2003 \mathrm{~A} / \mathrm{B}$ with frequencies

Cohort A Strategies 186

Cohort B Strategies 
O. Smaller Learning Communities Districts and Schools by Locale

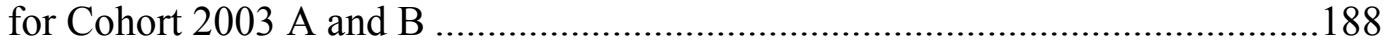

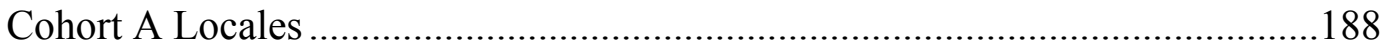

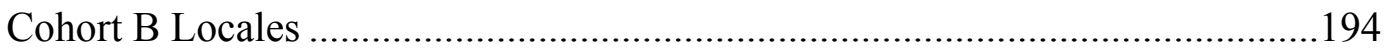

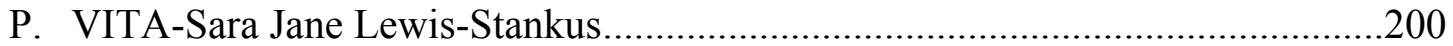




\section{TABLES}

Table1 Characteristics of the Bolman and Deal Four Frame Model

Table 2 The Structure of the Bolman \& Deal Leadership

Orientations (Other) Surveys

Table 3 Means and Standard Deviations of Principals' Four Leadership Frames by

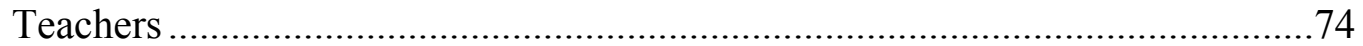

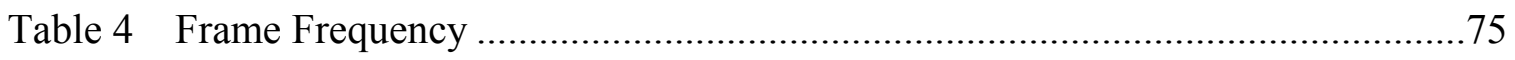

Table 5 Frequency Distribution by Frame Pattern...................................................... 77

Table 6 Frequency Distribution of Principals' Leadership Style by Locale ..................79

Table 7 Frequency Distribution of Principals' Leadership Style by Gender .................79

Table 8 Frequency Distribution of Principals' Leadership Style by School Size ...........81

Table 9 Frequency Distribution of Principals' Leadership Style by

Principals' Number of Years of Experience at Administration Position

Table 10 Pearson Correlation Matrix of Leadership Frames and Achievement Level

Table 11 Pearson Correlation Matrix of Leadership Style and

Achievement Level

Table 12 Means and Standard Deviations of Achievement Level by

Principal's Leadership Style.

Table 13 Frequency Distribution of Structures Implemented by

Schools by Principals' Leadership Style.

Table 14 Means and Standard Deviations of Structures Implemented by the

SLC School by Principal's Leadership Style.....

Table 15 Pearson Correlation Matrix of Leadership Frame and

Number of Structures Implemented by Schools

Table 16 Frequency Distribution of Strategies Implemented by

Schools by Principals' Leadership Style.

Table 17 Means and Standard Deviations of Strategies Implemented

by the SLC School by Principals' Leadership Style .90 
Table 18 Pearson Correlation Matrix of Leadership Frame and Number of Strategies Implemented by Schools.............................................................90

Table 19 Means and Standard Deviations of Achievement Level by School Location Category ............................................................................91

Table 20 Means and Standard Deviations of Achievement Level by School Size.

Table 21 Means and Standard Deviations of Achievement Level by Principals'

Years of Experience in Administration.

Table 22 Profile of the Typical High School Principal with a Smaller Learning Community .95 


\section{Chapter 1}

\section{Introduction}

External pressures and internal dissatisfaction from policymakers, practitioners, and parents are challenging high schools to meet the demands of the $21^{\text {st }}$ century and the next generation of high school students. Although the focus on high school reform cannot be attributed to any single factor or event, the tragic events that occurred at the Columbine High School advanced the reform movement throughout the nation, including the United States Department of Education's (USDE) agenda. Just as Columbine was the product of a fragmented school culture-filled with cliques and discord—large high schools of the $21^{\text {st }}$ century must evaluate the evidence and respond with much-needed reforms. High schools and school districts have begun to investigate the most effective high school practices. According to Assistant Secretary for Vocational and Adult Education Patricia McNeil, initial efforts focused on violence prevention along with an increase in the number of metal detectors and police resources (McNeil, 2000). However, after listening to the opinions of students, McNeil concluded that students need reforms focused on promoting support and establishing closer relationships with caring adults, which would result in a change in the school culture to provide a more positive environment for both students and adults (McNeil, 2000). The creation of a school culture that reflects mutual respect among administration, teachers, and students was the vanguard of the initial high school reform. High school would never be the same.

In addition, the issue of school size has been at the center of controversy for the past 40 years and continues to provoke debate today. School leaders are under pressure to meet the mandates of the No Child Left Behind Act of 2001. The role of principal has changed dramatically due to constant scrutiny of strong graduation rates, high academic achievement, and 
safety in schools. Many policymakers have concluded that large, consolidated high schools are not conducive to fostering a stronger sense of community. Research has consistently supported small schools, citing their countless benefits, such as increased academic achievement, improved attendance, and decreased discipline referrals (Cotton, 2001; Klonsky, 1998; Lee \& Smith, 1997). According to this research, smaller schools have direct implications for school cohesiveness and academic achievement (Cotton, 2001).

Today's research clearly points toward a distinct relationship between school size, attendance, student discipline, and student achievement (Cotton, 2001; Howley, 1994, Klonsky, 1995). Williams (1990) suggests that the optimal size for a secondary school is in the range of 400 to 800 students. Yet approximately fifty percent of American high schools enroll one thousand or more students (Cotton, 2001; Gladden, 1998), and some students attend schools enrolling as many as four to five thousand students.

School districts have examined the possibility of restructuring the traditional high school into Smaller Learning Communities. This is a multi-phased reform model that specifically targets high school organization and curriculum changes. One of the primary target populations is the ninth grade because that particular year can be one of the most emotionally, socially, and academically challenging times in the lives of children. An array of changes and challenges take place during the critical ninth grade transitional year. Research supports the theory that the ninth grade is the most critical point to intervene to prevent students from losing motivation and dropping out (Cotton, 2001). Smaller Learning Communities (SLC), such as schools within schools and ninth grade academies has assisted in crafting a smooth transition to high school and providing students with the attention they need during this critical time (Oxley, 2004). 
The No Child Left Behind Act of 2001 promoted the important purpose of Smaller Learning Communities even further. The law provided a defined structure to the discretionary grant status of the Smaller Learning Communities' grant competition and ensured that Smaller Learning Communities will continue to assist large public high schools, which are defined as schools that include grades 11 and 12 and enroll at least 1,000 students in grade 9 and above. Eligible strategies may include creating schools within schools or career academies, restructuring the school day, instituting personal adult advocates, developing teacher advisory systems, and implementing other innovations designed to create a more personalized high school experience for students thereby improving student achievement and performance (USDE, 2006).

Research suggests that smaller learning environments are a prime condition for boosting student achievement (Williams, 1990), attendance rates, school loyalty, and satisfaction with school and self-esteem. Furthermore, they also decrease the frequency of disciplinary actions and the use of drugs and alcohol (Raywid, 1995; Klonsky, 1995). This is especially true in at-risk populations, such as minorities and economically disadvantaged children (Cotton, 1996). Children and parents agree that smaller schools are safer and more helpful; in the interim, teachers feel that they have more opportunity to get to know and support their students (Fowler \& Walberg, 1991; Gregory, 1992; Stockard \& Mayberry, 1992).

Although the research on school size has been for the most part non-experimental, an increasing body of evidence suggests smaller schools may have advantages over larger schools (Fowler, 1992; Klonsky, 1995; Raywid, 1996). Increased student achievement is more likely when the school size is decreased as well as accompanied by other changes. Variables such as strong leadership, supportive adult relationships, freshmen transition programs, and the use of a number of strategies and structures within the large school to encourage school attachment can 
ensure improvement in student success. In addition, research conducted in the past fifteen years suggests that the positive outcomes linked with smaller schools stem from the schools' ability to build close, personal environments where teachers can work collaboratively, with a small set of students, to challenge students and support learning (Fowler \& Walberg, 1991; Gregory, 1992; Stockard \& Mayberry, 1992).

A range of structures and operational strategies designed to create a more personalized high school experience for students are thought to provide essential supports for smaller learning environments; some data suggest that these approaches offer considerable advantages to both teachers and students (Ziegler, 1993; Caroll, 1994). Structural changes for reorganizing large schools as a set of Smaller Learning Communities may include methods and strategies, such as establishing small learning clusters, houses, career academies, magnet programs, and schools within a school. Other activities may include freshmen transition activities, advisory and adult advocate systems, academic teaming, multi-year groupings, and extra help or accelerated learning options for students. In addition, groups of students entering below grade level may be grouped together as a method of providing intervention services. Such structural changes and personalization strategies, by themselves, are not likely to improve student academic achievement; interventions such as common planning, common students for teachers, and individualized academic and social support systems increase the likelihood of student success (USDE, 2006).

Smaller Learning Communities encourage school districts to set higher academic expectations for all students and to use these strategies to provide students with the valuable instruction and personalized academic and social support they need to meet those expectations. The leadership skills and abilities of principals are critical in ensuring the excellence of the 
Smaller Learning Communities program and the success of ninth grade students. The nature of this role requires twenty-first-century principals to employ a broad range of leadership approaches (Bensimon, 1989, 1990; Bolman \& Deal, 1991, 1992). Bolman and Deal term this type of leader as multi-framed. Studies show that effective leaders and effective organizations rely on using multiple frames (structural, human resource, political and symbolic) in order to gain different perspectives (Bolman \& Deal, 1991, 1992).

The current study will investigate the relationship between structural variables and student success. In addition, it will explore the relationship of the leadership styles and the success of ninth grade students.

\section{Statement of the Problem}

This study examines the relationship between the leadership styles of principals in Smaller Learning Communities, the number and types of structures and strategic configurations in high schools with Smaller Learning Communities, and the rates of student success of ninth graders. The major hypothesis examines whether there is a statistically significant relationship between the leadership style of principals in Smaller Learning Communities, the number and types of structures and strategic configurations, and the rate of student success of ninth grade students. The leadership styles are classified on the foundation of Bolman and Deal's (1984, 1990) cognitive frames (structural, human resource, political, and symbolic) to understand organizational behaviors and governance patterns.

\section{Research Questions}

This research investigates the leadership style of principals in Smaller Learning Communities, the numbers and types of structures and strategic configurations, and the rates of student success of ninth grade students in the respective schools. Student success is defined by 
the number of discipline referrals, academic success in core subject areas, and attendance rates. The study invited principals and faculty from schools that receive federal funding to participate in the survey. The study seeks to answer the following six research questions.

Question 1. What are the leadership styles (as measured by the four frames) of the principals in schools with Smaller Learning Communities?

Question 2. Are there differences in leadership styles (none, single, paired, and multiple) of principals by the demographic variables (locale (rural/urban), gender (male/female), size of the school (small/medium/large), and the principals' number of years of experience (emergent $=0-5$ years/mid-career $=6-10$ years/established $=$ more than 11 years

Question 3. Is there a significant relationship between the leadership (frame/s) of the principals (structural, human resource, political, and symbolic) with the level of discipline referral rates (number of referrals/number of students), levels of student achievement (grade point average of at least 2.0/passing level) in four subject areas (regular ninth grade English, regular algebra, regular ninth grade social studies, and regular ninth grade science) and attendance rates (attendance/number of students)?

Question 4. Is there a statistically significant relationship between the leadership style of the principals (none, single, paired, and multiple) with the level of discipline referral rates (number of referrals/number of students), levels of student achievement (grade point average of at least 2.0/passing level) in four subject areas (regular ninth grade English, regular algebra, regular ninth grade social studies, and regular ninth grade science) and attendance rates (attendance/number of students)?

Question 5. What are the differences between the various patterns of leadership styles (none, single, paired, and multiple) of principals in Smaller Learning Communities and the 
frequency of the six structures implemented by the school with Smaller Learning Communities — namely career academy/academies, house plans, freshman academies, themebased academies, and school within- a- school)?

Question 6. What are the differences between the various pattern of leadership styles (none, single, paired, and multiple) of principals in Smaller Learning Communities and the use of the six strategies implemented by Smaller Learning Communities schools—namely academic teaming, alternative scheduling, freshmen transition activities, teacher advisory systems, adult advocate systems, and individual/personalized academic plans—as measured by means and standard deviation on the six strategies (listed above) by each frame pattern (none, single, paired, and multiple)?

Research question $6 a$. What are the differences in the levels of student achievement (grade point average of at least /passing level) in the four subject areas (regular ninth grade English, regular algebra, regular ninth grade social studies, and regular ninth grade science) by locale (urban/rural)?

Research question $6 b$. What are the differences in the levels of student achievement (grade point average of at least /passing level) in the four subject areas (regular ninth grade English, regular algebra, regular ninth grade social studies, and regular ninth grade science) by school size (small, medium, and large)?

Research question $6 c$. What are the differences in the levels of student achievement (grade point average of at least /passing level) in the four subject areas (regular ninth grade English, regular algebra, regular ninth grade social studies, and regular ninth grade science) by the principals number of years of experience in administration (emergent $=0-5$ years, midcareer $=6-10$ years, established $=$ more than 11 years $)$. 


\section{Definition of Terms}

The terms mentioned here in brief will be discussed in greater detail in Chapter Two. Four Leadership Frames. According to Bolman and Deal (1984, 1990), leadership behavior can be characterized according to four perspectives or frames: structural, human resource, political and symbolic. These frames, mentioned here in brief, will be further discussed in Chapter 2.

The Structural Frame. Leaders who follow the structural frame emphasize rationality, goals, and efficiency, and have power to execute their decisions. The structural leader clearly defines the goals in order to be effective and is more likely to conduct activities by following the predetermined rules and policies (Bolman \& Deal 1992, 1997).

The Human Resource Frame. Leaders using this frame pay more attention to human needs and how organizations can meet those needs. Human resource leaders seek to lead the organization through openness, participation, and empowerment and view organizational members as the primary resource. The human resource leader attempts to build and maintain a harmonious relationship between the organization and individual (Bolman \& Deal 1992, 1997).

The Political Frame. Leaders adopting the political frame see organizations as arenas of continuing conflict and competition and competition for scarce resources among different groups with diverse agendas and interests. Political leaders are advocates and negotiators who value realism and pragmatism. They spend much of their time networking, creating coalitions, building a power base, and negotiating compromises (Bolman \& Deal 1992, 1997).

The Symbolic Frame. Leaders advocating the symbolic frame believe the world is chaotic, in which meaning and predictability are social creations, and facts are interpretative rather than objective. These leaders provide a shared sense of mission and identity and instill a 
sense of enthusiasm and commitment through charisma and drama. This leadership style will focus on myth, ritual, ceremony, stories, and other symbolic forms (Bolman \& Deal 1992, 1997). The No Frame Orientation Leadership Style. The principals who do not implement any frame orientation and are assumed to demonstrate a leadership style with none of the four frames listed above (Bolman \& Deal 1992, 1997).

The Single-Frame Orientation Leadership Style. This leadership style means the principal uses only a single frame (Bolman \& Deal 1992, 1997).

The Paired-Frame Orientation Leadership Style. This indicates a leadership style in which the principal uses two of the four frames (Bolman \& Deal 1992, 1997).

The Multiple-Frame Orientation Leadership Style. The multiple-frame orientation leadership style indicates the principal adopts more than two frames (Bolman \& Deal 1992, 1997).

Teachers. Teachers working in the high schools (grades 9-12) who hold various certifications in an array of content areas.

Smaller Learning Communities (SLC). A program initiative through the U.S. Department of Education, designed to assist large high schools to increase the academic achievement through the creation of smaller, more personalized learning environments. High schools enrolling more than 1,000 students may establish strategies such as small learning clusters, career academies, teacher-advisory mentoring, and other innovations designed to create more personalized instruction (United States Department of Education, 2006).

Structures. Creating smaller, more personalized learning cultures will involve initiatives generally utilized to gain the full benefits of a small learning environment. Examples of smaller 
school structures include academies, house plans, schools-within-schools, and magnet schools (United States Department of Education, 2006).

Strategies. Various methods used to enhance student learning, that are most likely to yield beneficial impacts. Examples include academic teaming, alternative scheduling, freshman transition activities, and teacher-advisory systems (United States Department of Education, 2006).

Locale. SLC Districts and Schools by locale are divided into nine subcategories (Large Central City, Mid-Size City, Urban-Fringe of Large City, Urban Fringe of Mid-Size City, Large Town, Small Town, Rural outside Metropolitan Statistical Area (MSA) and Rural, inside MSA and locale not available) in SLC summary reports. For the purposes of this study, locale will be divided into two categories: urban and rural. Urban will include the first four categories listed and rural, the last four (United States Department of Education, 2006).

Student Success. In this study, student success will be measured using attendance, academic achievement of at least a (at least a C) and discipline (misconduct) referrals.

Average Daily Attendance (ADA). The aggregate attendance of a school during a reporting period (normally a school year) divided by the number of days school is in session during this period. Only the days that the students are under the guidance and direction of teachers should be considered days in session.

Academic Success. Grades will be used to measure the extent that students have acquired certain information or mastered certain skills, usually as a result of specific instruction. This study will use the core subject areas for ninth grade students (Algebra I, Regular English 9, Regular Science 9 and Regular Social Studies 9). 
Core Subject Areas. All ninth grade students are required to take math, English, science and social studies. For the purposes of this study, algebra I, regular English 9, regular science 9 and regular social studies 9 will be the only courses used to collect student achievement data. Honors courses or other accelerated academic areas will not be included.

Discipline Referrals. When a teacher records a discipline (misconduct) and reports it to the administrator in charge of discipline at the high school, this constitutes a referral. The referral is then documented in the state educational reporting system.

\section{Significance of Study}

This study will investigate the leadership style of principals in Smaller Learning Communities, the number and types of structures and strategic configurations, and the rates of student success of ninth grade students in the SLC schools. Research in the early 1990's indicates that students in smaller schools are more likely to form relationships with peers and teachers, which in return will have positive effects on student educational outcomes (Cotton, 2001; Howley, 1994; Klonsky, 1995). Smaller schools are more likely to encourage relationships that bind students with peers and teachers and enable teachers to be better equipped to identify and respond to students' needs. (Cotton, 2001; Howley, 1994).

Critical to the success of any school reform is effective leadership. In well-run, smaller learning environments, students including at-risk students have markedly higher achievement, attend school more frequently, and have fewer discipline referrals (Cotton, 2001; Fowler \& Walberg, 1991; Howley, 1994; Klonsky, 1995). The leadership styles of principals in Smaller Learning Communities is an area of research that has not been completed, and little research exists regarding the success rates of ninth grade students in Smaller Learning Communities. This study will be the first research that has been conducted on leadership styles of principals in 
Smaller Learning Communities, the number and types of structures and strategic configurations, and the rates of student success of ninth graders using Bolman and Deal's $(1992,1997)$ frame of analysis. This study is significant for the following reasons:

1. The research results will assist principals in better understanding the influence of their leadership styles on ninth grade student success.

2. The findings will assist principals and other educational leaders in examining and adapting their own leadership behaviors. Superintendents can benefit from knowing which leadership frames are more likely to result in promotion of principals who increase student success in their respective schools.

3. The results will contribute to increased success of ninth grade students in Smaller Learning Communities by identifying concrete suggestions for future research, policy, and practice.

4. This study will inform those practitioners who are prepared to take action based on the latest research and knowledge of best practices and strengthen links between research, policy, and practice.

5. The research findings of this study will aid in the identification of the most promising SLC configurations, the relationship between Smaller Learning Communities structures and strategies, and student achievement.

\section{Limitations of the Study}

1. Different experiences, academic specializations, and personalities may influence principals' perceptions and the results of the surveys. 
2. This study only investigates the impact of principals' leadership on the success of ninth grade students and will not consider the influence of the roles of teachers, service personnel, other administration personnel (such as vice principals, deans, and department chairs), or SLC grant coordinators. This may limit the accuracy of the research.

3. Some indicators will not be measured or classified. These include: quality of principal's college education; experience, type, and quality of experience; and attitudes as well as the work environment; value-system(s) of employees; complexity of tasks performed by employees; school employees' need to be directed versus self-directed professionals and/or institutional norms; rewards, incentives and punishments available to the leader; extent of autonomy possessed by the leader; school programs; special education student quotients; and special enhancements or disadvantages of specific schools will not be measured or classified. As such, this may impose a limitation on the results of this study.

4. This study is limited strictly to quantitative data. Although qualitative site studies would yield valuable information, this research focuses on quantitative information only.

\section{Summary}

A key measure of the success of every school is student achievement. This study will examine the impact of leadership on student achievement in high schools with Smaller Learning Communities. Using Bolman and Deal's $(1992,1997)$ four-frame leadership model, this study will explore the relationship of the leadership style of principals in Smaller Learning Communities as well as the number and types of structures and strategic configurations and the success rates of ninth grade students. 
This chapter briefly introduced the plan to study the relationship between the leadership style of principals in Smaller Learning Communities and the rates of ninth grade student success in the respective schools. In addition, chapter one has outlined and developed the statement of the problem, created the research questions to be answered in this study, as well as described the significance and limitations, and summarized this study. In Chapter 2, a detailed literature review related to the study variables (leadership styles, school size, and ninth grade student success) will be presented. Chapter 3 will describe the methodology engaged in this study and will be composed of six sections: participants, instrumentations, research design, procedure, data analysis, and a brief summary. Chapter 4 will present the results of the study. Chapter 5 will discuss the research findings and present conclusions and suggestions for further research. 


\section{Chapter 2}

Literature Review

This chapter reviews the major literature related to the leadership styles of principals in smaller learning communities, the number and types of structures and strategic configurations, and the success rates of ninth-grade students. Chapter Two is organized by topics, including Bolman and Deal's $(1984,1990)$ four-frame model, research using the four-frame model, research relating to school size, smaller learning communities, and the changing role of principals in light of No Child Left Behind Act of 2001 (NCLB).

\section{Bolman and Deal's Four-Frame Model}

As previously mentioned in Chapter One, Bolman and Deal's four-frame leadership model will be discussed in detail here, followed by research on the model, including how the four-frame model has been utilized outside of the realm of education.

Bolman and Deal (1991) synthesized leadership theory into four cognitive perspectives and organized them into frames that assist leaders in decision-making with regard to each particular situation. The use of the frames can assist leaders in viewing events in new ways and shift perspective. Bolman and Deal presented "windows" to help the leader visualize and understand more broadly the challenges of the organization and potential available solutions.

The four-frame leadership model was created by melding a variety of organizational theories such as the trait theory, behavioral theory, situational and contingency theory and power and influence theory. These theories have been 
developed over the past several decades and are encompassed in Bolman and Deal's comprehensive theory. Bolman and Deal refer to multiple perspectives, or frames through which to view an organization. The windows and lenses that help bring the organization into focus serve as filters which give leaders order and aid in decisionmaking. The frames consist of the structural frame, the human resource frame, the political frame, and the symbolic frame. Each of the frames represents a specific perspective with its own assumptions and behaviors. The structural frame views the world from an orderly perspective with formal rules and procedures. The human resource frame assumes that goals will be met by addressing the needs of the members. The political frame involves conflict, alliances, and bartering to allocate scarce resources. Finally, the symbolic frame deals with culture, rituals, and symbols as opposed to rules and procedures. Many leaders tend to favor one or more of these frames (Bolman \& Deal, 1997, 1999, 2003). Each of the four frames is detailed below.

Structural frame. The structural frame emphasizes goals and efficiency, formal roles and relationships, and creates rules, procedures and hierarchies (Bolman and Deal, 1997). This frame is founded in the behavior theory by including the characteristics of task or initiating structure through directing and clarifying subordinates' roles, problem solving, and criticizing poor work. Structural leadership supports well-thought-out roles and relationships and emphasizes data analysis. The structural leader's focus is to assure the bottom line, set clear directions, hold people accountable for results, and attempt to solve organizational problems with new policies and rules or through restructuring (Bolman \& Deal, 1992, p. 270). 
Bolman and Deal (2003) based the structural frame on the following assumptions:

1. Organizations exist to achieve established goals and objectives.

2. Organizations increase efficiency and enhance performance through specialization and a clear division of labor.

3. Appropriate forms of coordination and control ensure that diverse efforts of individuals and units mesh.

4. Organizations work best when rationality prevails over personal preferences and extraneous pressures.

5. Structures must be designed to fit the organizations' circumstances, including their goals, technology, workforce, and environment.

6. Problems and performance gaps arise from structural deficiencies and can be remedied through analysis and restructuring (p. 45).

The structural frame view has two main intellectual roots, the work of renowned psychologists Fredrick Taylor (1996) and Henri Fayol (1996) and sociologist Max Weber (1946/1996) who developed theories that formed the foundation for this frame.

Taylor's (1996) theory of scientific management followed time and motion studies. His goal to increase productivity led him to the creation of a new division of labor among management and workers. Taylor believes that every task could be divided into a variety of smaller task components that drastically increase worker efficiency (Taylor, 1996). 
Fayol (1996) found ways to improve administration and designed fourteen principles that served as guidelines for managers. These concepts were designed to be flexible and adaptable by managers. He further proposed that adapting these principles required experience, intelligence, and preparation from the administrator. In other research, administration was defined in terms of five functions: planning, organizing, commanding, coordinating and controlling (Owens, 1995).

The second source of structural ideas stems from the work of the German economist and sociologist Max Weber, who outlined a "monocratic bureaucracy" that would use highly trained specialists, governed by rules with a strong hierarchy of authority (Weber, 1996).

Structural leaders are ultimately responsible for deciding which structure will best maximize the productivity and efficiency of their organizations. Structuralists will assign responsibilities to subordinates and develop policies and plans and create procedures and hierarchies to coordinate activities. The productivity of the organization depends on the degree of clarity of organizational goals and roles for the people defined by leaders and coordination of individuals and groups through both vertical (command, rule) and lateral (face-to-face, informal) strategies (Bolman \& Deal, 1993). Structural frame sometimes referred to as the bureaucratic frame, can be likened to a factory or machine because of the emphasis on systems and authority (Bolman \& Deal, 1997). According to Bolman and Deal, structural leaders succeed not because of their inspiration but because they have the right design for the times and are able to get their structural changes implemented (p. 352). Effective structural leaders share several characteristics: they do 
their homework, rethink the relationship between structure, strategy and environment, focus on implementation, experiment, evaluate, and adapt (Bolman \& Deal, 2003).

Human resource frame. The human resource frame is based upon studies from psychology and organizational behavior (Bolman \& Deal, 1991) and postulates that organizations are inhabited by people with needs, feelings, and prejudices (Bolman \& Deal, 1984, p. 5). Human resource leaders are passionate about "productivity through people" (Peters and Waterman, 1982). According to Bolman and Deal (1991), the human resource frame is based on the following assumptions:

1. Organizations exist to serve human needs rather than the reverse.

2. People and organizations need each other; organizations need ideas, energy and talent; people need careers, salaries and opportunities.

3. When the fit between the individual and the system is poor, one or both suffer, individuals will be exploited or will exploit the organization, or both will become victims.

4. A good fit benefit both, individuals find meaningful and satisfying work and organizations get the talent and energy they need to succeed.

To develop this type of effective leader, no single strategy is likely to be successful if used exclusively; accordingly, human resource leaders will utilize a number of strategies to involve employees and strengthen the bond between individual and organization. Successful human resource leaders will adjust the people to fit the organization (Bolman \& Deal, 1984, p. 4) or understand how to modify organizations to better meet the needs of the people within the organization (Bolman \& Deal, 1984, p. 5). 
Success typically requires a comprehensive strategy supported by a long-term human resource management philosophy (Bolman \& Deal, 2003).

Political frame. The political frame views organizations as living, screaming political arenas that host a complex web of individual and group interests (Bolman \& Deal, 2003). This frame is rooted in the work of political scientists. Five propositions summarize this perspective:

1. Organizations are coalitions of diverse individuals and interest groups.

2. Enduring differences exist among coalition members in values, beliefs, information, interests, and perceptions of reality.

3. Most important decisions involve allocating scarce resources.

4. Scarce resources and enduring differences make conflict central to organizational dynamics and underline power as the most important asset.

5. Goals and decisions emerge from bargaining, negotiation, and jockeying for position among competing stakeholders (Bolman \& Deal, p. 186).

The politically-oriented leaders understand the competition for resources, welcome the discourse of "status quo", and consequently are compelled to seek a workable solution for the organization. The political leaders use the interplay of interests and agendas among different individuals and groups as a constructive vehicle for achieving organizational goals for, building linkages to other stakeholders, and using persuasion, negotiation, coercion and compromise to gain control.

Symbolic frame. This frame forms ideas from organization theory and sociology. The symbolic frame is not based on the rationality of the first three frames; rather, organizations are viewed as being held together by shared values and culture instead of 
goals and policies (Bolman \& Deal, 1984). Deal and Kennedy (1982, p. 4) define culture more succinctly as "the way we do things around here." Culture is both a product and a process (Bolman \& Deal, p. 243).

Scholars associated with the symbolic frame include organizational theorist and sociologist Hofstede, (1984), and political scientists Dittmer (1977), Edelman, (1971) and psychologists, Freud and Jung; others include anthropologists such as Ortner (1973). The basis of this frame focuses on culture and symbols. Symbols express an organization's culture, the interwoven pattern of beliefs, values, practices and artifacts that define for members who they are and how they are to do things (Bolman \& Deal, p. 243). From the perspective of a symbolic leader organizations are viewed as tribes, theaters, carnivals or cultures propelled more by rituals, ceremonies, stories, heroes, and myths than by rules, policies and managerial authority (Bolman \& Deal, 1997). These leaders use this frame to focus not merely on team building, rather team spirit and uniting employees through a creation of a community of believers joined by shared faith and culture.

Bolman and Deal do not consider the four frames to be independent of one another. Many studies show that effective leaders and organizations rely on the use of multiple frames as essential tools (Bensimon, 1989; Birnbaum, 1989; Bolman \& Deal, 1997). The essence of reframing is to examine the same situation from multiple angles to develop a holistic picture. Those leaders who use several frames may demonstrate a higher level of cognitive differentiation and integration than those single-framed leaders (Bensimon, 1989). Organizations are complex and cannot be viewed through a singleframe prospective; consequently, effective leaders examine problems from different perspectives (Quinn, 1988). Central to the Bolman and Deal approach is the belief that 
frames influence what leaders see and do (Bensimon, 1989), and that wise leaders in present-day, complex organizations understand their strengths and work to expand them; it is the single frame leadership perspective that is likely to produce error and selfisolation for the manager (Bolman \& Deal, 1984). In summary, each frame is unique and is characterized by different beliefs and assumptions. Table 1 illustrates some major aspects of the theory.

Table 1

Characteristics of the Bolman and Deal Four Frame Model*

\begin{tabular}{|l|l|l|l|l|}
\hline Characteristics & Structural & Human Resource & Political & Symbolic \\
\hline Metaphor & Machine & Family & Jungle & Carnival \\
\hline $\begin{array}{l}\text { Central } \\
\text { Concepts }\end{array}$ & $\begin{array}{l}\text { Rules, roles, } \\
\text { policies }\end{array}$ & $\begin{array}{l}\text { Relationships, } \\
\text { needs, skills }\end{array}$ & $\begin{array}{l}\text { Power, Conflict, } \\
\text { competition }\end{array}$ & $\begin{array}{l}\text { Culture, } \\
\text { rituals }\end{array}$ \\
\hline Decision-making & Rational & $\begin{array}{l}\text { Open to produce } \\
\text { commitment }\end{array}$ & $\begin{array}{l}\text { Gain or exercise } \\
\text { power }\end{array}$ & $\begin{array}{l}\text { Confirm } \\
\text { values }\end{array}$ \\
\hline Leader & $\begin{array}{l}\text { Analyst, } \\
\text { architect }\end{array}$ & Catalyst, servant & $\begin{array}{l}\text { Advocate, } \\
\text { negotiator }\end{array}$ & $\begin{array}{l}\text { Prophet, } \\
\text { poet }\end{array}$ \\
\hline Process & $\begin{array}{l}\text { Analysis, } \\
\text { design }\end{array}$ & $\begin{array}{l}\text { Support, } \\
\text { empowerment }\end{array}$ & $\begin{array}{l}\text { Advocacy, } \\
\text { builds coalitions }\end{array}$ & Inspiration \\
\hline Communication & $\begin{array}{l}\text { Transmit } \\
\text { facts }\end{array}$ & $\begin{array}{l}\text { Exchange needs } \\
\text { and feelings }\end{array}$ & $\begin{array}{l}\text { Influence others } \\
\text { Tell } \\
\text { stories }\end{array}$ \\
\hline Motivation & Economic & Growth & Coercion & Symbols \\
\hline Challenge & $\begin{array}{l}\text { Attune } \\
\text { structure to } \\
\text { task }\end{array}$ & Align needs & $\begin{array}{l}\text { Develop agenda } \\
\text { and power base }\end{array}$ & $\begin{array}{l}\text { Create } \\
\text { meaning }\end{array}$ \\
\hline
\end{tabular}

*Adapted from Bolman and Deal, 1997.

According to many of the researchers in the past fifteen years, frame preference does influence leadership effectiveness, Bolman and Deals' research (1991, 1992, 1992b) and Bolman and Granell's (1999) studies of populations of managers in both business and 
education. No one style of leadership is best or appropriate in every situation (Hershey \& Blanchard, 1982). Rather, to be effective today, leaders must compete for survival and success while at the same time maintain high standards of fiscal, social, and personal trust (Jurkiewicz, 1993). Principals play a decisive role in the school improvement (Cotton, 2003), in a recent research study, Leithwood, Louis, Anderson and Wahlstrom's analysis of the research related to school leaders substantiates that leadership is second only to classroom instruction among all school factors related to student learning (Leithwood, et al, 2004). Researchers find the use of multiple frames was a consistent correlate of leadership effectiveness (Bensimon, 1989; Birnbaum, 1989; Bolman \& Deal, 1997). Leaders need multiple frames to survive in a "messy world of complexity, conflict and uncertainty that they inhabit" (Bolman \& Deal, 2003, p. 319). According to the theory, by using a greater number of perspectives or frames, managers and leaders are better enabled to gather complete information to assess situations and organizations, make clear judgments, and take effective actions (Turley, 2004). Bolman and Deal's research found that individuals who employ three or more frames are perceived as being more effective leaders than those who consistently use less than three frames (Bolman and Deal, 1991, 2003).

\section{Research Using Bolman and Deal's Four-Frame Model}

Bolman and Deal have taken the lead in the research using the leadership frame model. Both qualitative and quantitative studies continue to use the frames as the foundation for the research. Many of the studies address questions regarding the number frames and which frames are most often used by leaders. Bolman and Deal (1991, pg. 5) assert qualitative methods as particularly effective in studying the intricacy of how 
leaders think and how they frame their experiences, and are valuable in examining the relationship between the frames of leaders and their constituents.

Bolman and Deal also use qualitative methods to decide the quantity and type of frames leaders will use. The qualitative approach by Bolman and Deal, produce the narratives that evaluate what the leaders offer regarding their leadership experience. The criteria for coding frame responses are split into two categories for each frame: framerelated issues and frame-related actions (Bolman \& Deal, 1992). Most recently, this approach was examined in a study of Florida school administrators $(\mathrm{n}=48)$ (Bolman \& Deal, 1992), Singapore School Administrators ( $\mathrm{n}=220$ ) (Bolman \& Deal, 1992), Higher Education Administrators ( $\mathrm{n}=75)$ (Bolman \& Deal, 1991a), and Midwestern State School Administrators ( $\mathrm{n}=15)$ (Bolman \& Deal, 1991a), evidence concluded that most leaders rarely use more than two frames. In other research, Bolman and Deal's model was used as a scaffold to complete qualitative studies with higher education leaders. Researchers, Bensimon, Birnbaum, Neumann and Tierney conducted interviews with college presidents (Bensimon, 1989; Birnbaum, 1989, Neumann, 1989, Tierney, 1989). These studies illuminated the complexities of leadership and the importance of avoiding oversimplification of approach and research perspectives (Chaffee, 1989; Neumann \& Bensimon, 1990).

Cheng and Shum (1996) researchers for the Hong Kong Institute of Education studied the perceptions of women principals' leadership attitudes and teachers' work attitudes. Five dimensions of leadership were compared to Bolman and Deal's four frame model. Cheng's five dimensions of leadership are categorized by the following terms: structural, human, political, symbolic, and educational. In addition, this study 
measured leadership sex-role orientation (masculine, feminine, androgynous and undifferentiated). The undifferentiated or genderless approach may fail to acknowledge the existence of different sex-role orientations and the role gender plays in leadership functions. This was one of the first studies to investigate female principals, taking both sex-role orientation and multi-dimensions of leadership into consideration (Cheng \& Shum, 1996).

Cheng's (1994) addition of educational leadership as the fifth dimension refers to leadership influence through the generation and dissemination of educational knowledge and instructional information. In addition, the effective educational leader would champion teaching programs and demonstrate a strong supervision of teaching performance (Bolman and Deal, 1991, Cheng, 1994, Sergiovanni, 1984). In Cheng's (1994) study, the principal's leadership in terms of these five dimensions was found to be strongly associated with organizational effectiveness, school culture, positive principalteacher relationships, greater teacher participation in decision-making, higher teacher morale, and job satisfaction (Cheng, 1994). In Cheng's study (1995), he provided further evidence of the importance of the five dimensions with findings to support higher student performance and greater student attachment to school.

In the quantitative investigations, Bolman and Deal (1990, 1991, 1992, and 1993) used the survey instrument "Leadership Orientations". The instrument has two corresponding forms with two sections for each form: self and others. The first section is organized into eight separate dimensions of leadership, two for each frame. The second section contains a series of multiple-choice items. 
Bolman and Deal's (1992) quantitative research established that individual or combined frames were significantly associated with the effectiveness of the leaders and certain frame preference reflects leadership effectiveness. In addition, a leader's experience, age, gender, and other characteristics may impact the leader's use of multiple frames. For example, Bensimon (1989) and Neumann's (1989) study supported a correlation between college presidents' increased years of experience and the leadership strategies becoming more refined and multi-framed. Although Kelly (1997) and McClelland-Holt (2000) found no specific frame use by leaders with similar years of experience, they did find evidence of a correlation between age and the use of the political frame (Kelly 1997; Wolfe, 1998).

Many studies of school administrators found that the human resource frame was used most frequently (Davis, 1996; Durocher, 1995; Rivers, 1996). In a study using a sample of mangers in business and education, Bolman and Deal (2001) uncovered very similar scores on the structural and human resource area of the survey instrument. In 1992, Bolman and Deal used the Leadership Orientations (Self) Survey to collect information in a study of principals from Singapore $(\mathrm{n}=220)$ and Florida $(\mathrm{n}=48)$ and found that American principals used primarily the human resource frame and secondarily the structural frame. The pattern was the reverse in the principals from Singapore (Bolman \& Deal, 1992).

In another study, Chang (2004) analyzed the leadership orientation patterns of college-of-education department chairs who used no frame (56.8\%), single frame (14.8\%), paired frame (13.6\%), and multiple frame styles (12.8\%). The Mathis (1999) 
study of departmental chairs found that $32 \%$ used no leadership frame, $11 \%$ used one frame, and $36 \%$ used four frames.

The human resource frame was the preference of the leaders in Cantu's (1997) study of academic deans from 426 public American universities, followed by the structural, political, and symbolic frame leadership orientation. The human resource frame was most often used in other studies of higher education administrators (Borden, 2000; Miller, 1998; Mosser, 2000; Small, 2002; Turley, 2002).

Turley (1991) completed a study which used the frames to examine radiation therapy program directors' leadership approaches. The results of this study indicated that $73 \%$ of program directors consistently used the human resource frame. Fewer than half of respondents $(44 \%)$ demonstrated multiframe leadership, which concluded that the program directors would benefit from further leadership development because effective leadership is most associated with the use of the political and symbolic frames and with the consistent use of three or more frames (Bolman \& Deal, 1999; Cantu, 1997).

Research in medical-related fields has demonstrated the importance of multiframed leadership. Small (2002) examined nursing chairpersons as perceived by the faculty, Miller (1998) used the four-frame model to examine the leadership orientations of occupational therapy program directors, and Mosser (2000) studied the leadership of chairmen of baccalaureate nursing programs. Small's findings confirmed chairs are perceived by faculty as using no frames, then all four frames, single frame, multi-framed and then paired frame, using the human resource frame most often. Miller found that among occupational therapy program directors the human resource frame was most frequently used, followed by the symbolic frame. The structural frame showed the 
lowest frequency of use. Forty percent of the directors in Miller's study (1998) used multi-frame leadership (three or more frames). In Mosser's study (2000), 39.5\% used no frame, $16.6 \%$ used a single frame, $12.7 \%$ used paired frame, $9.2 \%$ used three frames and $22.1 \%$ used four frames.

In summary, clearly, the human resource frame was most frequently chosen leadership orientation in these research studies (Borden, 2000; Cantu, 1997; Chang, 2004; Davis, 1996; Durocher, 1995; Mathis, 1999; Mosser, 200; Small, 2002; Turley, 2002). In the qualitative studies, researchers studied leadership patterns of college presidents, senior administrators in higher education, department chairs, school district administrators and medical facilities, these studies reveal that leaders seldom use more than two frames and even more rarely use all four frames. The leaders who use two frames were less than twenty-five percent in every sample (Bolman \& Deal, 1991a). In many of the studies leaders are perceived as using no frame style of leadership (Chang, 2004; Miller, 1998, Mosser, 2000, Small, 2002) which indicates leaders are not perceived as having a predominant leadership style. According to Bolman and Deal these leaders may experience difficulty in leading their organizations efficiently and effectively (Bolman \& Deal, 1991b). Bensimon (1989) and Bolman and Deal (1991) encourage leaders to operate from the multi-frame approach, allowing flexibility in reframing circumstances from multiple perspectives.

\section{School Effectiveness Research}

In 1967, James B. Conant (then president of Harvard University), released his study that public high schools with an enrollment less than 400 students would be unable to offer a comprehensive and challenging academic program. Under Conant's proposed 
curriculum, comprehensive high schools (over 750 students) would include higher level math courses such as Calculus and Physics as well as French IV. Conant concluded that comprehensive high schools could offer a more rigorous and broad curriculum for less money, serving more students. Fueled by James Coleman's On Equality of Educational Opportunity (1966), Edmonds and other researchers wanted to establish that a student's family background and school's socioeconomic composition were not the top predictors of academic success (Edmonds, 1979; Levin \& Lezotte, Levine, 1992, Myers, 1996; Reynolds, Creemers, Nesselrodt, Shchaffer, Stringfield, \& Teddlie, 1994). Edmonds wanted to invalidate Coleman's report, and in doing so, began what has been termed the Effective Schools Movement (Chrispeels, 2002; Levine et al., 2000, March \& Peters, 2002; Taylor, 2002). This research identified correlates commonly found in effective schools: development and implementation of a clear vision and mission, the principals as strong instructional leaders, and a positive, safe and orderly school climate. In addition, in these schools, Edmond found an emphasis on academic achievement and time on task, as well as high expectations for all. Furthermore, the most effective schools were found using frequent and thorough monitoring of results, and strong parent and community partnerships with the schools (Edmonds, 1979).

Lezotte (2001) reported the Effective Schools Movement had evolved to include sub-groups including gender, ethnicity, disability and family structure. In addition, the original research focused primarily on mastery of essential core curriculum. However, currently, effective-schools research has broadened its scope to include problem-solving, higher-order thinking skills, creativity, and high-level communication skills (Levine, 1990). 
In other research, Taylor, Valentine, and Jones (1985) characterized effective schools into three categories: effective principals, effective classrooms, and effective teachers. The principals who were highly effective promoted student cognitive growth and supported improvement in teaching and learning. In effect, the principal would foster a favorable climate for learning (pp. 2-3). Effective classrooms were characterized with positive student behaviors, high student expectations, strong cognitive processing, and a positive climate and atmosphere. Effective teachers had strong classroom management and ability to engage student learning consistently (Taylor, Valentine, \& Jones, 1985).

Lezotte and Pepperl (1999) studied effective schools as a continual process of improvement and believed this led to learning for all. They identified eleven core beliefs in this process: all children can learn and come to school motivated to do so; schools control enough variables to assure that all children will learn; school stakeholders are the most qualified people to implement the needed changes; school personnel are already doing the best they know how to do, provided the conditions in which they have been placed; and school by school change is the best hope for reforming schools. Additionally, there are two kinds of schools in the United States: improving and declining schools. Other core beliefs include a belief that every school can improve; the needed capacity to improve the school resides within the school; and all adults in the school are important. This study found that change is a process not an event, and that the existing people are the best agents for change (pp. 19-32). 
Carter (2000) conducted case studies of twenty-one schools with low socioeconomic status (SES) students with high student achievement. The study included fifteen public schools, three charter schools, three private schools, one parochial and one rural school. Although the schools were diverse in many characteristics, their commonality was a high concentration of low SES and high academic achievement. When studied, Carter found the schools comprise these commonalities: principals were given the freedom to provide school leadership as they deemed necessary and appropriate, and held established rigorous school goals which identified all staff as accountable for increasing student achievement. Additionally, the principals provided leadership opportunities for master teachers, including team teaching, peer evaluation, and student progress. Principals monitored the results of regular and rigorous assessments, aligned to the curriculum and instruction. When academic achievement was increased, student discipline referrals decreased as principals worked diligently with parents to support student learning. Ultimately, time for learning and instruction was prioritized (Carter, 2002).

Penny Sebring, a senior research associate at the University of Chicago and a director of the Consortium on Chicago School and Anthony S. Bryk, a professor of education at the University of Chicago, senior director of the Consortium on Chicago School Research, and director of the Center for School Improvement conducted a study of public school principals of elementary schools in Chicago. In Sebring and Bryk's (2000) research, three areas in which effective leaders were exemplary were identified. This study recognized leadership style, reform strategies and the institutional focus (Sebring \& Bryk, 2000, p. 441). They also identified four effective strategies for 
effective reform: an inclusive, facilitative orientation; an institutional focus is on student learning; efficient management; and a reliance on a combination of pressure and support to motivate others. In their research, productive principals were able to articulate a vision for their schools. The principals would then involve teachers and parents to further elaborate and shape this vision. The effective principals seize opportunities to bring parents, teachers, and other staff members into leadership positions. Institutional focus is on student learning and setting high standards for teaching; understandings how children learn, and encouraging teachers to take risks and try new methods of teaching. This research also found that effective school leaders visit classrooms regularly, demonstrating their conviction and taking the instructional pulse of the school. Additionally, teachers have the materials they need to instruct without disruption and are encouraged to adopt new approaches to teaching (Sebring, 2000).

The study of the National Commission on Excellence in Education entitled, $A$ Nation at Risk, aided in the merger of the school effectiveness research with the national movement for school reform and the public outcry for sustained and continuous school improvement planning processes (National Commission on Excellence in Education, 1983). The report identified deficiencies in schools throughout the country and suggested the need for reform of the entire educational system in an effort to raise levels of student achievement scores (quality), while raising mean levels of student achievement among various sub-group populations of students (equity). A major public concern focused on the report findings that the United States' high school student achievement test scores had declined to lower levels than their counterparts from Japan, Korea, Europe and other countries throughout the world. This finding increased the fear that our nation would 
slowly lose its ability to compete economically with other leading industrial countries of the world.

West Virginia responded by creating the Jobs Through Education Act in 1996 (Senate Bill 300). This act served as the foundation for commitment from the West Virginia Department of Education to participate in the High Schools That Work Network of the Southern Regional Education Board. West Virginia began with a small number of pilot schools and had increased the number to 112 volunteering to participate in this initiative by the year 2000 (SREB, 2001). This school reform effort mirrored many of the tenets of the school effectiveness research; that given the appropriate instructional setting and variable time, all students could learn (Paine, 2002). The High Schools That Work went beyond this idea by expanding the premise to state that all students could learn academically challenging concepts as well as technical education skills and concepts (SREB, 2000a).

This high school reform effort developed three major goals: increasing math, science, problem solving; increasing technical achievement of student to levels at or above national averages; and to join together vocational and technical studies to include traditional college-preparatory studies. This reform effort was founded on ten key practices that strongly bear a resemblance to the tenants of the school effectiveness research (SREB 2000a): setting high expectations, increasing academic rigor, students actively engaged in learning, a strong student support system, a structured system to assure success of students who desire acceleration, using student assessment and program 
evaluation data to continuously improve curriculum, instruction, school climate, organization and management in order to advance student learning (SREB, 2000a). 


\section{Research Relating to School Size}

Comprehensive high schools of 400 students in the mid-1900s would be considered small today (Fowler, 1992). In comparison, in 2000, approximately 50 percent of American high schools enroll 1,000 or more students (Cotton, 2001; Gladden, 1998); and some high schools enrolling as many as 4,000 to 5,000 students, resulting in growing enrollments, school consolidation, and a decline of student achievement (Fowler, 1992; Klonsky, 1995; Raywid, 1996).

Howley (1989) found that the faith in larger schools persisted, virtually unchallenged, until at least the mid-1960's. The debate regarding school size truly began with the publication of Roger Barker and Paul Gump's 1964 book Big School, Small School: High School Size and Student Behavior (Cotton, 1996). This book revealed that students from smaller schools were involved in extracurricular activities more frequently and were more satisfied. These findings began to shake the foundational beliefs that large schools were more effective in meeting the needs of students (Howley, 1989).

Barker, (1986), Glass, (1982), and Lee and Smith, (1997), investigated the "ideal" size for a high school and declared 600 to 900 students as the "ideal" size. This research found that schools can be too small or too large, and there should be no less than 600 students in any given high school. The National Center for Education Statistics (2000) defines overcrowding as when the "number of students enrolled in the school is larger than the number of students the school was designed to accommodate" (pg. 45). 
In another study, Barker (1986) and Rogers (1992) found that schools with highest levels of student success had commonalities and identified specified practices and characteristics associated with effectiveness. This research indicates that size alone is not the determining factor in school effectiveness. Barker (1986) found the student-centered focus inherent as a characteristic and practice of effective schools. In these schools, discipline is normally not a serious problem, thereby resulting in an increase in time spent learning. Furthermore, Barker and Roger's research argues teachers still have a sense of control over what and how they teach, and that a minimum of bureaucracy allows for more flexibility in decision-making. In the classroom, low pupil-teacher ratios allow for more individualized instruction and more attention is given to students. In the smaller schools, relationships between students, teachers, administrators, and school board members tend to be closer and parental and community involvement tends to be stronger than in larger schools (p. 3). Ramirez (1990) examined the impact of a higher studentteacher ratio, higher student-per-guidance personnel ratio, and greater amount of school media resources in larger schools. However, higher student achievement or student outcomes were not related to larger school size.

Huang and Howley (1993) conducted another study that found student achievement was higher for students from disadvantaged families in small schools, than medium or large schools. Howley (1994) found that students from affluent families were less likely to be affected by school size than students from impoverished families. In his research, Howley concludes the optimal size for a school is dependent upon the community in which it exists and serves. 
Cotton (1996) identified twelve areas in which small schools are superior to large schools. Cotton (1996) examined 49 studies and evaluations on school size, school climate and student performance. She examined 103 documents which identified a relationship between school size and some aspect of schooling (Cotton, 1996, pg. 2). Large schools were determined to be ineffective in meeting the comprehensive needs of children. Smaller schools were found more effective in the areas of quality of curriculum, academic achievement, social behavior, participation in extracurricular activities, higher attendance rates, and lower dropout rates. In addition, students experience a stronger sense of belonging, higher self-concept, better attitudes, and more secure interpersonal relationships while teachers have higher staff morale. Smaller learning communities or schools within schools have similar effects according to Cotton (1996). Again, in 1997, Cotton's research found that students attending smaller schools have more positive attitudes and better behavior. In addition, student achievement in small schools was found to be equal to, or above those students attending larger schools.

Irmsher, (1997) and Meir (1996) found that minority and disadvantaged students are better served in smaller schools. This research found the most advantageous size of a school to be 300 to 400 students. Irmsher (1997) also found that large schools functioning may be compared to bureaucracies, while small schools are more comparable to communities. During the same year, in a study of 9,812 students in 789 public, Catholic, and elite private high schools, Lee and Smith (1997) found that high schools can be too small. This research established the ideal school enrollment between 600 and 900 students and concluded that school size is more critical when serving specific student populations, such as disadvantaged students. Although their numbers for ideal school size 
vary (300-400 vs. 600-900), both studies indicate that schools are far more effective when their populations are well below the current averages.

Wasley and Gladden's (2000) research provides substantial evidence that smaller high schools offer better student outcomes than larger high schools. This two year study focused on about 150 small schools founded in Chicago during 1990-97 and their progress through 1999. The high schools in this study had fewer than 400 students. Quantitative analyses covered demographic data; attendance; retention; dropout rates; and measures of academic achievement. Compared to the students in larger schools, smaller school students had better attendance rates, lower dropout rates, higher gradepoint averages, and high school graduation rates (Wasley, 2000).

Howley and Bicket's (2000) research espoused that large schools experienced a correlation between poverty and low achievement that was ten times stronger than small schools. This study established that smaller schools experience more success most especially at the middle grade levels. Additionally, minority students experienced more difficulty in achieving top performance in large schools with high poverty levels.

LaSage and Ye (2000) found that teachers working in small schools with smaller class sizes are able to work more effectively with students. In another study, Lee and Loeb (2000) found that teachers have a higher level of positive attitudes and students learn better in small schools. In this study, the influence of school size on students and teachers in Chicago's inner-city schools were examined; Lee and Loeb (2000) found teachers had a more positive attitude, resulting in a higher quality learning environment for students. 
Klonsky (2002) supported these findings and established school violence is reported less in smaller schools based on three reasons: better student visibility, a more professional community of teachers, and a greater sense of purpose. Klonsky's study (2002) attributes the relationship of a decrease in school violence and school size to a number of reasons: small schools are better able to combat school violence; better visibility of students due to lower student/teacher ratios; a more professional community of teachers as a result of more opportunity for teacher interaction and professional development; and a clear sense of purpose due to a greater focus on academic and character education (Klonsky, 2002).

Muir (2001) identified four issues of concern: the relationship between school size and student achievement; the importance of networking between students, parents and teachers; the different costs of different sizes of schools; and social benefits for students on a long term basis. Muir's research on optimal school size concludes the best possible student enrollment in any given school is between the range of 300 and 400. Muir states seven reasons small schools work best and presents the only possibility of successful reform efforts:

1. Governance. Teachers are better able to meet and communicate with one another.

2. Respect. A greater mutual respect exists among students and teachers because of closer personal relationships.

3. Simplicity. Less bureaucracy that leads to individualization for both teachers and students. 
4. Safety. Anonymity breeds contempt and anger; in a small school, strangers are easily spotted.

5. Parent Involvement. More natural opportunity can be found to build alliances between parents, teachers, and students.

6. Accountability. A greater level of peer accountability is created, and consequently, more concern regarding public character.

7. Belonging. Every student is known and relationships are stronger.

Viadero (2001) found that smaller schools have better attendance rates, lower drop out rates, and higher grades. Students feel safer, have fewer discipline problems, and participate more frequently in extracurricular activities. Other studies such as Johnson, Howley and Howley's (2002) found that affluent student populations experienced fewer effects from school size than did schools with disadvantaged or impoverished student populations.

Research on high school size conducted in the past thirty years suggests a need for smaller schools (Gregory, 2000). However, despite rising support for smaller schools, high schools have continued to grow in size. Muir (2001) projected that the movement toward small schools is not a passing trend. In his research, Muir targets four imperative issues when considering reform: the effect of the school size on student achievement; the importance of networking between students, parents, and teachers; cost differences in school sizes; and the long term social benefits for students of smaller schools. The disparity in reform efforts exists for several reasons according to reformer Ted Sizer (1996). High schools serve a multifaceted responsibility in their community serving as a 
source of community pride and a central gathering place. He furthermore refers to high schools as a "diabolically complicated system" (1996, p. xi). The high school is more than a place of learning; it may be one of the few entities that brings the community together.

The United States Department of Education (USDE) has responded to this research by generating a major high school reform effort termed Smaller Learning Communities (SLC). In an organized effort to redesign the American high school, large comprehensive high schools are divided into learning communities or schools within schools. Although schools differ in strategies and structures, the goal of the reform is improvement through school transformation (Oxley, 2004). This initiative encouraged school districts to apply for part of the $\$ 142$ million allocated through grants that would assist high schools in implementing reform efforts that reduce large high schools. The No Child Left Behind Act of 2001 details the important purpose of Smaller Learning Communities and promises to assist large public high schools in reform efforts. Although the funds could not be used to build new schools, the allowable activities include costs to reorganize schools, provisions to extend learning time, funds to provide professional development and support services for students, partnerships, and data collection with evaluation activities.

Restructuring schools is one way to reduce school size. Lee (2002) directed his research to determine how size impacts high schools and influences the organizational properties of a given school. In recent years, states with class-size-reduction programs have remained steady. In 2000, thirty-one states had such programs; currently that 
number has inched up to thirty-three states. Now, many states require school report cards to include information on class size or pupil-teacher ratios (USDOE, 2006). The Bill \& Melinda Gates Foundation, along with a number of other foundations and nonprofit organizations, have been in the vanguard of the movement for small, innovative schools. To date, the Gates Foundation has helped to reform more than one thousand schools and is diligent in its pursuit of increasing the number of schools involved. It has awarded \$51.2 million to New York's schools for the creation of sixty-seven small, theme-based schools (Herszenhorn, 2003).

Over the past decade or so, the number of states with laws permitting the formation of charter schools has progressively grown from twenty-five to forty (USDE, 2006). States differ considerably as to the date when they passed those laws. Minnesota enacted the first statewide Charter School Law in 1991. Maryland passed their Charter School Policy in 2003. As more states have allowed charter schools, which are publicly financed but operate free from many of the rules governing regular public schools, the number of such schools has climbed nationwide. In 1999, there were 1,680 charter schools. By 2005, there were 3,625. While 129 new charter schools opened in 1995-96, 424 new charter schools opened in 2004-2005. Today, more than 1 million students are enrolled in charter schools nationwide (USDE, 2006).

Howley (1994) found that middle-class students predominated in large urban schools as a result of changing residential patterns. The result is an overburdening of large inner-city schools with impoverished students (Howley, 1994). This research also reports that students in high socioeconomic status communities perform better in larger 
schools. Small size seems to benefit minority and low-income students more than middleand upper-class students (Lee and Smith 1996). Many of the nation's largest high schools are in urban areas, having high concentrations of disadvantaged students who are ill served by large school size (Irshmer, 1997).

Howley's research (2003) encouraged superintendents to sustain small high schools in their districts. Howley proposes that rural small schools are more sustainable when district leaders give priority to maintaining the small size of their schools. To determine the ideal number of students, one must consider the size of the community the school serves (Howley, 1994). Research indicates that affluent students thrive in larger schools, while low socio-economic status (SES) students seem to have higher achievement levels in smaller schools (Howley, 1994). Johnson, Howley and Howley's (2002) study of Arkansas schools and districts which provide service to students from different socioeconomic backgrounds confirmed this point. This research measured the relationship between size and achievement. Johnson et al. found that the negative influence of size was very weak in affluent settings and comparatively strong in impoverished areas. Student achievement is higher when students feel there is a caring environment, the foundation for learning has been laid (Rogers, 1992), and schools are better able to combat violence (Klonsky, 2002). Other studies, found that while larger schools may be able to offer a more diverse curriculum and a greater number of special programs, students may feel disconnected from the school's culture (Irmsher, 1997). In summary, although research regarding school size and its relationship to student achievement is mixed, it is in agreement that school size can be too small or too large (Howley, 2000; Huang., et al, 1993; Muir, 2001; Ramirez, 1990). The perfect 
student enrollment varied from study to study: Irmsher (1997) and Muir (1996) believe the ideal to be 300-400 students, while Barker (1986), Glass, (1982) and Lee \& Smith (1997) affirm 600-900 students as ideal. However, most current research points to evidence regarding the strong benefits of decreasing school size. The development of Smaller Learning Communities has provided the framework for schools to rethink their current practices, develop new structures and strategies for meeting the ever-changing needs of high school students, and to sustain long-term efforts to implement fully functioning and effective learning communities (Oxley, 2004). However, one commonality in national school reform is the priority placed on reduction of school size. The evidence does point to the importance of school size and student achievement, especially for students from low socioeconomic groups, and disadvantaged social and minority backgrounds.

\section{The Principal as the Instructional Leader}

In addition to the research conducted on school size, a great number of research studies have furthermore identified that a school's principal is a key factor in determining the success of an effective school (Hord, 1984; Terry 1988; Chrispeels, 2002). Not only school effectiveness, but Chrispeels established the connection between the principal's leadership and school climate (Chrispeels, 2002).

Senge (1990) describes the principal as a designer, steward and teacher in the learning organization. When operating as the designer, the principal designs the learning environment to allow the staff and other members to resolve their own issues, and to consequently, develop their talents and skills. As the steward, the principal develops the 
shared school vision and assists the teacher in fostering an environment where all are encouraged to develop meaningful learning and systematic understandings.

In the Cookson and Persell (1982) research of more than seventy-five studies pertaining to effectiveness of principals, their examination found nine recurring principal behaviors: demonstrating a commitment to academic goals, creating a climate of high expectations, functioning as an a instructional and forceful dynamic leader, consulting with others, creating order and discipline, obtaining resources, using academic time well and evaluating results.

Many studies have deemed school principals as instructional leaders with the ability to transform schools from bureaucratic to vibrant learning organizations (Dufour, 2000; Senge, 1990, 2000; Fullan, 1993). Stedman (1987) identified five primary factors for effective schools: 1) strong instructional leadership by the principal; 2) high expectation by teachers for student achievement; 3) emphasis on basic skills; 4) an orderly environment; and 5) frequent and systematic evaluations of students (p. 216-217). The importance of strong instructional leadership remains at the forefront of the body of literature regarding effective schools (Purkey et al, 1983), although there is no sole identified leadership behavior or practice that can be agreed upon to increase student achievement (Bossert et al., 1982; Good et al, 1986).

Day, Harris, and Hadfield (2001) concluded effective school principals are those which share common values with the stakeholders of the school and foster a climate of collaboration for developing new strategies. Effective administrators solve problems through a variety of approaches including personal negotiations. Successful principals maintain a strong focus on commitment to learning and personal and professional 
development of students and staff alike while modeling core values of respect, fairness, integrity and honesty (Day et al, 2001). The study concluded that morale, emotional attachment, integrity and social bonds among the staff were commanding stimulants to motivation and commitment (Day et al, 2001).

Goodwin (2002) attributes the changing role of principals to growing accountability requirements. This research established that the management tasks remain the primary responsibility of the principals and may lead the job to become overwhelming (Mendez, 1987). The recent shortage of applicants for all administrative positions in schools (Olson, 1999: Portin et al., 1998: Waxman, 1999) has prompted a number of studies into principalship, its characteristics, its description, its changing state, and its future.

Dwindling resources, burgeoning paperwork, crumbling facilities, increasing public criticisms and expectations, growing numbers of students with special needs and increasing demands by teachers and parents to participate in decision making pose serious challenges to principals at virtually all levels and in nearly every area of the country (Davis, 1998, p. 58).

Portin and other educational researchers (1998) found that the responsibilities of the principal have changed to meet the demands of special education legislation, curriculum and instruction issues, and a growing need to participate in the political world (Portin et al., 1998). An increasing challenge exists because of the shortage of potential administrators (Associated Press, 2000; Batenhorst, 2002, Cushing, Gilman \& LanmanGivens, 2001). Cushing, Kerrins, and Johnstone (2003) pointed out that the difficulty is not in the number of individuals becoming credentialed, but rather in the number 
applying for positions as principals. A national survey completed jointly for the National Association of Secondary School Principals and the National Association of Elementary School Principals by the Educational Research Service (NAESC, 1998) indicated 37\% of active principals were over 50 years of age; the number of principal and assistant principal positions will continue to increase and deficiencies are being noted in all areas, types and locations of schools (NAESC, 1998).

Cushing, Kerrins, and Johnstone (2003) suggested hiring practices that define specific roles for administrators include suggestions that management and instructional leadership are separate jobs and should be handled by different people rather than expecting one principal to harbor the burden of all of these leadership roles. Mendez (1987) suggested the principal have a managerial staff that operates as a team to care for the day-to-day business of the school. Kaplan and Owings (1999) promoted the concept of a principal with assistant principals as a leadership team, with management staff under the assistant principals to manage the daily operation of the school. LaRose (1987) added that when principals and assistants have skills that complement one another, the overall leadership is strengthened.

The demands of high-performance school leadership indicate a need for new ways to manage and lead educational organizations. The No Child Left Behind Act of 2001 requires strong accountability, and the mandates of the federal legislation are resolute regarding major transformations. These mandates may impact the methods schools use to teach, manage learning, monitor learning, and structure the learning environment, further supporting the use of administrative teams to bring about those changes (USDE, 2006). 
In the ever-changing world of education, leaders must constantly renew their personal mastery (Senge, 2000). This is an endless revision and growth of the individual leader's vision, current reality, and creative tension. A personal vision is the ability to look beyond the current situation; a creative tension is every effort a leader makes when faced with failure and challenge; and the personal vision involves perseverance, as well as a determination and confidence to reach the desired goal. According to Senge (2000): personal mastery is a set of practices that support people, children and adults, in keeping their dreams whole, while cultivating an awareness of the current reality around them. This awareness is both what people want and what they will often logically create. In organizations a state of tension naturally seeks resolution (Senge, 2000); successful leaders lead this process effectively.

The effective-schools research emphasized several indicators of success, including high expectations that all children can learn, a clear and achievable mission, a safe and orderly environment, and respectful behavior of students and staff (Drvian \& Butler, 2001; Dunne \& Delisio, 2001). In addition, other factors in the examination of effective schools encompassed achievement of basic skills, strong instructional leadership, and frequent assessment of students' progress (Johnson \& Johnson, 1996; Walbers, Bakalis, Bast, \& Baer: 1989). Additional studies found a positive school climate that fostered learning encouraged shared leaderships (Barker, 1986; Codianni \& Wilburn, 1983; Coyle \& Witcher, 1992). Another finding from the school effectiveness planning research was that highly effective schools had both a strong leadership component (Lezotte, 1989), as well as principals who served as effective instructional leaders. 
Efforts over the past decade have focused largely on improving academic content and the assessments that measure whether students are learning the content. To maintain annual yearly progress (AYP), states have increased accountability efforts in recent years, holding principals ultimately responsible for gaps in student achievement. To encourage accountability, all states now provide school report cards, which commonly include student test scores broken down by race, family income, limited English proficiency and disability. According to the National Center on Educational Accountability, a significant increase exists in the number of states with statewide student-identification systems. These systems attach unique codes to each student to allow tracking of student individual test-score data that can be linked to specific schools or teachers. Forty-one states have such a system in place for the 2005-06 school years, up from 25 states in 2004-05 (NCEA, 2006).

The impact of the NCLB legislation continues to unfold across the country, placing standards and accountability into the focus of educational reform. Principals must develop comprehensive plans that assure every student will gain proficiency in reading, math and science by the year 2014. Comprehensive plans must demonstrate progress from year to year in raising the percentage of students who are proficient in reading and math and in lessening the achievement gap between disadvantaged and minority students and their peers. These mandates have placed more pressure on administrators and teachers to use research and evidence-based practices in schools. Because most reform efforts are not successful without the strong leadership of principals, school leaders are required to take the initiative as the instructional leaders 
and leaders of school-wide reform efforts (Barth, 2001). To assure all students are being successful in the classroom, schools must guarantee that every classroom is staffed by a teacher qualified to teach in his or her subject area .

DuFour (2000) refers to the "learning-centered principal" in his research. In this case, leadership as a principal is transformed from one who focused on teaching to a more successful principal who focused on learning. As a "learning leader," the principal draws on the strengths of teachers, understands how they learn in teams, and implements a detailed plan of action to improve student achievement (Schmoker, 2005).

Most research does not disagree that the principal is an important component in determining the success of any reform effort. Redefining leadership to meet the needs of the twenty-first-century learner requires a systematic, intentional change in leadership practice. This takes courage and a focus on what is vital to increasing student achievement (Collins, 2001). DuFour describes two vital elements that should be the focus of the effective leader: teamwork and a "guaranteed and viable curriculum" (Marzano, 2003, pg. 23).

\section{Research Relating to Smaller Learning Communities}

The U.S. Department of Education's Smaller Learning Communities Grants Program provides funds to assist large high schools (1000 students or more) in planning to implement or expanding smaller learning communities (SLC). All SLCs share common goals: to increase student learning and academic rigor, to promote equity to close achievement gaps between groups of students, to support stakeholders, and to acquire knowledge of foundational research (Oxley, 2004). 
Cotton (2001) identified five elements of successful SLCs: (1) Selfdetermination-- Autonomy in decision-making, physical separateness, self-selection of teachers and students, and flexible scheduling must all be present to allow SLC members to create and realize their vision. (2) Identity-- SLCs develop distinctive programs with unique characteristics; (3) Personalization-- Instruction should be tailored to avoid tracking of student groups; (4) Support for teaching-- SLC teachers have authority and responsibility in which leadership does not only reside with administrators; teachers lead through professional learning communities; and (5) Functional Accountability-Assessment data is used to demonstrate learning and success.

Cook's (2000) and Oxley's (2001) research states that smaller learning communities must begin with the larger organization changing to accommodate the new practices. The learning community cannot simply be added on to the existing high school structure. This research found that the larger structure may limit SLCs in three ways: competition of traditional practices with those in the small learning communities, limited financial support in order to sustain the SLC reform effort and SLCs may be viewed as a means of dealing with only specific groups of students, such as low achievers and those in freshmen transition.

Successful completion of ninth grade is an early indicator of whether or not a school is able to sustain reform efforts. Small learning communities (SLC) are most effective when interdisciplinary team members share a common group of students and are thereby able to pool their knowledge of students, communicate consistent messages, and create coherent instructional programs. Common planning time is essential for team collaboration. Team collaboration heightens teachers' shared sense of responsibility for 
students' learning. Teams that instruct their classes in the SLC avoid conflicts with teaching responsibilities outside the team that might make team collaboration and the scheduling of common planning time difficult (Oxley, 2004). Dedicated building space also facilitates team collaboration and in addition reinforces student identification with the SLC.

The empirical records indicate that the size of the school has an indirect affect on student learning (Klonsky, 1998). Ultimately, size creates conditions for success, especially when rigor and high expectations exist. After reducing size, the benefits become evident very quickly. As a result, students experience a greater sense of belonging and are more satisfied with their schools (Cotton, 1996), and fewer discipline problems occur (Raywid, 2000). There is a noted decrease in crime, violence and gang participation (Cushman, 1997), alcohol and tobacco abuse (Klonsky, 1998) and dropout rates (Funk and Bailey, 1999). The positive consequences of SLC reform are an increase in student attendance (Klonsky, 1998), improved graduation rates, and higher postsecondary enrollment (Funk and Bailey, 1999).

In smaller learning communities, the principals are the key in communicating a shared vision in order to strengthen instructional practices. In the SLC, the role of the administrator is redefined. Although the importance of the principal as the instructional leader has not changed (Cotton, 2003), the demands and challenges can be overwhelming, especially to principals who are new to the building or community (Barnett \& Greenough, 2004, p.12). Strong leadership is one that involves vision, practice and action. Sergiovanni (1996) describes this as moral leadership as one that gives direction, and brings diverse people together for a common cause. This type of 
effective leadership according to Paine, facilitates a shared vision, provides the foundation for assured accomplishment of the school mission and assists with insight into teacher challenges while leading them to self-discovered solutions (Paine, 2002).

In the smaller learning communities, the members of the team begin to solve problems; make inquiry regarding challenges; and collaborate for the sake of accomplishing the shared vision. The successful teams are provided regular times for self-managing, preparation, planning and lesson development to assure a strong curriculum (Schmoker, 2005). This requires that the school principals redefine the professional development of teachers.

Lezotte (1989) found that effective principals set high expectations for themselves and their staff members, expected continuous professional development and improvement, and involved the staff in school improvement. In this research, the principals set teaching and learning at the forefront of the schools' missions and goals.

Barth (1990) maintains the principal as instructional leader as essential in increasing student achievement, maintaining a positive school climate, and assuring the success of professional development. In other research, common principal behaviors that would ultimately result in increased student achievement were identified: involvement of teachers in decision-making, use of data to direct mission, participation in staff development with teachers, support of teachers' implementation of new materials and curriculum, communication of clear goals and high expectations, involvement of community partners, and celebration of achievements (Bottoms, 2000).

Collins' (2001) research believed that effective teamwork is fundamental in schools focusing on decreasing the achievement gap. Collins found that organizations 
that simplified plans of improvement were more successful. His concept deems the practice of simple-minded diligence will triumph over multifaceted complexity (Collins, 2001, pg. 90-91). In the SLC, the principal's role is not one of control but one of support. By increasing the strength of the SLC teams, the principal focuses on student learning and increased student achievement.

Raywid (1995) cites the benefits sought by downsizing efforts are contingent upon the ability of the subunits or sub schools to establish a collective identity, projecting clear, identifiable boundaries and displaying perceptible differences-palpable to students-from whatever lies beyond those boundaries. The professional learning communities within the large, comprehensive high school are critical if student achievement is to increase according to this research.

In addition to downsizing, another effective intervention involves increased programming for the freshmen population. The ninth grade year is critical to the success of the high school student. The research from Cassel et.al (2001) alleges the typical student enters high school in the United States at the beginning of adolescence (14 years of age) and their high school years are characterized by change and search for personal identity. This is an especially difficult year for students making the transition from a very nurturing environment of eighth grade to a more academically and socially rigorous environment of the high school. Many high schools have begun their reform efforts by taking a closer look at student data as the true indicators of a struggling school: high failure rates, high absentee rates, lower test scores, and higher rates of discipline referrals. These indicators point toward a need for high school reform that will address the needs of the ninth grade student, especially for students at risk of school failure. 
Intervention during this critical transition year may involve strategies such as smaller teacher/student ratios, increased support services such as counseling, and academic coaches, and creation of a more supportive school environment. The most effective means of dealing with mental health problems is the choice of outlets, such as choral music, band, art, and athletics. These extracurricular activities can serve as a diversion from alcohol abuse, drug addiction, and other self-destructive behaviors (Rose, 2000). In today's society, a high school diploma is the key to future economic prospects. In particular, it potentially opens the door to postsecondary education. However, many young people perform poorly in high school or drop out, especially students who are members of minority or low socio-economic status (SES) families. During the critical ninth-grade transition year, those at-risk students can be identified through the SLC. Teachers are better able to build relationships with these students when they have a smaller student/teacher ratio.

Research suggests that during the transition year many students feel anonymous and isolated (Cassel \& Reger, 2000). This leaves many students feeling a lack of peer and adult support. The smaller learning community allows the students to become a part of a team, which increases the number of students they come into contact with on a daily basis. A shared schedule among a small group of students also allows teachers to collaborate regarding curricular, social, and disciplinary actions. In a traditional high school structure, teachers normally have few opportunities to interact with their colleagues regarding classroom instruction, student behavior and progress, and school mission. Through the implementation of the smaller learning communities, teachers are grouped into teams. This structure allows teachers to collaborate, identify, and resolve 
problems before they become overwhelming. Ideally, this group of teachers, with the guidance of the school principal, would be given the power of decision-making regarding curricular, disciplinary, and professional development activities.

In the Smaller Learning Communities model, these freshmen teachers, representing the core curricular areas,(English, math, science and social studies) meet daily during a common planning period to standardize expectations, develop collaboration between the content areas, and, when necessary, conference with parents, students, and other teachers. The effective team will also have the authority to modify the student's schedule, change teachers, or modify the curriculum to meet the specific needs of the student. Each student is scheduled with common core subject area teachers. Teachers can more effectively identify common problems and begin to examine possible solutions regarding areas of concern.

\section{Summary}

Literature on leadership, teaching, and learning styles in effective schools indicate that both teachers and students want more collaborative and experiential learning; smaller learning communities appear to meet this requirement. However, a common thread within the research indicates small size is not enough. While size matters, researchers have found that small by itself does not necessarily lead to improved student achievement. Research affirms the relationship between leadership behaviors, smaller schools, and higher student achievement (Lezotte, 2001; Fowler, 1995; Lee \& Smith, 1997). Principals are essential in influencing change through the persuasion of high expectations (Payne, 2004). Because of the significance of the findings, there are 
demands for more research that investigates the role of the principals in increasing student achievement. Likewise, many studies indicate that the students most adversely affected by large schools size are those who are minorities or economically disadvantaged (Cotton, 1996). The findings show characteristics that tend to promote increased student achievement--such as, strong instructional leadership, quality of the social environment, teacher collegiality, increased parent involvement and students' sense of attachment to the school--are easier to implement in small schools. Thus, implementation plans must address these other key components of promoting student achievement and not size alone. In Oxley's (2004) research she sited SLC programs that encompass at least a half-day block of the students' instructional day as effective in increasing the high school students' sense of community and academic achievement. Other research points to the importance of changing the culture of large high schools (Felner \& Adan, 1988; Fener et al., 1997 McMullan, Sipe, \& Wolf, 1994; Oxley, 1990, 1997b). Oxley (2004) named other key essential practices such as interdisciplinary curriculum arranged around topics of interest to students, rigorous standards-based curriculum, teacher collaboration with community partners, and students who are engaged in active, authentic inquiry. These are especially true when teaching the ninthgrade population. It appears that there is a growing gap between research and practice. This study looks at the relationship between leadership styles and student achievement of ninth grade students. Where other research studies have been inconclusive this study will begin to explore the possibility of a statistical relationship between the leadership styles of principals in Smaller Learning Communities and student achievement levels in their respective schools. 


\section{Chapter 3}

Methods

This research examines the relationship between the leadership styles of principals in Smaller Learning Communities and the rates of student success of ninthgrade students. This study also examines the relationship of the number of methods used in the high school to enhance student learning and the relationship between the leadership styles of the principals. In addition, it will be determined if there is a relationship between the leadership style of the principal and the number of initiatives utilized to gain the full benefit of the smaller learning environment (academies, house plans, schools within schools, etc.). This chapter discusses the methods used in this study. The chapter is structured in eight sections: research design, population, sampling, instrumentations, procedure, data analysis, confidentiality and anonymity and summary.

\section{Research Design}

To determine if there was a statistically significant relationship of the leadership style of principals in Smaller Learning Communities, the numbers and types of structures and strategic configurations and the rates of student success of ninth-grade students in the respective schools, the principal's leadership style was initially identified. Secondly, that style (none, single, paired- and multi-frame use) was analyzed with respect to the numbers and types of structures and strategic configurations. Thirdly, the style was analyzed with respect to the rates of student success of ninth-grade students in the respective schools. In this study, the design is appropriate because the two variables are the leadership style of the principals in Smaller Learning Communities and the rates of student success of ninth-grade students in the respective schools. The independent 
variable is categorical while the dependent variable is quantitative. According to the previous research (Bensimon, 1987; Cantu, 1997; Bethel, 1998; Bowen, 2004; Chang, 2004; Mathis, 1999; Mosser, 2001; Small, 2002), the principal's leadership styles vary in Bolman and Deal's four frames. The frames consist of the structural frame, the human resource frame, the political frame, and the symbolic frame, all of which were discussed extensively in chapters one and two. Each of the frames represents a specific perspective with its own assumptions and behaviors. The leaders may champion single frame, pairedframe, multi-frame orientations or possibly none at all. A single frame leader would use only one frame, a paired-frame would use two frames, a multi-frame leader would use more than two frames and finally, a no frame orientation would indicate the leader used no specific style. In this study, it will be determined if there is a significant statistical relationship between the leadership style of the principal in the high school with Smaller Learning Communities and the student achievement levels of the ninth grade student population. Accordingly, a causal-comparative design can be utilized in this research because it determines the cause or consequences of differences that already exist between or among groups of individuals (Fraenkel and Wallen, 2000).

\section{Population}

The population of this study was principals of Smaller Learning Communities and the ninth-grade students in the respective schools. There are two hundred and four schools in Cohort 2003-A and ninety-eight in Cohort 2003-B, for a total of 302 schools involved in the study. These schools are the 2003 grantees of the Smaller Learning Communities (SLC) grant funding. The first round of the grant funded the 204 schools in Cohort 2003-A, the second round of the grant funded 98 schools in Cohort 2003-B. 
These schools range in size and organization. However, they are all high schools that meet the guidelines of the SLC funding guidelines. Congress appropriated \$125 million to the Smaller Learning Communities program for FY 2001. In December of 2001, Congress appropriated $\$ 142$ million to the Smaller Learning Communities program for FY 2002 funds for the 2003 SLC competition. Title X, Part A, Section 10105 of the Elementary and Secondary Education Act as reauthorized by the Improving America's Schools Act of 1994; - Smaller Learning Communities: The Smaller Learning Communities Program provides grants to local educational agencies (LEAs) on behalf of large high schools to help the high schools downsize into Smaller Learning Communities. Large high schools are defined as those that include grades eleven and twelve and enroll at least one thousand students in grades nine and above. Grantees use a variety of downsizing activities, such as restructuring into academies, houses, schools-within-aschool, and magnet programs. They also employ strategies to make their learning environments smaller through freshman transition activities, multi-year groups, alternative scheduling, adult advocate or advisory systems, and academic teaming (USDE, 2006).

\section{Population}

All 302 high schools in the population were surveyed. Initially, a unique number was assigned to each school and their respective principals. The total number of schools was 302 and the total number of principals was 302 . Ten teacher surveys were mailed with the principal survey. The principals were asked to distribute the teacher surveys to the ninth grade Smaller Learning Communities teachers. The number of returned principal surveys was one hundred twenty-four (41\%). The total number of principals 
with teacher surveys returned is $99(33 \%)$. In order to run a complete analysis of the data, it was required that a principal and teacher survey be returned. If a principal returned their demographic survey and had no teacher surveys returned, it was not possible to run an analysis of the principals' leadership style. In addition, if it appeared that the teacher survey was skewed (for instance, the teachers answered five or zero on all Likert style survey questions), the teacher survey was excluded. As a result, after the data were extracted from teachers' and principal's surveys, 79 of the 99 principals (nearly $80 \%$ ) were used in most of the analysis.

\section{Instrumentation}

This research used two instruments: the Bolman and Deal's Leadership Orientations (Others) (See Appendix A) and a short survey given to each participating principal (Appendix C). The Leadership Orientation instrument was used by ninth-grade high school teachers from Smaller Learning Communities to collect data to identify principals' leadership style. A short inventory to collect data regarding the principal's gender, number of years of experience in education and number of years in administration was included in the packet of information sent to the school (Appendix C).

The Leadership Orientations (Others) Instrument

The Leadership Orientations (Others) Instrument, developed by Lee Bolman and Terry Deal in the 1980's is a survey instrument that measures orientations toward leading through each of the four frames. This version of the Bolman and Deal instrument is termed "others" because it is a rating completed by subordinates rating the leadership 
style of the principal, rather than the principal completing a self analysis. This version consists of three sections. The first section contains rating scales and the items are used to determine the frame or frames that the investigated administrator champions. Each of the four frames of leadership is represented by eight items. The items are in a consistent frame sequence: structural (item 1, 5, 9, 13, 17, 21, 25, 29,), human resource (items 2, 6, 10, 14, 18, 22, 26, 30), political (items 3, 7, 11, 15, 19, 23, 27, 31) and symbolic (items 4, $8,12,16,20,24,28,32)$. The second section contains six forced-choice items. The options under each item are arranged in the same sequence as the first section. The last section has two one-item measures: effectiveness as a manager, and effectiveness as a leader. Respondents use a five-point Likert scale to rate the degree to which they exhibit each leader behavior $(1=$ Never, $2=$ Occasionally, $3=$ Sometimes, $4=$ Often, and $5=$ Always $)$. A principal with a mean score on the questions of a section equal to or above 4.0 is classified as using that leadership frame.

The validity of the Leadership Orientations (Others) survey was established and reported by authors in an unpublished paper in 1990. A factor analysis of 681 higher education administrators, using principal components and varimax rotations, yielded a high degree of internal consistency (Bolman \& Deal, 1992). With regard to the reliability, the statistics for Leadership Orientations on the basis of 1309 colleague ratings for a multi-sector sample of managers in business and education reported on Lee Bolman's web page (http://www.leebolman.com/index.htm), titles as Potential Users of Leadership Orientations Instruments show that the split-half correlations for four frames is beyond 0.8, the Spearman-Brown coefficient, and Buttman (Rulon) coefficient exceed 0.9 . 
Table 2 demonstrates the Cronbach's alpha for the frame measures are very high, ranging from .91 to .93 (Bolman \& Deal, 1991). The Leadership Orientations (Others) survey instrument has been used in numerous studies (Bensimon, 1989; Bethel, 1998; Bolman \& Deal, 1991b; Bowen, 2004; Carter, 1995; Chang, 2004; Crist, 1999; Mathis, 1999; Mosser, 2000; Small, 2002).

Table 2

The Structure of the Bolman \& Deal Leadership Orientations (Other) Surveys

\begin{tabular}{lcc}
\hline Survey Section and Frame & $\begin{array}{c}\text { Reliability } \\
\text { (Coefficient Alpha) }\end{array}$ & $\begin{array}{c}\text { Number of Peers Reliability } \\
\text { Coefficients Reported }\end{array}$ \\
\hline Section I: & $r=.920$ & 1,309 \\
Structural frame & $r=.931$ & 1,331 \\
Human resource frame & $r=.913$ & 1,268 \\
Political frame & $r=.931$ & 1,315 \\
Symbolic frame & & \\
& & \\
Section II: & $r=.841$ & 1,229 \\
Structural Frame & $\mathrm{r}=.843$ & 1,233 \\
Human resource frame & $r=.799$ & 1,218 \\
Political Frame & $r=.842$ & 1,221 \\
Symbolic Frame & & \\
\hline
\end{tabular}

From Bolman, L. (2001). http://www.bsbpa.umkc.edu/classes/bolman/Default.htm

Permission to use the Bolman and Deal Leadership Orientations was granted by Lee Bolman (Appendix B).

\section{Procedure}

This research used a self-report survey procedure to collect data with a hard copy. The participants' names of the sampled principals and their mailing and E-mail addresses were available on the web and various directories in the United States Department of Education data base.

A letter to invite the selected principals $(\mathrm{N}=302)$ and their subordinates $(\mathrm{N}=3020)$ to participate in the study was sent via land mail. A hard copy of the Bolman and Deal's 
Leadership Orientations (Others) and the letter requesting participation in the survey was sent to each of the participating principals. The principals were asked to distribute the surveys to the ninth-grade teachers in the Smaller Learning Communities. In the teacher envelope, each contained a letter describing the importance of the research and inviting them to participate by completing the enclosed survey and returning it in the selfaddressed, stamped envelope. The principals were asked to complete a short inventory regarding their gender, number of years of experience in education and number of years in administration (Appendix C). In addition, the principals were asked to provide the number of ninth-grade D's and F's in science, social studies, algebra I and English. Each participant was asked to respond within two weeks by returning the questionnaire using the self-addressed, stamped envelope, or opting for the online version of the survey.

A follow-up cover letter (Appendix E) and another survey instrument were sent to those who did not respond within the two weeks to further request their participation. The respondents were given another two weeks to respond. A second-follow-up letter was sent to request the responses of those who did not respond within the two weeks after the first follow-up letter was mailed in an attempt to reach a fifty-percent response rate across all categories.

Finally, a third mailing (Appendix F) was sent to non-respondent principals from schools that had teacher responses documented. This letter invited these principals to send in their principal survey in order for their school to be included in this research project. 


\section{Data Analysis}

The data were generated from the Bolman and Deal's Leadership (Others). The statistical methods utilized to analyze the data in order to determine the relationship between the leadership styles of principals, as measured by the four leadership frames are described in the research questions in this section. The Statistical Analysis System (SAS) or SPSS was used for the required statistical computations. An alpha level of .05 was the level of significance for this study and .01 and .001 levels were reported as well.

Question 1. What are the leadership styles (as measured by the four frames) of the principals in schools with Smaller Learning Communities?

The Bolman and Deal's Leadership Orientations (Others) was utilized to collect data regarding question one. The overall mean and standard deviation of each frame were computed. Following, the mean of each leadership frame was computed individually. A principal whose mean score reported by his or her subordinates was 4.0 or above on the 5-point Likert scale was considered to be espousing that frame. The overall mean, standard deviation by the four frames, and the number of the respondents who were using each of the four frames were reported. Frequencies and percentage of the principals who utilized various patterns of none, single, paired, and multi-frame were also identified and reported.

Question 2. Are there differences in leadership styles (none, single, paired and multiple) of principals by the demographic variables locale (rural/urban), gender (male/female), size of the school (small/medium/large), and the principals' 
number of years of experience $($ emergent $=0-5$ years, mid-career $=6-10$ years, established $=$ more than 11 years $) ?$

To examine Research Question 2, four chi-squares were conducted on leadership styles (none, single, pair, and multiple) by demographic variables (Locale, Gender, School Size, and Years of Experience).

Question 3. Is there a statistically significant relationship between the leadership (frame/s) of the principals (structural, human resource, political, and symbolic) with the level of discipline referral rates (number of referrals/number of students), levels of student achievement (Grade Point Average of at least 2.0/passing level) in four subject areas (regular ninth-grade English, regular algebra, regular ninth-grade social studies, and regular ninth-grade science) and attendance rates (attendance/number of students)?

To examine Research Question 3, Twenty-four Pearson correlations were conducted between the four frames (structural, human resources, political, and symbolic) with referral rate (number of referrals/number of students), four subject areas (English, algebra, social studies, and science), and attendance rates (attendance/number of students).

Question 4. Is there a statistically significant relationship between the leadership styles of the principals (none, single, paired, and multiple) with the level of discipline referral rates (number of referrals/number of students), levels of student achievement (grade point average of at least 2.0/passing level) in four subject areas (regular ninth-grade English, regular algebra, regular ninth-grade 
social studies, and regular ninth-grade science) and attendance rates (attendance/number of students)?

To examine Research Question 4, Twenty-four Pearson correlations were conducted between the four Leadership styles (none, single, paired, and multiple) with referral rate (number of referrals/number of students), four subject areas (English, algebra, social studies, and science), and attendance rates (attendance/number of students).

Question 5. What are the differences between the various patterns of leadership styles (none, single, paired and multiple) of principals in Smaller Learning Communities, and the frequency of the six structures implemented by the SLC school (career academies, freshman academy, house plans, theme-based academies and school-within-a-school)?

To examine Research Question 5, six cross tabulations were conducted on frame pattern by structures (career academy/academies, freshmen academy, house plans, school-within-a-school, theme-based academies, community/communities) structures one through six and (Yes versus No).

Question 6. What are the differences between the various leadership styles (none, single, paired and multiple) of principals in Smaller Learning Communities and the use of the six strategies implemented by SLC schools (academic teaming, alternative scheduling, freshmen transition activities, teacher advisory systems, adult advocate systems and individual/personalized academic plans) as measured by means and standard deviation on the six strategies (listed above) by each frame pattern (none, single, paired, and multiple)? 
To examine Research Question 6, means and standard deviations were calculated for the six strategies (academic teaming, teacher advisory systems, individual/personalized academic plans, alternative scheduling, freshmen transition activities, and dual enrollment) by each leadership style (none, single, paired, and multiple).

Research question $6 a$. What are the differences in the levels of student achievement (grade point average of at least 2.0/passing level) in the four subject areas (regular ninth-grade English, regular algebra, regular ninth-grade social studies, and regular ninth-grade science) by locale (urban/rural)?

To examine Research Question 6a, a MANOVA and 4 ANOVAs were conducted on the 4 subjects (English, algebra, social studies, and science) by Locale. Assumptions of MANOVA — normality, homogeneity of variance/covariance matrices_-will be assessed.

Research question $6 b$. What are the differences in the levels of student achievement (Grade Point Average of at least 2.0 passing level) in the four subject areas (regular ninth-grade English, regular algebra, regular ninth-grade social studies, and regular ninth-grade science) by school size (small, medium and large)?

To examine Research Question 6b, a MANOVA and 4 ANOVAs were conducted on the 4 subjects (English, algebra, social studies, and science) by school size (small, medium, and large). Assumptions of MANOVA—normality, homogeneity of variance/covariance matrices — will be assessed. 
Research question $6 c$. What are the differences in the levels of student achievement (grade point average of at least 2.0/passing level) in the four subject areas (regular ninth-grade English, regular algebra, regular ninth-grade social studies, and regular ninth-grade science) by the principals number of years of experience in administration (emergent $=0-5$ years $/$ mid-career $=6-10$ years/established=more than 11 years)?

To examine Research Question 6c, a MANOVA and 4 ANOVAs were conducted on the 4 subjects (English, algebra, social studies, and science) by years (emergent, mid-career, established). Assumptions of MANOVAnormality, homogeneity of variance/covariance matrices—were assessed.

\section{Confidentiality and Anonymity}

This study was dependent upon responses from human subjects and requires their voluntary participation. Their anonymity and confidentiality was protected consistent with the Institutional Review Board (IRB) standards and policies. In the cover letter, the subjects were provided with information such as the purpose of the research, a comment that participation is voluntary, the right to not respond to every item, and the assurance of confidentiality and anonymity. Participant codes were assigned to protect the identity of each of the respondents. Cover letters are included in appendices and are labeled accordingly: cover letter to principals (Appendix D), cover letter second mailing (Appendix E), cover letter principal third mailing (Appendix F), and cover letter to ninth grade teacher (Appendix G). Survey responses were coded with numbers for subsequent use and all identities were kept confidential. Approval by the West Virginia University 
Institutional Review Board for the Protection of Human Subjects is documented in Appendix H.

\section{Summary}

In this chapter, the method used to examine the relationship between the leadership styles of principals in Smaller Learning Communities, the numbers and types of structures and strategic configurations and the rates of student success of ninth-grade students in the respective schools was described. The Bolman and Deal's Leadership Orientation (Others) was used to collect data to answer the six research questions. In addition the principals were asked to provide information regarding their gender, years of experience, school locale and size. Also included on the principal survey was the number of D's and F's of ninth-grade students during first semester 2005/2006 school year. The survey was mailed to the subjects and the participants responded by using the selfaddressed, stamped-envelope. The Statistical Analysis System (SAS) and SPSS were used for statistical computations to analyze the data. An alpha level of .05 was the criterion level of significance for this study, and .01 and .001 levels were reported as well. The results of the data analysis are presented in Chapter 4. 


\section{Chapter 4}

\section{Results}

This chapter presents the results of the study regarding the relationship between the leadership styles of principals in smaller learning communities, the number and types of structures and strategic configurations in high schools with smaller learning communities, and the rates of success of $9^{\text {th }}$ graders. The major hypothesis examines whether there is a statistically significant relationship between the leadership style of principals in smaller learning communities, the number and types of structures and strategic configurations, and the rate of student success of 9 th grade students. The first section contains the demographic data for principals and teacher respondents. The second section describes the approaches used to deal with missing values. The third section presents the results of the examination of the reliability of the survey instruments, leadership orientations (other) and the principal survey. The fourth section analyzes the data within the framework of the six research questions. The chapter concludes with a summary.

\section{Survey Responses}

The population of this study was principals of smaller learning communities and their 9th grade students. There are 204 schools in Cohort 2003-A and 98 in Cohort 2003-B, for a total of 302 schools. These schools are the 2003 recipients of the Smaller Learning Communities (SLC) grant funding. The first round of the grant funded the 204 schools in Cohort 2003-A, the second round of the grant funded the 98 schools in Cohort 2003-B. These schools vary in size and organization. 
The 2003 SLC recipients completed the first principal and teacher surveys in April, 2006. Each school received one principal survey and ten teacher surveys, totaling 3,020 teachers and 302 principals surveyed. Although the data regarding the specific number of ninth grade teachers at each school was not collected, it was understood, but not confirmed, that most schools in the study would have at least 10 ninth grade teachers. After three mailings to invite the selected schools to participate in this study, 456 teacher and 124 principal surveys were tabulated. Fifteen of the 124 principals requested to be removed from the study. Thirty of the returned principal surveys did not have corresponding teacher surveys. The valid response rate was $33.1 \%(100 / 302)$ for principals and $15.1 \%$ (456/3020) for teachers, A total of 456 teachers completed the leadership orientation surveys; these 456 teachers evaluated 99 principals. On average 4.6 teachers rated each principal's frame use.

Among the 79 principal respondents, 47 were male, 32 were female, and 20 respondents did not report gender (table 6). The teacher surveys did not identify the gender of the responding teacher. The data analysis by demographic and school variables in the following sections only included those records with complete information. The records with missing data were excluded, so the total number of participating schools or principals in the analyses by different demographic variables may or may not be exactly the same.

\section{Reliability of Scales}

Bolman and Deal's Leadership Orientations (Other) Survey has been used in business, industry and higher education. These settings vary in culture and demographic setting. 
Reliability statistics for leadership orientations (based on approximately 1,300 colleague ratings for a multi-sector sample of managers in business and education) is located on the Bolman and Deal website (http://www.bloch.umkc.edu/classes/bolman/new page $1 . \mathrm{htm})$.

\section{Leadership Orientation (other)}

The Leadership Orientation (other) is used to measure the leadership orientation of principals based on teacher rating on a 32-item responses survey. The principals' leadership orientation is categorized into four frames (structural, human resource, political, and symbolic). Teachers complete the survey questions using a five-point Likert scale ( $1=$ Never, $2=$ occasionally, $3=$ Sometimes, $4=$ Often, and 5=Always) to rate their principals' leadership style.

\section{Major Findings}

The major findings of the data analysis as they pertain to each of the research questions are presented in this section.

Question 1. What are the leadership styles (as measured by the four frames) of the principals in schools with smaller learning communities?

To answer this question, the means and standard deviations of the principals' four leadership frames as evaluated by teachers will be calculated first. Then, the frequency distribution of principals' leadership style and frame pattern for each style will be reported. 
Table 3 shows the means and standard deviations of principals' four leadership frames according to the teachers' perception. The means of the structural $(\mathrm{M}=3.8, \mathrm{ST}=.87)$, human resource $(\mathrm{M}=3.8, \mathrm{ST}=.94)$, and political $(\mathrm{M}=3.8, \mathrm{ST}=.91)$ frames are the same with a slightly different standard deviation. The mean of the symbolic frame is 3.7 with a standard deviation of .95 . This indicates that the degree to which the use of the four leadership frames by the principals from smaller learning communities is quite similar as perceived by teachers.

Table 3

Means and Standard Deviations of Principals' Four Leadership Frames by Teachers

\begin{tabular}{lcc}
\hline \multicolumn{1}{c}{ Frame } & Mean & Standard Deviation \\
\hline Structural & 3.8 & 0.87 \\
Human Resource & 3.8 & 0.94 \\
Political & 3.8 & 0.91 \\
Symbolic & 3.7 & 0.95 \\
\hline N=456 & &
\end{tabular}

$\mathrm{N}=456$

Table 4 shows the frame frequency distribution among the principals in this study.

The structural frame was the most frequently used among the principals, with 43 principals espousing this frame. This may indicate the principals in high schools with Smaller Learning Communities ability to provide clarity, predictability and security while prescribing formal roles (Bolman, 1999). In Bolman and Deal's article Four Steps to Keeping Change Efforts Heading in the Right Direction, the authors indicate that reform may undermine existing structures, creating uncertainty, insecurity and doubt. When teachers become unsure about their duties, confused about how to relate to other teachers and staff, and unsure of whom is in charge, confusion begins to rule. In order to minimize such difficulties, change efforts must anticipate structural issues and work to 
realign roles and relationships (Bolman, 1999). The teachers in this study rated most of the principals using the structural frame, which is representative of one-third of the principals in the survey.

Following the structural frame, there are 37 principals identified as espousing the human resource frame. These thirty seven principals are representative of one-fourth of the one-hundred-forty-five frames identified. According to the teacher ratings, only 33 principals used the political frame and 32 principals used the symbolic frame.

This finding is somewhat different than other similar studies using the Others instrument. In Chang's study (2004), he found that department chairs were rated by faculty as using the human resource frame most frequently (29.6\%), with the structural following (27.2\%). Likewise, in Bowen's study (2004) of West Virginia University Extension Service County Coordinators, the human resource frame had the highest rate of endorsement, followed by the structural frame.

Table 4

Frame Frequency

\begin{tabular}{lc|c}
\hline \multicolumn{1}{c|}{ Frame } & Frequency & Percentage \\
\hline Structural & 43 & $30 \%$ \\
Human Resource & 37 & $25 \%$ \\
Political & 33 & $23 \%$ \\
Symbolic & 32 & $22 \%$ \\
TOTAL & 145 & $100 \%$ \\
\hline
\end{tabular}

Table 5 shows the frequency distribution of principals' leadership style and frame pattern for each style as reported by teachers. Of the 99 principals whose uses of leadership frames were evaluated by teachers, 48 were reported as not using any frames. 
In other words, their scores on all four frames were averaged lower than 4 . This cohort accounts for about $50 \%$ of all participants. The participating teachers rated 11 principals as using only one of four leadership frames, accounting for $11 \%$. They also believe that nine percent of the principals they assessed used any two of four leadership frames. Finally, approximately one-third of principals were reported using multiple frames, either three or four. The chi-square test for independence indicates that there is a significant preference on the implementation of leadership style by principals, $\chi^{2}(3, n=99)=41.08$, $p<.001$.

Table 5 presents the frame pattern of single, paired, and multiple leadership styles. As for the single leadership style, the majority of rated principals espoused the structural frame (about 64\%), followed by the human resource and political frames, each accounting for $18 \%$. No one was reported as using the symbolic frame.

The espousers of the paired-leadership style tend to use the combination of the structural and political frames. This is followed by the combinations of the structural and human resource frames, and the human resource and symbolic frames. Teachers reported that the combination of the structural and symbolic frames, and the human resource and political frames was only used each by one principal (11\%). The combination of the political and symbolic frames was not used by the participating principals according to teachers' rating.

The data were extracted from teachers' survey and the principal's survey. According to teachers' survey, 99 principals were evaluated, so the Table 4 includes 99 principals with a leadership frame pattern. However, among these 99 principals who were rated by teachers, only 79 responded to the survey; these were used to extract demographic or 
school information. All of the 99 principals were included in the frame pattern analysis. However, when analyzing data by demographic or school variables, only 79 schools or principals were included rather than all 99.

Table 5

Frequency Distribution by Frame Pattern

\begin{tabular}{|c|c|c|c|}
\hline Category/Pattern & $\mathrm{F}$ & $\begin{array}{c}\% \\
\text { (as to category) }\end{array}$ & $\begin{array}{c}\% \\
\text { (as to total) }\end{array}$ \\
\hline No-frame & 48 & 100.0 & 48.5 \\
\hline \multicolumn{4}{|l|}{ Single-frame } \\
\hline Structural & 7 & 63.6 & 7.1 \\
\hline Human Resource & 2 & 18.2 & 2.0 \\
\hline Political & 2 & 18.2 & 2.0 \\
\hline Symbolic & 0 & 0.0 & 0.0 \\
\hline Sub-Total & 11 & 100.0 & 11.1 \\
\hline \multicolumn{4}{|l|}{ Paired-frame } \\
\hline Structural/Human Resource & 2 & 22.2 & 2.0 \\
\hline Structural/Political & 3 & 33.3 & 2.0 \\
\hline Structural/Symbolic & 1 & 11.1 & 1.0 \\
\hline Human Resource/Political & 1 & 11.1 & 1.0 \\
\hline Human Resource/Symbolic & 2 & 22.2 & 2.0 \\
\hline Political/Symbolic & 0 & 0.0 & 0.0 \\
\hline Sub-Total & 9 & 100.0 & 9.0 \\
\hline \multicolumn{4}{|l|}{ Multi-Frame } \\
\hline Structural/Human Resource/Political & 1 & 3.2 & 1.0 \\
\hline Structural/Human Recourses/Symbolic & 4 & 12.9 & 4.1 \\
\hline Structural/Political/Symbolic & 1 & 3.2 & 1.0 \\
\hline Human Resource/Political/Symbolic & 1 & 3.2 & 1.0 \\
\hline Structural/Human Resource/ Political/Symbolic & 24 & 77.4 & 24.2 \\
\hline
\end{tabular}


Sub-Total

100.0

31.1

Total

99

100.0

As demonstrated in Table 5, within the multi-framed principals, a vast majority of principals $(77 \%)$ followed a four-frame pattern. Of the 31 multi-framed principals, four principals used the combination of the structural, human resource, and political frames. Three principals espoused the combined structural, the human resource, and the political, the structural, the symbolic, and political, and the human resource, the symbolic, and the political, respectively frames; each accounts for only about $3 \%$.

Question 2. Are there differences in leadership styles (none, single, paired and multiple) of principals by the demographic variables (locale (rural/urban), gender (male/female), size of the school (small/medium/large), and the principals' number of years of experience $($ emergent $=0-5$ years $/$ mid-career $=6-10$ years/established $=$ more than 11 years)?

The participating principals were classified into two groups according to their school's geographical location. Those principals from schools located in large or mid-size central cities were categorized as "From Schools Located in a City," while those from schools located in rural, small town, urban fringe of large city or urban fringe of mid-size city was defined as "From Other Schools." As shown in Table 6, 41 principals were from schools located in a city and 58 were from other schools.

Table 6 also presents principals' leadership style by school location. More than half of principals from schools located in a city did not use any frame as reported by teachers, while about $43 \%$ of principals from other schools were rated as non-frame espousers by their subordinates. The second leadership style preference of the principals from schools 
located in either a city or other areas was multiple-frame, accounting for $24 \%$ and $36 \%$, respectively. The third leadership preference for those principals from schools located in a city was paired-frame, while it was single-frame for those principals from schools located in other areas. However, the chi-square test for independence did not show any significant relationship between school location and principals' leadership style as reported by teachers, $\chi^{2}(3, \mathrm{n}=99)=6.72, p>.05$. In other words, the frequency distribution of principals' leadership style is not significantly different by school location.

Table 6

Frequency Distribution of Principals' Leadership Style by Locale

\begin{tabular}{lcccc} 
& \multicolumn{2}{c}{ Schools Located in a City } & \multicolumn{2}{c}{ Other Schools } \\
\cline { 2 - 5 } \multicolumn{1}{c}{ Style } & Frequency & $\%$ & Frequency & $\%$ \\
\hline Non-Frame & 23 & 56.1 & 25 & 43.1 \\
Single-Frame & 2 & 4.9 & 9 & 15.5 \\
Paired-Frame & 6 & 14.6 & 3 & 5.2 \\
Multiple-Frame & 10 & 24.4 & 21 & 36.2 \\
Total & 41 & 100 & 58 & 100 \\
\hline
\end{tabular}

The frequency distribution of principals' leadership style by gender is reported in Table 7 . About $55 \%$ of male principals were reported as using a non-frame leadership style, while nearly $41 \%$ of their female counterparts followed the same style. The second largest group of male principals was composed of those who used multiple frames, (about one-fourth), while female principals tied for the first place in the use of non-frame and multi-frame leadership styles. The percentages of the female and male principals following a single- or paired-frame leadership style were very close, around $10 \%$. However, the chi-square test did not show a significant relationship between principals' leadership style and gender, $\chi^{2}(3, \mathrm{n}=79)=2.25, p>.05$. 
Table 7

Frequency Distribution of Principals'Leadership Style by Gender

\begin{tabular}{|c|c|c|c|c|}
\hline \multirow[b]{2}{*}{ Style } & \multicolumn{2}{|c|}{ Male } & \multicolumn{2}{|c|}{ Female } \\
\hline & Frequency & $\%$ & Frequency & $\%$ \\
\hline Non-Frame & 26 & 55.3 & 13 & 40.6 \\
\hline Single-Frame & 4 & 8.5 & 3 & 9.4 \\
\hline Paired-Frame & 5 & 10.6 & 3 & 9.4 \\
\hline Multiple-Frame & 12 & 25.5 & 13 & 40.6 \\
\hline Total & 47 & 25.5 & 32 & 40.6 \\
\hline
\end{tabular}

The analysis of principals' leadership style was also conducted by principal group based on the number of students enrolling in their schools. Principals were "From Small Schools" if their schools enrolled fewer than 400 students; principals from schools with enrollment from 400 to 599 were "From Medium Schools;" and other principals (from schools with an enrollment equal to or greater than 600) were "From Large Schools." As Table 8 shows, 21 principals were from small and medium schools, respectively, and 33 were from large schools.

As shown in Table $8(n=78$, one principal did not report school size), the teachers from small schools reported that nearly $38 \%$ of their principals used multiple frames, while the teachers from the medium and large schools, respectively, reported that about $26 \%$ and $30 \%$ of their principals followed this leadership style. The percentages of non-frame leadership style users in small, medium, and large schools were $42 \%, 58 \%$, and $48 \%$, respectively. For the paired-frame leadership style, five principals (21\%) from small schools used this style; one (3\%) was from medium schools; and only two (about 9\%) were from large schools. Teachers in small schools did not perceive that any of their principals used single-frame leadership style, while the teachers from medium or large schools reported that only two and three principals from their schools used this leadership 
style, respectively. Again, the chi-square test did not discover any significant relationship between the principals' leadership style and the size of their schools, $\chi^{2}(6, n=78)=8.64$, $p>.05$.

Table 8

Frequency Distribution of Principals'Leadership Style by School Size

\begin{tabular}{lllllll}
\hline \multicolumn{1}{c}{ Style } & \multicolumn{2}{c}{$\begin{array}{c}\text { Small } \\
(<400)\end{array}$} & \multicolumn{2}{c}{$\begin{array}{c}\text { Medium } \\
(400-599)\end{array}$} & \multicolumn{2}{c}{$\begin{array}{c}\text { Large } \\
(>=600)\end{array}$} \\
\cline { 2 - 7 } & Frequency & $\%$ & Frequency & $\%$ & Frequency & $\%$ \\
\hline Non-Frame & 10 & 41.7 & 18 & 58.1 & 11 & 47.8 \\
Single-Frame & 0 & 0.0 & 4 & 12.9 & 3 & 12.0 \\
Paired-Frame & 5 & 20.8 & 1 & 3.2 & 2 & 8.7 \\
Multiple-Frame & 9 & 37.5 & 8 & 25.8 & 7 & 30.5 \\
Total & 24 & 100.0 & 31 & 100.0 & 23 & 100.0 \\
\hline
\end{tabular}

Table 9 shows the frequency distribution of principals' leadership style by principals' experience in an administrative position. The term "emergent" describes principals with 0-5 years of experience in administration, "mid-career" is used to describe principals with 6-10 years of administrative experience and "established" describes principals with 11 years or more. Half of principals with less than five years of experience in administration positions were reported as using multiple frames, while only about $18 \%$ of principals with six to ten years of experience and $33 \%$ of principals with equal to or more than 11 years of experience used this leadership style. Conversely, more than half of the principals with more than six years of experience had a non-frame leadership style, while nearly $31 \%$ of principals with less than six years of experience followed a non-frame leadership theory according to teachers rating. The remainder of the principals espoused either a single-frame style or paired-frame style. However, there does not exist a significant relationship between principals' leadership style and their experience in an administrative position as perceived by teachers, $\chi^{2}(6, n=79)=6.33, p>.05$. 
Table 9

Frequency Distribution of Principals'Leadership Style by Principals' Number of Years of Experience at Administration Position

\begin{tabular}{lllllll}
\hline \multicolumn{1}{c}{ Style } & \multicolumn{2}{c}{$\begin{array}{c}\text { Emergent } \\
\text { (0-5 Years) }\end{array}$} & \multicolumn{2}{c}{$\begin{array}{c}\text { Mid-Career } \\
\text { (6-10 Years) }\end{array}$} & \multicolumn{2}{c}{$\begin{array}{c}\text { Established } \\
\text { (11 Years or More) }\end{array}$} \\
\cline { 2 - 7 } & Frequency & $\%$ & Frequency & $\%$ & Frequency & $\%$ \\
\hline Non-Frame & 5 & 31.3 & 15 & 55.6 & 19 & 52.8 \\
Single-Frame & 2 & 12.5 & 3 & 3.8 & 2 & 5.6 \\
Paired-Frame & 1 & 6.2 & 4 & 14.8 & 3 & 8.3 \\
Multiple-Frame & 8 & 50.0 & 5 & 18.5 & 12 & 33.3 \\
Total & 16 & 100.0 & 27 & 100.0 & 36 & 100.0 \\
\hline
\end{tabular}

Question 3. Is there a statistically significant relationship between the leadership (frame/s) of the principals (structural, human resource, political, and symbolic) with the level of discipline referral rates (number of referrals/number of students), levels of student achievement (Grade Point Average of at least 2.0/passing level) in four subject areas (regular ninth grade English, regular algebra, regular ninth grade social studies, and regular ninth grade science) and attendance rates (attendance/number of students)?

Since the data of the level of discipline referral rates and attendance rates are incomplete, the analysis for this question was only conducted to examine if there was a statistically significant relationship between the leadership frames and levels of student achievement. The level of student learning achievement in this and the following analyses was defined as the ratio of those whose GPA was at least 2.0 (passing level) to all the ninth graders attending to each of the four subject classes.

Table 9 presents Pearson correlation matrix of leadership frames and achievement level. The human resource frame has a negative correlation with student achievement in English and Social Studies. All other relationships between leadership frames and student achievement on subjects appear positive. However, the analysis indicates that there is no 
significant relationship between the four frames and the level of student achievement on four subjects (English, Algebra, Social Studies, and Science). This means that the degree of the principals' use of four leadership frames as reported by teacher does not have a significant influence on the student academic achievement in these four subjects.

Table 10

Pearson Correlation Matrix of Leadership Frames and Achievement Level

\begin{tabular}{lcccc}
\hline & English & Algebra & Social Studies & Science \\
\hline Structural & .0233 & .1573 & .0412 & .1222 \\
Human Resource & -.0407 & .1098 & -.0031 & .0539 \\
Political & .0690 & .1629 & .0912 & .1067 \\
Symbolic & .0065 & .0901 & .0203 & .0652 \\
\hline
\end{tabular}

Question 4. Is there a statistically significant relationship between the leadership styles of the principals (none, single, paired, and multiple) with the level of discipline referral rates (number of referrals/number of students), levels of student achievement (Grade Point Average of at least 2.0/passing level) in four subject areas (regular ninth grade English, regular algebra, regular ninth grade social studies, and regular ninth grade science) and attendance rates (attendance/number of students)?

Again, because the data of discipline referral rates and attendance rates are not complete, the analysis was only conducted to investigate the relationship between the leadership style and levels of student achievement. In addition, to conduct this analysis, the leadership style was recoded as non-frame $=0$, single-frame $=1$, paired-frame $=2$, and multiple-frame $=3$.

As presented in Table 11, there is a negative correlation of leadership style with student achievement in English and a positive correlation with the other three subjects. This means that the more frames a principal uses, the lower the level of student achievement in English, but the higher the level of student achievement in Algebra, 
Social Studies, and Science. However, the Pearson analysis did not find any significant correlation of leadership style with the level of student achievement in any subjects.

Table 11-

Pearson Correlation Matrix of Leadership Style and Achievement Level

\begin{tabular}{lcccc}
\hline & English & Algebra & Social Studies & Science \\
\hline Leadership Style & -.0029 & .1569 & .0767 & .1113 \\
\hline
\end{tabular}

Table 12 presents the means and standard deviations of learning achievement in four subjects by principals' leadership style. Students from schools with a principal using a paired-leadership style demonstrated a highest achievement in English, algebra, and science, while those from schools with a principal using a single-frame leadership style had a highest mean ratio of achievement in social studies. In contrast, students from schools whose principals followed a non- or single-frame leadership style revealed a lowest demonstration of achievement in social studies $(\mathrm{M}=.80, \mathrm{SD}=.17)$, and English $(\mathrm{M}=.76, \mathrm{SD}=.17)$, Algebra $(\mathrm{M}=.72, \mathrm{SD}=.22)$, and science $(\mathrm{M}=.75, \mathrm{SD}=.19)$, respectively. The ANOVA did not find any significant differences of student achievement in all four subjects by principals' leadership style. 
Table 12

Means and Standard Deviations of Achievement Level by Principal's Leadership Style

\begin{tabular}{lcccccc}
\hline & $\begin{array}{c}\text { Non- } \\
\text { Frame }\end{array}$ & $\begin{array}{c}\text { Single- } \\
\text { Frame }\end{array}$ & $\begin{array}{c}\text { Paired- } \\
\text { Frame }\end{array}$ & $\begin{array}{c}\text { Multiple- } \\
\text { Frame }\end{array}$ & $F$ & $p$ \\
\hline English & & & & & & \\
$M$ & .80 & .76 & .81 & .79 & .22 & .88 \\
$S D$ & .12 & .17 & .14 & .15 & & \\
Algebra & & & & & & \\
$M$ & .76 & .72 & .85 & .81 & 1.08 & .36 \\
$S D$ & .19 & .22 & .12 & .15 & & \\
Social & & & & & & \\
studies & .80 & .83 & .82 & .82 & .18 & .91 \\
$M$ & .17 & .18 & .13 & .12 & & \\
$S D$ & & & & & & \\
Science & .75 & .76 & .82 & .78 & .51 & .68 \\
$M$ & .19 & .14 & .13 & .17 & & \\
$S D$ & & & & & & \\
\hline
\end{tabular}

Question 5. What are the differences between the various patterns of leadership styles (none, single, paired and multiple) of principals in smaller learning communities and the frequency of the six structures implemented by the SLC school (career academy/academies, freshman academy, house plans, freshman academies, theme-based academies and school-within-a-school)?

The table below shows a very similar distribution of structures implemented by schools by principals' leadership style. Principals not using any frames are more likely to implement the structure of freshman academies, while those using single- or paired-frame leadership style are more likely to use career academies. Principals following multipleframe leadership theory use these two structures equally. Since more than $50 \%$ of the cells are less than five, the chi-square test was not conducted. 
Table 13

Frequency Distribution of Structures Implemented by Schools by Principals' Leadership Style

\begin{tabular}{|c|c|c|c|c|c|c|c|c|}
\hline \multirow[t]{2}{*}{ Structure } & \multicolumn{2}{|c|}{ None } & \multicolumn{2}{|c|}{ Single } & \multicolumn{2}{|c|}{ Paired } & \multicolumn{2}{|c|}{ Multiple } \\
\hline & \# & $\%$ & \# & $\%$ & \# & $\%$ & $\#$ & $\%$ \\
\hline $\begin{array}{l}\text { Career Academy } \\
\text { /Academies }\end{array}$ & 16 & 43.2 & 5 & 71.4 & 5 & 62.5 & 11 & 44.4 \\
\hline $\begin{array}{l}\text { Freshman Academy/ } \\
\text { Academies }\end{array}$ & 19 & 51.4 & 2 & 28.6 & 4 & 50.0 & 11 & 44.4 \\
\hline House Plans & 4 & 10.8 & 1 & 14.3 & 1 & 12.5 & 3 & 12.0 \\
\hline Theme-Based Academies & 2 & 5.4 & 1 & 14.3 & 2 & 25.0 & 1 & 4.0 \\
\hline School-Within-a-School & 5 & 13.5 & 1 & 14.3 & 0 & 0.0 & 5 & 20.0 \\
\hline Total Number of Schools ${ }^{\mathrm{a}}$ & 37 & & 7 & & 8 & & 25 & \\
\hline
\end{tabular}

a. "Total Number of Schools" by leadership style refers to the number of schools with principals using the stated leadership style. A school may implement more than one structure, so it may appear more than once in the column for each leadership style if it implements more than one structure. Therefore, the sum of the number of structures in each column by leadership style may be higher than the number of schools. The percentage for each structure was calculated by dividing the number of structures implemented by schools by "Total Number of Schools," so the sum of percentages for each leadership style may be more than 100 percent.

Table 14, following, shows the means and standard deviations of structures implemented by schools by principals' leadership style. The mean of structures implemented was calculated by counting the structures used by the schools by principals' leadership style, and then divided by the total number of principals in each group by leadership style. Some schools might implement more than one structure, while others might not implement any. Schools with principals using paired-frame leadership style have the highest mean, followed by schools with principals using single-frame leadership style, while schools with principals using no-frame or multiple-frame leadership style has 
the lowest mean. The ANOVA test did not show any significant difference of the means of structures implemented by schools by principals' leadership style, $F_{(3,75)}=.60, p>.05$.

Table 14

Means and Standard Deviations of Structures Implemented by the SLC School by Principals' Leadership Style

\begin{tabular}{lcccccc}
\hline & $\begin{array}{c}\text { Non- } \\
\text { Frame }\end{array}$ & $\begin{array}{c}\text { Single- } \\
\text { Frame }\end{array}$ & $\begin{array}{c}\text { Paired- } \\
\text { Frame }\end{array}$ & $\begin{array}{c}\text { Multiple- } \\
\text { Frame }\end{array}$ & $F$ & $P$ \\
\hline$M$ & 1.2 & 1.4 & 1.5 & 1.2 & .60 & .61 \\
$S D$ & .72 & .53 & .53 & .79 & & \\
\hline
\end{tabular}

The Pearson correlation coefficients were calculated between the number of the structures implemented by school and principal leadership frame as reported by teacher. The Pearson analysis found a significant correlation between the number of structures adopted by the SLC schools and leadership frame as shown in Table 15. This indicates that the higher a principal was scored by teacher on the structural, political, and symbolic frames, the more structures his or her school implemented.

Table 15

Pearson Correlation Matrix of Leadership Frame and Number of Structures Implemented by Schools

\begin{tabular}{lcccc} 
& Structural & Human Resource & Political & Symbolic \\
\hline $\begin{array}{l}\text { Number of } \\
\text { Structure }\end{array}$ & $.2050^{*}$ & .1776 & $.2463^{*}$ & $.2429 *$ \\
\hline $\mathrm{N}=99 ;{ }^{*} p<.05$ & & & & \\
\hline
\end{tabular}

Question 6. What are there differences between the various leadership styles (none, single, paired and multiple) of principals in smaller learning communities and the use of the six strategies implemented by SLC schools (academic teaming, alternative scheduling, freshmen transition activities, teacher advisory systems, adult advocate systems and Individual/Personalized Academic Plans) as measured by means and standard deviation on the six strategies (listed above) by each frame pattern (none, single, paired, and multiple)? 
To answer this question, the number of strategies each school implemented was calculated first. One school might implement one or more strategies, so if a school implemented more than one strategy, the principal appears more than one time in the corresponding leadership style column. For example, if School A implemented two strategies and its principal is a non-frame leadership espouser, he or she will appear twice in the column "None." The total number of schools in each column for leadership style indicates the number of unique schools whose principal used the corresponding leadership style. Secondly, the mean of number of strategies implemented by learning communities by principals' leadership style was computed and ANOVA was conducted to examine if there is a significant difference of the mean of the number of strategies among schools by principals' leadership style. Finally, the relationship of each frame (structural, human resource, political, and symbolic) with the number of strategies implemented by the communities was analyzed.

Table 16 reports the frequency distribution of strategies implemented by smaller learning communities by principals' leadership style. The most frequently implemented strategy by learning communities with a principal using non-frame leadership style is Teacher Advisory Systems, while it is Academic Teaming for those with a principal using single-, paired-, or multiple frame leadership style. They account for more than three-thirds of schools in each leadership style category.

The least frequently implemented strategy for schools with a principal using nonframe leadership style was Adult Advocate Systems, while it is Freshman Transition Activities for those schools with a principal using single-frame leadership style and it is 
Alternative Scheduling for those whose principal followed a multiple frame leadership theory.

Table 16

Frequency Distribution of Strategies Implemented by Schools by Principals ' Leadership Style

\begin{tabular}{|c|c|c|c|c|c|c|c|c|}
\hline \multirow[t]{2}{*}{ Strategy } & \multicolumn{2}{|c|}{ None } & \multicolumn{2}{|c|}{ Single } & \multicolumn{2}{|c|}{ Paired } & \multicolumn{2}{|c|}{ Multiple } \\
\hline & \# & $\%$ & \# & $\%$ & \# & $\%$ & $\#$ & $\%$ \\
\hline Academic Teaming & 26 & 70.3 & 6 & 85.7 & 7 & 87.5 & 19 & 76.0 \\
\hline Alternative Scheduling & 21 & 56.8 & 5 & 71.4 & 5 & 62.5 & 7 & 28.0 \\
\hline $\begin{array}{l}\text { Freshmen Transition } \\
\text { Activities }\end{array}$ & 20 & 54.1 & 2 & 28.6 & 7 & 87.5 & 15 & 60.0 \\
\hline Teacher Advisory Systems & 30 & 81.1 & 4 & 57.1 & 6 & 75.0 & 18 & 72.0 \\
\hline Adult Advocate Systems & 11 & 29.7 & 3 & 42.9 & 3 & 37.5 & 9 & 36.0 \\
\hline $\begin{array}{l}\text { Individual/Personalized } \\
\text { Academic Plans }\end{array}$ & 19 & 51.3 & 5 & 71.4 & 5 & 62.5 & 10 & 40.0 \\
\hline Total Number of Schools ${ }^{\mathrm{a}}$ & 37 & & 7 & & 8 & & 25 & \\
\hline
\end{tabular}

a. "Total Number of Schools" by leadership style refers to the number of schools with principals using the stated leadership style. A school may implement more than one strategy, so it may appear more than once in the column for each leadership style if it implements more than one strategy. Therefore, the sum of the number of strategies in each column by leadership style may be higher than the number of schools. The percentage for each strategy was calculated by dividing the number of structures implemented by schools by "Total Number of Schools," so the sum of percentages for each leadership style may be larger than 100 percent.

The mean and standard deviations of the number of strategies implemented by the SLC schools by principals' leadership style are presented in Table 17. Each of the schools with a principal using a paired-frame leadership style implemented the most strategies on average $(\mathrm{m}=2.63, \mathrm{SD}=.92)$. This is followed by the schools with a principal using multiple or single-frame leadership style $(\mathrm{M}=2.52, \mathrm{SD}=.87 ; \mathrm{M}=2.57, \mathrm{SD}=.53)$. The 
schools whose principals were reported not using any frames implemented the least strategies $(\mathrm{M}=2.26, \mathrm{SD}=.94)$. However, the ANOVA did not indicate a significant difference of the number of strategies used by the schools by principals' leadership style $F(3,75)=.75, p>.05$.

Table 17

Means and Standard Deviations of Strategies Implemented by the SLC School by Principals' Leadership Style

\begin{tabular}{|c|c|c|c|c|c|c|}
\hline & $\begin{array}{l}\text { Non- } \\
\text { Frame }\end{array}$ & $\begin{array}{l}\text { Single- } \\
\text { Frame }\end{array}$ & $\begin{array}{l}\text { Paired- } \\
\text { Frame }\end{array}$ & $\begin{array}{l}\text { Multiple- } \\
\text { Frame }\end{array}$ & $F$ & $p$ \\
\hline$M$ & 2.26 & 2.57 & 2.63 & 2.52 & .75 & .53 \\
\hline$S D$ & .94 & .53 & .92 & .87 & & \\
\hline
\end{tabular}

As indicated in Table 18, the number of strategies implemented by the SLC schools is related to all leadership frames. However, the Pearson analysis only indicates that there is a significant correlation between the number of the strategies implemented by schools with the structural, the political, and symbolic frames. This result indicates that the higher a principal was scored on the structural, political, and symbolic frames by teachers, the more strategies out of academic teaming, alternative scheduling, freshmen transition activities, teacher advisory systems, adult advocate systems, and individual/personalized academic plans their schools implemented. The frame with the most strategies was the paired frame, but not a statistically significant level.

Table 18

Pearson Correlation Matrix of Leadership Frame and Number of Strategies Implemented by Schools

\begin{tabular}{lcccc}
\hline & Structural & Human Resource & Political & Symbolic \\
\hline Number of & $.2076^{*}$ & .1892 & $.2201^{*}$ & $.2022^{*}$ \\
Strategies & & & & \\
\hline $\mathrm{N}=99 ;{ }^{*} p<.05$ & & & &
\end{tabular}


Research question 6a. What are the differences in the levels of student achievement (Grade Point Average of at least 2.0/passing level) in the four subject areas (regular ninth grade English, regular algebra, regular ninth grade social studies, and regular ninth grade science) by locale (urban/rural)?

Table 19 reports student learning achievement level in English, algebra, social studies, and science by school location (city versus other). The means of all the four subjects of the students from schools located in other areas are higher than the means of those students from the schools located in cities. However, $t$ test did not indicate that the difference was significant.

Table19

Means and Standard Deviations of Achievement Level by School Location Category

\begin{tabular}{lcccc}
\hline \multicolumn{1}{c}{ City } & Other & t & $p$ \\
\hline English & & & & .27 \\
$M$ & .79 & .81 & 1.13 & \\
$S D$ & .14 & .13 & & .18 \\
Algebra & & & 1.33 & \\
$M$ & .75 & .81 & & .59 \\
$S D$ & .16 & .19 & & \\
Social & & & .55 & .18 \\
studies & .80 & .82 & & \\
$M$ & .14 & .16 & & \\
$S D$ & & & & \\
Science & .74 & .79 & & \\
$M$ & .17 & .17 & & \\
$S D$ & & & & \\
\hline
\end{tabular}

Research question $6 b$. What are the differences in the levels of student achievement (Grade Point Average of at least 2.0/passing level) in the four subject areas (regular ninth grade English, regular algebra, regular ninth grade social studies, and regular ninth grade science) by school size (small, medium and large)? 
Table 20 reports the means and standard deviations of student learning achievement in four subjects by school size. Students from smaller schools demonstrated a higher achievement level in all four subjects than those from medium and large schools, while the large schools showed a lowest student learning achievement in all four subjects. However, the ANOVA only indicates a significant difference of student learning achievement in algebra by school size, $F(3,75)=3.29, \mathrm{p}<.05$. The post hoc test (Tukey test) was further conducted and found that learning achievement of students from smaller schools in algebra significantly higher than that of the students from larger schools.

However, there was no significantly different of learning achievement of students between small and medium schools, and nor between medium and large schools.

\section{Table 20}

Means and Standard Deviations of Achievement Level by School Size

\begin{tabular}{lccccc}
\hline & Small & Medium & Large & F & $p$ \\
\hline English & & & & & \\
$M$ & .82 & .80 & .77 & .88 & .42 \\
$S D$ & .12 & .14 & .15 & & \\
Algebra & & & & & $.04^{*}$ \\
$M$ & .85 & .78 & .72 & 3.29 & \\
$S D$ & .14 & .15 & .22 & & \\
Social & & & & & .16 \\
studies & .84 & .83 & .76 & 1.87 & \\
$M$ & .12 & .14 & .18 & & \\
$S D$ & & .77 & .71 & 2.01 & \\
Science & .14 & .15 & .22 & & \\
$M$ & & & & & \\
$S D$ & & & & &
\end{tabular}

Research question 6c. What are the differences in the levels of student achievement (Grade Point Average of at least 2.0/passing level) in the four subject areas (regular ninth grade English, regular algebra, regular ninth grade social studies, and regular ninth grade 
science) by the principals number of years of experience in administration (emergent $=0$ 5 years/mid-career $=6-10$ years/established=more than 11 years $) ?$

Table 21 presents the means and standard deviations of student learning achievement level by principals' years of experience in administration. Students from schools with a principal having more than 11 years of experience in administration showed a highest achievement level in all four subjects, $\mathrm{M}=.81, \mathrm{SD}=16$ for English, $\mathrm{M}=.78, \mathrm{SD}=.19$ for Algebra, $\mathrm{M}=.82, \mathrm{SD}=.16$ for Social studies, and $\mathrm{M}=.78, \mathrm{SD}=.19$ for Science. Students from schools with a principal having six to 10 years of experience in administration have a lowest mean of achievement level in three subject, English $(\mathrm{M}=.77, \mathrm{SD}=.13)$, algebra $(\mathrm{M}=.77, \mathrm{SD}=.17)$, and science $(\mathrm{M}=.75, \mathrm{SD}=.16)$, while students from schools with a principal having less than six years of experience in administration demonstrated the lowest achievement level in social studies $(\mathrm{M}=.79, \mathrm{SD}=.13)$. However, the ANOVA did not find any significant difference of student achievement level by principals' length of experience in administration.

Table 21

Means and Standard Deviations of Achievement Level by Principals' Years of Experience in Administration

\begin{tabular}{lccccc}
\hline & Emergent & Mid-Career & Established & $\mathrm{F}$ & $p$ \\
\hline English & & & & & \\
$M$ & .80 & .77 & .81 & .88 & .42 \\
$S D$ & .15 & .13 & .14 & & \\
Algebra & & & & & \\
$M$ & .80 & .77 & .78 & .16 & .85 \\
$S D$ & .15 & .17 & .19 & & \\
Social studies & & & & .17 & .84 \\
$M$ & .79 & .81 & .82 & & \\
$S D$ & .13 & .15 & .16 & .78 & \\
Science & .77 & .75 & .78 & .25 & \\
$M$ & .13 & .16 & .19 & & \\
$S D$ & & & & \\
\hline
\end{tabular}


Table 22 reflects a profile of the typical high school principal in this study. By collecting this data, we learn that well over half of the principals are male. This finding is consistent with national data. In Steve Paine's (2002) study of school administrators, he found that 85 percent of the West Virginia superintendents are male. In this same study, Dr. Paine profiled the typical West Virginia high school principal and found that 100 percent of the principals in his study to be male in gender (Paine, 2002). Another interesting finding in this study is again consistent with the national statistics. The average number of years these principals have been in education is twenty six years and the average number of years in educational administration is thirteen years. This reflects the national concern that the United States will be facing one of the most massive transformations of leadership in a century (Peterson, et. Al., 2001). By some estimates, more than half of all principals are expected to retire in the next five years. This presents school districts with both challenges and opportunities for positive change to recruit a new group of leaders. It is apparent that the groups of high school principals in this study have been in education for a number of years and are for the most part, experienced administrators.

It was surprising to find that well over half of the administrators in this study held a Masters degree as their highest degree earned. These principals represented sixty one percent of the total population. Only one fourth (24\%) of the principals held a doctorate in education, and even lower, merely four percent held a Ph.D. as their highest degree earned. Virtually one half of the principals held a degree in educational leadership or administration (42\%) and practically all of the principals in this study held traditional degrees $(94 \%)$ as opposed to nontraditional means of certification. 
Table 22

Profile of the Typical High School Principal with a Smaller Learning Community

\begin{tabular}{|c|c|}
\hline Variable & Study Finding \\
\hline \multirow[t]{2}{*}{ Gender } & Male (64\%) \\
\hline & Female $(36 \%)$ \\
\hline Age & 49 years (average) \\
\hline Number of Years in Education & 26 years (average) \\
\hline Number of Years in Administration & 12.05 years (average) \\
\hline \multirow[t]{6}{*}{ Highest Degree Earned } & M.A. $(61 \%)$ \\
\hline & Ed.D. $(24 \%)$ \\
\hline & Ph.D. (4\%) \\
\hline & J.D. $(.9 \%)$ \\
\hline & B.A. /B.S. $(3 \%)$ \\
\hline & Ed. Specialist Certification (8\%) \\
\hline \multirow[t]{7}{*}{ Area of Major in highest degree earned } & Educational Administration/Leadership (42\%) \\
\hline & Education (7\%) \\
\hline & Administration/Supervision (6\%) \\
\hline & Curriculum/Instruction ( $5 \%$ ) \\
\hline & English $(5 \%)$ \\
\hline & Urban Secondary Education (3\%) \\
\hline & Other $(32 \%)$ \\
\hline \multirow[t]{2}{*}{ Certification (traditional/alternative) } & Traditional (94\%) \\
\hline & Alternative $(6 \%)$ \\
\hline
\end{tabular}




\section{Summary}

In summary, the principals in smaller learning communities tend to use the structural, human resource, political, and symbolic frames equally as reported by teachers. However, the principals are mostly likely to use non-frame leadership style. This is followed by multiple frame leadership style. With respect to multiple-frame style, the principals prefer using all four frames rather than three frames.

Principals' demographic variables (gender and length of experience in administration) and school information (location and size) do not have a significant influence on principals' use of leadership style. There is no significant correlation of principals' use of leadership frames and style with student learning achievement in English, algebra, social studies, and science.

The number of structures and strategies implemented by the Smaller Learning Communities was not correlated with principals' leadership style. However, it was significantly correlated with principals' use of the structural, political, and symbolic frames according to teachers' reports. The higher the principals were rated on these three frames, the more structures and strategies their schools implemented.

Students from schools located in other areas rather than in cities had a higher learning achievement level in all four subjects (English, algebra, social studies, and science), but the difference was not significant. Also, students from small schools (fewer than 400 students) were reported to have the highest level of achievement in all four subjects than those from medium and large schools; again the analysis of variance did not show a significant difference. In addition, students from the schools with a principal having more 
than 11 years of experience in an administrative position reflects a higher mean of

learning achievement in English, social studies, and science, but not significantly higher.

These results will be discussed in greater detail in Chapter Five. 


\section{Chapter 5}

\section{Conclusions and Recommendations}

This chapter forms conclusions based on the major findings relevant to the leadership styles of school principals in Smaller Learning Communities. This chapter is comprised of three major sections: a study summary, conclusions, and recommendations for future practice and research.

\section{Summary of Study}

This study examined the relationship between the leadership styles of school principals in Smaller Learning Communities, the number and types of structures and strategic configurations in high schools with Smaller Learning Communities (SLC), and the success rates of ninth-graders. The major focus is on whether there is a statistically significant relationship between the leadership style of principals in Smaller Learning Communities and the success rate of ninth-grade students. Leadership styles are classified based on Bolman and Deal's $(1984,1990)$ cognitive frames - structural, human resource, political, and symbolic — which define organizational behaviors and governance patterns. This study also examines the number of structures and strategies used in the SLC and the relationship to the leadership style of the principal. The structures include organizational characteristics that assure the learning environments in a large school will remain small. These may include a number of structures such as, academies, house plans, a schoolwithin-a-school, and magnet schools. In an effort to make students feel more connected to each other, and adults, large high schools with SLC's develop strategies to take advantage of the smaller learning environments. Implementation of strategies such as freshmen academies, multi-year grouping, alternative scheduling, adult advocate system, 
teacher advisory systems and academic teaming, may be related to the leadership style of the principal.

\section{Conclusions}

The conclusions are based on an analysis of the research questions guiding this study. General Pattern of Principals' Leadership Styles

The frequency distribution of leadership styles reports that teachers view their principals as using the no-frame pattern most often (48.5\%). This was followed by the multi-framed leader $(31.1 \%)$, the single-frame leader $(11.1 \%)$ and the paired-frame leader (9\%). The leadership styles of principals of Smaller Learning Communities do not differ from that of leaders in studies such as that of Chang's college department chairs; in Chang's study, $56.8 \%$ of the participating faculty did not use a particular frame (2004) and in Griffins (2005) 24.2\%. Similarly, in Bowen's study of county program coordinators, $39.4 \%$ were found to use no-frame, and nearly three-fourths of the county coordinators used either the no-frame or the single-frame style (2004). Mosser's study (2000) found nearly $40 \%$ of participating nursing department chairs had no leadership style, and Small's study (2002) found 31.7\% of nursing department chairs using no-frame leadership style.

The predominance of a no-frame style (48.5\%) in this study is higher than in most of the previously mentioned studies. When the Chi-square test for independence was conducted, it indicated a significant preference on the implementation of the no-frame leadership style by high school principals in this study. According to Bolman and Deal, principals who lack a significant leadership style may be challenged in their ability to view organizations from multiple angles and may not be prepared to deal with the many 
issues with which they will be faced (1997). Although the four frames are not independent of each other, Bolman and Deal found that effective leadership is frequently associated with the number of frames used (Bolman, 2003). Bolman's research indicates that the perception of leaders using three or more frames is more effective than that of those who use fewer than three frames (Bolman, 2003). When using multiple frames, the leader is able to reframe a situation and to examine it from multiple viewpoints to develop a more holistic perspective.

Only $11 \%$ of the principals in this study employed the single-frame method of leadership. This was different than the findings in recent research such as Griffins' study (2005) of chairpersons of biology and English departments, where he found that the single frame orientation was the most frequently used leadership style (32.9\%). This compares to Mathis (1999) 11.0\%, Chang (2004) 14.8\%, Mosser (2000)16.6\%, and Small (2002) with $20.8 \%$ of the leaders espousing a single-frame leaderships style. In the current study, of the single frame leaders, nearly $64 \%$ were perceived by their teachers as using the structural frame. The structural frame is based on the assumptions of and belief in rationality and formal arrangements. These leaders believe organizational charts, rules, and standard operating procedures and policies minimize problems and increase quality and performance (Bolman, 1997). In a similar study, Chang found that the singleframed, structural leader had a better technology infrastructure and was more likely to provide both technical and administrative support while attending to key issues (Chang, 2004). The structural principals in this study may have designed and designated roles within the Smaller Learning Communities to such an extent that the presence of singleframed leadership is apparent. The work of principals is typically very complex with 
many managerial requirements, hundreds of short tasks of enormous variety (Peterson, 2001). Mintzberg (1973) described the work of a manager as characterized by brevity, fragmentation and variety. Due to the managerial nature of a principalship of a large high school, the high rate of structural leadership was not surprising. The structural leaders may serve Smaller Learning Communities very well, attending to the bottom line, valuing analysis and data, and addressing school problems by developing new policies or restructuring. However, Bolman and Deal caution, that effectiveness as a manager can be associated with the structural frame, but the primary determinants of a successful leader are the symbolic and political frames (Bolman \& Deal, 1997, p. 278). Based on this belief, the leaders in the Smaller Learning Communities may be effectively managing their schools, but not necessarily effective leaders.

The paired-frame leaders accounted for only $9 \%$ of the Smaller Learning Communities' principals' leadership styles. This differs from findings in other studies, such as Crist (1999), who found 36.5\% of leaders using paired-frame leadership, and Mosser (2000) who documented $12.7 \%$ of the leaders using paired-frame. Bowen's study (2004) found $15.1 \%$ paired-frame leaders, and Chang (2004) found $13.6 \%$ of leaders in his study engaging in the paired-frame leadership style. Other studies such as Griffin (2005) noted $25.0 \%$, espousing the paired-frame orientation, while other studies such as Small (2002) found $10.9 \%$ and Mathis (1999) found only $8.7 \%$.

In this study, the principals who espoused a paired-frame orientation, structural/political framed leaders represent $33 \%$ of those leaders. This finding is different from Griffin's study (2005) where the paired frame leader was primarily structural-human resource frames. In other studies of academic department chairs, 
Mathis (1999) reported the social-political frames and the political-symbolic frames as most frequently employed. Although, those principals using only the structural frame may be effective managers but not effective leaders, when the structural leadership frame is coupled with the political frame, the structural/political framed leader is potentially highly effective. The political leader is usually persuasive, influential and has the ability to mobilize people and resources, while the structural leaders focus on management of the organization (Boleman, 2003). These results would suggest that the principals in this study would benefit from leadership development activities to expand the perspectives from which they view their leadership roles.

Finally, the principals who are multi-frame leaders made up $31 \%$ of the principals' leadership styles in this study. Other studies found much lower incidence of the multiframe leadership style: Crist (1999) found only 8.5\%, Mosser (2000) documented 22.1\%, Bowen (2004) 12.1\%, Chang (2004) 14.8\% and Griffin (2005) 18.1\%. With the exception of one study, where Mathis (1999) had a high incidence (48.2\%), of multiframed leaders. Bensimon's study of higher education presidents found that multi-frame orientations were more prevalent among presidents from large universities than among those from smaller colleges (1989).

In high schools with Smaller Learning Communities, leadership is guided by decision-making that involves all stakeholders. In these settings, the multi-framed leadership style may facilitate decentralization of authority and shared decision-making, which is consistent with the goals of Smaller Learning Communities. According the Bolman and Deal (2003) model, principals with multi-framed leadership styles in this study (31\%) are exerting effective leadership. 


\section{Demographic Effect on Leadership Styles}

This study is a national study involving schools from locations across the United States. Caution was used in making firm conclusions when the small cell group $(n=99)$ were sorted into subgroups by demographic characteristics, since some cell numbers were too small for the analyses.

\section{School Location}

The schools in this study represent high schools from 32 states, including Hawaii and New Mexico. The schools are representative of both rural and urban areas, with student populations which are culturally and socio-economically diverse. School locations were varied, including locales such as the Bronx and New York City in New York; Yukon, Oklahoma; Las Vegas, Nevada; Billings, Montana; Lansing, Michigan; Poulsbo, Washington; Pawtucket, Rhode Island; Overland Park, Kansas; Honolulu, Hawaii; Milwaukee, Wisconsin; Philadelphia, Pennsylvania; and Avondale, Arizona.

There was a slight difference in the non-frame leadership style in principals from schools located in a city $(56.1 \%)$ as compared to those principals from schools located in other areas (43.1\%). However, this difference was not statistically significant. Other research suggests that school location does not impact student achievement. For example, while studying school locale, Howley (1994) found that middle-class students predominated in large urban schools as a result of changing residential patterns and that large inner-city school were overburdened with impoverished students. The impoverished students have higher achievement levels in smaller schools according to Howley's research (1994). In other research, evidence that students in communities of high socioeconomic status perform better in larger schools, while small size seems to benefit 
minority and low-income students (Lee and Smith 1996). However, many of the nation's largest high schools are in urban areas with high concentrations of disadvantaged students who are ill-served by large school size (Irshmer, 1997).

\section{Gender}

Fifty-five percent of the male principals in this study were perceived as exhibiting non-framed leadership styles, while nearly forty one percent of the female principals were perceived as having non-framed styles. Therefore, a greater percentage of male principals did not demonstrate a distinct leadership style, compared to their female counterparts. Among female principals, the distribution of non-frame and multi-framed female leaders were both at nearly $41 \%$; however, the frequency of non-framed leaders (55.3\%) among male principals was more than twice that of multi-framed leaders (25.5\%). Consequently, the males were more commonly non-framed leaders than the females, and the females were more commonly multi-framed than the males. Similar findings were established in Bowen's study (2004), in which male extension agents were found to use the no-frame style more frequently than did their female counterparts.

Findings vary in studies that used gender as a variable, Thompson (2000) used Bolman and Deal's Others to examine the differences in gender. Thompson examined a "balanced" or "unbalanced" orientation of leadership, leadership characteristics, and the perceived effectiveness of educational leaders. The findings suggest that any differences in the perceived effectiveness of educational leaders in the three leadership type groups are equally true for male and female leaders, and that male and female educational leaders were perceived to be equally effective in their respective organizations despite the stereotypical connotations asserted in previous research (Thompson, 2000). In addition, 
no significant differences were found between men and women in their leadership characteristics or frame use. This study is in contrast to existing research-supported evidence from studies such as Chang (2004), McClellan-Holt (2000) and Turley (2002). In Chang's study he found gender as a significant variable. The female faculty chairs displayed no frame leadership pattern at the rate of 70 percent (Chang, 2004). In Turley's study (2002) of radiation therapy program directors, although she found that nearly eighty percent of the program directors included in the survey were female, there was no significance found within the leadership styles and gender.

\section{School Size}

In this study, there was a statistically significant difference in student achievement in Algebra by school size as students from smaller schools demonstrate higher achievement than did students from larger schools. Students from smaller school demonstrated a higher achievement level in all four subjects than those from medium and large schools, while the large schools showed a lowest student learning achievement in all four subjects. However, the ANOVA only indicates a significant difference of student learning achievement in algebra by school size. In this study the finding that learning achievement of students from smaller schools was significantly higher in algebra than that of the students from larger schools was not surprising based on the research regarding school size. In a similar study, Lee \& Smith (1997) examined 9,812 sets of student records from789 high schools. In this research, they found that students in high schools smaller than 600 , and larger than 900 , experienced lower achievement in reading and mathematics. This effect was stronger for schools with more students of low socioeconomic-status (Lee \& Smith, 1997). 
The findings regarding the relationship of school size and student achievement vary from study to study, according to Overbay's summation of the research (2003). Roeder (2002) studied elementary, middle and high schools in Kentucky, in this research it was found that smaller school size had no significant relationship to achievement, rather, poverty was a greater predictor of academic success. In other research regarding the benefits of small schools, Mary Anne Raywid, a professor emeritus of education at Hofstra University in Hempstead, N.Y., has established research supporting superiority of smaller schools over larger, more impersonal settings. Raywid asserts that the advantages of smaller schools have been established with clarity and a confidence rare in the annals of education (Raywid, 2000). According to Debra Viadero, researcher and writer for Education Week, concludes that studies conducted over the past 10 to 15 years suggest that in smaller schools, students come to class more often, drop out less, earn better grades, participate more often in extracurricular activities, feel safer, and show fewer behavior problems (Viadero, 2001).

In this study, there was no statistically significant difference between the achievement level in the other subjects among students from smaller schools than that of students from medium and large schools.

Sociological research on school size suggests small schools have advantages over larger schools, particularly because relationships among staff and students tend to be more personalized (Ready, 2004). This could have contributed to the significant difference that exists in algebra achievement between students in small schools and those in large schools. The increase in student achievement in algebra could also be related to class size since, in a smaller class, a student has more opportunities to get involved in 
practices and discussions. The research of LaSage and Ye (2000) found that teachers working in small schools with smaller class sizes are able to work more effectively with students. Lee and Smith (1997) found a curvilinear relationship between high school size and achievement. According to their findings, high school achievement rises as enrollment rises to 600 , remains steady up to about 900 , and then drops with increasing school size (Overbay, 2003). In a study of students and teachers in Chicago's inner-city schools, Lee and Loeb (2000) found that teachers have more positive attitudes and students learn better in small schools. It appears that school size does impact student achievement in the area of Algebra. Future studies that investigate strategies to increase student achievement in the other core subject areas of English, social studies and sciences would be beneficial in practice and policy development.

Administrative Experience

There was no statistically significant difference in this study between the achievement of students from schools with a principal who had more than 11 years of administrative and students from schools with a principal who had less than 11 years of experience. Similar studies have used administrator's age as a variable. In studies such as Chang's study of leadership styles of faculty chairs, established leaders were more likely to espouse a multi-frame leadership style (Chang, 2004). In other studies were age was used as a variable, it was found that the more established the leader, the higher the likelihood of the leader using the political frame (Kelly, 1997; Wolf, 1998). Although both Bensimon and Neumann (1989) found that years of experience are directly related to the use of complex leadership approaches, the current research found no significant relationship between years of experience and student achievement. 
Many of the key elements of an effective school with a smaller learning community are practices that encourage autonomy. In such an environment, the SLC would maintain as much control as reasonable over space, schedule, budget, curriculum, instruction and personnel (NWREL, 2005). Considering the shared leadership and decision-making among all stakeholders, it is evident that the experience of the principal is not clearly related to student achievement in this study.

\section{Relationship of Individual Leadership Frames and Student Academic Achievement}

Under the federal NCLB Act, principals are mandated to serve first and foremost as instructional leaders in their schools (NCLB, as cited in Lockwood, 2005). This Act mandates that every school has leadership that results in improved student performance and that leadership begins with the school principal. The lack of a statistically significant relationship between leadership and student achievement is a possible indicator that, in Smaller Learning Communities, other variables that were not measured in this study have a stronger impact on student achievement. Cotton (2001) identified five key elements to a successful smaller learning community: self determination, identity, personalization, support for teaching, and functional accountability. Under these five elements, the Smaller Learning Community has autonomy in decision-making, in developing distinctive programs of study, and in allowing teachers to identify and respond to students' strengths and needs by tailoring instruction. In turn, the teachers assume authority and responsibility for educating their students (Oxley, 2004). The fact that school leadership does not reside solely in the administrative staff may explain the results of this study. The optimal SLC principal may allow teachers to lead and take an active 
role in multiple practices to increase student achievement. The emphasis of the teaching and learning teams in the SLC may decrease the impact of the principal's leadership style on student achievement.

\section{Relationship of Individual Leadership Frames and Use of Strategies and Structures}

Use of structures. Smaller school structures have a number of groupings and possibilities, which may include academies, house plans, schools-within-schools, and magnet schools (USDE, 2006). Structures are sub-groups within the schools organized around different themes, such as career academies. A number of the schools implemented house plans, in which students are divided into groups and take some or all of their classes with a common group of students.

In this study, the number of structures implemented was not statistically correlated with the principals' leadership style. However, the number of structures was positively correlated with the principals' use of the structural, political and symbolic frames. The higher the principals were rated on these three frames, the more structures the schools implemented. Because principals using the structural frame tend to focus on goals, policies, technology and environment, these leaders may be better prepared to assess the aspects of the current practices that pose a barrier to improved reform and practice. In addition, the principals who employ the political and symbolic frames are using their skills in advocacy and inspiration to determine what aspects of current practice can and should be preserved.

The reform efforts that take place in the development of a smaller learning environment require focus and determination on the part of the administrator. John Kotter (1998), a Professor of Leadership at Harvard Business School, believes that leaders exist 
at all levels of an organization. At the edges of the organization, leaders are accountable for less territory. Although these tertiary leaders' vision may sound more basic, according to Kotter, they perform the same leadership role as their more senior counterparts (Kotter, 1998). In a Smaller Learning Communities, the teachers in the $9^{\text {th }}$ grade SLC may provide the momentum for reform and challenging the status quo (Kotter, 1998). The future of the Smaller Learning Community can be greatly enhanced by multi-framed leadership. Understanding the importance of the structures will increase the likelihood of a successful Smaller Learning Community.

Use of strategies. Effective downsizing of large high schools necessitates that leadership employ a number of strategies in order to achieve the full benefits of the smaller learning environment (USDE, 2006). The number of strategies was positively correlated with the principals' use of the structural, political and symbolic frames; the higher the principals were rated on these three frames, the more strategies the schools implemented. The structural leader looks beyond the teachers to examine the purpose of the work. This leader will understand that there is no one best way to organize, but the right structure or strategy depends on the schools' goals, technology and environment (Bolman, 2003).

The Smaller Learning Communities are encouraged to implement strategies that take advantage of the smaller environments and encourage positive relationships among students and staff. Strategies that prove effective include student, teacher and community involvement; teachers increasing positive relationships with students, teachers sharing common groups of students, and working to involve parents and community in instructional support and academic enhancement. 


\section{Recommendations}

Recommendations for Practice

Making high schools smaller is not a universal remedy for high schools of the twenty-first century; however, by improving leadership practices to create a more personalized learning environment, more reform strategies may be fostered. The law calls for principals to have instructional leadership qualities that will allow teachers to teach and students to learn (NCLB, 2001). In order to meet the strict mandates of No Child Left Behind, instructional leadership has moved to the forefront of any reform effort. This calls for schools to go beyond superficial quick fixes and inadequately implemented innovations alleged to improve student learning (WVDE, 2004). Principals are mandated to be knowledgeable and to practice research-based strategies that increase student achievement. The research conducted by the West Virginia Department of Education points clearly to the significant impact of leadership that develops and implements a clear vision and mission with high expectations for all (WVDE, 2004). In the comprehensive literature review, few studies have been found regarding the impact of leadership behavior in the Smaller Learning Communities on student achievement. With nearly half of the principals having a no-frame leadership pattern, this study indicates the need for more multifaceted leadership styles among principals.

According to the data regarding the typical high school principal in this study, we understand that many of our principals were nearing retirement age. This is consistent with state and national data regarding school administrators and implies a major challenge and a great chance to recruit and train thousands of exceptional new principals for school districts (Peterson, 2001). Because of impending retirements, school districts 
and post-secondary instructions are facing a formidable task of recruiting and training new leaders for the twenty-first century. Preparation for strong leaders must certainly require new principals to receive professional development activities encouraging them to become multi-framed in their leadership approaches.

Following the correlate of effective schools, research indicates the importance of strong instructional leadership (Lezotte, 2001). Large high schools present a number of challenges for school leaders; compounding the monumental administrative tasks, leaders are faced with NCLB accountability mandates and clear expectations to increase student success. In order to increase effectiveness, principals need to possess skills in the structural, human resource, political and symbolic leadership frames. In effect, principals with improved multi-framed leadership approaches will enhance student success. Findings, then, include the following:

1. As part of the continuing professional development activities, principals from high schools with Smaller Learning Communities may be periodically assessed by using the Bolman and Deal Leadership Orientation (Self) survey instrument. This will allow principals to identify their current dominant leadership style and to monitor how their style changes or remains the same over time. This practice may lead to greater awareness of leadership styles and potentially increase leadership effectiveness.

2. It is important that principals from large high schools with Smaller Learning Communities understand the use of the frames. These principals should receive training regarding the Bolman and Deal frames and other multi-perspective leadership methods. In order to heighten awareness of circumstances in which the frames are valuable for decision making. The development of case study simulations in which high school principals could apply the different frames 
might assist principals in improvement of assessing when a specific frame may be best utilized.

3. This training may involve simulation modules in order to be most beneficial for leaders. Each training module would be based on the Bolman \& Deal fourframe approach to leadership. This training would include specific behaviors related to each frame. For example, to develop the symbolic leadership frame, a module may include behaviors related to inspiration and use of symbols to capture of attention and leave impressions. The module for the political framework may include successful leadership behaviors associated with building linkages to stakeholders with frequent use of persuasion and negotiation to build alliances.

4. Increasing and refining professional development offerings may help to cultivate multi-framed leaders in large high schools with Smaller Learning Communities.

5. With the impending retirement of many principals in the high schools with Smaller Learning Communities, school districts will begin to recruit, train and hire new principals. Understanding the use of the four frame model may assist those who are involved in the selection of the new principals. It is important that those involved in the selection and hiring process be familiar with the use of the leadership frames. This may require county administrators, personnel managers and superintendents be trained in the Bolman and Deal frame model. In addition, new principal candidates may be assessed with regard to their utilization of the leadership frames as part of the interview process. This information may perhaps assist in determining the best potential candidate.

6. The capability to change the culture of large high schools and lead a major reform attempt requires principals to be visionary and multi-framed in their leadership styles. Multi-framed leadership demands that principals be knowledgeable of best practices and practices that support increased student achievement. National, state and local programs must agree on consistent definitions and support systems that will encourage and sustain new leadership as new reform efforts are initiated. 
7. Implementation of a support system will help to ensure quality leadership. State and federal agencies may design mentor programs to support new and practicing principals and county office leadership. Such programs would encourage highly qualified leaders to persist in their response to ongoing reform efforts.

\section{Recommendations for Further Study}

1. To explore the impact of learning communities on student outcomes, future studies could address these issues more comprehensively by testing one or more specific groups within the learning communities using a random assignment experimental design. The results from such a study would provide empirical, causal evidence regarding the fundamental aspects of Smaller Learning Communities that lead to improved student outcomes.

2. Future research may further investigate the true impact that principal's leadership behaviors have on student achievement to help explain why students in some high schools academically outperform students in other high schools.

3. Further research could include a differential impact study that compares two different communities' structures and strategies at a specific site against the control group. For example, the study could be done on career academies and freshmen transition academies, with and without student support services.

4. A study involving the creation of an experimental design between the control and experimental groups is also recommended. For example, a study could be conducted to compare principals in Smaller Learning Communities and principals in conventional high school settings to see if differences exist in their leadership styles and to compare the resulting outcomes of student success.

5. Future research could investigate the principals in the SLC schools and any demonstration of specific instructional leadership behaviors that impacted student achievement. Were any of the instructional leadership behaviors the result of 
leaders' commitment to the SLC grant and the operation and implementation of the SLC grant? Can high levels of student achievement in these high schools be attributed in any way to the support provided by the USDE through grant funding?

6. Subsequent studies may include a combination of qualitative and quantitative methods which may be useful in measuring leadership frame use. This may also assist in understanding the high percentages of principals in Smaller Learning Communities who lack leadership styles.

7. Studies may be conducted to contrast principals' self-perceived frame use with teacher perceptions of principals' use of the leadership frame and the resulting influence on student achievement. This research may investigate the possible difference between what teachers perceive the principals' leadership style to be and what the principal views his or her style to be.

8. Future studies may investigate the role that professional values and philosophies play in shaping the worldviews, perspectives, background in leadership theory and ultimately the leadership approaches of the principals in the Smaller Learning Communities.

9. Similar studies may involve qualitative studies to examine the relationships between classroom teachers and their school principals. These findings may assist in developing best practices and providing insight to effective leadership behaviors in high-performing schools.

10. Studies that investigate the mid-career principal (principals with 6-10 years of experience) may serve beneficial. This study indicates slightly lower student achievement during these years of leadership. Further study may serve beneficial in designing professional development activities for this group of leaders. 


\section{REFERENCES}

Barker, B. (1986). Advantages of small schools (Report No. RC-015607). Las Cruces, NM: Clearinghouse on Rural Education and Small Schools. (ERIC Document Reproduction Service No. ED 265 988)

Barnett, L.G., \& Greenough, R. (2004). Regional needs assessment 2004: Northwest educators' priorities for improving low-performing schools. Portland, OR: Northwest regional Educational Laboratory.

Barth, J. J. (2001). The investigation of the relationship between middle school organizational health, school size, and school achievement in the areas of reading, mathematics, and language. Unpublished dissertation, West Virginia University, Morgantown, West Virginia.

Barth, R. (1990). Improving schools from within. San Francisco: Jossey-Bass.

Barth, R. S. (2001). Teacher leader. Phi Delta Kappan, 82(6), 443-449.

Batenhorst, G. (2002). The assistant principalship as preparation for the principalship: A study of the perspectives of St. Louis area secondary school principals. Dissertation Abstracts International, 63, 04A. (UMI No. 1194)

Beck, L., \& Murphy, J. (1992). Searching for a robust understanding of the principalship. Educational Administration Quarterly, 28, 387-396.

Bensimon, E. M. (1989). The meaning of "good presidential leadership": A frame analysis. The Review of Higher Education, 12 (2), 107-123.

Bensimon, E. A., Newumann, A., \& Birnbaum, R. (1989). Making sense of administrative leadership: The "1" word in higher education. (ASHE-ERIC Higher Education Report No.1). Washington, DC: The George Washington University. 
Birnbaum, R. (1989). The implicit leadership theories of college and university presidents. The Review of Higher Education, 12(2), 125-136.

Bista, M. B., \& Glasman, N. S. (1998). Principals' perceptions of their approaches to organizational leadership: Revisiting Bolman and Deal. Journal of School Leadership, 8, 26-48.

Bolman, L. G. (2001). Lee Bolman Web page [On-line]. Retrieved on August 31, 2006, from http://www.bsbpa.umkc.edu/classes/bolman

Bolman, L. (2003). Using leadership orientations. Section IV: Reliability of leadership orientation scales. Retrieved August 31, 2006, from http://www.bsbpa.umkc.edu/classes/bolman/new_page 1. htm.

Bolman, L.G. \& Deal, T. E. (1999). Four Steps to Keeping Change Efforts Heading in the Right Direction. Journal for quality \& Participation; May/June 99, Vol. 22 Issue 3, p6, 6p, 1c. ISSN: $1040-9602$.

Bolman, L. G. \& Deal, T. E. (1984). Modern approaches to understanding and managing organizations. San Francisco, CA: Jossey-Bass Publishers.

Bolman, L., \& Deal T. E. (1990). Leadership orientations. Brookline, MA: Leadership Frameworks.

Bolman, L. G., \& Deal, T. E. (1991a). Image of leadership. (Report No. 7). Nashville, TN: National Center for Educational Leadership. (ERIC Document Reproduction Service No. ED 332 345)

Bolman, L. G., \& Deal, T. E. (1991b). Leadership and management effectiveness: A multiframe, multi-sector analysis. Human Resource Management, 30(4), 509-534. 
Bolman, L.G. \& Deal, T. E. (1992a). Leading and managing: Effects of context, culture and gender. Education Administration Quarterly, 28(3), 314-329.

Bolman, L. G. \& Deal, T. E. (1992b). Reframing leadership: The effects of leaders' images of leadership. In K. E. Clark, M. B. Clark, and D. Campbell (Eds.), Impact of leadership. Greensboro, N.C.: Center for Creative Leadership.

Bolman, L. G., \& Deal, T. E. (1993). Every day epistemology in school leadership: Patterns and prospects. In P. Hallinger, K. Leithwood, \& J. Murphy (Eds.), Cognitive perspectives on educational leadership (pp. 21-33). New York and London: Teacher College Press.

Bolman, L. G., \& Deal, T. E. (1994). Looking for leadership: Another search party’s report. Educational Administration Quarterly, 30(1), 77-96.

Bolman, L. G., \& Deal, T. E. (1997). Reframing organization: Artistry, choice and leadership (2nd ed.). San Francisco: Jossey-Bass.

Bolman, L. G., \& Deal, T. E. (1999). Four steps to keeping change efforts heading in the right direction. Journal for Quality \& Participation, 22 (3).

Bolman, L. G., \& Granell, E. (1999). Versatile leadership: A comparative analysis of reframing in Venezuelan managers. Paper presented at the World Conference of the IberoAmerican Academy of Management, Madrid.

Borden, M.P. (2000). Leadership orientations of area campus administrators in Florida's state university and community college systems: A frame analysis. (Doctoral dissertation, University of Central Florida, 2000). Dissertation Abstracts International,61, (10A). (UMI Dissertation Services Item: 199990629).

Bossert, S. T., Dwyer, D. D., Rowen, B., \& Lee, G. V. (1982). The instructional management role of the principal. Education Administration Quarterly, 18, 34-64. 
Bottoms, G. (2000). Lessons learned for improving student achievement. Presentation made at Middle Schools that Work Pre-Conference, sponsored by Southern Regional Education Board, Atlanta, Georgia.

Bowen, Elaine. (2004). Perspectives on the Leadership Styles of West Virginia University Extension Service County Program Coordinators. Dissertation, West Virginia University.

Brewster, Cory \& Klump, Jennifer. (2005) Leadership Practices of Successful Principals. Northwest Regional Educational Laboratory. Portland, OR..

Cantu, D. A., (1997). The leadership frames of academic deans randomly selected and nominated as exceptionally effective at public colleges. Unpublished dissertation. Jonesboro, Arkansas, Arkansas State University.

Cassel, R. N. (1990). The quest for identity, drug abuse, and identity crisis. Instructional Psychology, XVII(3), 155-158.

Cassel, R. N. (2000). Student failure must always be associated with teacher failure. Instructional Psychology, 27(2), 110-111.

Cassel, R. N., Chow, P., DeMoulin, D. F., \& Reiger, R. (2001). Identifying high school freshmen with serious atypical behavior and mental health problems for delinquency prevention purposes. Education, 121(2), 257-263.

Chaffee, E. E. (1989). Leadership in higher education: Variations on a theme. The Review of Higher Education, 12(2), 167-175.

Chang, T. (2004). Leadership styles of department chairs and faculty utilization of instructional technology. Unpublished dissertation, Morgantown, West Virginia University. 
Cheng, Y. C. (1991). Leadership style of principals and organizational process in secondary schools. Journal of Educational Administration, 29(2), 25-37.

Cheng, Y. C. (1994). Principal's leadership as a critical indicator of school performance: Evidence from multi-levels of primary schools. School Effectiveness and School Improvement: An International Journal of Research, Policy, and Practice, 5(3), 299317.

Chrispeels, J. H. (2002). The California center for effective schools: The Oxnard School District partnership. Phi Delta Kappan, 83(5), 382-387.

Codianni, A. V., \& Wilburn, G. (1983). More effective schooling from research to practice. New York, NY: Columbia University Press.

Coleman, J. (1966). On equality of educational opportunity. Washington, DC: US Department of Health, Education, and Welfare, Office of Education/National Center for Education Statistics.

Coleman, J., \& Hoffer, T. (1987). Public and private high schools: The impact on communities. New York: Basic Books, Inc.

Collins, J. (2001). Good to be great. Fast Company, 51(1), 90-104.

Conant, J. B. (1959). The American high school today. New York: McGraw Hill.

Cookson, P. W., \& Persell, C. (1982). The effective principal in action. NASSP Bulletin, 22-29.

Cook, A. (2000). The transformation of one large urban high school: The Julia Richman Education Complex. In E. Clinchy (Ed.), Creating new schools: How small schools are changing American education (pp. 101-120). New York, NY: Teachers College Press.

Cotton, K. (1996). School Size, School Climate, and Student Performance. Portland: Northwest Regional Educational Laboratory. 
Cotton, K. (1996). Affective and social benefits of small-scale schooling. [ERIC Digest].

Charleston, WV: ERIC Clearinghouse on Rural Education and Small Schools. EDO-RC96-5.

Cotton, K. (2001). New small learning communities: Findings from recent literature. Portland, OR: Northwest Regional Educational Laboratory. (ERIC Document Reproduction Service No. ED459539)

Cotton, K. (2003). Principals and student achievement; what the research says. Alexandria, VA: Association for Supervision and Curriculum Development.

Coyle, L. M. \& Witcher, A. E. (1992). Transforming the idea into action. Urban Education, 26(4), 390-401.

Crist, B. E. (1999). A study of the relationship of the job satisfaction of chief academic officers of institutions of higher education and the perceived leadership style of the institution's president. Unpublished dissertation, West Virginia University.

Cushing, K., Kerrins, J. J., \& Johnstone, T. (2003). Disappearing principals. Leadership, 32(50), $28-29,37$.

Cushman, K. (1997). Why small schools are essential. Horace, 13(3), 3-4.

Davis, S. H. (1998). Superintendents' perspectives on the involuntary departure of public school principals: The most frequent reasons why principals lose their jobs. Education Administration Quarterly, 34(1), 58-91.

Davis, T. I. (1996). The ways administrators work: A study of the theoretical frames of leadership used by female and male secondary school principals in Pennsylvania. Dissertation Abstracts International (UMI No. 9632022) 
Day, C., Harris, A., \& Hadfield, M. (2001). Challenging the orthodoxy of effective school leadership. International Journal of Leadership in Education, 4(1), 39-56.

Department of Education. (2004, March 15). Smaller learning communities program; Notices. In: Federal Register, 69(50), (FR Doc 04-5817)

Dufour, R. (2000). The superintendent as staff developer. School Administrator. Retrieved August 30, 2006, from http://www.aasa.org/publications/sa/2000_09/dufour.htm

Durocher, E. A. (1995). Leadership orientations of school administrators: A survey of nationally recognized school leaders. Dissertation Abstracts International (UMI No. 9620148)

Edmonds, R. (1979). Effective schools for the urban poor. Educational leadership, 37(1), 1527. Education secretary suggests academy. (2000, September 15). The Charleston Gazette, p. 6A. Fayol, H. (1996). General principles of management. In J. Shafritz \& J. Ott, (Eds.), Classics of organizational theory (4th ed., pp. 52-65). Belmont, CA: Wadsworth.

Felner, R. D., \& Adan, A. M. (1988). The school transitional environment project: An ecological intervention and evaluation. In R. H. Price, E. L. Cowen, R. P. Lorion, \& J. Ramos-McKay (Eds.), Fourteen ounces of prevention: A casebook for practitioners (pp. 111-122). Washington, DC: American Psychological Association.

Felner, R. D., Jackson, A. W., Kasak, D., Mulhall, P., Brand, S., \& Flowers, N. (1997). The impact of school reform for the middle years: Longitudinal study of a network engaged in turning points-based comprehensive school transformation. Phi Delta Kappan, 78(7), $528-532,541-550$.

Fowler, W. J., Jr. (1992, April). What do we know about school size: What should we know? Paper presented at the annual meeting of the American Educational Research Association, San Francisco, CA. (ERIC Document Reproduction Service No. 347 675) 
Fowler, W. J., Jr. (1995). School size and student outcomes. In H. J. Walberg (Ed.), Organizational influences on educational productivity (pp. 3-25). Greenwich, CT: JAI Press, Inc.

Fowler, W. J., Jr., \& Walberg, H. J. (1991). School size, characteristics, and outcomes. Educational Evaluation and Policy Analysis 13(2), 189-202.

Fraenkel, J. R., \& Wallen, N. E. (2000) How to Design and Evaluate Research in Education (5th Ed.). Columbus, Ohio: McGraw-Hill.

Fullan, M. (1993). Change forces: Probing the depths of educational reform. London: Falmer Press.

Fullan, M. (1982). The meaning of educational change. New York: Teachers College Press.

Funk, P., \& Bailey, J. (1999). Small schools, big results: Nebraska high school completion and postsecondary enrollment rates by size of school district. Nebraska Alliance for Rural Education.

Gamble, M. W. (2003). 'Living logos': Framing the discourse of the university presidency. Unpublished dissertation, Morgantown, West Virginia University.

Gilman, D.A. \& Lanman-Givens, B. (2001). Where have all the principals gone? Educational Leadership, 58(5), 72-75.

Gladden, M. (1998). The small schools movement: A review of the literature. In M. Fine \& J. I. Somerville (Eds.), Small schools, big imaginations: A creative look at urban public schools (pp.113-137). Chicago, IL: Cross City Campaign for Urban School Reform.

Good, T. L., \& Brophy, J. E. (1986). School effects (3rd Ed.). In M. C. Wittrock (Ed.), Handbook of Research on Teaching (pp. 570-602). New York: Macmillan. 
Gregory, T. (1992). Small is too big: Achieving a critical anti-mass in the high school. Hubert H. Humphrey Institute of Public Affairs, Minnesota University, Minneapolis, MN. (ERIC Document Reproduction Service No. ED 361 159)

Gregory, T. (2000). School reform and the no-man's-land of high school size. (ERIC Document Reproduction Service No. ED 451 981)

Gregory, T. (2001). Breaking up large high schools: Five common (and understandable) errors of execution. (ERIC Digest No. EDO-RC-01-6). Charleston, WV: ERIC Clearinghouse on Educational Management. (ERIC Document Reproduction Service No. ED 459 049).

Griffin, Marshall, S. (2005). A Comparison of the Leadership Orientations of Chairpersons of Biology and English Departments at Baccalaureate and Master's Institutions in the Southern Region. Dissertation from West Virginia University. Retrieved from http://kitkat.wvu.edu:8080/files/3863/Griffin_M_dissertation.pdf.

Heimovics, R. D., Herman, R. D., \& Jurkiewicz, C. L. (1995). The political dimension of effective nonprofit executive leadership. Nonprofit Management and Leadership: A Quarterly Journal, 5(3), 233-248.

Heimovics, R. D., Herman, R. D., \& Jurkiewicz Coughlin, C. L. (1993). Executive leadership and resource dependence in nonprofit organizations: A frame analysis. Public Administration Review, 53(5), 419-427.

Hershey, P., \& Blanchard, K. H. (1982). Management of organizational behavior: Utilizing human resources (4th ed.). Englewood Cliffs, NJ: Prentice-Hall.

Herszenhorn, D. M. (2003, September 18). Gates gives money to New York City to start 67 schools. New York Times, p. 1. 
Hord, S. M. (1984). The effects of principal styles on school improvement (Clearinghouse No. EA017382). Austin, TX: Clearinghouse on Educational Management. (ERIC Document Reproduction Service No. ED 251 971)

Howley, C. B. (1994). The academic effectiveness of small-scale schooling. Charleston, W.V.: ERIC Clearinghouse on Rural Education and Small Schools. (ERIC Document Reproduction Service No. ED 372 897)

Howley, C. B., \& Bickel, R. (2000). When it comes to schooling...small works: School size, poverty and student achievement. Randolph, VT: Rural School and Community Trust. (ERIC Document Reproduction Service No. ED 447 973)

Hoy, W. K., \& Miskel, C. G. (1996). Educational administration: Theory, research, and practice (5th ed.). New York, NY: McGraw-Hill.

Huang, G., \& Howley, C. (1993). Mitigating disadvantage: Effects of small-scale schooling on student achievement in Alaska. Journal of Research I Rural Education, 9(3), 137-149.

Irmsher, K. (1997). School size. (ERIC Digest Number 113). (ERIC Document Reproduction Service No. ED 414 614)

Jarrett, D. (2000). Sometimes a Great Notion. Northwest Education, 6(2), Retrieved on August 28, 2006, from http://www.nwrel.org/nwedu/winter_00/2a.html

Johnson, J. D., Howley, C. B., \& Howley, A. A. (2002). Size, excellence, and equity: A report on Arkansas schools and districts. Charleston, WV: ERIC Clearinghouse on Rural Education and Small Schools. (ERIC Document Reproduction Service No. ED 459 987)

Johnson, W. L., \& Johnson, A. M. (1996). Assessing school climate priorities: A Texas study. Clearing House, 70(2), 64-66. 
Jones, M. J. (2003). The relationship between class size, school size, and student achievement in private, independent high schools. Unpublished dissertation. Athens, Georgia: University of Georgia.

Jurkiewicz, C. L., \& Brown, R. G. (1993). The P/E ratio that really counts. Working Paper. Department of Political Science, University of North Carolina at Charlotte.

Kaplan, L., \& Owings, W. (1999). Assistant principals: The case for shared instructional leadership. NASSP Bulletin, 83(610), 80-94.

Kelly, J. H. (1997). Leadership orientations of executives in business and industry and administrators in higher education. Dissertation Abstracts International. (UMI No. 9841309) Retrieved August 28, 2006, from Digital Dissertations database.

Klonsky, M. (1995). Small schools: The numbers tell a story. A review of the research and current experiences. Chicago, IL: University of Illinois, College of Education, Small Schools Workshop. (ERIC Document Reproduction Service No. ED 386 517)

Klonsky, M. (1998). Small schools: The numbers tell a story. Working Paper. The University of Illinois at Chicago, Small Schools Workshop.

Kotter, J. P. (1990). What leaders really Do. Harvard Business Review, 68(3), 103-111. Kotter, John P. (1998). Winning at Change. Leader to Leader. 10 (Fall 1998): 27-33.

LaRose, L. (1987). Professional development for new assistant principals. Educational Leadership, 44, 49-51.

LaSage, E., \& Ye, R. (2000, January). A study of the relationship between students' achievement, school size, and gender. Paper presented at the annual meeting of the Southwest Educational Research Association, Dallas, Texas. (ERIC Document Reproduction Service No. ED 445 072) 
Lee, V. E. (2000). School size and the organization of secondary schools. In M. T. Hallinan (Ed.), Handbook of the sociology of education. New York: Kluwer Academic /Plenum.

Lee, V. E., \& Loeb, S. (2000). School size in Chicago elementary schools: Effects on teachers' attitudes and student achievement. American School Board Journal, 37(1), 3-31.

Lee, V. E., \& Smith, J. B. (1993). Effects of high school restructuring and size on gains in achievement and engagement for early secondary school students. Madison, WI: Wisconsin Center for Education Research.

Lee, V. E., \& Smith J. B. (1996, April). High school size, which works best and for whom? Paper presented at the annual meeting of the American Educational Research Association, New York, NY.

Lee, V. E., \& Smith, J. B. (1997). High school size: Which works best and for whom? Educational Evaluation and Policy Analysis, 19(3), 205-227.

Leithwood, K., Louis, K.S., Anderson, S., and Wahlstrom, K. (2004). How leadership influences student learning. New York, NY: Wallace Foundation.

Levine, D. U. (1992). An interpretive review of U.S. research and practice dealing with unusually effective schools. In D. Reynolds \& P. Cuttance (Eds.), School effectiveness: Research, policy, and practice (pp. 25-47). New York, NY: Cassell Villiers House.

Levine, D. U., Cooper, E. J., \& Hilliard, A. (2000). National urban alliance professional development model for improving achievement in the context of effective school research. The Journal of Negro Education, 69(4), 305-322.

Levine, D. U., \& Lezotte, L. W. (1990). Unusually effective schools: A review and analysis of research and practice. Madison, WI: National Center for Effective Schools Research and Development. 
Lezotte, L. (2001). Revolutionary and evolutionary: The effective schools movement. Okemos, Mich.: Effective Schools Products, Ltd.

Lezotte, L. W., \& Pepperl, J. C. (1999). The effective schools process: A proven path to learning for all. Okemos, MI: Effective Schools Products, Ltd.

Lockwood, A.T. (2005). Principal leadership for accountability: Optimizing the use of Title II resources [Topical summary]. Portland, OR: Norwest Regional Educational Laboratory;. Retrieved October 12, 2006 from www.nwrel.org/planning/reports/ accountability/index.html

March, J. K., \& Peters, K. H. (2002). Curriculum development and instructional design in the effective schools process. Phi Delta Kappan, 83(5), 379-381.

Marzano, R. (2003). What works in school: Translating research into action. Alexandria, VA: Association for Supervision and Curriculum Development.

Mathis, S. G. (1999). The relationship of leadership frame use of departmental chairs to faculty job satisfaction as perceived by selected departmental faculty members. Dissertation Abstracts International, 60, 6-A.

McClelland-Holt, J. E. (2000). Leadership orientations of student personnel professional. Dissertation Abstracts International. (UMI No. 9977819) Retrieved August 27, 2006, from Digital Dissertations database.

McNeil, Patricia. (2000) Sometimes a Great Notion, Northwest Education Magazine, Volume 6, Number 2. URL: http://www.nwrel.org/nwedu/winter_00/2a.html.

Michael, C. M. (2003). The relationship of the transformational leadership of the administrators in America's middle college high schools and their feeder institutions to selected 
indicators of effectiveness. (Doctoral dissertation, Marshall University, 2003).

Dissertation Abstracts International, 64(07A), 2332.

Miller, P.A. (1998). Directors/Chairpersons of Occupational Therapy Professional Programs: A Study of Leadership in Higher Education. Unpublished dissertation. Teachers College, Columbia University.

Mintzberg, Henry. (1973). The Nature of Managerial Work. New York. Harper Row.

Mosser, N. R. (2000). A study of the relationship between the perceived leadership style of nursing chairpersons and the organizational climate in baccalaureate nursing programs. Dissertation Abstracts International. (UMI No. AA 19999952)

Muir, E. (2001). Smaller schools: How much more than a fad? American Educator, 24(4), 4046.

Myers, K. (Ed.). (1996). School improvement in practice. Bristol, PA: The Falmer Press.

National Center for Education Statistics (2000). Condition of America's public school facilities: 1999. Washington, D.C.

National Commission on Excellence in Education. (1983). A nation at risk: The imperative for educational reform. Washington, D.C.: United States Department of Education.

Neumann, A. (1989). Strategic leadership: The changing orientations of college presidents. The Review of Higher Education, 12(2), 137-151.

Neumann, A., \& Bensimon, E. M. (1990). Constructing the presidency of college presidents' images of their leadership roles: A comparative study. Journal of Higher Education, 61(6), 678-701.

Northwest Regional Educational Laboratory (2004). Schools Making Progress, Glenville High School, School Description Series, No. 9., www.nwrel.org. 
Northwest Regional Educational Laboratory (2005). Serving Smaller Learning Communities. http://www.nwrel.org/scpd/sslc/elements.shtml.

Olson, L. (1999). Demand for principals growing but candidates not applying. Education Week, $28(1), 20$.

Overbay, A. (2003). School size, a review of the literature. (E \& R Report No. 03.03). Wake County Public Schools. Evaluation and Research Department.

Owens, R. (1995). Organizational behavior in education (5th ed.). Needham Heights, MA: Allyn and Bacon.

Oxley, D. (2001). Organizing schools into small learning communities. NASSP Bulletin, 85(625), $5-16$.

Oxley, D. (2004). Smaller learning communities: Implementing and deepening practice. Northwest Regional Educational Laboratory, Portland, Oregon.

Paine, S. L. (2002). The relationship of superintendent instructional leadership behavior and student achievement in high performing high schools that work network public high schools in West Virginia. Unpublished dissertation, Morgantown, West Virginia University.

Peters, T. J., \& Waterman, R. H. (1982). In search of excellence. New York: HarperCollins.

Peterson, Kent; Kelley, Carolyn (2001). Leadership. v30 n3 p8-11. Jan-Feb. 2001.

Peterson, Kent. (1998). Realities and Reform: Living with the Daily Realities of Principals' Work. Instructional Leader. Texas Elementary Principals Association.

Portin, B., Shen, J., \& Williams, R. (1998). The changing principalship and its impact: Voices from principals. NASSP Bulletin, 82(602), 1-8. 
Price, D. (2005). Learning communities and student success in postsecondary education. Working Paper. American University.

Purkey, S. C., \& Smith, M. S. (1983). Effective schools: A review. Elementary School Journal, $8,427-452$.

Quinn, R. E. (1988). Beyond rational management. San Francisco, CA: Jossey-Bass Publishers.

Rallis, S., \& Highsmith, M. (1986). The myth of the "great principal": Questions of school management and instructional leadership. Phi Delta Kappan, 68, 300-304.

Raywid, M.A. (1995). The subschools/small schools movement--taking stock. Madison, WI: Center on Organization and Restructuring of Schools. (ERIC Document Reproduction Service No. ED 397 490)

Raywid, M. A. (1996). Taking stock: The movement to create mini-schools, schools-withinschools, and separate small school. Madison, WI: Center on Organizing and Restructuring of Schools. (ERIC Document Reproduction Service No. ED 393 958)

Raywid, M., \& Oshiyama, L. (2000). Musings in the wake of Columbine: What can schools do? Phi Delta Kappan, 81(6), 444-449.

Ready, D., Lee, V., \& Welner, K. (2004). Educational equity and school structure: School size, overcrowding, and schools-within-schools. Blackwell Publishing Limited.

Reents, J. N. (2002, March). Isolating 9th graders: Separate schools ease the academic and social transition for high school-bound student. School Administrator.

Reynolds, D., Creemers, B. P., Nesselrodt, P. S., Schaffer, E. C., Stringfield, S., \& Teddlie, C. (1994). Advances in school effectiveness research and practice. Tarrytown, NY: Elsevier Science Inc. 
Richardson, M.D., Flanigan, J.L., Prickett, R.L., \& Short, P.M. (1991, November). The changing roles of the school principal: A research synthesis. Paper presented at the annual meeting of the Mid-South Educational Research Association, Lexington, KY.

Rivers, P. G. (1996). A frame analysis of principals’ leadership orientations (multiframe thinking). (Doctoral dissertation, University of Central Florida, 1996). Dissertation Abstracts International. (UMI No. AAG9637016)

Roeder, P.W. (2002). Resisting the urge to merge; Does school size matter? Eric Document Reproduction Service No. ED 464793.

Rogers, B. (1992). Small is beautiful. Chicago, IL: Coalition of Essential Schools Center. (ERIC Document Reproduction Service No. ED 361 163)

Rose, L. C. (2000). Pay attention to the public. Phi Delta Kappan, 82(1), 2.

Rose, L. C., \& Gallup, A. M. (2000). The 32nd annual Phi Delta Kappa/Gallup poll of the public's attitudes toward the public schools. Phi Delta Kappan, 82(1), 41-66.

Schmoker, M. (2005). Fundamentals of leadership. Southwest Educational Development Laboratory (SEDL). Retrieved August 30, 2006, from http://www.sedl.org/pubs/

Sebring, Penny B., Bryk, Anthony S. (2000). School Leadership and the Bottom Line in Chicago. Phi Delta Kappan: Feb2000, Vol. 81 Issue 6, p440, 4p, 1bw. Retrieved from http://search.ebscohost.com/login.aspx?direct=true \&db=aph\&AN=2770168\&site=ehostlive.

Senge, P. (1990). The fifth discipline: The art and practice of the learning organization. London: Doubleday. 
Senge, P. M., Cambron-Mccabe, N., Lucas, T., Smith, B., Dutton, J., \& Kleiner, A. (2000).

Schools that learn: A fifth discipline fieldbook for educators, parents and everyone who cares about education. New York: Currency Doubleday.

Sergiovanni, T. J. (1992). Reflections on administrative theory and practice in schools. Educational Administration Quarterly, 28(3), 304-11.

Shum, L. S., \& Cheng, Y. C. (1996). Perceptions of woman principal's leadership and teacher's work attitudes. Journal of Educational Administration, 35(2), 168-188.

Sizer, T. R. (1996). Horace's hope: What works for the American high school. Boston: Houghton-Mifflin.

Small, T. T. (2002). A study of the relationship between the perceived leadership style of nursing chairpersons and the organizational effectiveness of baccalaureate nursing programs. Unpublished doctoral dissertation, West Virginia University. Retrieved August 26, 2006, from http://etd.wvu./templates/showETD.cfm?recnum=2424

Southern Regional Education Board. (2000a). New Partnerships and a national network to improve high school education. Atlanta, Ga. Retrieved August 28, 2006, from http://www.sreb.org/programs/hstw/bacground

Southern Regional Education Board. (2000b). What is the high schools that work assessment? Atlanta, Ga. Retrieved August 28, 2006, from http://www.sreb.org/programs/hstw/Assessment/WhatIsAssessment.asp

Southern Regional Education Board. (2001). High schools that work composite, West Virginia, 2000 assessment. Atlanta, Ga.

Stedman, L. C. (1987). It's time we changed the effective school formula. Phi Delta Kappan, 69, 214-224. 
Stockard, J., \& Mayberry, M. (1992). Effective Educational Environments. Newbury Park, CA; Corwin Press, Inc.

Taylor, A., Valentine, B., \& Jones, M. (1985). What research says about: Effective schools, number 1. West Haven, CT: National Education Association.

Taylor, B. O. (2002). The effective school process: Alive and well. Phi Delta Kappan, 83(5), 375-378.

Taylor, F. (1996). The principles of scientific management. In J.M. Shafritz \& J.S. Ott (Eds.), Classics of organizational theory (4th ed., pp. 66-79). Belmont, CA: Wadsworth.

Thompson, M.D. (2000). Gender, leadership orientation, and effectiveness: Testing the theoretical models of Bolman and Deal and Quinn. Sex Roles, 42 (11/12); 969-992.

Terry, K. W. (1988). Secondary school teachers' perceptions of principals' leadership behaviors in selected effective and regular secondary school (Doctoral dissertation, Northwestern State University of Louisiana, 1988). Dissertation Abstracts International, 49, 1340.

Tierney, W. G. (1989). Symbolism and presidential perceptions of leadership. The Review of Higher Education, 12(2), 153-166.

Turley, C. L. (2002). Radiation therapy program directors: A frames analysis of leadership in higher education. Unpublished dissertation. The George Washington University.

Turley, C. L. (2004). A frames analysis of radiation therapy program director leadership. Radiation Therapist, 13(1), 15-19.

United States Department of Education. (2006). Quality counts, 2006, a decade of standardsbased education. Education Week, 25(17), 6-101. 
United States Department of Education. (2006). Smaller learning communities program: An outline of the program. Retrieved on August 30, 2006, from http:/www.ed.gov/programs/slcp/index.html

Viadero, Debra. (2001). Smaller is Better. Education Week. 11/28/2001, Vol. 21 Issue 13, p28, 3p, 3c. Retrieved from: search.ebscohost.com/login.aspx?direct=true \&db=aph\&AN=5667507\&site=ehost-live.

Walberg, H. J., \& Walber, H. J., III. (1994). Losing local control. Educational Researcher, 23, $19-26$.

Wasley, P. A., Fine, M., Gladden, M., Holland, N. E., King, S. P., Mosak, E., \& Powell, L. C. (2000). Small schools, great strides: A study of new small schools in Chicago. New York, NY: Bank Street College of Education.

Waxman, W. (1999, October). Three things that can be done now to make a principal's job easier. NewsLeader, 47(2), 10.

Weber, M. (1996). Bureaucracy. In J.S. Ott, (Ed.), Classics of organizational theory (4th ed., pp. 80-85). Belmont, CA: Wadsworth.

West Virginia Department of Education, (2004). Curriculum Practices of High Performing School Systems, WV Achieves, October, 2004. WVDE, Framework for High Performing School Systems.

Williams, D. T. (1990). The dimensions of education: Recent research on school size. Working Paper Series, Clemson, SC: Clemson University, Strom Thurmond Institute of Government and Public Affairs.

Wimpelberg, R. K. (1987). Managerial images and school effectiveness. Administrators' Notebook, 32, 1-4. 
Wolf, R.A. (1998). Campus safety directors: A leadership frame analysis (Doctoral dissertation, University of Central Florida, 1998). [On-line]. Dissertation Abstracts International. Abstract from: dissertation Abstracts Online File: UMI Dissertation Services Item: 9910810. 


\section{LEADERSHIP ORIENTATIONS (OTHER)}

(c) 1990, Lee G. Bolman and Terrence E. Deal, all rights reserved-Unique \#

Name of person described: Principal

This questionnaire asks you to describe your principal in terms of leadership and management style.

\section{Leader Behaviors}

You are asked to indicate how often each item is true of the person that you are rating.

Please use the following scale in answering each item.

$\begin{array}{lccll}1 & 2 & 3 & 4 & 5 \\ \text { Never } & \text { Occasionally } & \text { Sometimes } & \text { Often } & \text { Always }\end{array}$

So, you would answer ' 1 ' for an item that is never true of the person you are describing, '2' for one that is occasionally true, ' 3 ' for one that is sometimes true, and so on. Be discriminating!

1. Thinks very clearly and logically.

2. Shows high levels of support and concern for others.

3. Shows exceptional ability to mobilize people and resources to get things done.

4. Inspires others to do their best.

5. Strongly emphasizes careful planning and clear time lines.

6. Builds trust through open and collaborative relationships.

7. Is a very skillful and shrewd negotiator.

8. Is highly charismatic.

9. Approaches problems through logical analysis and careful thinking.

10. Shows high sensitivity and concern for others' needs and feelings.

11. Is unusually persuasive and influential.

12. Is an inspiration to others.

13. D Develops and implements clear, logical policies and procedures.

14. Fosters high levels of participation and involvement in decisions.

15. Anticipates and deals adroitly with organizational conflict.

16. Is highly imaginative and creative.

17. Approaches problems with facts and logic.

18. Is consistently helpful and responsive to others.

19. Is very effective in getting support from people with influence and power.

20. Communicates a strong and challenging vision and sense of mission.

21. Sets specific, measurable goals and holds people accountable for results.

22. L Listens well and is unusually receptive to other people's ideas and input.

23. Is politically very sensitive and skillful.

24. Sees beyond current realities to create exciting new opportunities.

25. Has extraordinary attention to detail.

26. Gives personal recognition for work well done.

27. Develops alliances to build a strong base of support.

28. Generates loyalty and enthusiasm.

29._Strongly believes in clear structure and a chain of command.

30. Is a highly participative manager.

31._ Succeeds in the face of conflict and opposition.

32. Serves as an influential model of organizational aspirations and values. 
I. Leadership Style: This section asks you to describe the leadership style of your principal. For each item, give the number " 4 " to the phrase that best describes your principal, " 3 " to the item that is next best, and on down to " 1 " for the item that is least like this person.

1. The individual's strongest skills are:

a. Analytic skills

b. Interpersonal skills

c. Political skills

d. Ability to excite and motivate

2. The best way to describe this person:

a. Technical expert

b. Good listener

c. Skilled negotiator

d. Inspirational leader

3. What this individual does best is:

a. Make good decisions

b. Coach and develop people

c. Build strong alliance and a power base

d. Energize and inspire others

4. What people are most likely to notice about this person is:

a. Attention to detail

b. Concern for people

c. Ability to succeed, in the face of conflict and opposition

d. Charisma

5. This individual's most important leadership trait is:

a. Clear, logical thinking

b. Caring and support for others

c. Toughness and aggressiveness

d. Imagination and creativity

6. This person is best described as:

a. An analyst

b. A humanist

c. A politician

d. A visionary

III. Overall rating

Compared to other individuals that you have known with comparable levels of experience and responsibility, how would you rate this person on:

1. Overall effectiveness as a manager.

123

Bottom 20\%

Middle 20\%

4

Top 20\%

2. Overall effectiveness as a leader.

1

Bottom 20\%
2

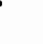

3

Middle 20\%
5

Top 20\% 
RE: Permission to use leadership orientation instrument

This message has been scanned for known vinuses.

From: Lee Bolman

To: sarastankus@aol.com

Subject: RE: Permission to use leadership orientation instrument

Date: Wed, 25 Jan 2006 10:35:51 -0600

Dear Ms. Stankus:

I am pleased to offer you permission to use the Leadership Orientations Survey in your dissertation research.

Best wishes.

Lee G. Bolman

Marion Bloch/Missouri Chair in Leadership

Bloch School of Business and Public Administration

University of Missouri-Kansas City

5100 Rockhill Road

Kansas City, MO 64110

Tel: (816) 235-5407

Fax: (816) 235-6529

Email: bolmanl@umkc.edu

From: sarastankus@aol.com [mailto:sarastankus@aol.com]

Sent: Tuesday, January 24, 2006 8:35 PM

To: bolmanl@umkc.edu

Subjoct: Permission to use leadership orientation instrument

Dear Dr. Bolman,

I request your permission to use the Leadership Orientations (Self) and Leadership Orientations (Other) survey instruments as part of my dissertation entitled "A study of the relationship between the leadership styles of principals in smaller learning communities, the number and types of structures and strategic configurations and the rates of student success of ninth grade students." I am a doctoral candidate at West Virginia University in Educational Leadership Studies. I understand the conditions under which you grant permission such as, the results of my research will be made available to you upon request. Your work has been truly inspirational and it is my hope that you will grant permission to continue this research. Again thank you for considering this request.

Sincerely,

Sara Stankus 


\section{West KrginiaUniversity.}

November 23, 2005

Dr. Lee G. Bolman

Bloch School of Business and Public Administration

University of Missouri - Kansas City

5100 Rockhill Road

Kansas City, Missouri 64110

Dear Dr. Bolman:

I am a doctoral candidate in Higher Education Administration at West Virginia University and am preparing my dissertation prospectus. The title is "A STUDY OF THE RELATIONSHIP BETWEEN LEADERSHIP STYLES OF PRINCIPALS IN SMALLER LEARNING

COMMUNITIES AND THE NUMBER OF STRUCTURES AND STRATEGIC CONFIGURATIONS AND THE RATES OF STUDENT SUCCESS OF 9TH GRADERS.” It is my hope that you will grant permission to use your Leadership Orientations (Others) instrument to examine the relationship between the principals leadership style and student success. I understand that, should you grant permission, I will provide to you a copy of any reports, publications, papers or theses resulting from this research. I also agree to provide a copy of the data file from this research if you request it.

If you have any questions, you my contact me by E-mail at sarastankus@aol.com, by phone 304-4730305 or my mailing address:

HC 36 Box 170

Buckhannon, West Virginia 26201

I am looking for forward to hearing from you. Thank you for your time and consideration.

Sincerely,

Sara Stankus

Doctoral Student

Educational Leadership Studies

West Virginia University

Advisor. Dr. Richard Hartnett

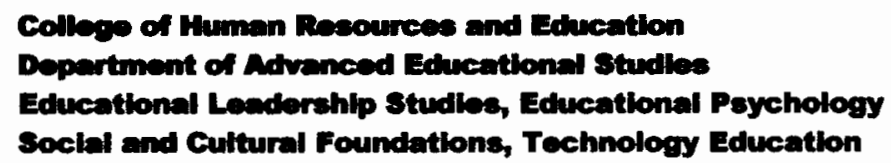

Phone: 304-293-5703

Allen Hull

P.O. Box 6122

Morgantown, WV 26506-6122

Equal Opportunities/Affirmative Action Institution 


\section{Principal Survoy}

Gender: __ Male _ Female

Age

Number of Years in Education (at the end of this year)

Number of Years in Administration (at the end of this year)

Highest degree earned

Area of Major in highest degree earned

Certification (traditional or alternative)

How many ninth graders in your school

How many D's or F's in $9^{\text {th }}$ grade during first semester $2005 / 2006$ school year in:

English

Algebra I

Social Studies

Science

Thank you for your time and support. Please retum the completed survey in the enclosed self-addressed-stamped envelope by May 1, 2006.

Please give the enclosed teacher surveys to ten $9^{\text {th }}$ grade teachers of your choice.

Unique number 


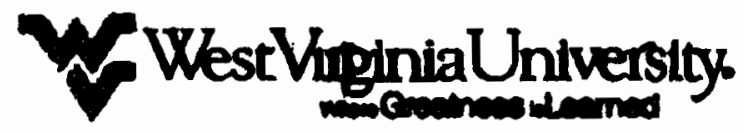

APPAOVED GY THE COLLEE OF HUMAN RESOURCES \& EDUCATION DATE:
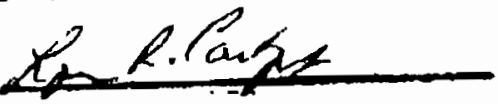

\section{Dear High School Principal}

You are in e very important position in the public educational system, and your time is valuable. You have been selected to participate in a study which concerns how your leadership impacts the academic achievement of the ninth grade students. in your building.

I am completing a doctoral study at West Virginia University, Morgantown, which is concemed with the role of the principal in ninth grade student achievement. This is an important study that has never been done before. This study will look specifically at Cohort 3 Smaller Leaming Communities grantees (your school is one of these schools). We all know ninth grade students face many challenges. This study will help us understand how to best help our ninth grade students.

Your particlpation in this study is entirely voluntary, and you do not have to respond to every item or question. Your signature is not required on this questionnaire. Your responses will remain anonymous and confidentiality will be maintained. The enclosed demographic questionnaire has been reviewed by education professionals and will take approximately 10 minutes to complete. For a copy of the results of this survey, please send your e-mail request to sarastankus@eol.com.

Retum of your completed questionnaire in the enclosed envelope before May 1, 2006 would be appreciated. I am asking that you distribute the enclosed teacher surveys to ten $9^{\text {h }}$ grade teachers. The teachers will complete the surveys and then return them to me in the envelope provided. Again, thank you very much for your cooperation.

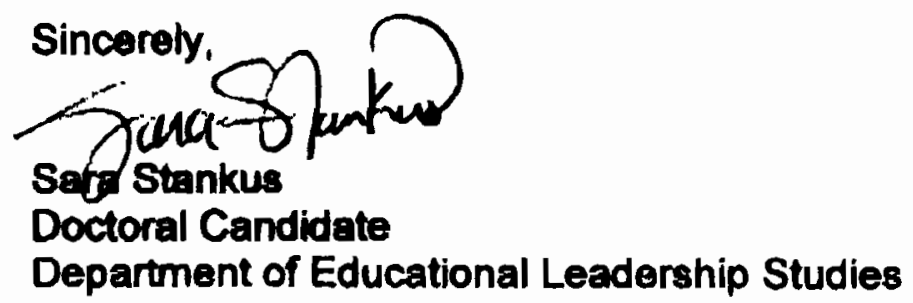




\section{WestVirginiaUniversity.}

High School of Principal

Principal

2616 Jeff Rd

Harvest , AL 35749

Dear

Your position in as a school leader involves enormous responsibility and commitment of time. All of us are busier these days than we would like, and most of us have a difficult time staying ahead of the obligations which are essential and required.

You may recall a questionnaire you received earlier this month regarding a study of high school principals in Cohort 3 of the Smaller Learning Communities grants. This study is concerned with the role of the principals in ninth grade student achievement.

Because your responses are so important to this study, and because I have not received your completed questionnaire, I have enclosed another copy.

I encourage you to take ten minutes (estimated time) out of your day to complete the questionnaire and then use the enclosed self-addressed, stamped envelope for your return. As indicated earlier, a summary of the results of this study may be obtained by sending your e-mail request to sarastankus@aol.com.

Thark you for taking time to complete this important survey.

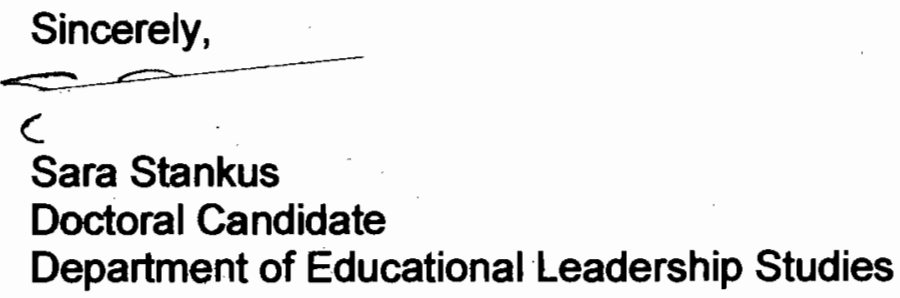


WestVirginiaUniversity.

Dear Principal

The good news... I have received your teacher surveys!

The bad news.... I have not received your survey.

Funding for the Smaller Learning Communities programming depends on solid research. This research project focuses specifically on the at-risk $9^{\text {th }}$ grade populations in high schools with S.L.C. funding.

Your response is critical. Your teachers have taken their valuable time to complete their surveys. Your school can not be included without your response. Please take a few minutes today to complete the enclosed survey.

Thank you,

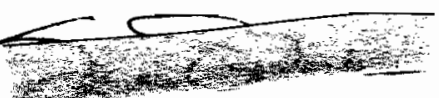

Sara Stankus

sarastankus@aol.com 
DATE:

Dear Ninth Grade Teacher:

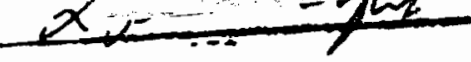

You are in a very important position in the public educational system, and your time is valuable. You have been selected to participate in a study which concerns how your principals' leadership style impacts the academic achievement of the ninth grade students in your building.

I am completing a doctoral study at West Virginia University, Morgantown, which is concerned with the role of the principal in ninth grade student achievement. This is an important study that has never been done before. This study will look specifically at Cohort 3 Smaller Learning Communities grantees (your school is one of these schools). We all know ninth grade students face many challenges. This study will help us understand how to best help our ninth grade students.

Your participation in this study is entirely voluntary, and you do not have to respond to every item or question. Your signature is not required on this questionnaire. Your responses will remain anonymous and confidentiality will be maintained. The enclosed demographic questionnaire has been reviewed by education professionals and will take approximately 15 minutes to complete. For a copy of the results of this survey, please send your e-mail request to sarastankus@aol.com.

Return of your completed questionnaire in the enclosed envelope before May 1, 2006 would be appreciated. Thank you very much for your cooperation.

Sincerely,

Sara Stankus

Doctoral Candidate

Department of Educational Leadership Studies 


\section{WestVirginiaUniversity}

College of Muman Resources and Education

Aprll 10, 2006

\section{MEMORANDUM}

TO: $\quad$ Sara Jane Lewis-Stankus

FROM: Lynn Cartwright $\not{ }_{y} \quad$ Interlm Associate Dean

RE: $\quad$ Human Resources \& Education H.S. \$2006-027

Tille: "A Study of the Relationship Between the Leadership Styles of Principals in Smaller Learning Communities, the Number of Structures and Strategic Conflgurations and the Rates of Student Success of $9^{\text {th }}$ Graders"

Your Application for Exemptlon for the above-captioned research project has been reviewed under the Human Subjects Policies and has been approved. Attached are the originals of your cover letters with the signed stamp of approval. These must accompany your surveys or questlonnaires.

This exemption will remain in effect on the condition that the research is carried out exactly as described in the appllcation.

Best wishes for the success of your research.

cc: Deans Office

Student Advising and Records

Richard Hartnett. Advisor 

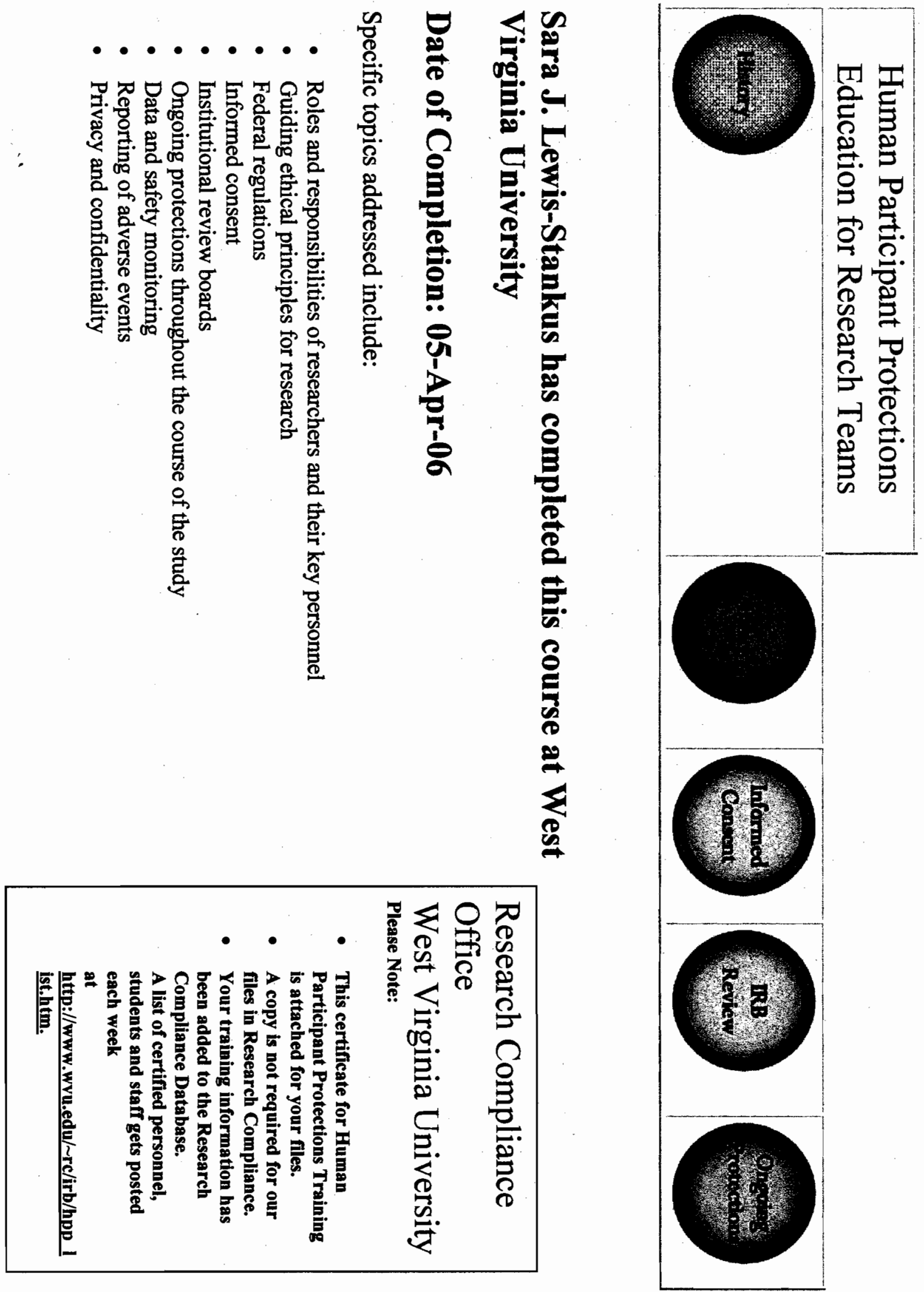


\title{
SWATIRRI.TARNINGCONMLNTTISS
}

\section{Your s search of the SLC Awards Database found 204 schools.}

The search results below include 204 schools from 86 districts sorted by state, then by district, then by school I

Showing 200 records per page:

Pages: 1 | 2

\section{Alabama}

\author{
Madison County School District \\ School Name \\ Sparkman High School (9-12)
}

\author{
Cohort Structures \\ 2003-A Freshman Academy \\ Career Academy / Academi
}

\section{Arkansas}

\section{Little Rock School District}

School Name

Central High School (9-12)

\author{
Cohort Structures \\ 2003-A Freshman Academy \\ Magnet Schools \\ Career-based Communities
}

J.A. Fair High School (9-12)

2003-A Magnet Schools Freshman Academy

\section{California}

Berkeley Unified School District School Name

Berkeley High School (9-12)

\section{Cohort Structures}

2003-A Freshman Clusters / Teams Sophomore Clusters / Tear College / Career / Tech Aca

\section{Dixon Unified School District}

Dixon High School (9-12)

2003-A Freshman Academy House Plans

Upper-grade Academies

Fremont Unified School District

American High School (9-12)

2003-A House Plans

Career Academy / Academi Theme-Based Academies

Fresno Unified School District 
Roosevelt High School (9-12)

\section{APPENDIX I}

\section{Lodi Unified School District}

Lodi High School (9-12)

Los Angeles Unified School District

Birmingham High School (9-12)

Carson High School (9-12)

Fremont High School (9-12)

Narbonne High School (9-12)

Petaluma Joint Union High School District

Casa Grande High School (9-12)

Petaluma High School (9-12)

\section{Sacramento City Unified School District}

C.K.McClatchy High School (9-12)

John F. Kennedy High School (9-12)

\section{San Bernardino County Superintendent of Schools}

Eisenhower High School (9-12)

Pacific High School (9-12)

Rialto High School (9-12)

San Bernardino Hlgh School (9-12)

Serrano High School (9-12)

\section{San Diego Unified School District}

Clairemont High School (9-12)

Crawford High School (9-12)

Henry High School (9-12)

Hoover High School (9-12)
2003-A School-Within-A-School Career Academy / Academi Theme-Based Academles

2003-A Career Academy / Academi

2003-A Freshman Academy Theme-Based Academies Alternative Education Acad

2003-A Career Academy / Academi Freshman Community / Co

2003-A House Plans

Freshman 8 Sophomore AC Theme-Based Academies

2003-A Theme-Based Academies

2003-A Career Academy / Academi Freshman Clusters / Teams

2003-A Grade-level Communities

2003-A Career Academy / Academi Magnet Schools

2003-A Career Academy / Academi

2003-A Career Academy / Academi House Plans

2003-A House Plans Theme-Based Academies

2003-A House Plans Career Academy / Academi

2003-A House Plans Career Academy / Academi

2003-A House Plans Career Academy / Academi

2003-A Theme-Based Academies

2003-A School-Within-A-School

2003-A Theme-Based Academles

2003-A Theme-Based Academies 
Kearny High School (9-12)

Madison High School (9-12)

Mission Bay High School (9-12)

Morse High School (9-12)

San Diego High School (9-12)

Serra High School (9-12)

San Dieguito Union High School District

La Costa Canyon High School (9-12)

Washington Unified School District

River City High School (9-12)

West Contra Costa Unified School Distrlct

Richmond High School (9-12)

\section{Colorado}

Harrison School District (El Paso County) School Name

Sierra High School (9-12)

\section{Poudre School District}

Poudre High School (9-12)

\section{Connecticut}

\section{East Hartford Publlc Schools}

School Name

East Hartford High School (9-12)

\section{District of Columbia}

District of Columbia Public Schools

School Name

Ballou High School (9-12)

Dunbar High School \& Pre-Engineering (9-12)

Eastern High School (9-12)
APPENDIX I

2003-A

2003-A

House Plans

Career Academy / Academi
2003-A Spphomore Academy / ACa Themongre Academy Aca

\author{
Cohort Structures \\ 2003-A Freshman Academy \\ Senior Academy \\ Career Academy / Academi
}

$\begin{array}{ll}\text { Cohort } & \text { Structures } \\ \text { 2003-A } & \text { Freshman Academies } \\ \text { 2003-A Freshman Academies } \\ \text { 2003-A Freshman Acadernles }\end{array}$ 
Wilson High School (9-12)

\section{APPENDIX I}

\section{Delaware}

\section{Christina School District}

School Name

Christiana High School (9-12)

Glasgow High School (9-12)

Newark High School (9-12)

\section{Florida}

\section{Lake County School District}

School Name

South Lake High School (9-12)

\section{Manatee County School District}

Bayshore High School (9-12)

Lakewood Ranch High School (9-12)

Manatee High School (9-12)

Palmetto High School (9-12)

Southeast High School (9-12)

\section{Miami - Dade County School District}

American High School (9-12)

G. Holmes Braddock High School (9-12)

Miami Beach High School (9-12)

Miaml Central High School (9-12)

North Mlami Beach High School (9-12)

South Dade High School (9-12)

\section{Pinellas County School District}

Largo High School (9-12)
2003-A Freshman Academles

\section{Cohort Structures \\ 2003-A Therne-Based Academies}

2003-A Career Acadermy / Academi School-Within-A-School

2003-A Freshman Community / Co Career Academy / AcademI

2003-A Career Acodemy / Academi School-W/thin-A-School

2003-A Career Academy / Academ School-Within-A-School

2003-A Career Academy / Academ School-Within-A-School

2003-A Career Academy / Academ!

2003-A Career Academy / Academi

2003-A Career Academy / Academi

2003-A Career Academy / Academi

2003-A Career Academy / Academi

2003-A Career Academy / Academi

2003-A Theme-Based Academles 


\section{APPENDIX I}

Osceola High School (9-12)

St. Petersburg High School (9-12)

\section{Sarasota County School Board}

North Port High School (9-12)

Volusia County School District

New Smyrna Beach Hiqh School (9-12)

\section{Georgia}

\section{Dougherty County School System}

School Name

Dougherty High School (9-12)

Monroe High School (9-12)

Lowndes County School District

Camden County High School (9-12)

Jackson Hiah School (9-12)

Lowndes High School (9-12)

\section{Iowa}

Waterloo Community School District School Name

East High School (9-12)

West High School (9-12)

West Des Moines Community School District

Valley High School (10-12)

\section{Cohort Structures \\ 2003-A Magnet Schooks Freshmon Academies Theme-Based Academies \\ 2003-A Magnet Schools Freshman Academies Career Academy / Academi \\ 2003-A Freshman Academy Upper-grade Communities School-Within-A-School \\ 2003-A Freshman Academy Upper-grade Communities School-Within-A-School \\ 2003-A Freshman Academy Upper-grade Communitles School-Within-A-School}

\author{
Cohort Structures \\ 2003-A Freshman Custers / Team: \\ 2003-A Freshman Custers / Teams
}

2003-A House Plans

\section{Illinois}

Alton Community Unit School District \#11 
School Name

Alton High School (9-12)

Chicago Public Schools District \#299

Chicago Vocational Career Academy (9-12)

George Washington High School (9-12)

DuPage School District / Addison Trail High School

Addlson Trail High School (9-12)

Edwardsville School District \#7

Edwardsville High School (9-12)

Kankakee School District \#111

Kankakee High School (9-12)

Woodstock Community Unit School District \#200

Woodstock High School (9-12)

\section{Kansas}

Blue Valley Unified School District \#229

School Name

Blue Valley High School (9-12)

Blue Valley North High School (9-12)

Blue Valley Northwest High School (9-12)

Blue Valley West Hiah School (9-12)

Wichita Unified School District \#259

West High School (9-12)

\section{Kentucky}

Covington Independent Public Schools

School Name

Holmes High School (10-12)

\section{Owensboro Public Schools}

Owensboro Hiah School (9-12)
APPENDIX I

2003-A

2003-A

2003-A

2003-A

2003-A

2003-A

Grade-level Communittes

\author{
Cohort Structures \\ 2003-A Freshman Academy \\ Sophomore Academy / Aca \\ Career Academy / Academi \\ 2003-A Freshman Academy \\ Sophomore Academy / Aca \\ Career Academy / Academi \\ 2003-A House Plans \\ 2003-A Career Academy / Academi
}

2003-A Freshman Academies Career Academy / Academi 


\section{Massachusetts}

\section{New Bedford Public Schools}

School Name

New Bedford High School (9-12)

\section{Newton Public Schools}

Newton North High School (9-12)

Newton South High School (9-12)

\section{Maryland}

\author{
Baltimore County Public Schools \\ School Name \\ Dundalk High School (9-12) \\ Kenwood High School (9-12) \\ Lansdowne High School (9-12) \\ Milford Mill Hiqh School (9-12) \\ Overlea High School (9-12) \\ Owings Mills High School (9-12) \\ Parkville High School (9-12) \\ Plkesville High School (9-12) \\ Randallstown Hiqh School (9-12) \\ Woodlawn High School (9-12)
}

\section{Montana}

\author{
Billings Public Schools -- High Schools \\ School Name \\ Senior High School (9-12) \\ Skyview High School (9-12)
}

\section{APPENDIX I}

2003-A House Plans Theme-Based Academies

2003-A House Plans Theme-Based Academies

\author{
Cohort Structures \\ 2003-A Freshman Academy \\ 2003-A Freshman Academy \\ Career Academy / Academi \\ 2003-A Freshman Academy \\ Career Academy / Academi \\ 2003-A Freshman Academy \\ Career Academy / Academl \\ 2003-A Freshman Academy \\ Career Academy / Academi \\ 2003-A Freshman Academy \\ 2003-A Freshman Academy \\ Career Academy / Academ \\ 2003-A Freshman Academy \\ 2003-A Freshman Academy \\ Career Academy / Academi \\ 2003-A Freshman Academy \\ Career Acodemy / Academi
}


West High School (9-12)

\section{North Carolina}

\author{
Cumberland County Public Schools \\ School Name \\ South Vlew High School (9-12) \\ Gaston County Public Schools \\ Ashbrook High School (9-12) \\ East Gaston High School (9-12) \\ Forestview High School (9-12) \\ Hunter Huss High School (9-12) \\ North Gaston High School (9-12) \\ South Point High School (9-12)
}

\section{Onslow County Public Schools \\ Jacksonville High School (9-12)}

\section{Union County Public Schools}

North Iredell High School (9-12)

Parkwood High School (9-12)

Piedmont High School (9-12)

Statesville High School (9-12)

Sun Valley High School (9-12)

Weddington High School (9-12)

West Iredell High School (9-12)

\section{APPENDIX I}

2003-A

\author{
Cohort Structures \\ 2003-A Freshman Academy \\ 2003-A Freshman Academy \\ Upper-grade Academies \\ 2003-A Freshman Academy \\ Upper-grade Academies \\ 2003-A Freshman Academy \\ Upper-grade Academles \\ 2003-A Freshman Academy \\ Upper-grade Academies \\ 2003-A Freshman Academy \\ Upper-grade Academies \\ 2003-A Freshman Academy \\ Upper-grade Academies
}

2003-A Freshman Academy Career Academy / Academi School-Within-A-School

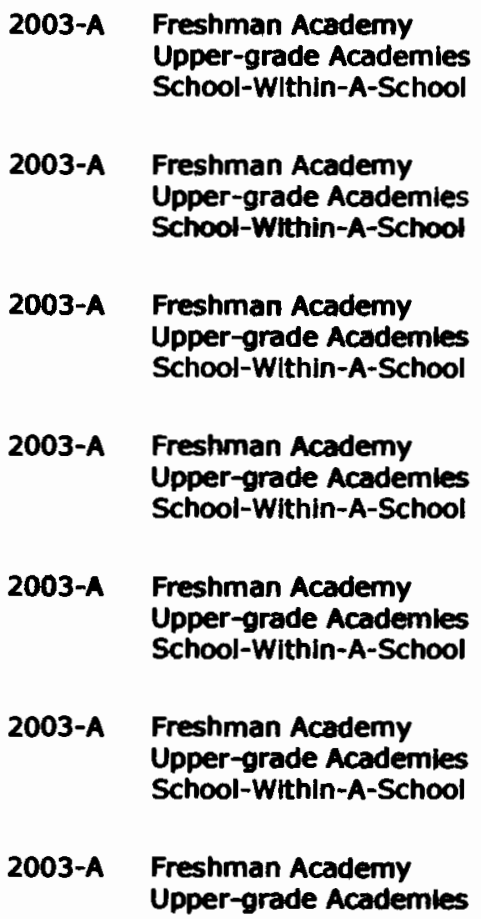
Upper-grade Academies School-Within-A-School

2003-A Freshman Academy Upper-grade Academies School-Within-A-School

2003-A Freshman Academy Upper-grade Academies School-Within-A-School

2003-A Freshman Academy Upper-grade Academies School-Within-A-School

2003-A Freshman Academy Upper-grade Academies School-Within-A-School

2003-A Freshman Academy Upper-grade Academies School-Within-A-School

2003-A Freshman Academy Upper-grade Academies 
School-Within-A-School

\title{
Nebraska
}

Papillion - La Vista Public Schools

School Name

Papillion-La Vista High School (9-12)

\section{APPENDIX I}

Papillion-La Vista South High School (9-12)

$\begin{array}{ll}\begin{array}{l}\text { Cohort } \\ \text { 2003-A }\end{array} & \begin{array}{l}\text { Structures } \\ \text { School-WIthin-A-School } \\ \text { Career Academy / Academi }\end{array} \\ \text { 2003-A } & \text { Career Academy / Academi }\end{array}$

\section{New Jersey}

\section{East Orange School District}

School Name

East Orange Campus 9 (9)

Cohort Structures

2003-A House Plans

Freshman Clusters / Teams

East Orange Campus High School (10-12)

2003-A

Career Academy / Academi

\section{Plainffeld Publlc Schools}

Plainfleld High School (9-12)

2003-A Freshman Academy

Theme-Based Communitie:

\section{Princeton Regional Schools}

Princeton High School (9-12)

2003-A Freshman Academles Career Academy / Academi

\section{New Mexico}

\section{Albuquerque Public Schools}

School Name

Highland High School (9-12)

Manzano High School (9-12)

Valley High School (9-12)

\author{
Cohort Structures \\ 2003-A Freshman Acaderny \\ Career Academy / AcademI \\ 2003-A Freshman Academy \\ Career Academy / Academi \\ 2003-A Freshman Academy \\ Career Academy / Academi \\ School-WithIn-A-School
}

\section{Nevada}

\section{Clark County School District}

\section{School Name}

Basic High School (9-12)

Bonanza High School (9-12)

$\begin{array}{cl}\text { Cohort } & \begin{array}{l}\text { Structures } \\ \text { 2003-A }\end{array} \\ \begin{array}{l}\text { Freshman Academy } \\ \text { Career Academy / Academi }\end{array} \\ \text { 2003-A } & \begin{array}{l}\text { Freshman Academy } \\ \text { Senior Academy } \\ \text { Career Academy / Academi }\end{array}\end{array}$


Chaparral High School (9-12)

Rancho High School (9-12)
Western High School (9-12)

\section{APPENDIX I}

\section{New York}

\section{New York City Public Schools}

School Name

Alfred E. Smith High School (9-12)

Chelsea High School (9-12)

Grace Dodge High School (9-12)

High School of Graphic Communication Arts (9-12)

Queens Vocational and Technical High School (9-12)

William E. Grady Technical Hiah School (9-12)

William H. Maxwell Career and Technical High School (9-12)

\section{Syracuse City School District}

Corcoran High School (9-12)

Fowler Hlgh School (9-12)

Henninger High School (9-12)

Nottingham High School (9-12)

\section{Warwick Valley Central School District}

Warwick Valley High School (9-12)
2003-A Freshman Academy Career Academy / Academi

2003-A Career Academy / Academl Freshmen Academy

2003-A Career Academy / Academi Freshman Academy

2003-A Frestman Academy Freshman Community / Co Theme-Based Communitie

\section{Ohio}

\section{Canton City Schools}

School Neme

McKInley High School (9-12)

Cohort Structures

2003-A Other school-defined struct 
APPENDIX I

Timken High School (9-12)

Cleveland Heights - University Helghts Clty Schools

Cleveland Heights High School (9-12)

Cleveland Municipal School District

East High School (9-12)

Columbus Public Schools

Brookhaven High School (9-12)

West High School (9-12)

\section{Lima City School District}

Lima Senior High School (9-12)

\section{Oklahoma}

\section{Choctaw - Nicoma Park Public Schools}

School Name

Choctaw High School (10-12)

Yukon Public Schools

Yukon High School (9-12)

\section{Oregon}

Beaverton School District $\mathbf{4 8 3}$

School Name

Beaverton High School (9-12)

Bend - La Pine Public Schools

Bend High School (9-12)

Mountain View High School (9-12)

Summit High School (9-12)

\section{Oregon Chy School District}

Oregon City High School (9-12)
House Plans

2003-A

Career Academy / Academi House Plans

2003-A

Autonomous Acodemies / S

2003-A School-W/thin-A-School

2003-A School-Within-A-School

2003-A Freshman Acadermy

Career Academy / AcademI

2003-A School-W/thin-A-School

\section{Cohort Structures \\ 2003-A Freshman Clusters / Teams Sophomore Clusters / Tear Career Academy / Academi}

2003-A Freshman Clusters / Teams Freshman Community / Co Career Academy / Academi

2003-A Freshman Clusters / Teams Sophomore Community / C Acedemic Communities

2003-A Freshman Clusters / Teams Sophomore Clusters / Tear Career Academy / Academi

2003-A Other school-defined struct 
Redmond School District \#21

Redmond High School (9-12)

\section{Pennsylvania}

Greater Johnstown School District

School Name

Greater Johnstown High (9-12)

\section{Haverford Township School District}

Haverford High School (9-12)

\section{Rhode Island}

\section{Coventry Public Schools}

school Name

Coventry High School (9-12)

Lincoln High School (9-12)

Shea High School (9-12)

Tolman High School (9-12)

West Warwick High School (9-12)

\section{South Carolina}

\section{Greenville County School District}

School Name

Berea High School (9-12)

Hillcrest High School (9-12)

JL Mann High School (9-12)

Mauldin High School (9-12)

Travelers Rest High School (9-12)

Wade Hampton High School (9-12)

\section{APPENDIX I}

2003-A House Plans

Career Academy / Academi

Cohort Structures

2003-A Fresiman Academy Career Academy / Academ

2003-A Freshman Academies Theme-Based Academies

$\begin{array}{cl}\text { Cohort } & \text { Structures } \\ 2003-A & \text { Freshman Clusters / Teams } \\ 2003-A & \text { Freshman Clusters / Teams } \\ 2003-A & \text { Freshman Communtty / Co } \\ 2003-A & \begin{array}{l}\text { Upper-grade Academiles } \\ \text { Freshman Community / Co } \\ \text { Sophomore Community / C }\end{array} \\ 2003-A & \begin{array}{l}\text { House Plans } \\ \text { Career Academy / Academi }\end{array}\end{array}$

Cohort Structures

2003-A Freshman Academy School-Within-A-School

2003-A Freshman Academy School-Within-A-School

2003-A Freshman Academy School-Within-A-School

2003-A Freshman Academy School-Within-A-School

2003-A Freshman Academy School-Within-A-School

2003-A Freshman Academy School-Whthin-A-School 


\section{Pickens County School District}

Easley High School (9-12)

Pickens High School (9-12)

\section{Texas}

\section{Bastrop Independent School District}

School Nome

Bastrop High School (9-12)

\section{Cedar HIII Independent School District \\ Cedar Hill His School (9-12)}

\section{Dallas Independent School District \\ Bryan Adams High School (9-12)}

Hillcrest High School (9-12)

Jefferson High School (9-12)

Moises Molina High School (9-12)

North Dallas Hiah School (9-12)

Samuell High School (9-12)

Spruce High School (9-12)

Sunset High School (9-12)

W.T.White High School (9-12)

\section{APPENDIX I}

\author{
2003-A Freshman Academies \\ Career-based Communities \\ 2003-A Freshman Academies \\ Career-based Communities
}

2003-A House Plans

2003-A House Plans

Freshman Communlty / Co Sophomore Community / C Theme-Based Academies

2003-A Freshman Communlty / Co Sophomore Community / C House Plans Theme-Based Academies

2003-A House Plans Freshman Community / Co Sophomore Community / C Theme-Based Academies

2003-A House Plans

Freshman Community / Co Sophomore Community / C Theme-Based Academles

2003-A Freshman Communtty / Co Sophomore Communtty / C House Plans Theme-Based Academles

2003-A Freshman Communtty / Co Sophomore Community / C House Plans Theme-Based Academies

2003-A Freshman Communtty / Co Sophomore Communtty / C House Plans Theme-Based Academies

2003-A Freshman Communtty / Co Sophomore Community / C House Plans

Theme-Based Academies

2003-A Freshman Communtty / Co Sophomore Community / C 


\section{APPENDIX I}

Wilson Hiqh School (9-12)

\section{East Central Independent School District}

East Central High School (9-12)

\section{Houston Independent School District}

Austin High School (9-12)

Jones High school (9-12)

Jordan High School (9-12)

Madison High School (9-12)

Worthing High School (9-12)

San Antonlo Independent School District

Fox Technical High School (9-12)

Lanier High School (9-12)

Sam Houston High School (9-12)

Southwest Independent School District

Southwest High School (9-12)

\section{Virginia}

Rockingham County Public Schools

School Name

Broadway Hlgh School (9-12)

Spotswood High School (9-12)

Turner Ashby High School (9-12)
2003-A

2003-A

2003-A

2003-A

2003-A

2003-A

2003-A

2003-A

2003-A

2003-A

2003-A
House Plans

Theme-Based Academles

Freshman Community / Co Sophomore Community / C House Plans

Theme-Based Academies

House Plans

Freshman Clusters / Teams

Career Academy / Academ Freshman Clusters / Teams Sophomore Clusters / Tear

Career Academy / Academi Freshman Clusters / Team: Sophomore Clusters / Tear

Career Academy / Academi

Freshman Clusters / Teams Sophomore Clusters / Tear Career Academy / Academ

Freshman Clusters / Teams Sophomore Clusters / Tear Career Academy / Academi
Cohort Structures
2003-A House Plans
2003-A Freshman Community / Co
2003-A Freshman Community / Co

\section{Washington}

Clover Park School Dlstrict \#400

School Name

Cohort Structures 
Lakes High School (9-12)

Highline School District \#401

Evergreen High School (9-12)

Highline High School (9-12)

Mt.Rainier High School (9-12)

Tyee High School (9-12)
2003-A Career Academy / Academi

\section{APPENDIX I}

$2003-A$
$2003-A$ Sophomore Academy / Aca Career-based Communities

2003-A House Plans

Showing 200 reconds per page:

Pages: 1 | 2

If you have a question about the SLC database, please send an e-mall to Lacy Wood at Iwood@st $\mathbf{r}$ 


\title{
APPENDIX J
}

\section{SWAII.R I.FARNIVGCOMULNITIFS}

\section{Your s search of the SLC Awards Database found 98 schools.}

The search results below include 98 schools from 57 districts sorted by state, then by district, then by school ni

\section{Arkansas}

\section{Conway Public School District}

School Name

Conway High School East (9-10)

$\begin{array}{ll}\begin{array}{l}\text { Cohort } \\ \text { 2003-B }\end{array} & \begin{array}{l}\text { Structures } \\ \text { Freshman Community / Commu } \\ \text { Career Academy / Academies }\end{array} \\ \text { 2003-B } & \text { Career Academy / Academies }\end{array}$

Conway High School West (11-12)

2003-B

Cohort Structures

Agua Fria High School (9-12)

2003-B Freshman Community / Commu Sophomore Community / Comm Other school-defined structures

\section{California}

\author{
Folsom - Cordova Unified School District \\ School Name \\ Folsom High School (9-12) \\ Fontana Unified School District \\ Henry J.Kaiser High School (9-12)

\section{Inglewood Unified School District} \\ Morningside High School (9-12)

\section{Los Angeles Unified School District} \\ Garfield High School (9-12) \\ North Hollywood High School (9-12) \\ San Fernando High School (9-12)
}

Cohort Structures

2003-B Freshman Community / Commu

2003-B House Plans

Career Academy / Academies

2003-B House Plans

2003-B House Plans

Magnet Schools

Theme-Based Academies

2003-B

Career Academy / Academies

2003-B Magnet Schools

Career Academy / Academies 
Napa Valley Unified School District

Vintage High School (9-12)

San Jose Unified School District

San Jose High Academy (9-12)

Willow Glen High School (9-12)

Simi Valley Unified School District

Santa Susana High School (9-12)

\section{Colorado}

Adams County School District No. 1/ Mapleton

School Name

Skyview High School (9-12)

\section{District of Columbia}

Friendship Public Charter School, Inc.

School Name

Friendship Edison Collegiate Academy (9-12)

\section{Florida}

\section{Collier County School District}

School Name

Immokalee High School (9-12)

St. Lucie County School District

St. Lucie West Centennial Hiah School (9-12)

\section{Georgia}

\section{Houston County School District}

School Name

Tabor Academy at Northside High School (9-12)

\section{Madison County School District}

Madison County High School (9-12)

\section{APPENDIX J}

2003-B House Plans

Theme-Based Academies

2003-B Other school-defined structures

2003-B Other school-defined structures

2003-B School-Within-A-School Theme-Based Academies
Cohort Structures

2003-B Freshman Academies Sophomore Academy / AcademI Career Academy / Academles

2003-B School-Within-A-School

Cohort Structures

2003-B Freshman Academy Freshman Clusters / Teams

2003-B Freshman Academy 


\section{Hawaii}

Hawaii Department of Education, Kalani \& Maui Complex Areas

School Name

Kalani High School (9-12)

Maui High School (9-12)

\section{Idaho}

Nampa School District \#132

School Name

Nampa High School (9-12)

Skyview High School (9-12)

Twin Falls School District \#411

O'Leary Junior High School (7-9)

Robert Stuart Junior High School (7-9)

Twin Falls High School (10-12)

\section{Indiana}

Bartholomew Consolidated School Corporation

School Name

Columbus East Hlgh School (9-12)

Goshen Community Schools

Goshen Hiah School (9-12)

\section{Maine}

\section{Sanford School District}

School Name

Sanford High School (9-12)

\section{Michigan}

\section{Farmington Public Schools}

School Name

\section{Cohort Structures \\ 2003-B House Plans \\ Career-based Communities \\ 2003-B House Plans \\ Career-based Communities}

$\begin{array}{cl}\text { 2003-B } & \text { House Plans } \\ \text { 2003-B } & \text { House Plans } \\ \text { 2003-B } & \begin{array}{l}\text { House Plans } \\ \text { Career-based Communitles }\end{array}\end{array}$

Cohort Structures

2003-B Freshman Clusters / Teams

2003-B Freshman Clusters / Teams Limited English Proficient Acade

\author{
Cohort Structures \\ 2003-B Freshman Clusters / Teams \\ Sophomore Clusters / Teams \\ Other school-deflned structures
}


Harrison High School (9-12)

Huron Valley Schools

Lakeland High School (9-12)

Lansing School District

Eastern High School (9-12)

Everett High School (9-12)

Sexton High School (9-12)

Plymouth - Canton Community Schools

Canton High School (9-12)

Plymouth High School (9-12)

Salem High School (9-12)

Ypsilanti Public School

YpsilantI HIgh School (9-12)

\section{Minnesota}

\section{Rochester Public Schools}

School Name

Century High School (9-12)

John Marshall High School (9-12)

Mayo High School (9-12)

\section{Missouri}

\section{St. Louis Public Schools}

School Name

Gateway Instltute of Technology (9-12)

\section{North Carolina}

\section{Alamance - Burlington Public Schools}

\section{APPENDIX J}

2003-B Freshman \& Sophomore Acaden House Plans

Career Academy / Academles

$\begin{array}{cl}\text { 2003-B } & \begin{array}{l}\text { Freshman Academy } \\ \text { Upper-grade Communitles }\end{array} \\ \text { 2003-B } & \begin{array}{l}\text { Freshman Academy } \\ \text { Upper-grade Communities }\end{array} \\ \text { 2003-B } & \begin{array}{l}\text { Freshman Academy } \\ \text { Upper-grade Communities }\end{array}\end{array}$

2003-B Freshman Community / Commu Sophomore Community / Comm

2003-B Freshman Community / Commu Sophomore Community / Comm

2003-B

\section{Freshman Community / Commu} Sophomore Community / Comm

2003-B House Plans

Sophomore Clusters / Teams Career-based Communities

$\begin{array}{ll}\text { Cohort } & \text { Structures } \\ \text { 2003-B } & \text { Freshman Clusters / Teams } \\ \text { 2003-B } & \text { Freshman Clusters / Teams } \\ \text { 2003-B } & \text { Freshman Clusters / Teams }\end{array}$

Cohort Structures

2003-B House Plans

Career-based Communities 
Southern Alamance High School (9-12) APPENDIX J

Walter Williams High School (9-12)

Western Alamance High School (9-12)

\section{Cumberland County Public Schools}

Westover High School (9-12)

\section{Guilford County Public Schools}

Andrews High School (9-12)

High Point Central High School (9-12)

Southwest High School (9-12)

Hoke County Public Schools

Hoke High School (9-12)

\section{Scotland County Public Schools \\ Scotland High School (9-12)}

\section{Nebraska}

\section{Lincoln Public Schools}

School Name

Uncoln North Star High School (9-12)

\section{New Jersey}

\section{Hackensack Public Schools}

School Name

Hackensack High School (9-12)

\section{Pemberton Township School District}

Pemberton Township High School (9-12)

\author{
2003-B Freshman Academy \\ Career Academy / Academies \\ 2003-B Freshman Academy \\ Career Academy / Academies \\ 2003-B Career Academy / Academles \\ 2003-B Freshman Academy \\ Career Academy / Academies
}

2003-B Magnet Schools

Career Academy / Academles

2003-B Magnet Schools

Career Academy / Academies

2003-B Magnet Schools

Career Academy / Academles

2003-B Freshman Academy

Career Academy / Academies

2003-B Freshman Academles School-Within-A-School

Cohort Structures

2003-B Career Academy / Academies

\section{Cohort Structures}

2003-B Freshman Academy Sophomore Academy / Academi Career Academy / Academies

2003-B Freshman Academy Sophomore Acaderny / Academi Theme-Based Academies

Cohort Structures 
Cimmaron-Memorial High School (9-12) APPENDIX J

Durango High School (9-12)

Valley High School (9-12)

\section{New York}

\section{Buffalo City School District}

School Name

McKInley Vocational High School (9-12)

\section{Longwood Central School District}

Longwood High School (9-12)

\section{Mount Vernon City School District}

Mount Vernon High School (9-12)

\section{William Floyd School District}

William Floyd Hiah School (9-12)

\section{Oklahoma}

Norman Public Schools ISD \#29; Cleveland County School Name

Norman High School (9-12)

Norman North High School (9-12)

\section{Pennsylvania}

\author{
Harrisburg School District \\ School Name \\ Harrisburq High School (9-12)

\section{Philadelphia City School District} \\ Edward Bok High School (9-12) \\ Frankford High School (9-12) \\ Lincoln High School (9-12) \\ Northeast High School (9-12) \\ Roxborough High School (9-12)
}

2003-B Freshman Academy Career Academy / Academies

2003-B

Freshman Academy Career Academy / Academies

2003-B

\section{Freshman Academy}

Career Academy / Academles

\author{
Cohort Structures \\ 2003-B Career Academy / Academles \\ 2003-B Freshman Academy \\ Grade-level Academies \\ 2003-B Grade-level Communities \\ 2003-B Interest-based Academies / Con
}

Cohort Structures

2003-B Other school-defined structures

2003-B Freshman Academies Career Academy / Academles

2003-B Freshman Academles Career Academy / Academies

2003-B Freshman Academies Career Academy / Academles

2003-B Freshman Academles Career Academy / Academles

2003-B Freshman Academles 


\section{APPENDIX J}

University City High School (9-12)

Washington High School (9-12)

\section{South Carolina}

\section{Charleston County School District}

School Name

Stall High School (9-12)

Stratford High School (9-12)

Summerville High School (9-12)

Wando High School (9-12)

West Ashley High School (9-12)

\section{Lancaster County School District}

Lancaster High School (9-12)

\section{Texas}

\section{Amarillo Independent School District} School Name

Palo Duro Hiqh School (9-12)

Tascosa High School (9-12)

\section{Austin Independent School District}

Charles Akins High School (9-12)

Sidney Lanier High School (9-12)

Stephen F. Austin High School (9-12)

\section{Birdville Independent School District}

Birdwell High School (9-12)
Career Academy / Academies

2003-B Freshman Academies Career Academy / Academles

2003-B Theme-Based Academies Career Academy / Academles

2003-B Freshman Academy Career Academy / Academies

\section{Cohort Structures \\ 2003-B Career Academy / Academies Freshman Academy \\ 2003-B Career Academy / Academles Freshman Academy}

\section{3-B Freshman Academy Career Academy / Academies \\ 2003-B Freshman Academy Career Academy / Academies \\ 2003-B Freshman Academy Career Academy / Academies}

2003-B Freshman Academy Theme-Based Communtties 
Haltom High School (9-12)

Richland High School (9-12)

Clear Creek Independent School District

Clear Brook High School (9-12)

Clear Creek High School (9-12)

Clear Lake High School (9-12)

Irving Independent School District

Academy of Irving Independent School District (9-12)

Midway Independent School District

Midway Hiah School (9-12)

San Antonio Independent School District

Burbank High School (9-12)

Jefferson Hiqh School (9-12)

\section{Utah}

\section{Davis School District}

School Name

Davis High School (10-12)

Jordan School District

Copper Hills High School (10-12)

\section{Washington}

\section{Evergreen School District \#114}

School Name

Evergreen High School (9-12)

Heritage High School (9-12)

Mountain View High School (9-12)

\section{North Kitsap School District}

North Kitsap High School (9-12)
APPENDIX J

Theme-Based Academies
2003-B

2003-B

Career Academy / Academles

2003-B House Plans

2003-B School-Within-A-School

2003-B Schoot-Within-A-School

\author{
Cohort Structures \\ 2003-B Freshman Academy \\ Career Academy / Academles \\ 2003-B Freshman Academy \\ Career Academy / Academies \\ 2003-B Freshman Academy \\ House Plans
}

2003-B Interest-based Academies / Con 
If you have a question about the SLC database, please send an e-mail to Lacy Wood at Iwood@st

\section{APPENDIX J}




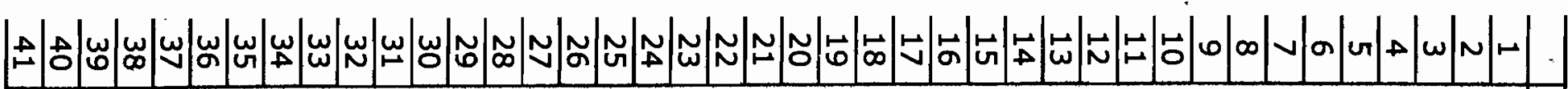

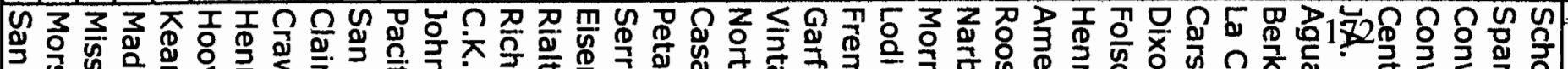

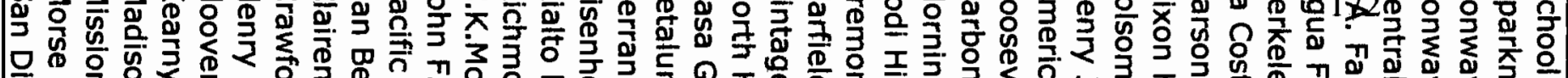

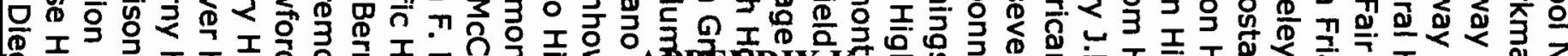

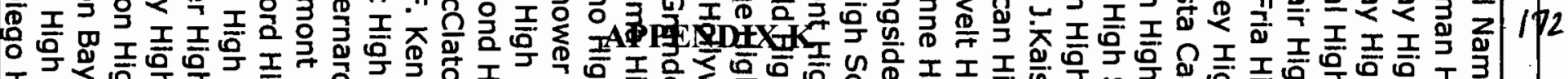

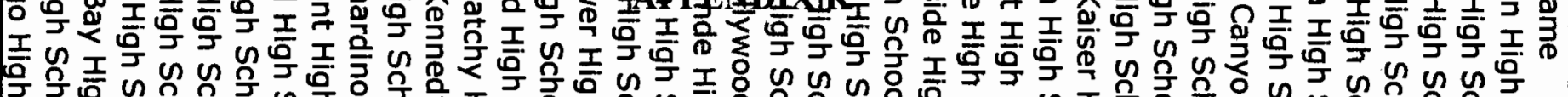

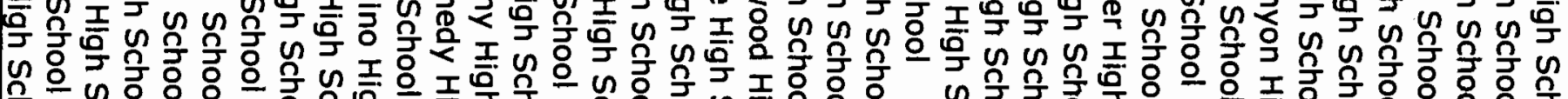

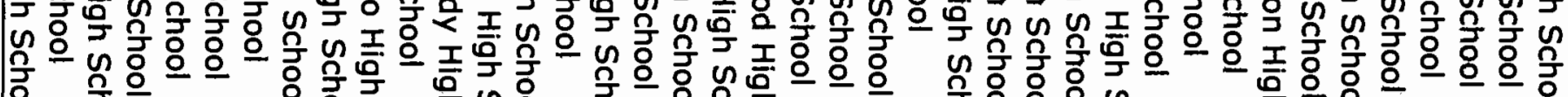

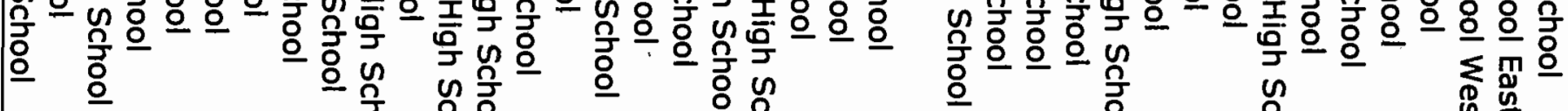

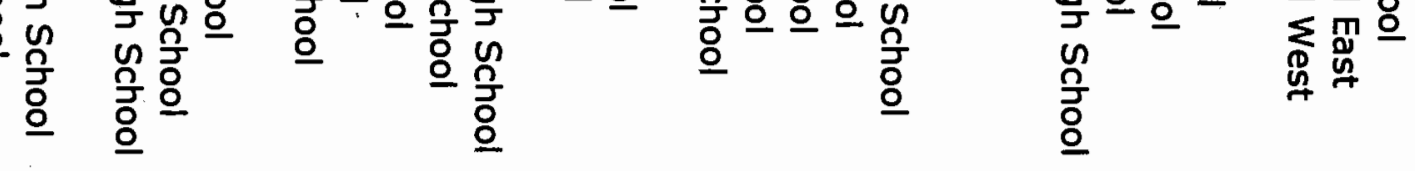

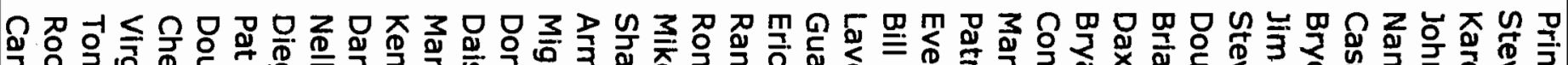

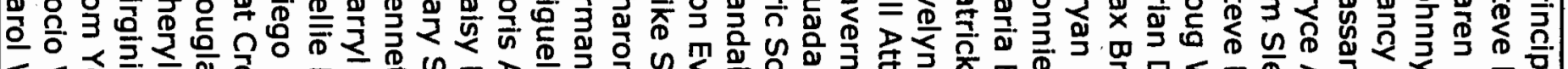

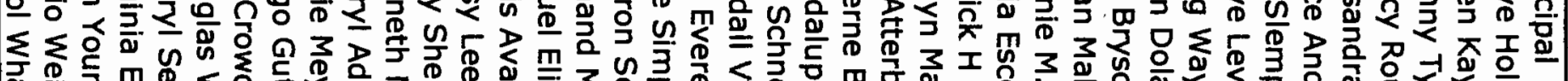

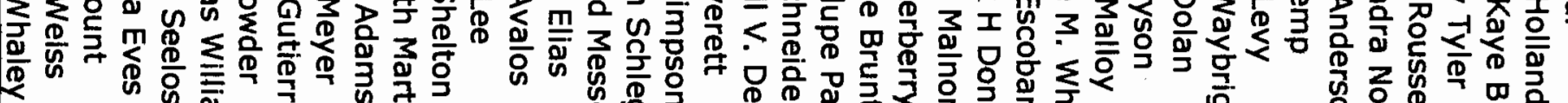

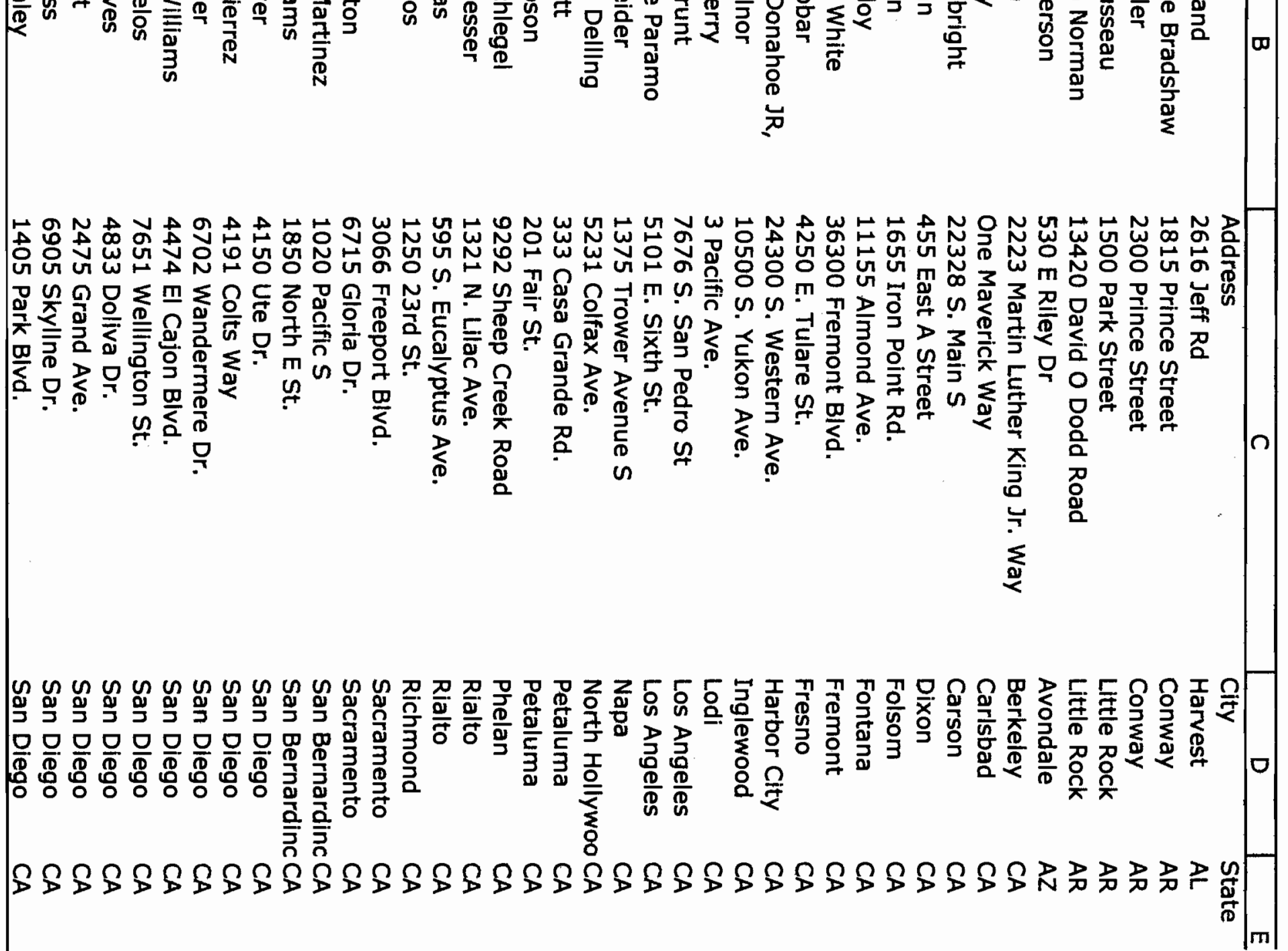

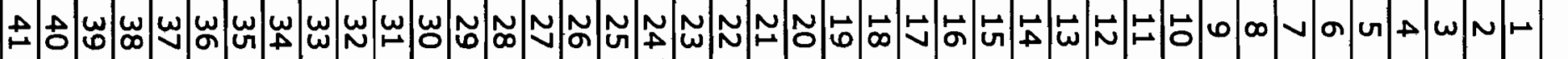
$00000000000000000000000000000000000 N N N N N$

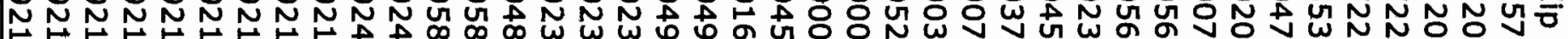

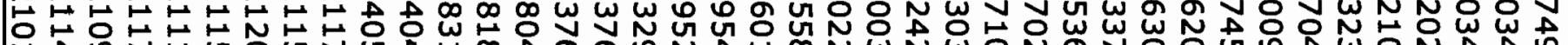
P A S N

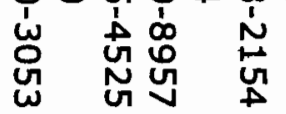


舟

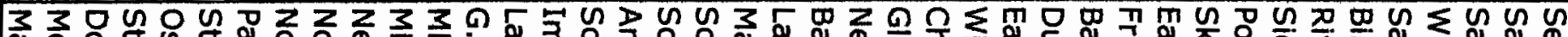

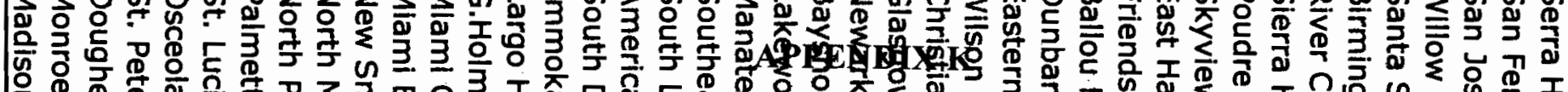

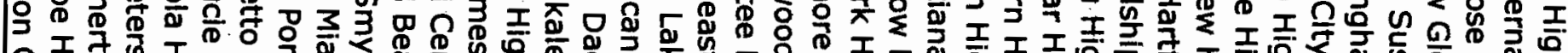

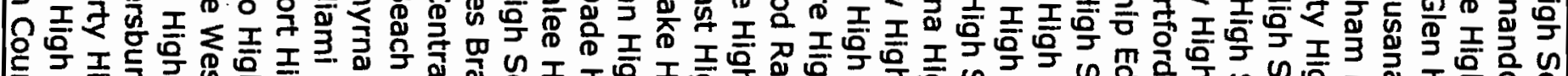

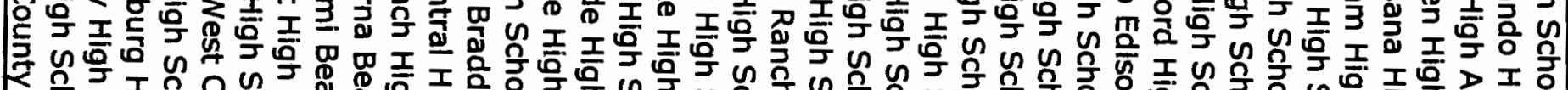
국

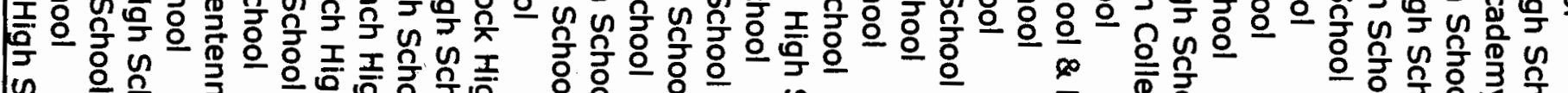

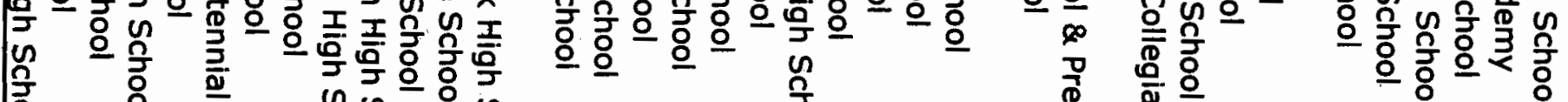

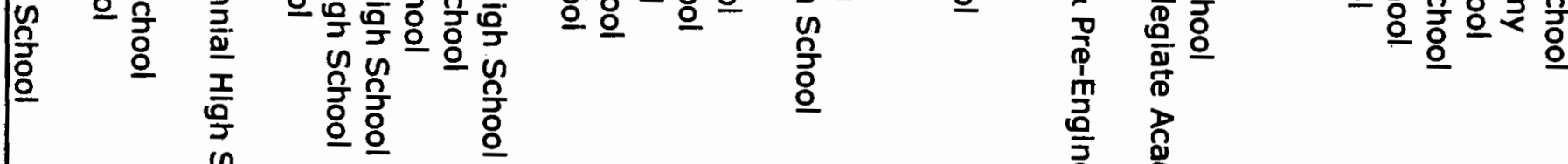

(n)

을 ฉ

Qิْ

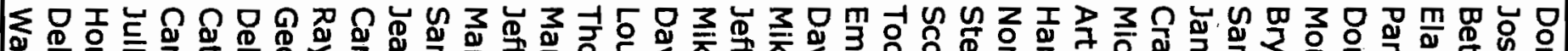

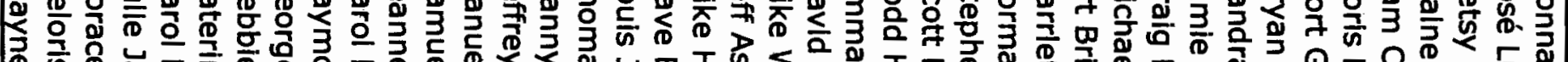
巾 的历

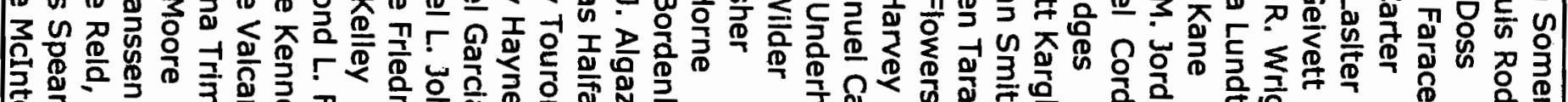

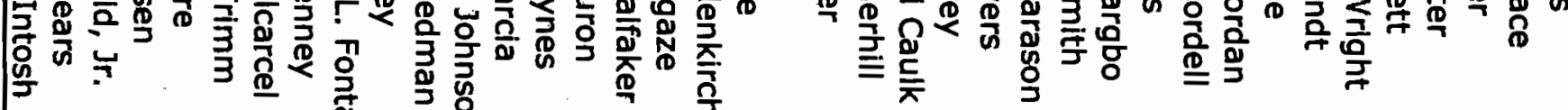
웅 吾 马

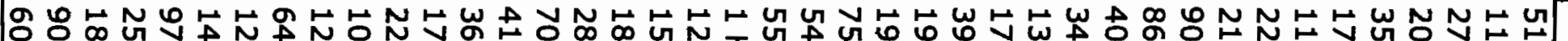

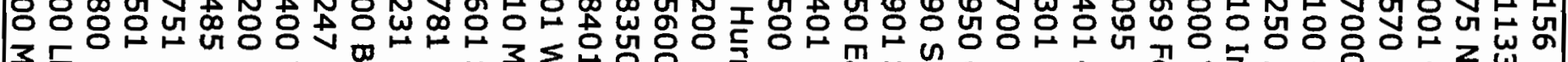

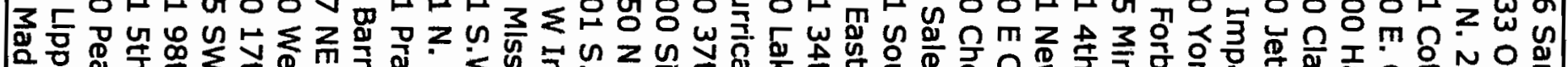

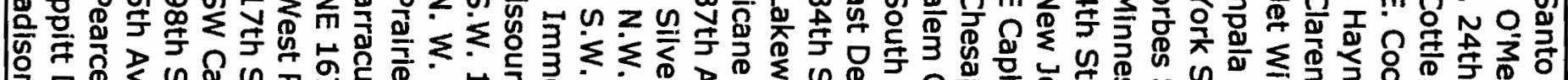

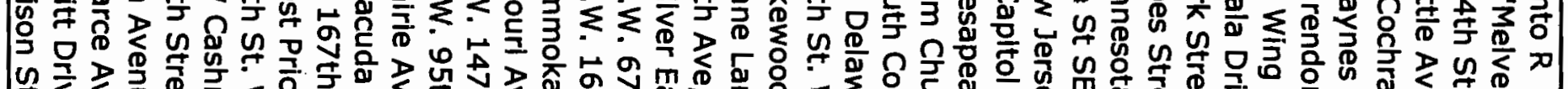

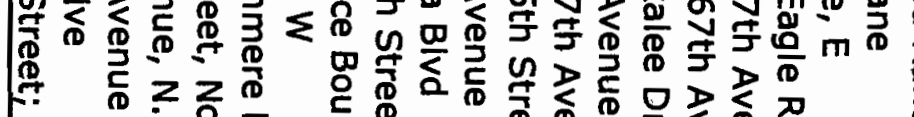

(0)

\%

茯

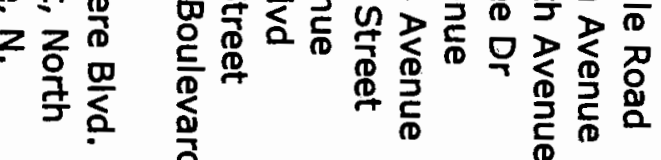

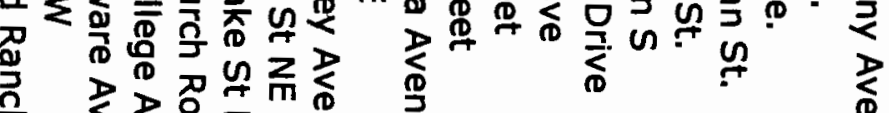

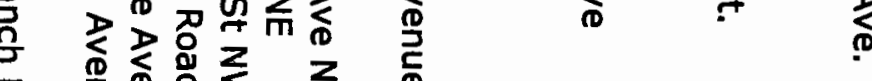

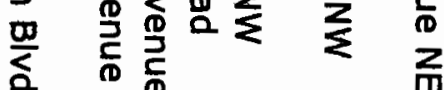

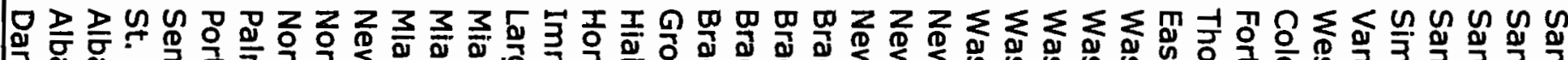

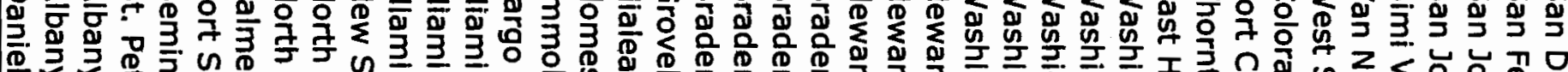

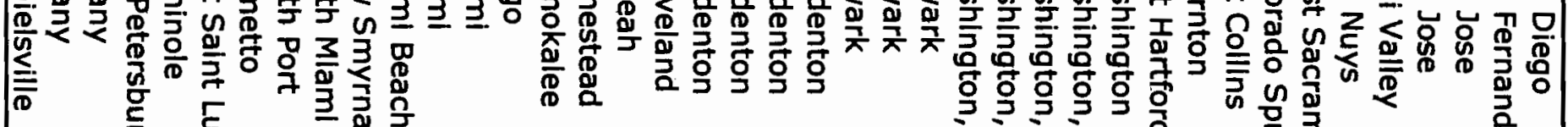

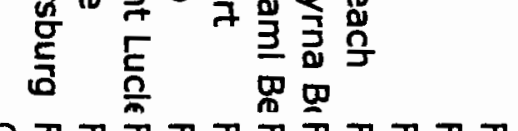

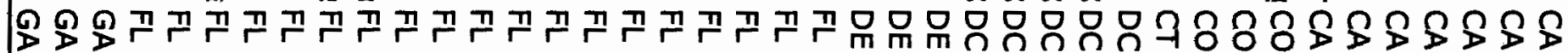
N

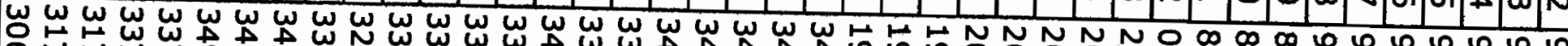

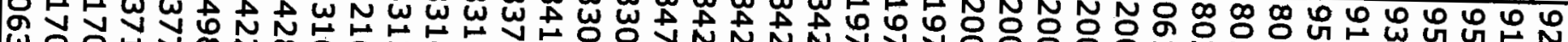
$\omega$ w 


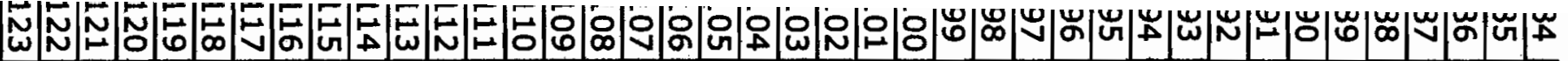

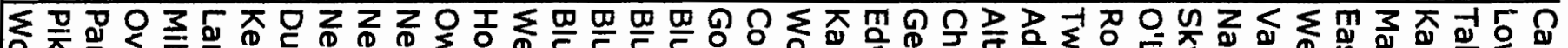

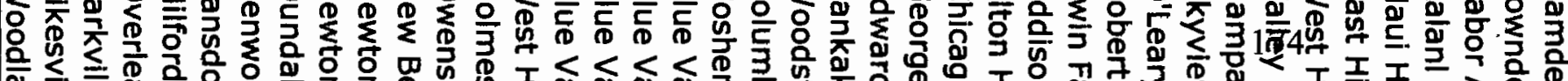

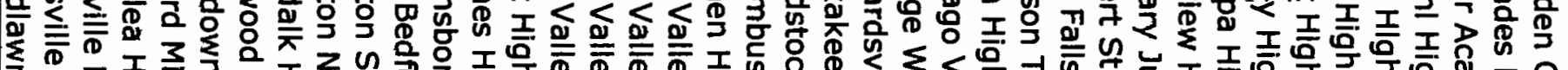

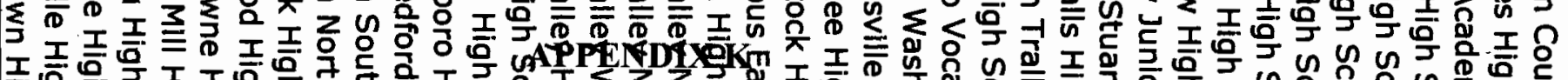

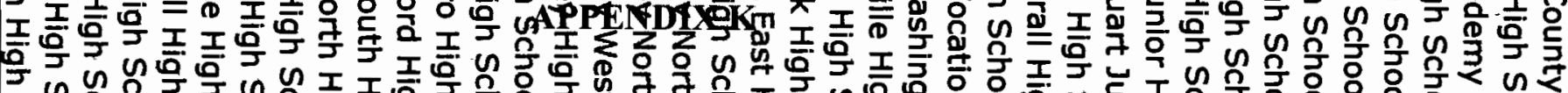

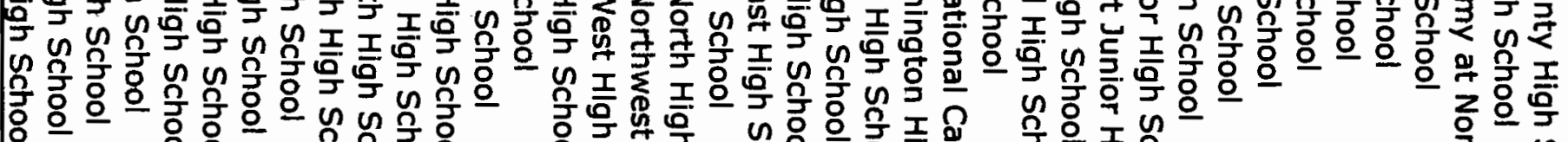

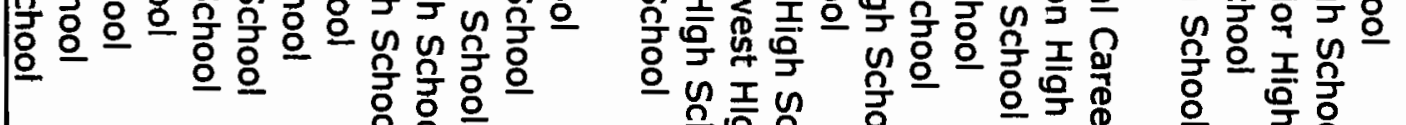

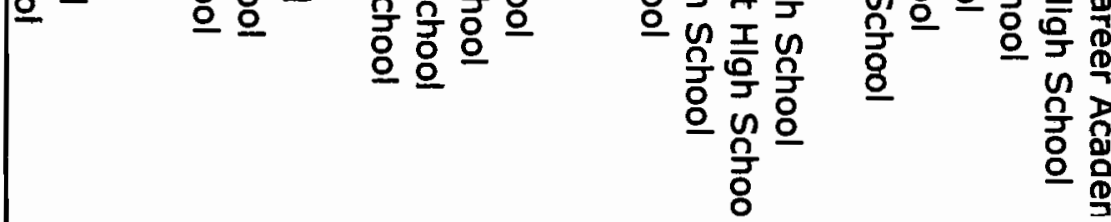

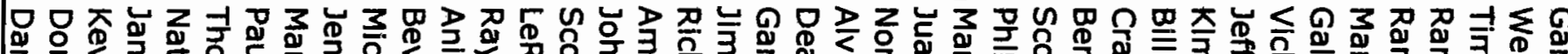

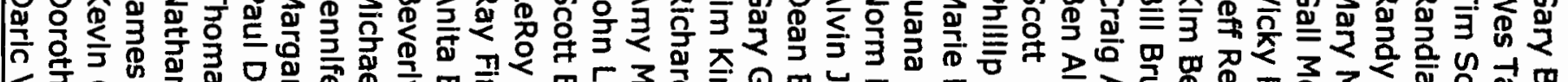

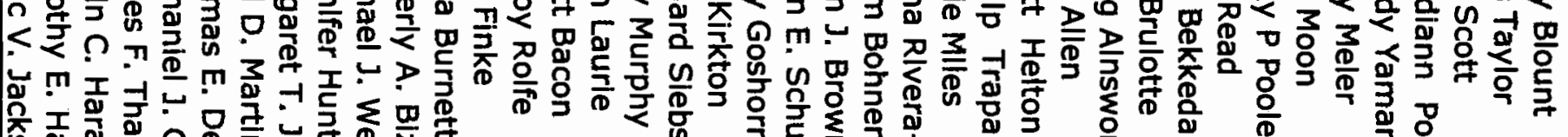

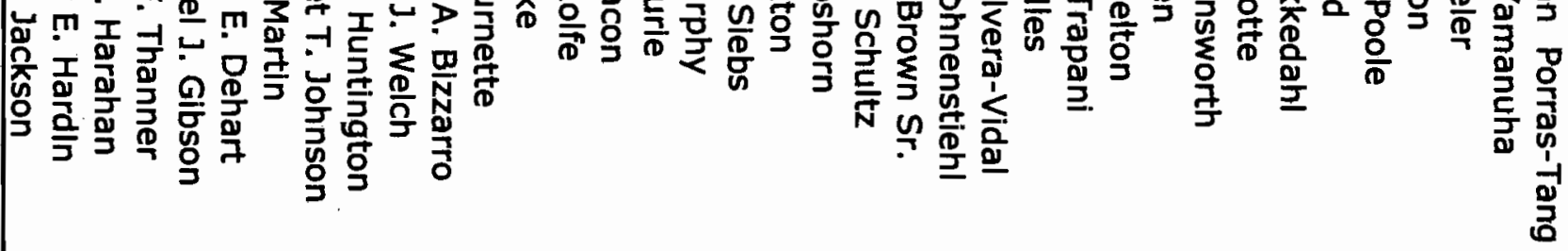



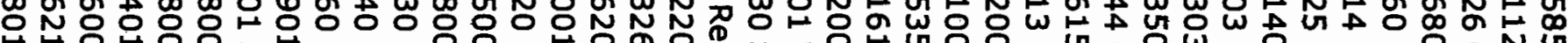
之下

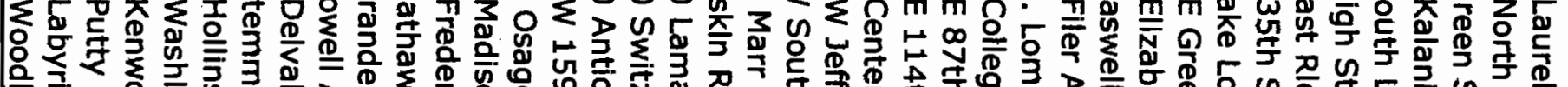

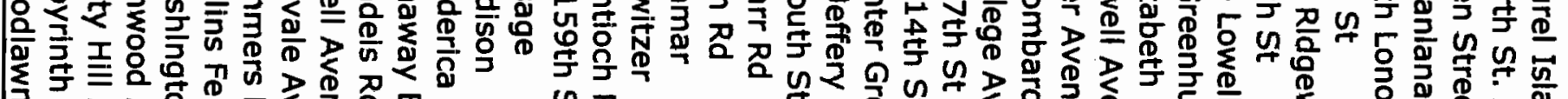

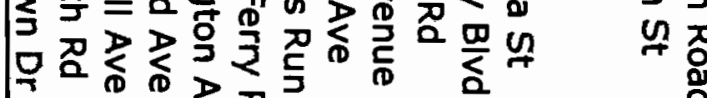

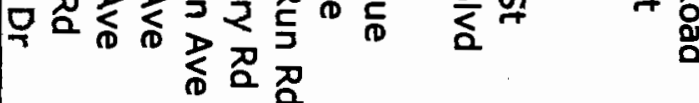
$\rightarrow \underset{+}{0}$ \$ิ

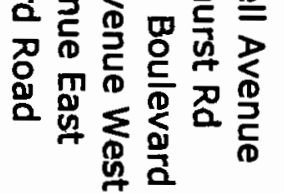

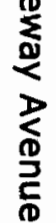
응 变 $\frac{1}{\bar{c}}$

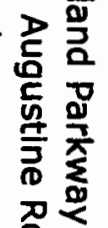
\&

哭罚罚罚罚罚罚之

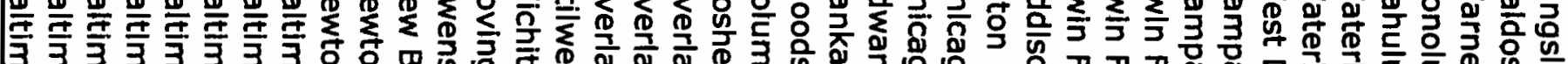

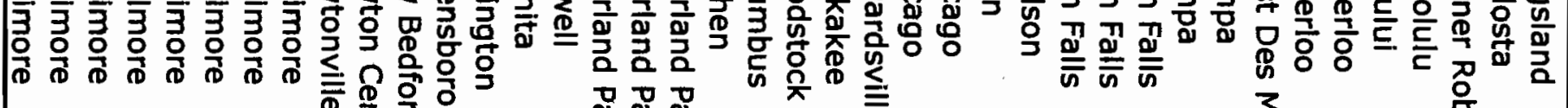

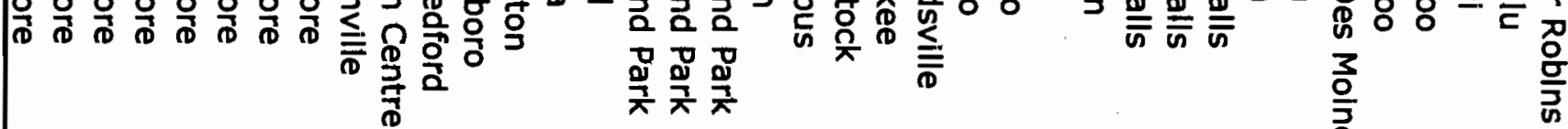

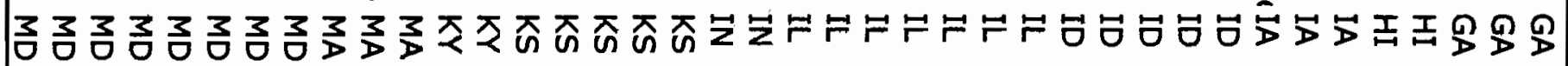

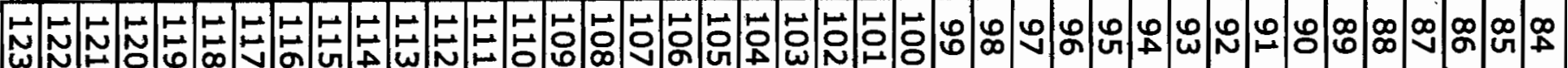
NNNNNNNNOOOA

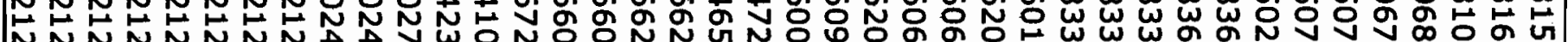
N N N N N N N

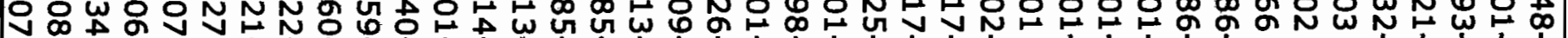

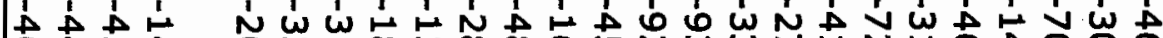

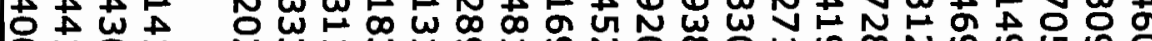

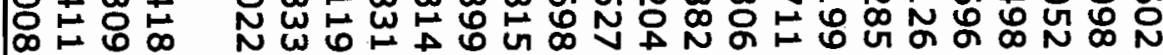

A

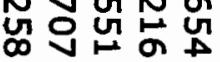

N $\tilde{N}$

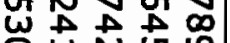




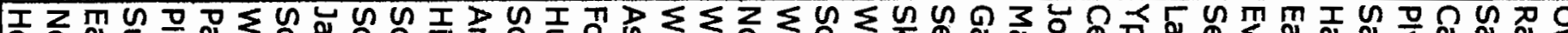

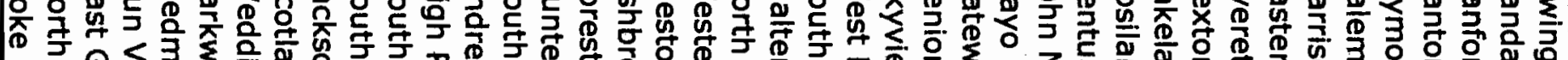

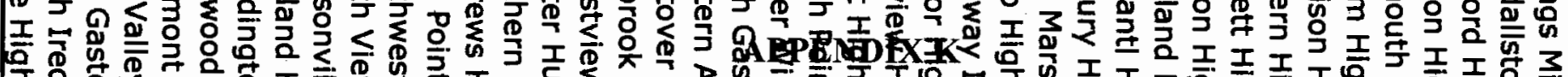

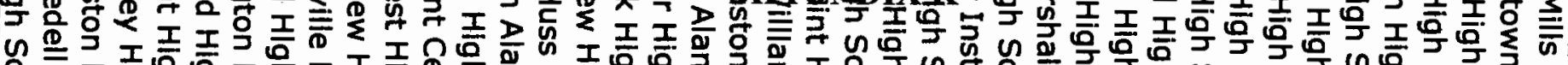

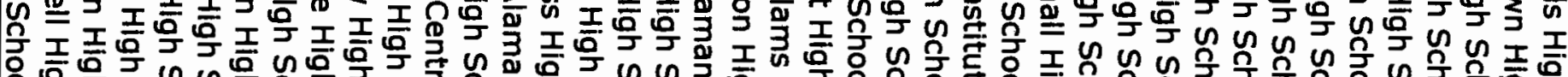

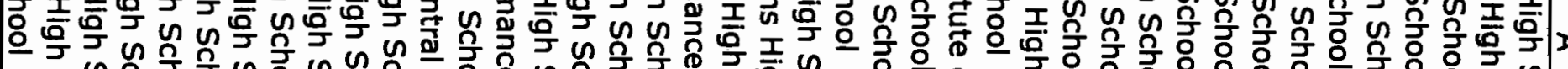

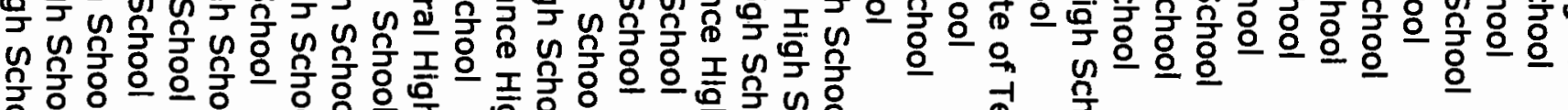

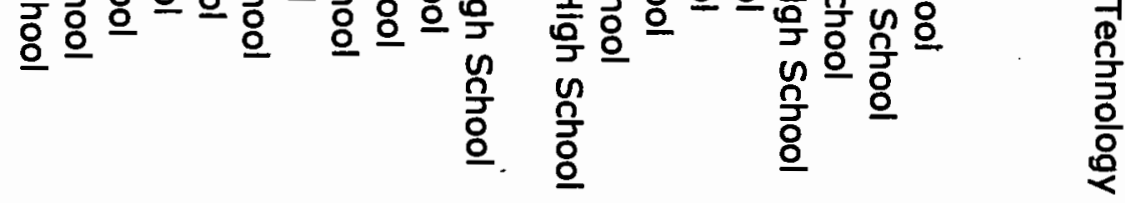

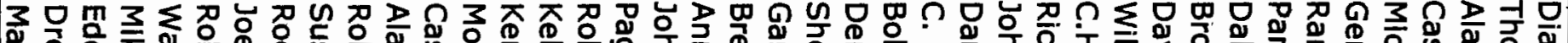

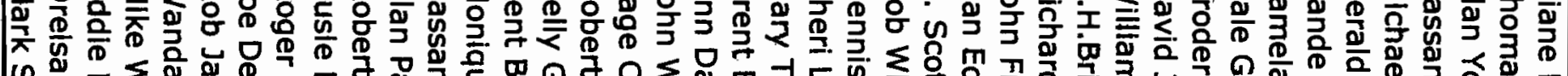

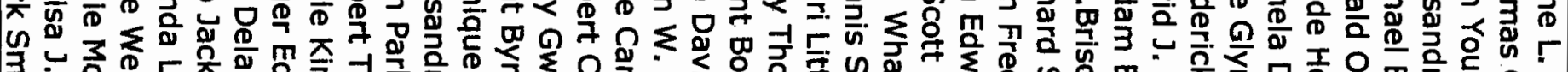

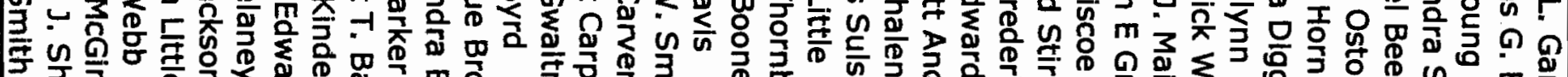

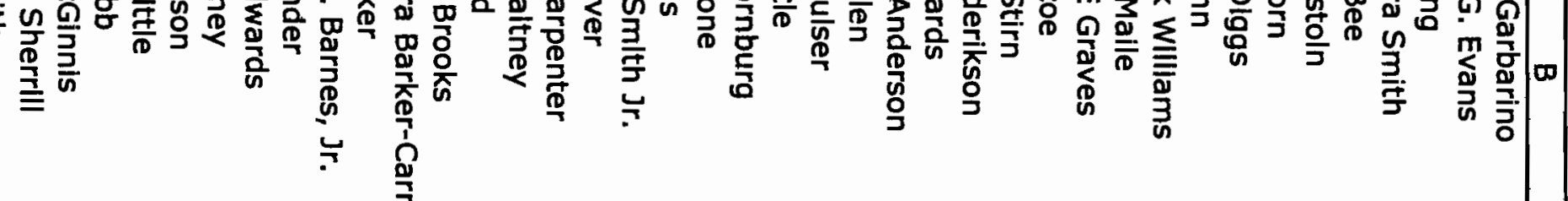

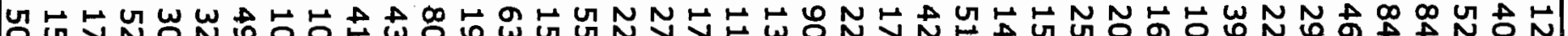
U U ग 思 음

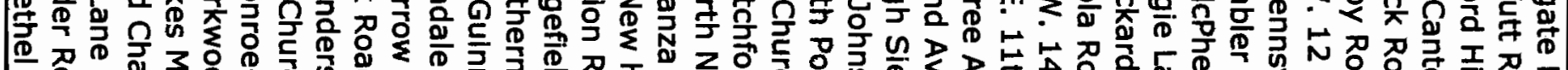

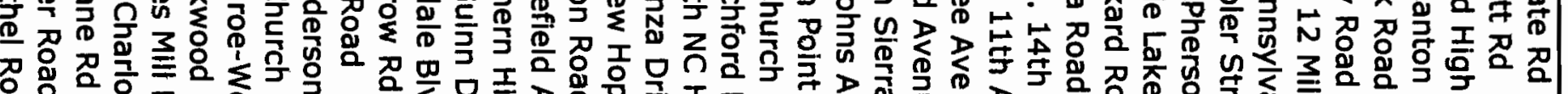

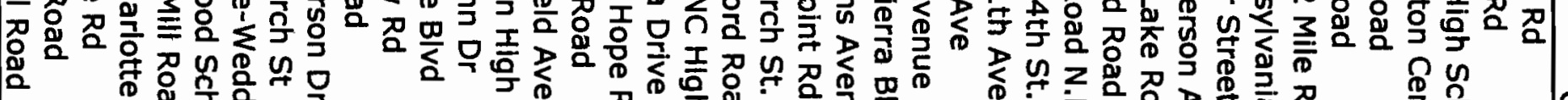

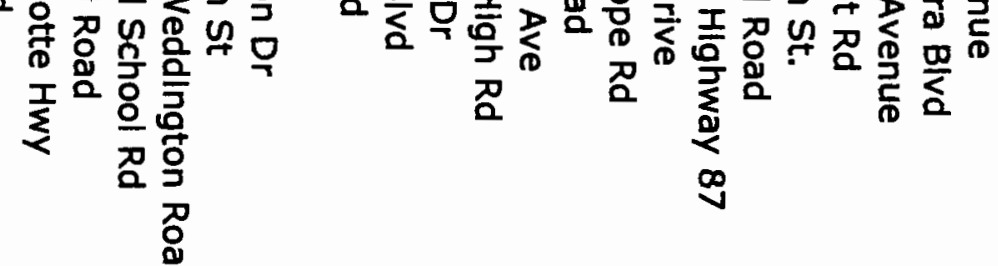

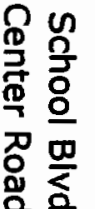
ฏ

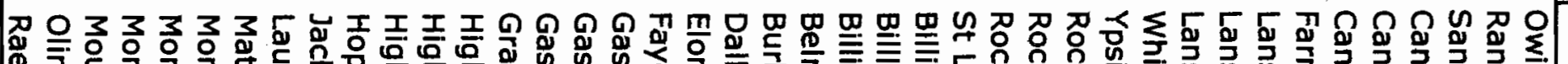
蛀

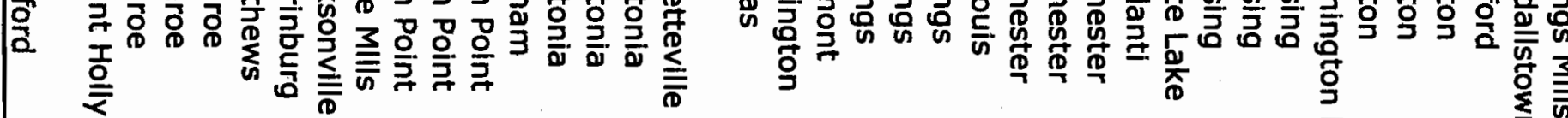

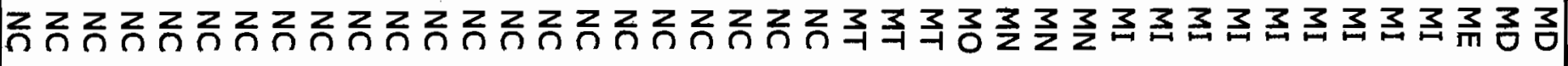

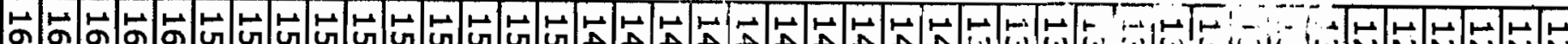

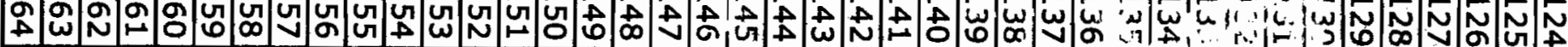

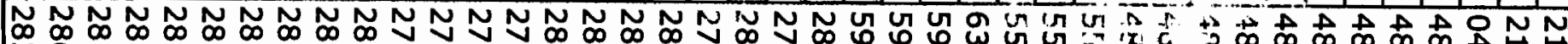

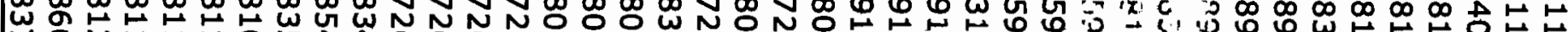

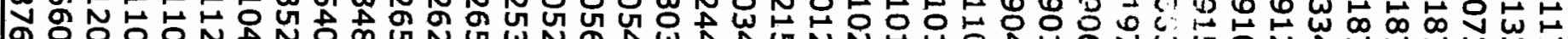

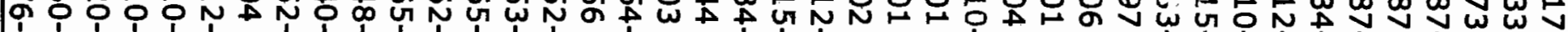

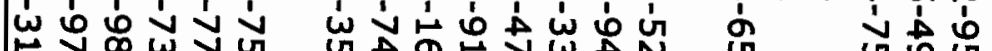
N ปै $\infty$ o 


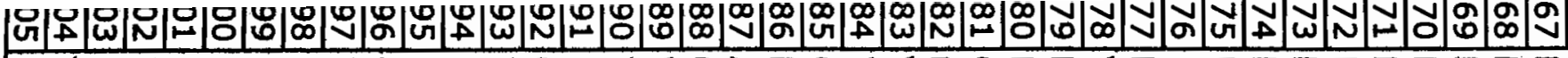

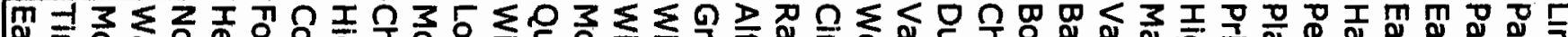

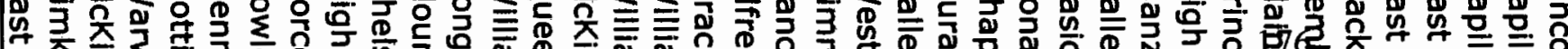

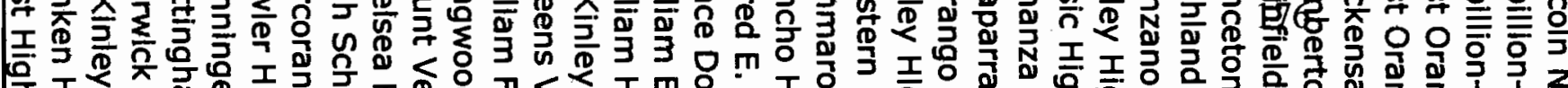

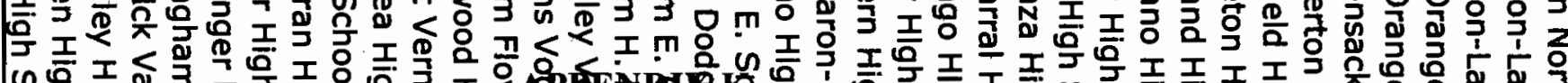

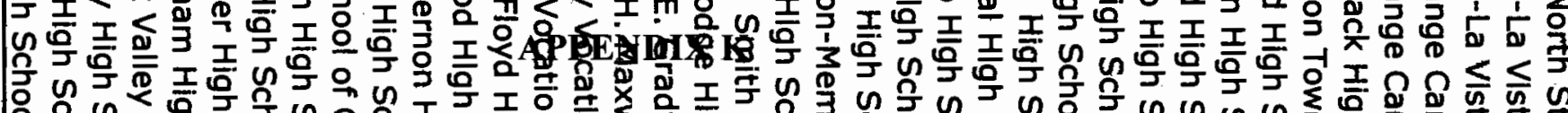

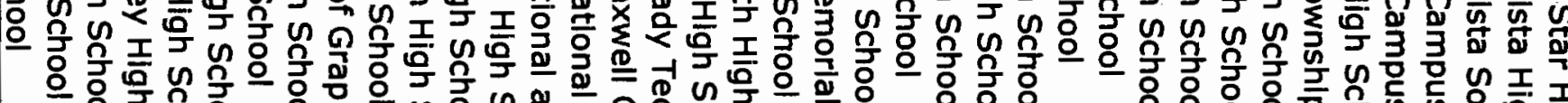

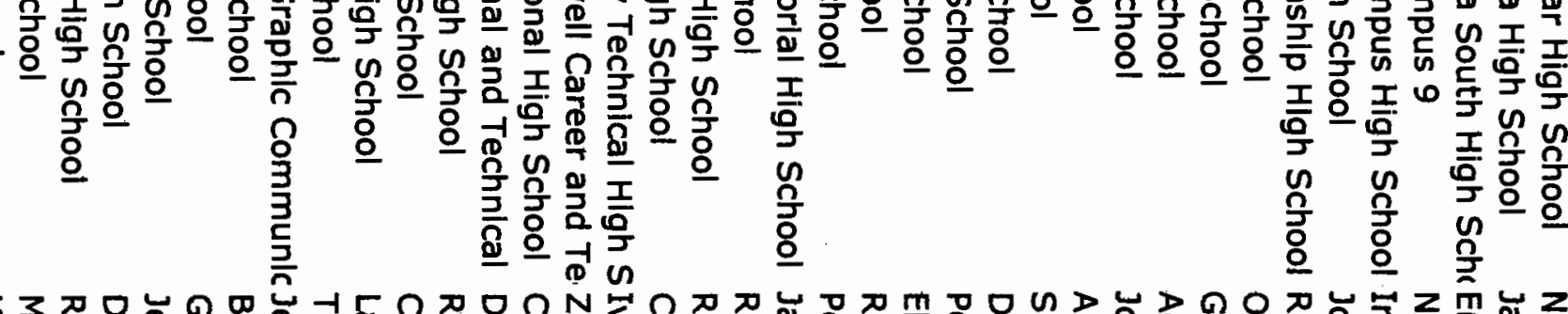

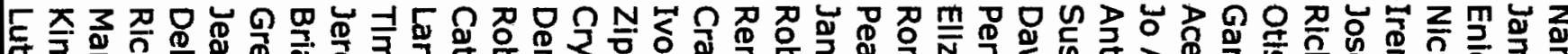

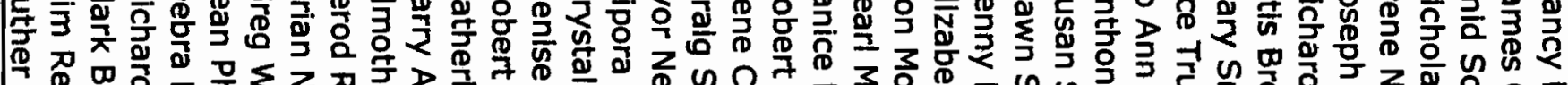

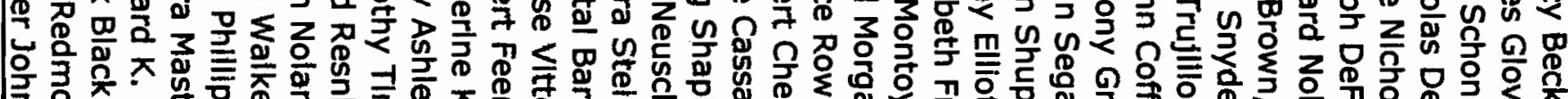

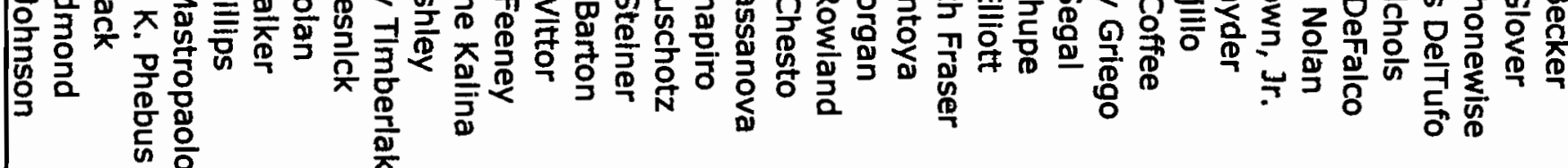

H MN

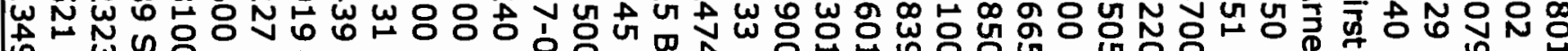
武

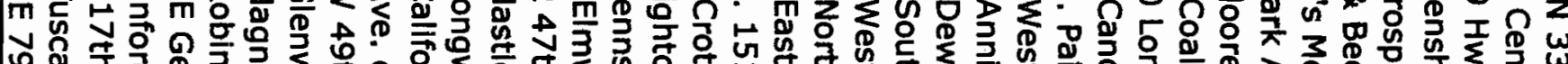

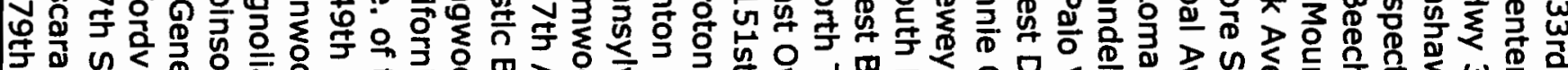

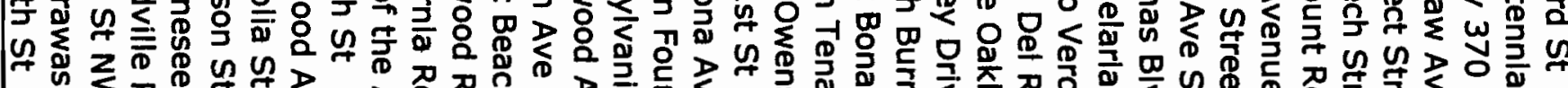

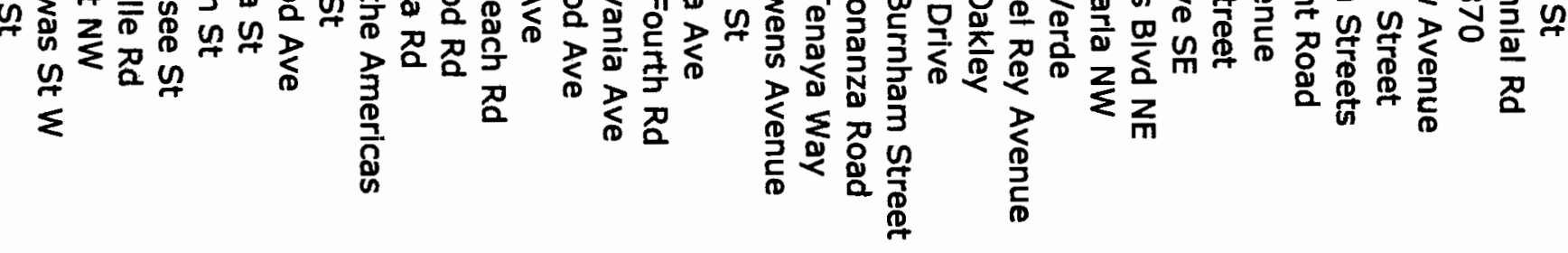

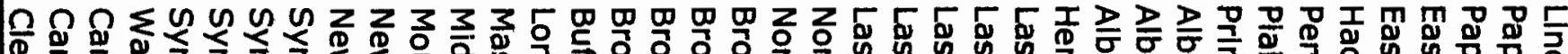

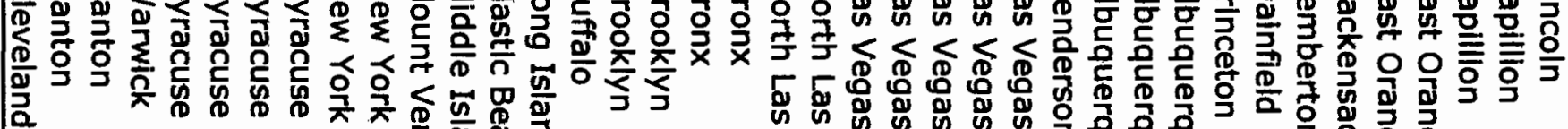

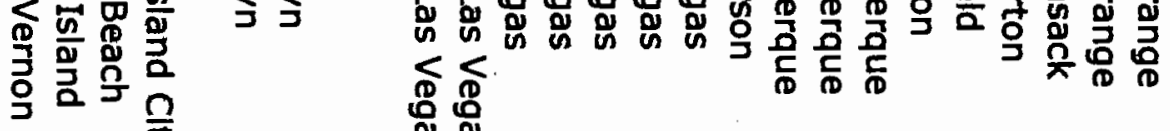

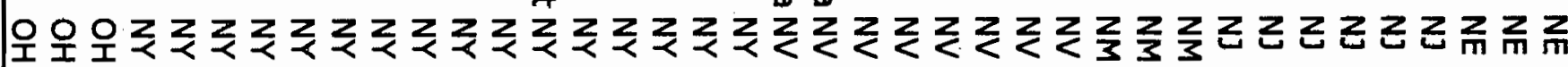

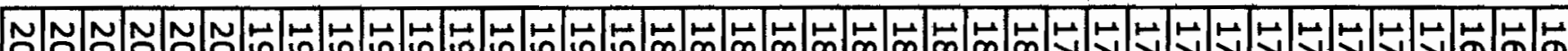

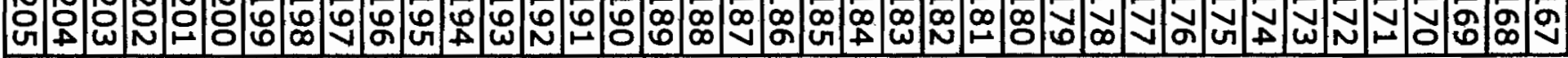
A A H H

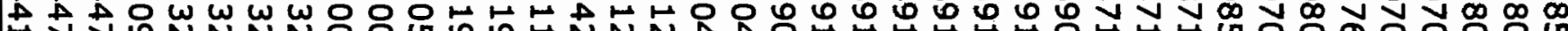

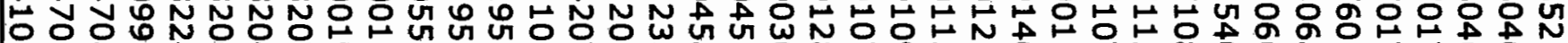
w

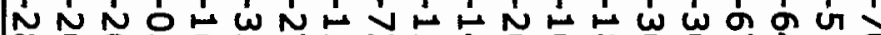

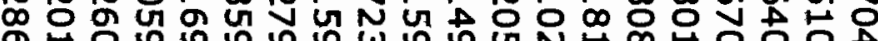

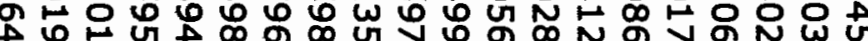

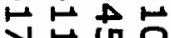

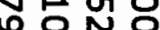

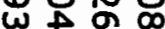

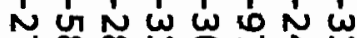
$\checkmark n$

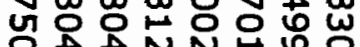

N $\underset{\infty}{\infty}$ 


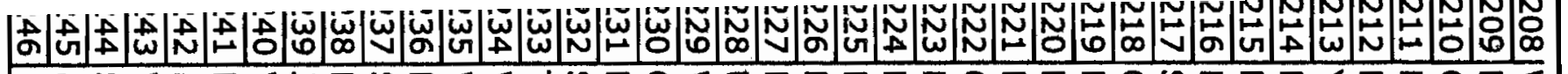

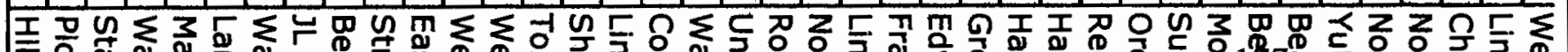

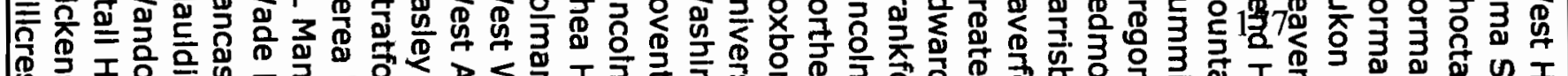

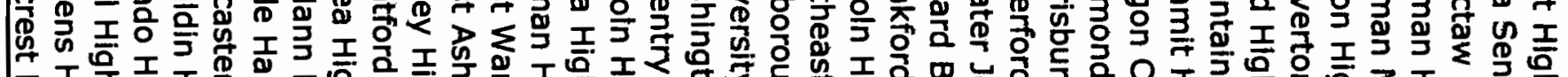

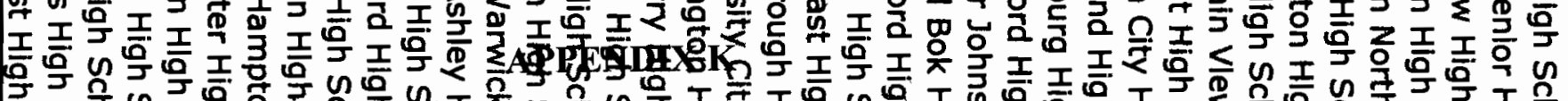

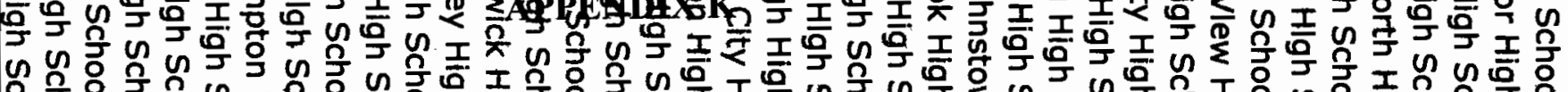

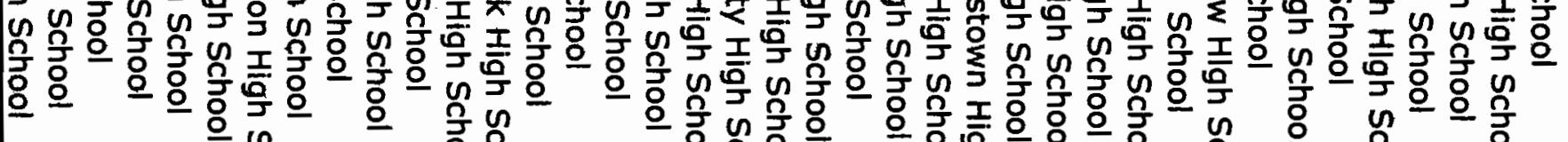

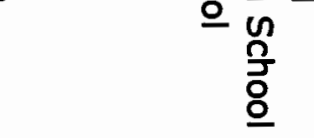
으 응
오 웅 으
으 윽

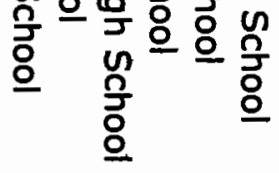

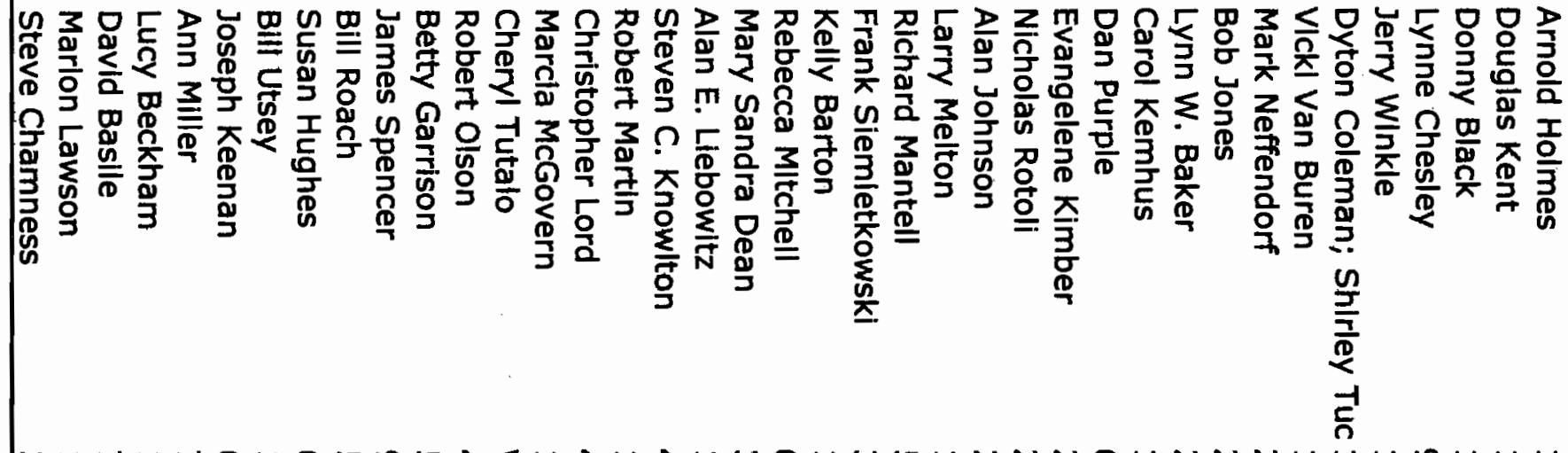

W

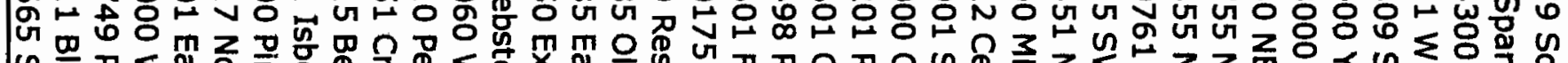

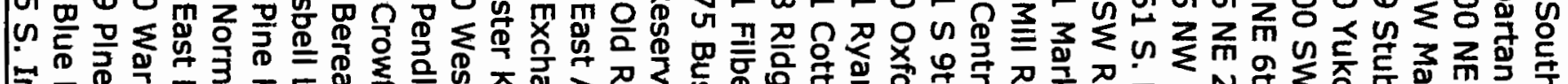

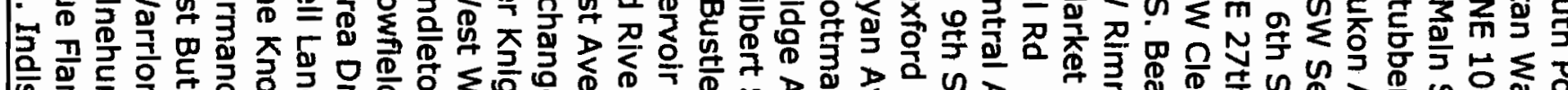

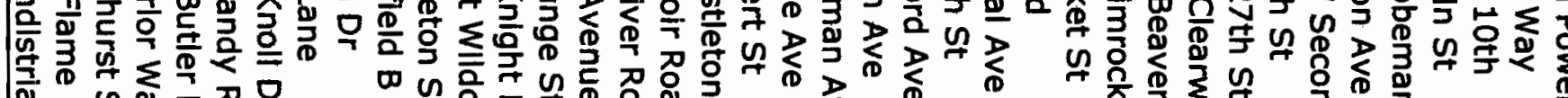

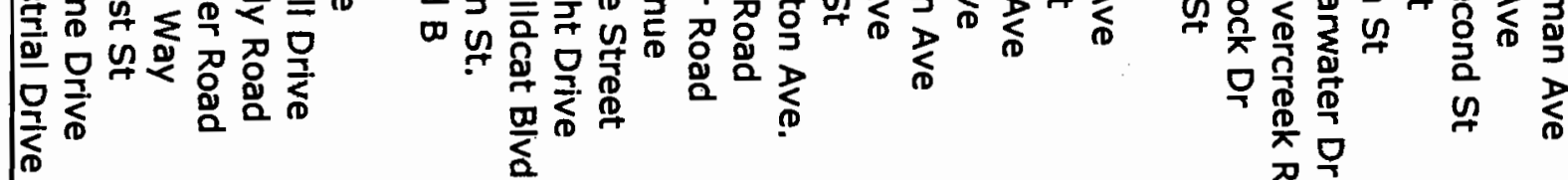
뭉

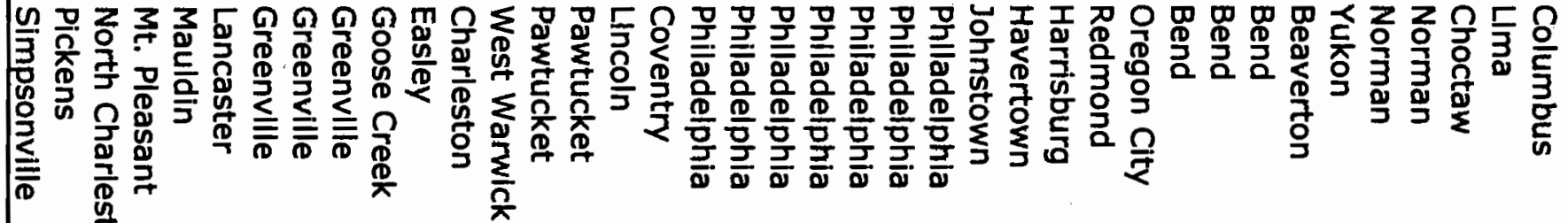

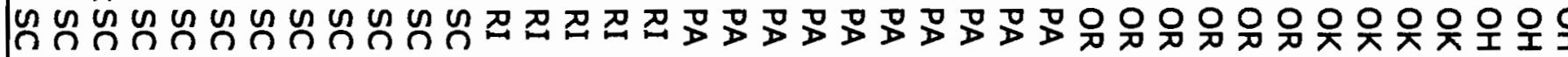

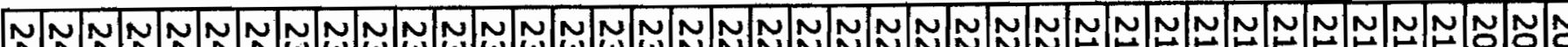

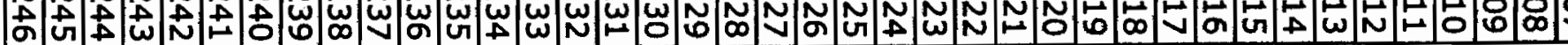
NNNNN N N N N N N O O O O O H ○ \%

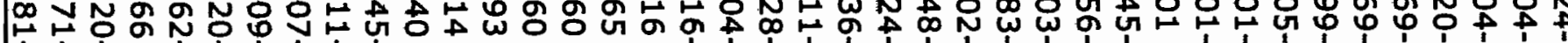

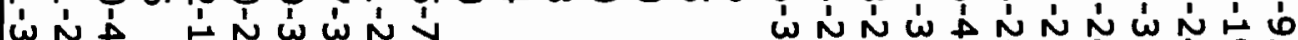
N $\infty$ N $\omega \stackrel{\infty}{\infty}$

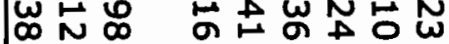

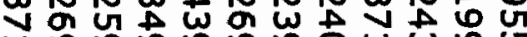

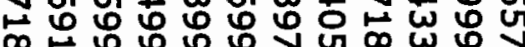
in U⿺辶寸 


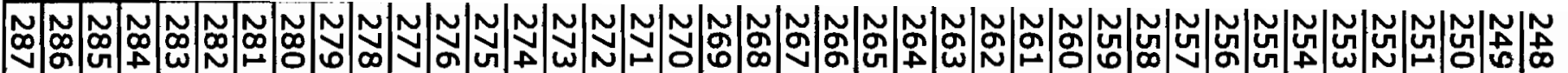

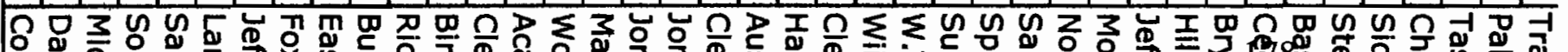

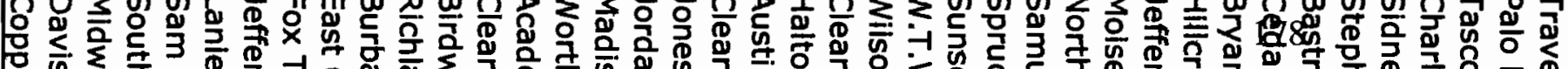

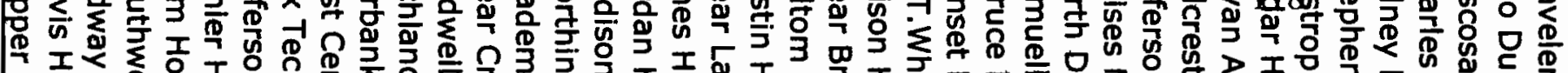

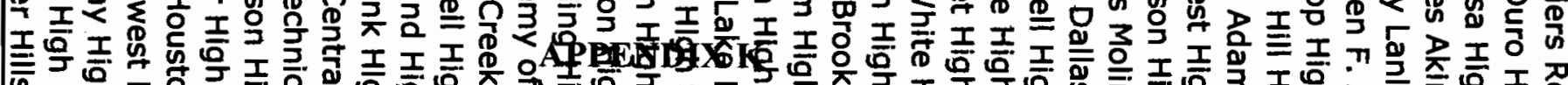

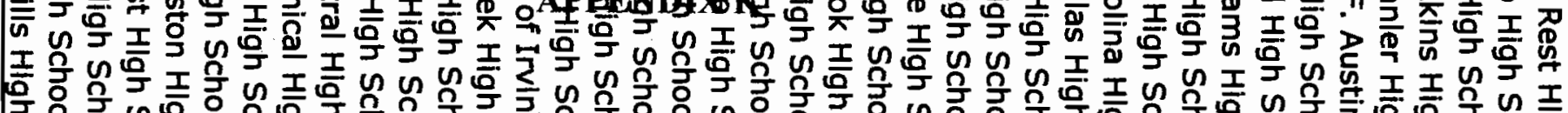

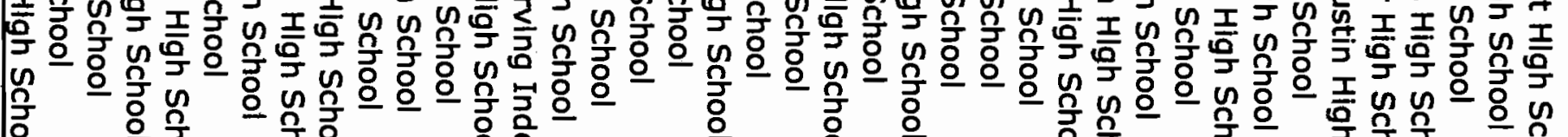

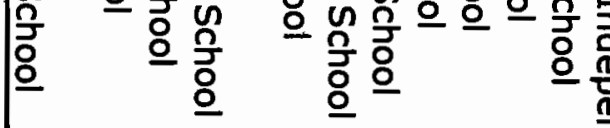

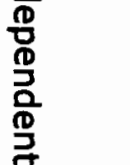

ㅇํㅇํํ응 응

동으응

ํํำ

us

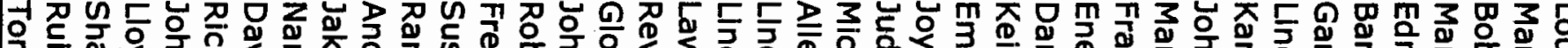

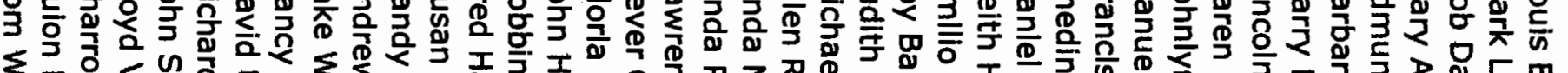

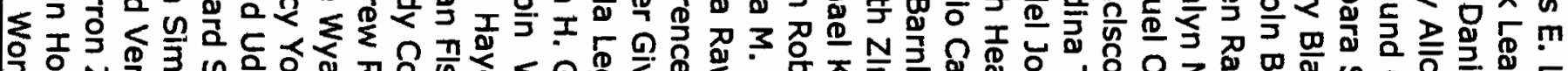

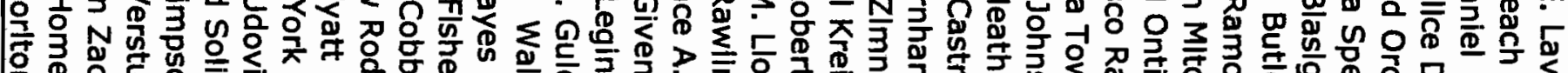

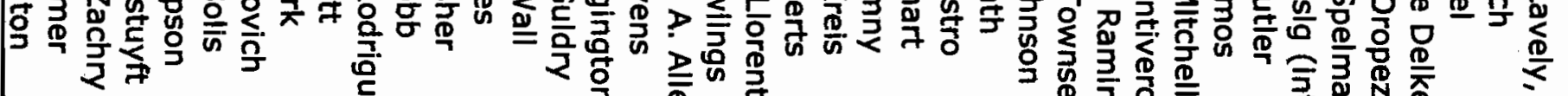

U

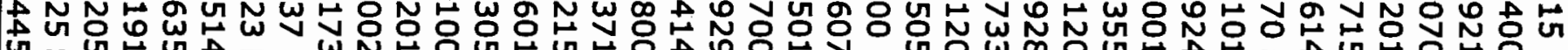
u v u

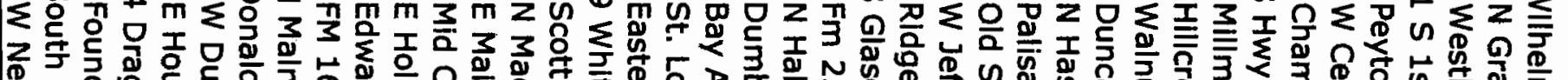
事

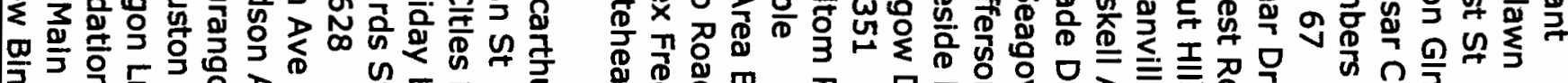

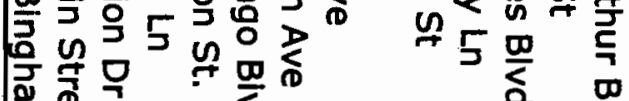

㶾常

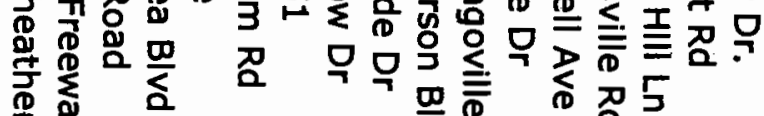

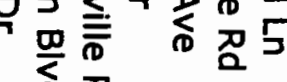
衣召

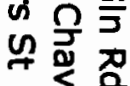
象

$\frac{1}{\xi}$

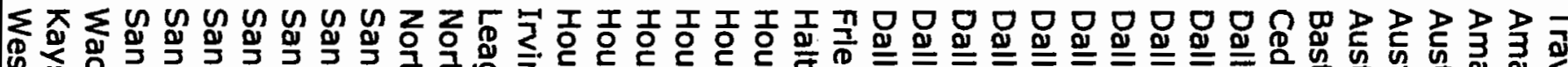

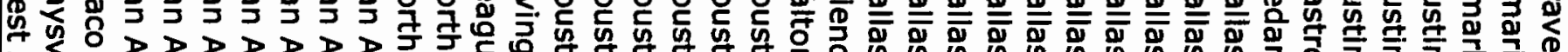

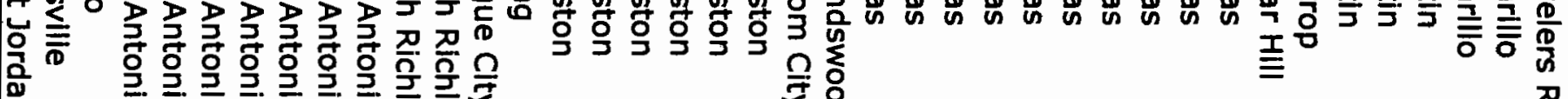
然 觉

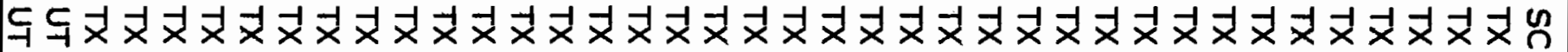

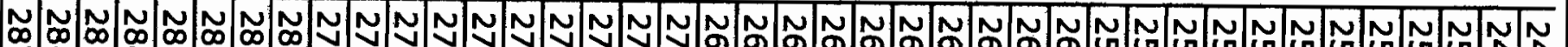

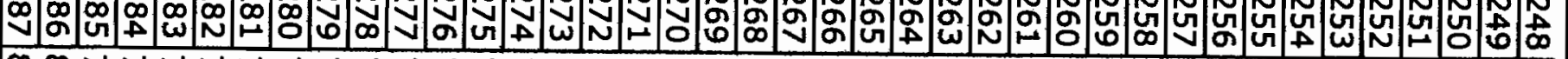
$\infty$ †

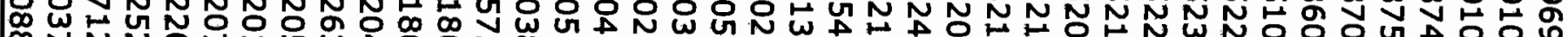
幽 N N

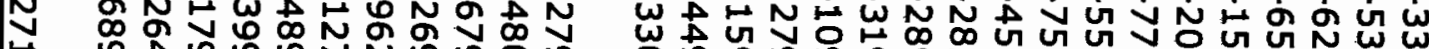




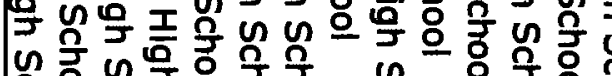

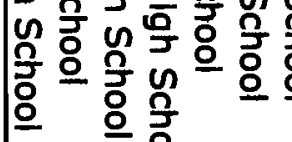

으

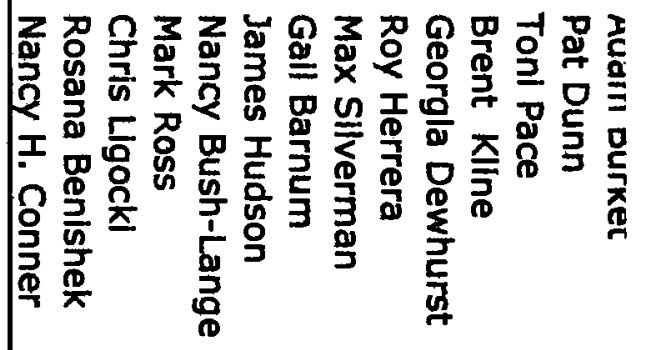

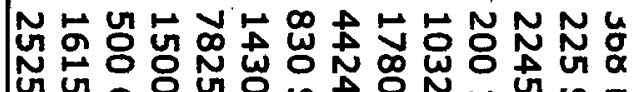
zm

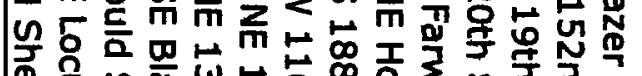

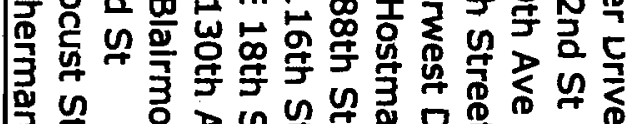
บับ $\frac{\mathbf{g}}{\mathbf{s}}$ 일 욤 员 以 $\sum^{n} \underline{\Sigma}$

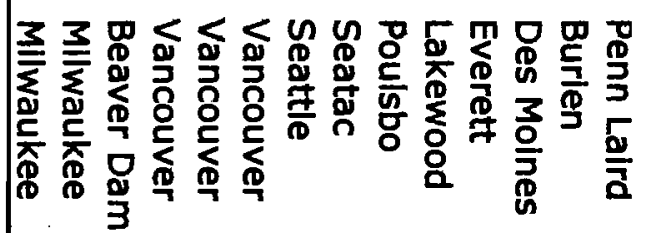
$\sum_{i} \sum_{i} \sum_{D} \sum_{D} \sum_{D} \sum_{D} \sum_{D} \sum_{D} \sum_{D} \sum_{D}$

$\omega|\omega| \omega|\omega| N|N| N|N| N|N| N|N| N \mid N$ 家| जU $\underset{N}{\omega} \omega_{0}^{\infty} \infty$

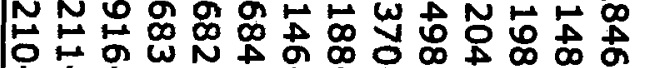
完 岕 : 


\title{
APPENDIX L
}

\section{Structures and Strategies}

\author{
Smaller Learning Community Structures \\ Smaller school structures have a number of categories. Effective downsizing initiatives generally utilize multiple \\ strategies to gain the full benefits of a small learning environment. Examples of smalier school structures include \\ academies, house plans, schools-within-schools, and magnet schools. Small school structures, implemented \\ along with other complementary strategies that enhance student learning, are most likely to yield beneficial \\ impacts.
}

\begin{abstract}
Structure I: Academies
Academies are sub-groups within schools, organized around particular themes. For example, career academies combine key principles of the school-to-career movement - integrating academic and vocational instruction, providing work-based learning opportunities for students, and preparing students for post-secondary education and employment - with the personalized learning environment of a small, focused learning community. Teachers and students integrate academic and occupation-related classes as a way to enhance real-world relevance and maintain high academic standards. Local employer partnerships provide program planning guidance, mentors, and work internships. Career academies share with other restructuring initiatives an emphasis on bullding relationships between students and adults (teachers as well as work-site supervisors and other employer representatives).
\end{abstract}

\section{Structure II: Houses Plans}

House plans divide students in a large school into groups of several hundred, either across grade levels or by grade levels. Students take some or all courses with their house members and from their house teachers. House arrangements may be yearlong or multi-year arrangements. House plans personalize the high school experience, but usually have limited effect on curriculum or instruction. Each house usually has its own discipline plan, student government, social activities, and other extracurricular activities, although students may aiso participate in activities of the larger school. Grouping ninth-graders into a separate house is one way to ease freshman transition to high school.

\section{Structure III: A School-Within-a-School}

A school-within-a-school is a small, autonomous program housed within a larger school building. Schoolswithin-schools are generally responsible to the district rather than to the host school's principal, and are formally authorized by the superintendent and/or board of education. Schools-within-schools have their own culture, program, personnel, students, budget, and school space, (negotiating the use of common space with the host school in the same way office building tenants arrange for use of shared conference facilities). Like academies, the school-within-a-school structure supports constructive relationships between and among students and teachers by grouping students together each year to take core courses with the same group of teachers, thus increasing the supports students receive from peers, teachers, and other adults.

\section{Structure IV: Maqnet Schools}

Magnet programs use a specialty core focus (such as math, science, creative arts, or a career theme or cluster) to attract students from the entire school district. Students in a magnet program stay together for their core classes and may take other courses with non-magnet students.

\section{Smaller Learning Community Strateqies}

Specific strategies that take advantage of a downsized school can be implemented at the sub-school unit level within an entire building, or district-wide. Most of these strategies have the advantage of making students feel more connected to each other, to adults, and to their school group. Strategies that are particularly effective in making schools "feel" smaller may be implemented on their own or in conjunction with one of the structural approaches.

\section{Strategy I: Freshman Transition Activities}

Freshman transition activities help ease the difficulties students often encounter as they move from middle to high school. Some schools place all first-year students in their own academy or house setting, sometimes in a separate wing or even a separate building, with extra supports from adults. In other cases, freshman transition includes mentoring from older students, or special career exploration classes designed to set the context for high school as a pathway to college and careers.

\section{Strategy II: Multi-vear Groups}

Multi-year groups, in which several teachers stay with a group of students over a period of two or more years, foster trust and intimacy between students and teachers. This strategy is similar to "looping ${ }_{r}$ a strategy used in 


\section{APPENDIX L}

elementary or middle schools when groups of students stay together with a teacher for more than one year. A multi-year group is a strategy for keeping several teachers with a group of students for a set period of time.

\section{Strategy III: Alternative Scheduling}

Alternative scheduling allows teachers to develop lessons that are more compatible with learning objectives. Alternative scheduling is also conducive to arranging for work-based learning opportunities and integrating business and community volunteers into the curriculum. The length of the class period, the school day, and the school year can be changed to support academic achievement. This is most easily done in smaller schools. One of the more common alternatives, "block scheduling," provides extended class periods that provide teachers with the time necessary for in-depth lessons and experiential learning. These arrangements permit more time for tutoring and intensive projects, facilitate enrichment, and allow lagging students to catch up and advanced students to delve into topics more deeply. They give schools the ability to set a schedule that best suits their needs.

\section{Strategy IV: Adult Advocate Systems}

Adult advocate systems ensure that at least one adult knows each student well. One quarter of students report being concerned that they and their friends lack an adult who talks with them about problems and decisions, (Shell Poll, Summer 1999). Teachers, counselors, community volunteers, and other school staff can fulfill this "caring adult" role, helping personalize students' experiences in even the largest schools. By meeting with 15-20 students, individually or in small groups, on a regular basis over several years, adult advocates can provide rapport, academic and personal guidance; and links to additional resources when needed. Training for adult advocates and administrative support for the advocate system are critical elements for success.

\section{Strategy V: Teacher Advisory Systems}

Teacher advisory systems are similar to adult advocate systems; they organize adults to personalize the high school experience and support academic achievement, working with small groups of students. Some schools and districts establish advisory classes that meet weekly; others schedule students for less formal one-on-one or group time with teachers. Advisory activities may include helping students develop personal learning plans, introducing students to career clusters, helping students select courses, and working with students on postsecondary plans and pre-employment skills.

\section{Strategy VI; Academic Teaming}

Academic teaming organizes groups of teachers across departments, so that teachers share the same students rather than the same subject. This strategy has much the same effect as a house structure. Teaming links teachers, who teach different subjects, in a team that shares responsibility for the curriculum, instruction, evaiuation, and sometimes scheduling and discipline of a group of 100-150 students. Teams share the same planning time, and sometimes share a specific area of the school building. Though more commonly used in middle schools, academic teaming is showing up in restructuring high schools as a way to personalize the learning environment by providing an integrated view of students' progress and creating a group of teachers who can focus together on the whole student. Teams can build a sense of community into the school, enabling students to learn more so they can meet higher standards, (George and McEwin, April 1999; Legters, January 1999). 


\title{
$\mathbf{S} \mid \mathbf{E} \mathbf{D} \mathbf{L}$
}

\section{APPENDIX M}

\section{SUAIT.RT.FARNINGCOMWLNITIFS}

\section{Summary: List of 89 SLC Strategies in Use by the 2003-A SLC Cohort}

\author{
View structures implemented by the 2003-A SLC cohort Go
}

Click on a column heading to sort the list by that heading.

\begin{tabular}{|c|c|c|}
\hline & Strategy & $\begin{array}{l}\text { \# of Schools } \\
\text { Implementing this S }\end{array}$ \\
\hline 1 & Academic Teaming & 148 \\
\hline 2 & Teacher Advisory Systems & 136 \\
\hline 3 & Individual / Personalized Academic Plans & $\underline{120}$ \\
\hline 4 & Alternative Scheduling & 115 \\
\hline 5 & Freshman Transition Activities & 111 \\
\hline 6 & Dual Enrollment & 93 \\
\hline 7 & Adult Advocate Systems & 85 \\
\hline 8 & Tutoring & 80 \\
\hline 9 & Parent / Family Involvement & $\underline{75}$ \\
\hline 10 & Advanced Placement Courses & 72 \\
\hline 11 & Acceleration Programs & 71 \\
\hline 12 & Remediation Program & 59 \\
\hline 13 & Mentoring & $\underline{5} 5$ \\
\hline 14 & Extended-Day Programs & 50 \\
\hline 15 & Advancement Via Individual Determination (AVID) & 47 \\
\hline 16 & Double Dose of Core Subjects & $\underline{42}$ \\
\hline 17 & Multi-Year Groups & 36 \\
\hline 18 & Senior / Culminating Project & $\underline{36}$ \\
\hline 19 & Literacy Program & $\underline{35}$ \\
\hline 20 & Attendance Improvement Program & 33 \\
\hline 21 & Job Shadowing & 33 \\
\hline 22 & Service-learning Program & $\underline{33}$ \\
\hline 23 & Career Counseling / Guidance & 32 \\
\hline 24 & Community Service Projects & 32 \\
\hline 25 & Credit Recovery Program & 32 \\
\hline 26 & Internships / Apprenticeships & 32 \\
\hline 27 & Portfolios & 32 \\
\hline
\end{tabular}




\begin{tabular}{|c|c|c|}
\hline 28 & Partnerships with Businesses & 29 \\
\hline 29 & Differentiated Instruction & 25 \\
\hline 30 & Technology Integration & 25 \\
\hline 31 & Partnerships with Post-secondary Institutions & 23 \\
\hline 32 & Work-based Learning & 23 \\
\hline 33 & Mentoring by Peers & 22 \\
\hline 34 & Counseling Services & 21 \\
\hline 35 & Community Involvement / Partnerships & 20 \\
\hline 36 & Math / Literacy Emphasis & $\underline{20}$ \\
\hline 37 & Award / Incentive Program & 18 \\
\hline 38 & Tutoring by Peers & 18 \\
\hline 39 & Behavior Intervention Program & 17 \\
\hline 40 & Project-based Learning & 16 \\
\hline 41 & Reading Intervention & 16 \\
\hline 42 & College Preparatory Program & $1 \underline{5}$ \\
\hline 43 & Career Pathways & 14 \\
\hline 44 & College / Career Planning Resources & 14 \\
\hline 45 & Seven Habits of Highly Effective Teens & 12 \\
\hline 46 & Looping & 11 \\
\hline 47 & Community-based Learning Experiences & 10 \\
\hline 48 & Pyramid of Interventions & $\underline{9}$ \\
\hline 49 & Alternative Discipline Model & 8 \\
\hline 50 & Curriculum Mapping & $\underline{8}$ \\
\hline 51 & Math Skills Program & $\underline{7}$ \\
\hline 52 & Portfolios (Career) & $\underline{6}$ \\
\hline 53 & Problem-based Learning & $\underline{6}$ \\
\hline 54 & Multi-Cultural Support Program & 5 \\
\hline 55 & International Baccalaureate Program & $\underline{2}$ \\
\hline 56 & Portfolios (Performance) & $\underline{2}$ \\
\hline 57 & Twillight School Program & 2 \\
\hline 58 & Vertically / Horizontally Aligned Curriculum & $\underline{2}$ \\
\hline 59 & Collaborative Planning for Teachers & 1 \\
\hline 60 & Evening / Night Classes & $\underline{1}$ \\
\hline 61 & Facillty Construction / Renovation & $\underline{1}$ \\
\hline 62 & Leadership Program & 1 \\
\hline 63 & Mentoring by College, Business, or Community Partners & $\underline{1}$ \\
\hline 64 & Outreach Program & $\underline{1}$ \\
\hline 65 & Portfolios (Senior) & $\underline{1}$ \\
\hline 66 & Reading and Writing Skills Program & 1 \\
\hline
\end{tabular}




\section{APPENDIX M}

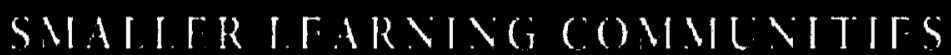

\section{Summary: List of 89 SLC Strategies in Use by the 2003-B SLC Cohort}

View structures implemented by the 2003-B SLC cohort Go

Click on a column heading to sort the list by that heading.

\begin{tabular}{|c|c|c|}
\hline & Strategy & $\begin{array}{l}\text { \# of Schools } \\
\text { Implementing this Stri }\end{array}$ \\
\hline 1 & Freshman Transition Activities & $\underline{65}$ \\
\hline 2 & Academic Teaming & $\underline{59}$ \\
\hline 3 & Teacher Advisory Systems & 57 \\
\hline 4 & Alternative Scheduling & $\underline{55}$ \\
\hline 5 & Individual / Personalized Academic Plans & 33 \\
\hline 6 & Tutoring & $\underline{28}$ \\
\hline 7 & Dual Enrollment & 26. \\
\hline 8 & Parent / Family Involvement & 23 \\
\hline 9 & Remediation Program & $\underline{23}$ \\
\hline 10 & Acceleration Programs & 19 \\
\hline 11 & Advanced Placement Courses & 19 \\
\hline 12 & Adult Advocate Systems & $\underline{18}$ \\
\hline 13 & Intervention Program for At-Risk Students & 18 \\
\hline 14 & Advancement Via Individual Determination (AVID) & 16 \\
\hline 15 & Counseling Services & $\underline{16}$ \\
\hline 16 & Mentoring & 16 \\
\hline 17 & Job Shadowing & $\underline{15}$ \\
\hline 18 & Senior / Culminating Project & 15 \\
\hline 19 & Career Counseling / Guidance & $\underline{14}$ \\
\hline 20 & College Preparatory Program & $\underline{14}$ \\
\hline 21 & Mentoring by Peers & 14 \\
\hline 22 & Reading Intervention & $\underline{14}$ \\
\hline 23 & Attendance Improvement Program & 12 \\
\hline 24 & Community Involvement / Partnerships & $\underline{12}$ \\
\hline 25 & Internships / Apprenticeships & 12 \\
\hline 26 & Math / Literacy Emphasis & 12 \\
\hline 27 & Multi-Year Groups & $\underline{12}$ \\
\hline
\end{tabular}




\begin{tabular}{|c|c|c|}
\hline 28 & Extended-Day Programs & 11 \\
\hline 29 & Math Skills Program & 9 \\
\hline 30 & School-to-Career Program & $\underline{9}$ \\
\hline 31 & Double Dose of Core Subjects & $\underline{8}$ \\
\hline 32 & Partnerships with Businesses & 8 \\
\hline 33 & Portfolios & 8 \\
\hline 34 & College / Career Planning Resources & 7 \\
\hline 35 & Credit Recovery Program & $\underline{6}$ \\
\hline 36 & GEAR UP & 6 \\
\hline 37 & Pyramid of Interventions & 6 \\
\hline 38 & Reading and Writing Skills Program & $\underline{6}$ \\
\hline 39 & Service-learning Program & 6 \\
\hline 40 & Collaborative Planning for Teachers & 5 \\
\hline 41 & Technology Integration & 5 \\
\hline 42 & Alternative Discipline Model & 4 \\
\hline 43 & Award / Incentive Program & 4 \\
\hline 44 & College Credit Courses & 4 \\
\hline 45 & Community-based Learning Experiences & 4 \\
\hline 46 & Leadership Program & 4 \\
\hline 47 & Literacy Program & 4 \\
\hline 48 & Work-based Learning & 4 \\
\hline 49 & Community Service Projects & 3 \\
\hline 50 & Curriculum Mapping & $\underline{3}$ \\
\hline 51 & International Baccalaureate Program & $\underline{3}$ \\
\hline 52 & Looping & 3 \\
\hline 53 & Partnerships with Post-secondary Institutions & $\underline{3}$ \\
\hline 54 & Career Pathways & $\underline{2}$ \\
\hline 55 & Differentiated Instruction & 2 \\
\hline 56 & Independent Study & $\underline{2}$ \\
\hline 57 & Project-based Learning & $\underline{2}$ \\
\hline 58 & Seven Habits of Highly Effective Teens & 2 \\
\hline 59 & Vertically / Horizontally Aligned Curriculum & $\underline{2}$ \\
\hline 60 & Behavior Intervention Program & $\underline{1}$ \\
\hline 61 & Diversity Training & 1 \\
\hline 62 & Integrated Curriculum & $\underline{1}$ \\
\hline 63 & Problem-based Learning & $\underline{1}$ \\
\hline 64 & Tutoring by Peers & 1 \\
\hline 65 & Twilight School Program & $\underline{1}$ \\
\hline
\end{tabular}

$-$ 


\section{SWAITER IFARNINGCOMNL NITITS}

Summary: List of 36 SLC Structures in Use by the 2003-B SLC Cohort

View structures implemented by the 2003-B SLC cohort

Go

Click on a column heading to sort the list by that heading.

\begin{tabular}{|c|c|c|}
\hline & Structure & $\begin{array}{l}\text { \# of Schools } \\
\text { Implementing this Structure }\end{array}$ \\
\hline 1 & Career Academy / Academies & $4 \underline{6}$ \\
\hline 2 & Freshman Academy & 32 \\
\hline 3 & House Plans & 18 \\
\hline 4 & Freshman Clusters / Teams & 11 \\
\hline 5 & Freshman Academies & 10 \\
\hline 6 & School-Within-A-School & 8 \\
\hline 7 & Theme-Based Academies & 8 \\
\hline 8 & Freshman Community / Communities & 7 \\
\hline 9 & Other school-defined structures & $\underline{6}$ \\
\hline 10 & Career-based Communities & $\underline{5}$ \\
\hline 11 & Magnet Schools & $\underline{5}$ \\
\hline 12 & Sophomore Academy / Academles & 4 \\
\hline 13 & Sophomore Community / Communities & 4 \\
\hline 14 & Theme-Based Communities & 3 \\
\hline 15 & Upper-grade Communities & $\underline{3}$ \\
\hline 16 & Interest-based Academies / Communities & $\underline{2}$ \\
\hline 17 & Sophomore Clusters / Teams & 2 \\
\hline 18 & Achievement Academy & 1 \\
\hline 19 & Advisory-based Communities & $\underline{1}$ \\
\hline 20 & Freshman \& Sophomore Academy & 1 \\
\hline 21 & Grade-level Academies & 1 \\
\hline 22 & Grade-level Communitles & 1 \\
\hline 23 & Limlted English Proficient Academy & $\underline{1}$ \\
\hline
\end{tabular}




\section{SEDL}

\section{SWAIIFR IFARNINGCONML NITITS}

\section{Summary: List of 36 SLC Structures in Use by the 2003-A SLC Cohort}

View structures implemented by the 2003-A SLC cohort Go

Cllck on a column heading to sort the list by that heading.

\begin{tabular}{|c|c|c|}
\hline & Structure & $\begin{array}{l}\text { \# of Schools } \\
\text { Implementing this Structure }\end{array}$ \\
\hline 1 & Career Academy / Academles & 90 \\
\hline 2 & Freshman Academy & $\underline{70}$ \\
\hline 3 & House Plans & 39 \\
\hline 4 & School-Within-A-School & 36 \\
\hline 5 & Theme-Based Academies & 32 \\
\hline 6 & Freshman Community / Communities & 22 \\
\hline 7 & Freshman Clusters / Teams & 17 \\
\hline 8 & Upper-grade Academles & $\underline{15}$ \\
\hline 9 & Freshman Academies & 14 \\
\hline 10 & Sophomore Community / Communities & 13 \\
\hline 11 & Sophomore Clusters / Teams & $\underline{9}$ \\
\hline 12 & Career-based Communities & $\underline{7}$ \\
\hline 13 & Magnet Schools & $\underline{5}$ \\
\hline 14 & Vertical Smaller Learning Communities & 5 \\
\hline 15 & Sophomore Academy / Academies & 4 \\
\hline 16 & Theme-Based Communities & 4 \\
\hline 17 & Freshman \& Sophomore Academy & $\underline{3}$ \\
\hline 18 & Grade-level Communities & $\underline{3}$ \\
\hline 19 & Upper-grade Communities & $\underline{3}$ \\
\hline 20 & Autonomous Academies / Schools & $\underline{2}$ \\
\hline 21 & Grade-level Academies & 2 \\
\hline 22 & Other school-defined structures & 2 \\
\hline 23 & Senior Academy & $\underline{2}$ \\
\hline 24 & Academic Communities & 1 \\
\hline 25 & Alternative Education Academy & $\underline{1}$ \\
\hline 26 & College / Career / Tech Academies & 1 \\
\hline
\end{tabular}


S E $\mathbf{E} \mathbf{D L}$

\section{SWATIERTIFARIVGCOMNLNTTIS}

Summary: SLC Districts and Schools by Locale for SLC Cohort 2003-A

View locale summary for the 2003-A SLC cohort

Go

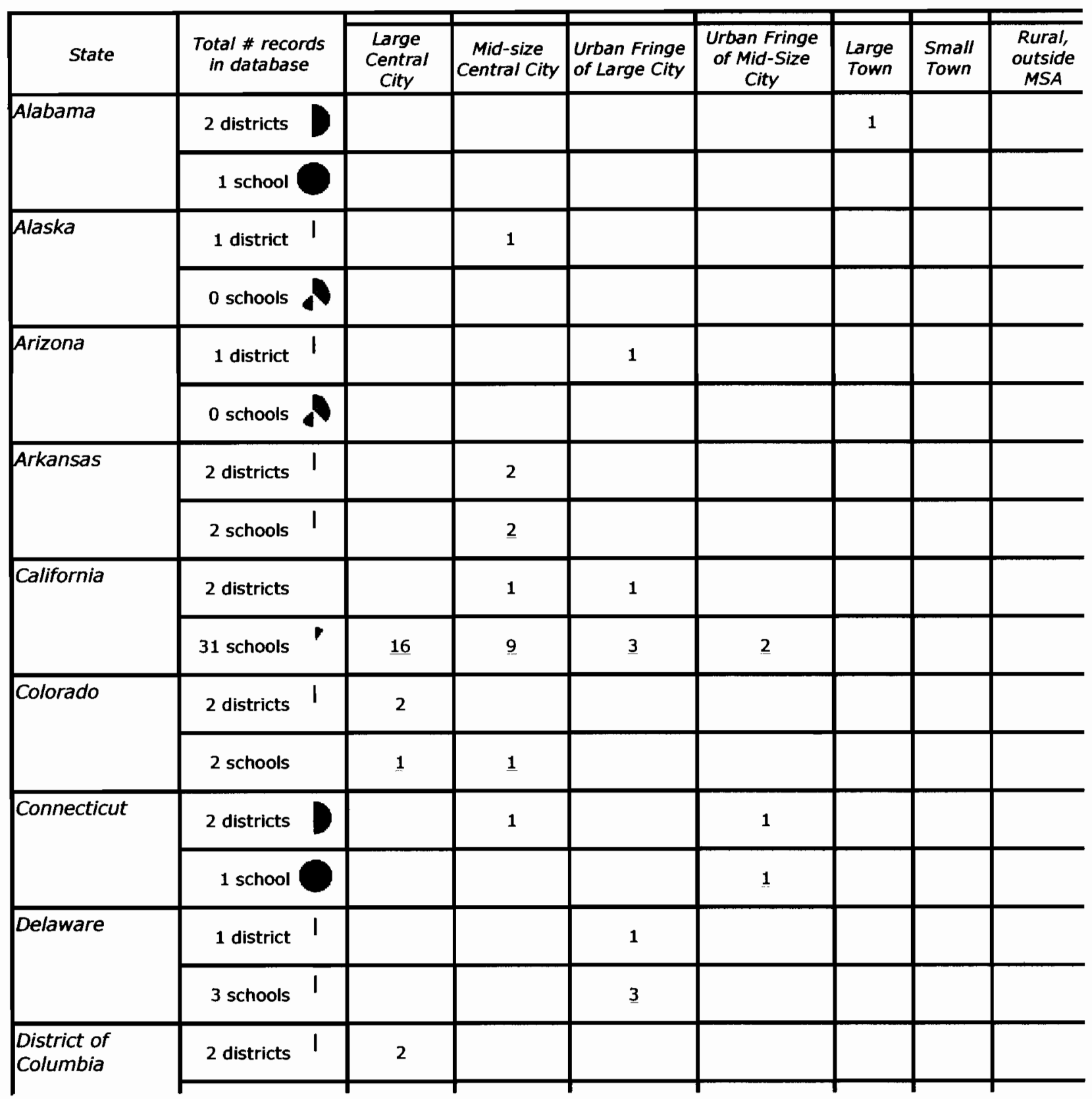


Page 2 of 6

APPENDIX 0

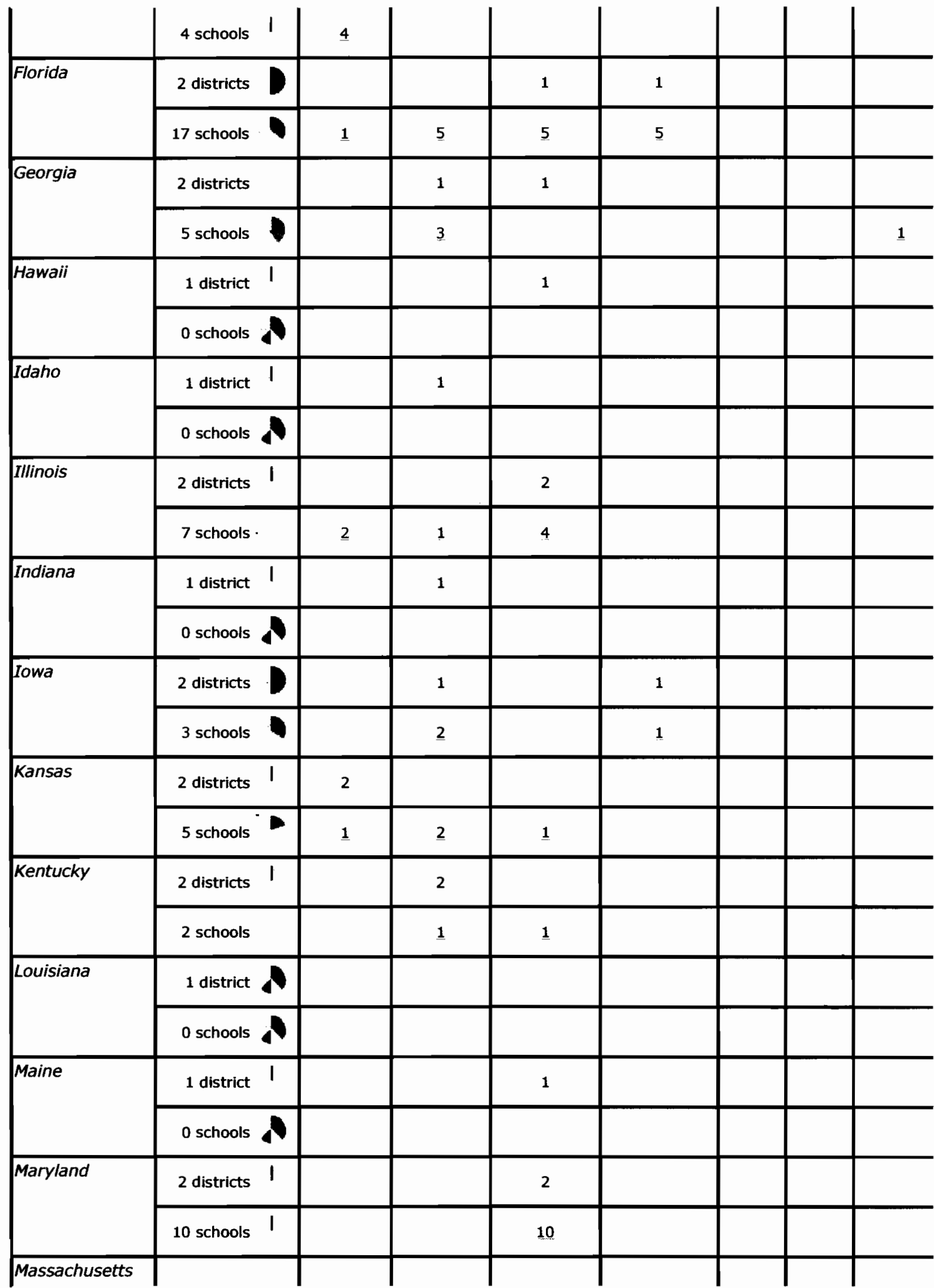




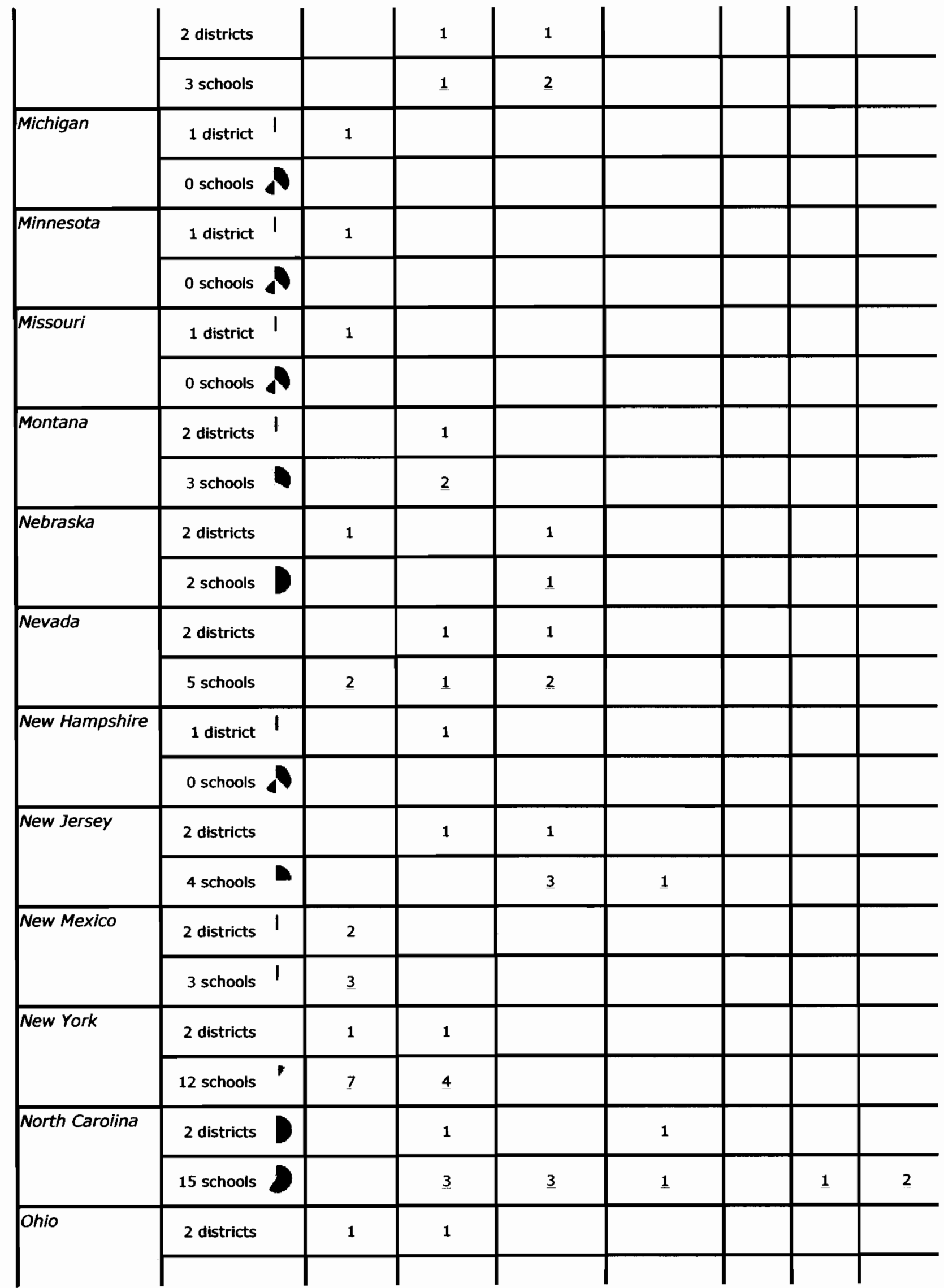


APPENDIX 0

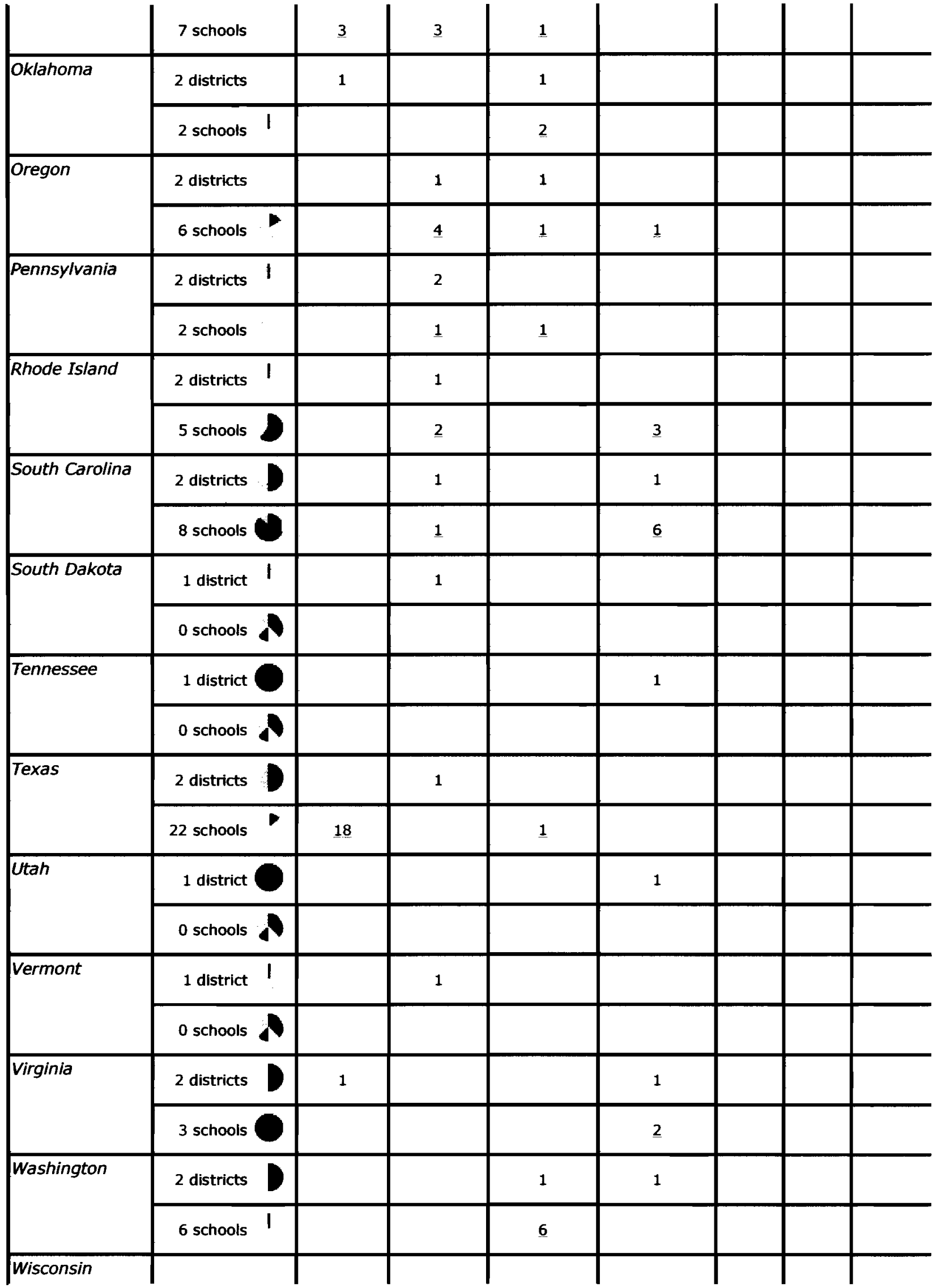




\begin{tabular}{|c|c|c|c|c|c|c|c|c|}
\hline & 2 districts & & 1 & & & & 1 & \\
\hline & 3 schools & 2 & & & & & 1 & \\
\hline \multirow[t]{2}{*}{ West Virginia } & 1 district & & & & & & 1 & \\
\hline & 0 schools & & & & & & & \\
\hline State & $\begin{array}{c}\text { Total \# records } \\
\text { in database }\end{array}$ & $\begin{array}{c}\text { Large } \\
\text { Central } \\
\text { City }\end{array}$ & $\begin{array}{c}\text { Mid-size } \\
\text { Central City }\end{array}$ & $\begin{array}{l}\text { Urban Fringe } \\
\text { of Large City }\end{array}$ & $\begin{array}{c}\text { Urban Fringe } \\
\text { of Mid-Size } \\
\text { City }\end{array}$ & $\begin{array}{l}\text { Large } \\
\text { Town }\end{array}$ & $\begin{array}{l}\text { Small } \\
\text { Town }\end{array}$ & $\begin{array}{c}\text { Rural, } \\
\text { outside } \\
\text { MSA }\end{array}$ \\
\hline \multirow{2}{*}{ Total } & 79 districts & 16 & 28 & 18 & 9 & 1 & 2 & 0 \\
\hline & 204 schools & 60 & 48 & 50 & 23 & 0 & 2 & 3 \\
\hline
\end{tabular}

Note: No data has yet been entered for the following states: BIA, MS, ND, PR, WY

\section{Locales of Districts Receiving SLC Funds: All States}

Large Central City (16) (21.05\%)

Mid-size Central City (28)

(36.84\%)
Rural, inside MSA (2)

(2.63\%)

Rural, outside MSA (0)

(0.00\%)

Small Town (2)

(2.63\%)

Large Town (1)

(1.32\%)

Urban Fringe of Mid-size City (9) (11.84\%)

Urban Fringe of Large City (18) (23.68\%) 


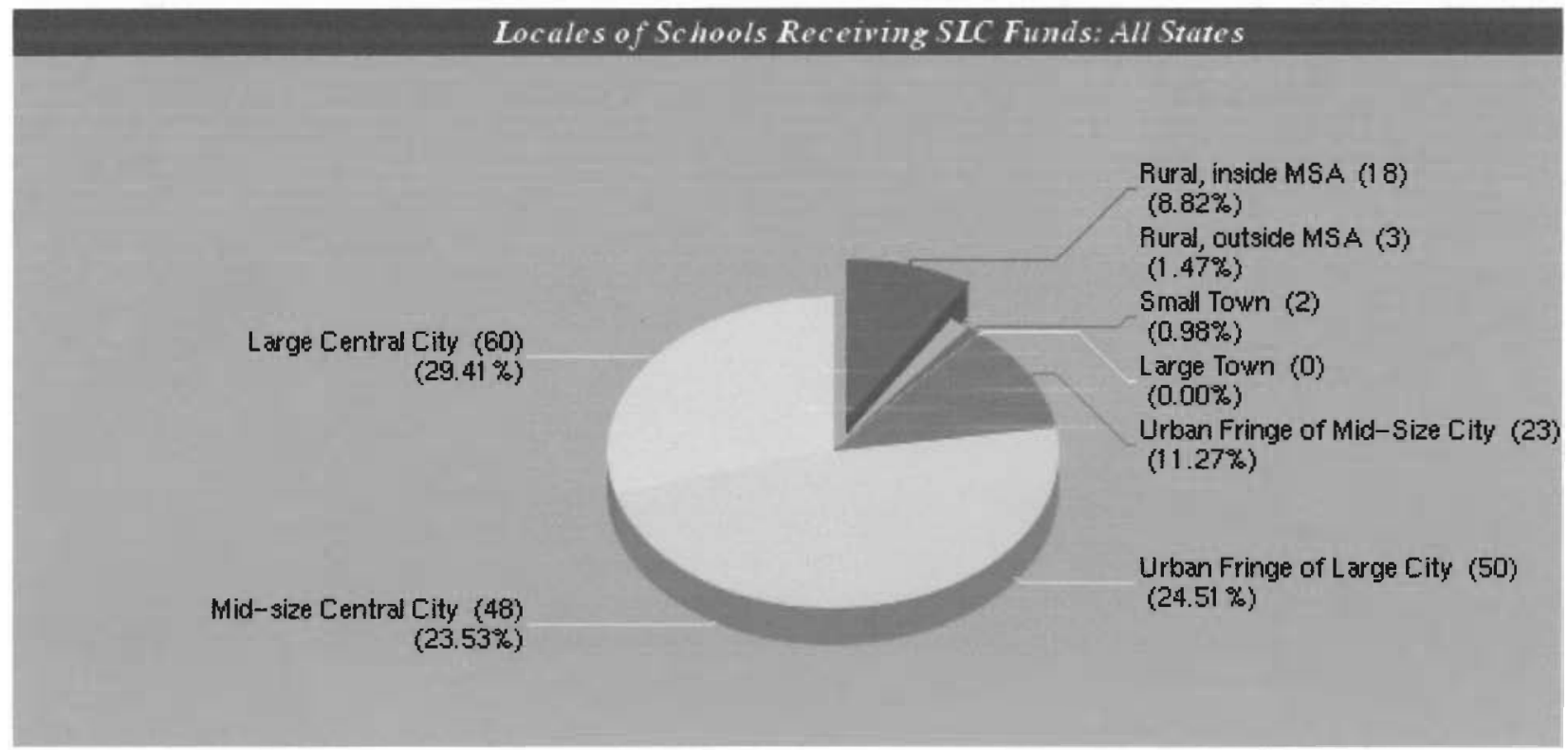

If you have a question about the SLC database, please send an e-mail to Lacy Wood at Iwood@St 


\section{S $\mathbf{E} \mathbf{D} \mathbf{L}$}

\section{SMAI.I.R L.EARNING COMMUNITIFS Amad Dabbas}

Search tor 5 Le schook and Oistrots

Adymed Searih

SLE ELmorary Chros

StE Struteres and

Summary: SLC Districts and Schools by Locale for SLC Cohort 2003-B View locale summary for the 2003-B SLC cohort Go

\begin{tabular}{|c|c|c|c|c|c|c|c|c|}
\hline State & $\begin{array}{l}\text { Total \# records } \\
\text { in database }\end{array}$ & $\begin{array}{c}\text { Large } \\
\text { Central } \\
\text { City }\end{array}$ & $\begin{array}{c}\text { Mid-size } \\
\text { Central City }\end{array}$ & $\begin{array}{l}\text { Urban Fringe } \\
\text { of Large City }\end{array}$ & $\begin{array}{c}\text { Urban Fringe } \\
\text { of Mid-Size } \\
\text { City }\end{array}$ & $\begin{array}{l}\text { Large } \\
\text { Town }\end{array}$ & $\begin{array}{l}\text { Small } \\
\text { Town }\end{array}$ & $\begin{array}{c}\text { Rural, } \\
\text { outside } \\
\text { MSA }\end{array}$ \\
\hline \multirow[t]{2}{*}{ Alabama } & 1 district & & & & & 1 & & \\
\hline & 0 schools & & & & & & & \\
\hline Alaska & 1 district & & 1 & & & & & \\
\hline \multirow[t]{2}{*}{ Arizona } & 2 districts & & & 2 & & & & \\
\hline & 1 school & & & $\underline{1}$ & & & & \\
\hline \multirow[t]{2}{*}{ Arkansas } & 2 districts & & 1 & & 1 & & & \\
\hline & 2 schools & & & & $\underline{2}$ & & & \\
\hline \multirow[t]{2}{*}{ California } & 2 districts & & 1 & 1 & & & & \\
\hline & 10 schools & 4 & 2 & $\underline{3}$ & $\underline{1}$ & & & \\
\hline \multirow[t]{2}{*}{ Colorado } & 2 districts & 1 & & 1 & & & & \\
\hline & 1 school | & & & 1 & & & & \\
\hline Connecticut & 1 district & & 1 & & & & & \\
\hline Delaware & 1 district & & & 1 & & & & \\
\hline $\begin{array}{l}\text { District of } \\
\text { Columbia }\end{array}$ & 2 districts & 2 & & & & & & \\
\hline
\end{tabular}


Page 2 of 6

APPENDIX 0

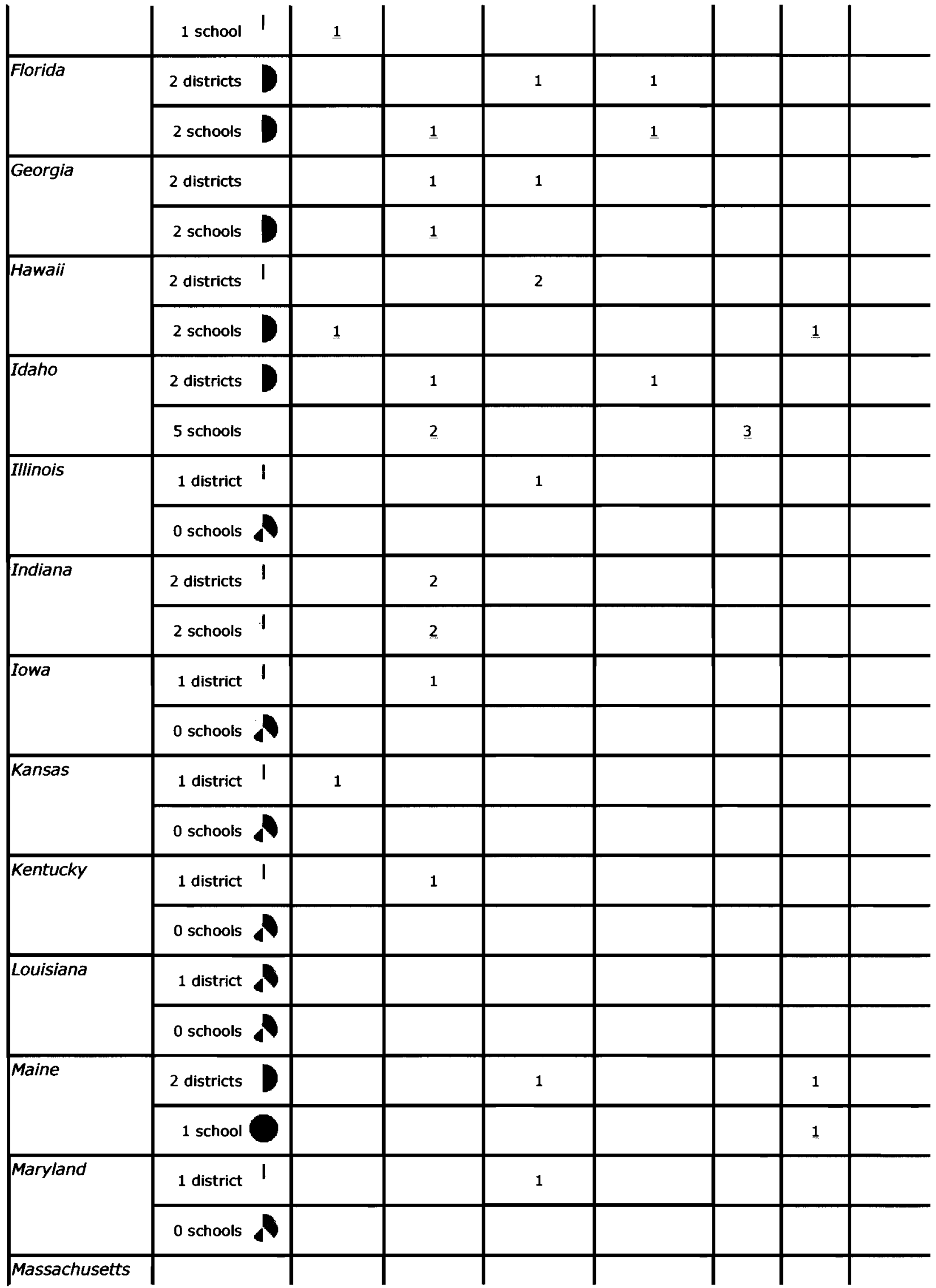


Page 3 of 6

APPENDIX 0

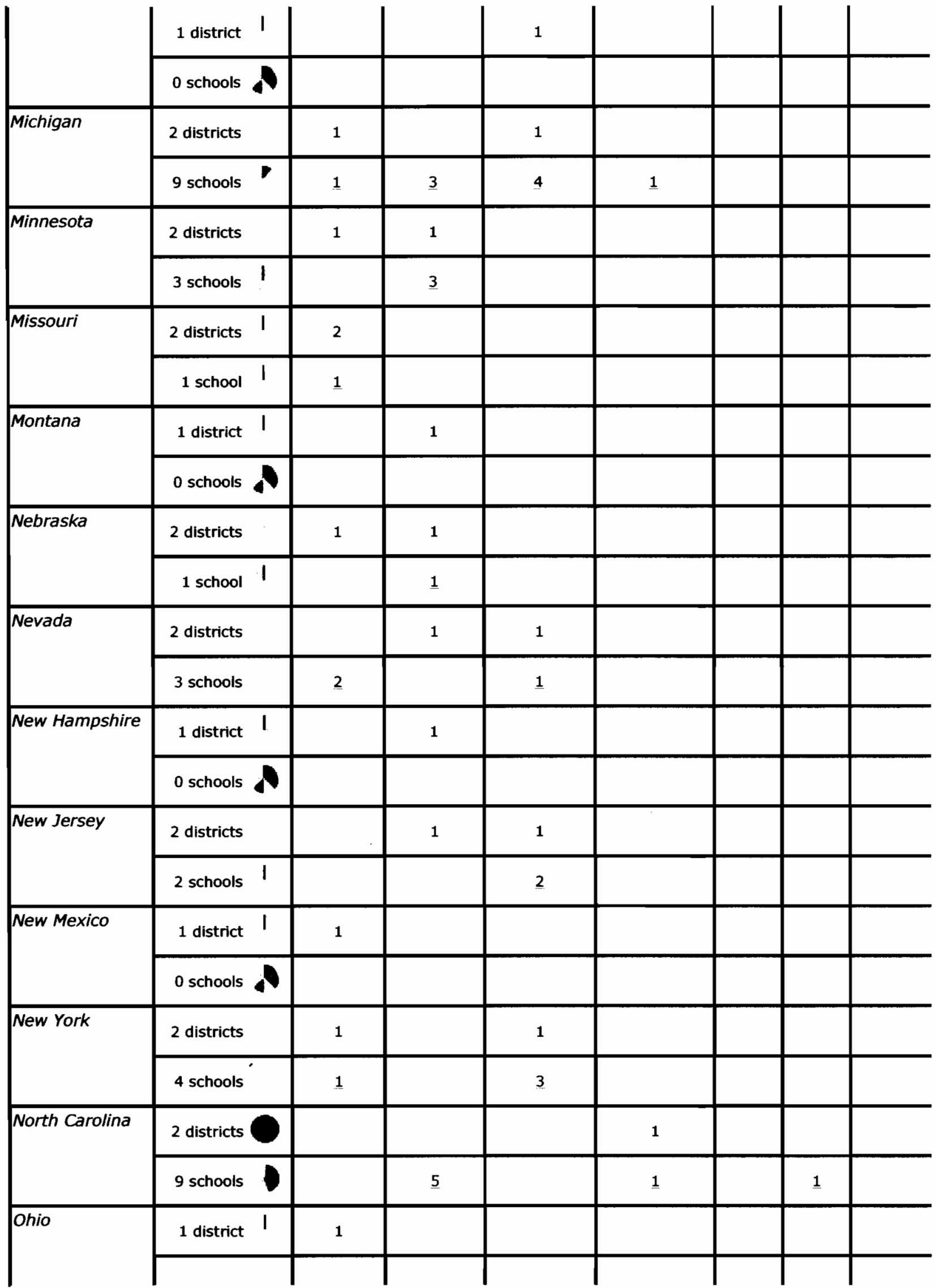




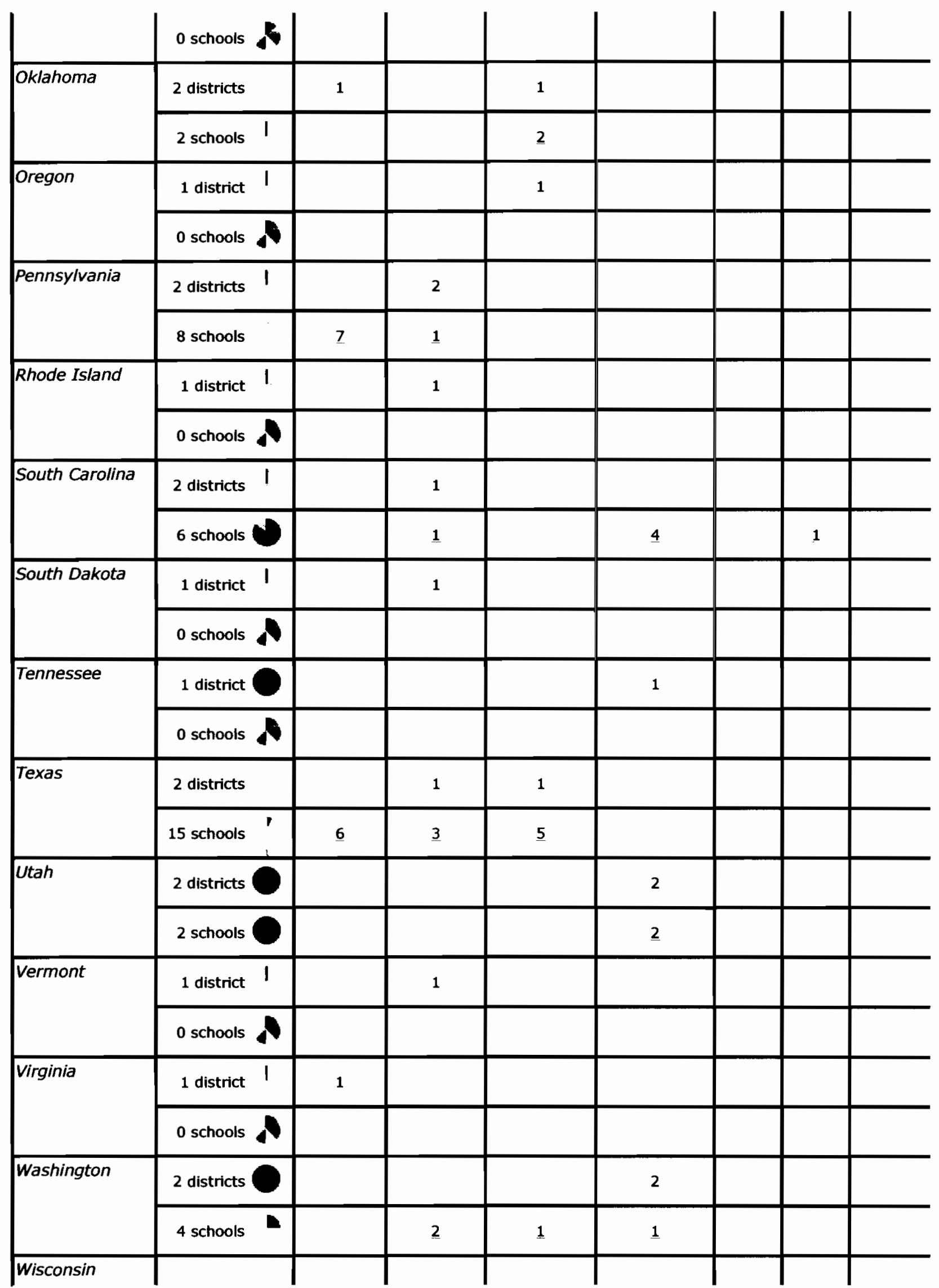


APPENDIX O

\begin{tabular}{|c|c|c|c|c|c|c|c|c|}
\hline & 1 district & & 1 & & & & & \\
\hline & 0 schools & & & & & & & \\
\hline \multirow[t]{2}{*}{ West Virginia } & 1 district & & & & & & 1 & \\
\hline & 0 schools $R$ & & & & & & & \\
\hline State & $\begin{array}{l}\text { Total \# records } \\
\text { in database }\end{array}$ & $\begin{array}{c}\text { Large } \\
\text { Central } \\
\text { City } \\
\end{array}$ & $\begin{array}{c}\text { Mid-size } \\
\text { Central City }\end{array}$ & $\begin{array}{l}\text { Urban Fringe } \\
\text { of Large City }\end{array}$ & $\begin{array}{c}\text { Urban Fringe } \\
\text { of Mid-Size } \\
\text { City }\end{array}$ & $\begin{array}{l}\text { Large } \\
\text { Town }\end{array}$ & $\begin{array}{l}\text { Small } \\
\text { Town }\end{array}$ & $\begin{array}{c}\text { Rural, } \\
\text { outside } \\
\text { MSA }\end{array}$ \\
\hline \multirow{2}{*}{ Total } & 73 districts & 14 & 24 & 20 & 9 & 1 & 2 & 0 \\
\hline & 98 schools & 24 & 27 & 23 & 13 & 3 & 4 & 0 \\
\hline
\end{tabular}

Note: No data has yet been entered for the following states: BIA, MS, ND, PR, WY

\section{Locales of Districts Receiving SLC Funds: All States}

Large Central City (14)

$(19.72 \%)$

Mid-size Central City' (24)

$(33.80 \%)$
Fiural, inside MSA (1)

(1.41 z)

Rural, outside MSA (0)

(0.00\%)

Small Town (2)

(2.82\%)

Large Town (1)

(1.41\%)

Urban Fringe of Wid-Size City (9) (12.68\%)

Urban Fringe of Large City (20) (28.17\%) 


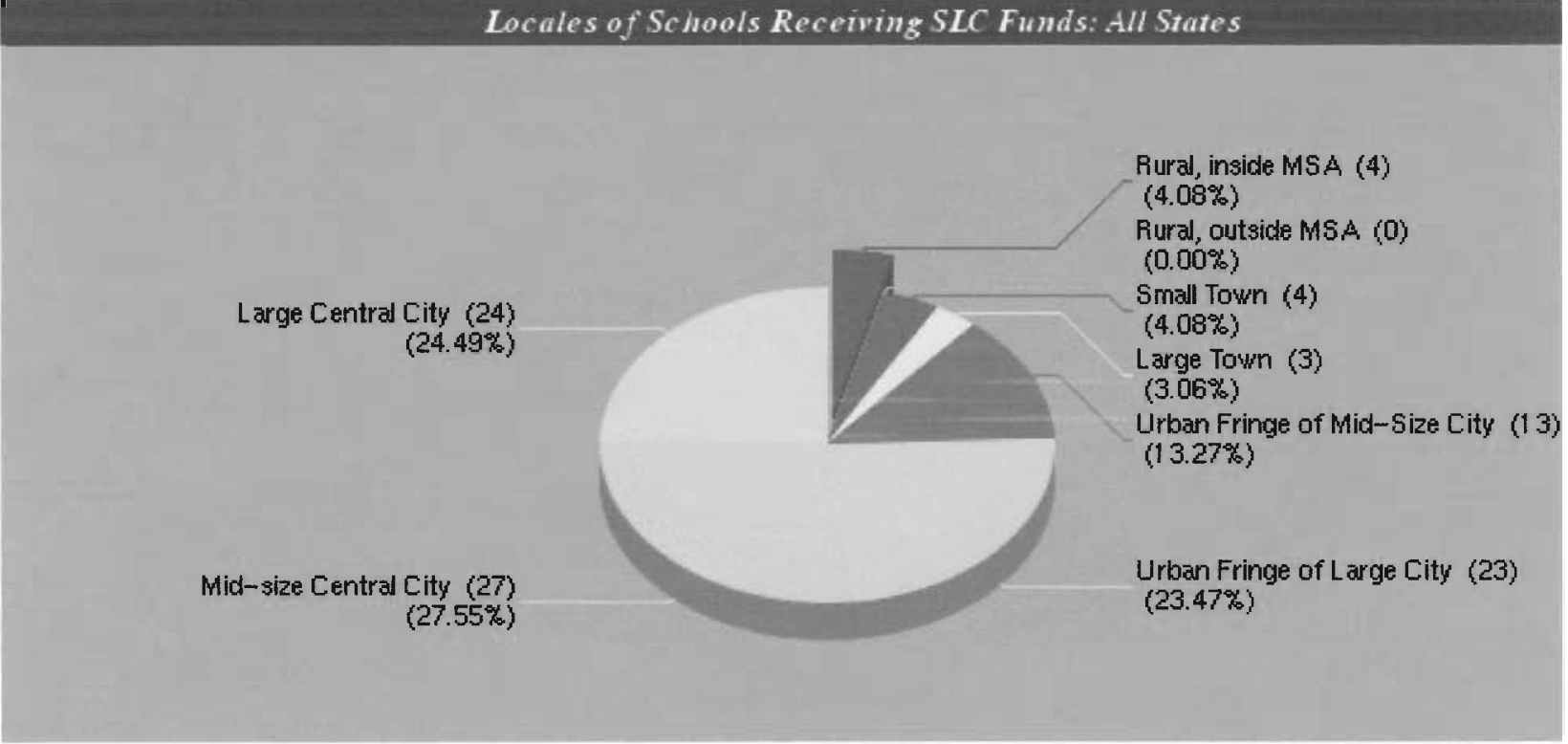

If you have a question about the SLC database, please send an e-mail to Lacy Wood at Iwood@se 


\section{Sara Lewis-Stankus- VITA}

Education

Licensure, Certification and Specialization

\section{Experience}

West Virginia University: Completed all course work for Doctorate in Advanced Educational Leadership. GPA: 3.9 Overall.

West Virginia Graduate College, Master of Arts, GPA: 3.9 Overall. Graduation Date: 12/94. Major: School Counseling PreK-12, Areas of Emphasis: Community Agency, Correctional and Career Development Counseling; Included Substance Abuse Education/Marriage \& Family Counseling.

West Virginia Wesleyan College, Bachelor of Arts, GPA: 3.4 Overall. Graduation Date: 12/89. Double Major: Elementary Education \& Specific Learning Disabilities K-12. Reading Specialization.

Licensed Professional Counselor (L.P.C.) License \# 1315, Nationally Certified School Counselor, Nationally Certified Counselor, State Certified School Counselor K-12, Certified Principal, Certified General Supervisor, Certified Superintendent, Certified Elementary Education Teacher K-8, Certified Specific Learning Disabilities Teacher K12 and Reading Specialization K-12. Certified Life Skills Trainer, Certified NOT (Not On Tobacco) Trainer/Facilitator, Certified Ruby Payne "Understanding the Structure of Poverty" Trainer.

\section{Upshur County Board of Education, Buckhannon Upshur High School,} Buckhannon, WV 472-3720, Principal: Don Swisher. Sept. 2001 to present. Job Title: School Counselor. Work with secondary students in preparation for post secondary experience. College going, financial aid, scheduling, Individual/Group Counseling, Teen Institute, Raze, and TATU Advisor, Leo Advisor (2004),Collaboration with \& referral to outside agencies, teacher consultation, Parent Contacts, Supervisor WWWC Bonner Scholars, Tutoring Program. Work closely with community agency/business to support strong partnerships for scholarship participation. Supervised four new counselor interns from both Marshall and WVU.

Marshall University, Huntington, WV, /Supervisor: Dr. Robert Rubenstein, Job Title: Faculty/ Supervisor Counseling Interns. Supervised Masters level students who were completing their counseling internships/practicum's in agency and school settings.

\footnotetext{
Upshur County Board of Education, Union/Hodgesville Elementary, Buckhannon, WV 472-5480, Supervisor: Allen Beer, Principals: Roy Pettit, Ann Mickel. Date: October 2000 to 2001. Job Title: Elementary School Counselor. Implementation of "Climbing The Mountains of Intolerance" Grant. Serve in two elementary schools. Responsible for developmental guidance, Get Real About Violence Program Maintenance, Individual/Group Counseling, Peer Mediation Training/Program, Collaboration with \& referral to outside agencies, teacher consultation, Parent Contacts, Supervision of WVWC Counseling Interns.
} 
Elkins Middle School, Elkins, WV 636-9176, Principal: David Roth, Date: 9/97 to 10/00. Job Title: School Counselor Grades 6-8. Responsiblities: Individual/Group Therapy, Career Counseling/advising, Test Interpretation/administration, develop/implement transition plans/activities for $6^{\text {th }} \& 8^{\text {th }}$ grade students, Coordinate Day on Campus, Plan Career Shadowing through business school, Training staff at EMS in specialized areas (i.e. Domestic Violence, reporting child neglect/abuse, tolerance) Responsible for school-wide drug ed./prevention programs. Implementing and designing the Respect \& Protect.

National Health Promotion Associates, Hartsdale, NY. National Trainer for the Life Skills Program. Trained in Orlando, Florida. This is a drug prevention/intervention program delivered in the classroom setting.

West Virginia State Department of Education, Charleston, WV. Life Skills Trainer 98/99 to present. Assisted in training over 800 teachers during the summer /school year of 99/2000. Currently training teachers throughout the state. Contracted by State Dept. to develop training agendas for trainers.

Aha! Process Inc., January 2000 to present, Trained in Las Vegas, Nevada as a Certified Trainer using Ruby Payne's Model "A Framework For Understanding Poverty" Worked through WVU to present a class to Upshur County Teachers Sept. 2002- Jan. 2003. Presented County Staff Development to all service personnel.

Robert Bland Middle School, Weston, WV. Principal: Marcella Linger, Date: 9/92 to 6/97, Job Title: Teacher Subject Areas: $6^{\text {th }}$ grade SLD English, Reading, Math, \& Study Skills. Provided academic support \& intervention to students with single or multiple disabilities. IEP writing/implementation. LRE designed inclusion plans/modifications in collaboration with regular ed. Teachers.

East Main Elementary School, Main Street, Buckhannon, WV. Principal: Libby Lee, Date: 9/90 to 6/92. Position: Adapted Second Grade Teacher.

Upshur County Board of Education, Buckhannon, WV. Substitute Teacher; $12 / 89$ to $6-90$. 


\section{Sara Stankus- VITA}

\section{Listed below is specific expertise in various leadership areas and related professional activities.}

\section{Curriculum development and assessment at the school, county, and/or state levels.} During my experience at BUHS, I have worked hand-in-hand with principals in charge of curriculum. In addition to my formal training at RESA, Mr. Don Dolan trained me to analyze data to determine master schedules. During this process we recognized the importance of teacher involvement in development of a master schedule. I also worked with Mrs. Sherry McDaniels, associate principal in charge of curriculum to enter master schedule, student schedules and course design. During this process, curricular offerings that assure both academic rigor and remediation for students at all levels were offered.

I served on the school curriculum team at Buckhannon Upshur High School from 2001 to 2004. When working in a large secondary school with nearly 1200 students it is inevitable that as counselor I become involved in curriculum development. The administrative team continually considers possible new electives, acceleration for students who desire academic challenge and remediation for those students that need more academic assistance. Vocational education as well as other specialized programs at the high school level continues to challenge the curriculum design at BUHS. I worked closely with Mike Cutright, director Fred Eberle Technical Center and Linda Cronin our regional Tech Prep representative to assure increase and success of vocational programs at BUHS.

Throughout my career I have maintained a strong interest in curriculum and curriculum development. When working as a counselor in the elementary schools, it was necessary to choose quality developmental guidance curriculum. We worked as a team of counselors and maintained researched based programs throughout Upshur County. When I taught second grade at Main Street Elementary, in an "Adaptive Second Grade" classroom, in which the students had completed a year of second grade and came to this classroom for remediation. I designed the curriculum that best suited the student's need. When working as special educator, again the IEP was designed to assist in choosing curriculum, modify curriculum and provide academic support that would allow the student to succeed in the given setting.

\section{WVDE Cadre:}

I have worked with WVDE, Office of Healthy Schools and a specialized Cadre of trainers, training Middle School Teachers throughout the state in the Life Skills Program. In addition, we trained the teachers in Philadelphia School Districts using the same model. I was also contracted to develop and create an annotated trainers agenda and training modules that would condense the training for multi-leveled teachers.

\section{Classroom Management:}

My training in classroom management is extensive. I have taught at the elementary and middle school level. In addition my experience as an elementary, middle 
and high school counselor have given me experience at all levels in the classroom. My graduate work in counseling is a basis of understanding human behavior and a foundation for effectively working with students/adults in the classroom or any other setting.

My undergraduate training is in special education. This program of study has provided specific training with behavioral disordered students, learning disabled, $A D D / A D H D$, etc.

\section{Technology:}

At Buckhannon Upshur High I have worked with the administrative team in development of the master schedule. This involves extensive use and training in WVEIS. Following the conclusion of each midterm and semester report, I supply principal Swisher with data regarding academic progress by grade, curricular areas and individual teacher. This data is used to remediate or identify weak areas.

I worked with the Healthy Schools Master CADRE to develop CSHP (Coordinated School Health Program) modules to present to various community, civic and school groups and am very comfortable using Word, power point, emailing, and other aspects of basic technology. I have served on various school teams to develop technology plans to increase available technology in school settings.

\section{Organization and Management}

My work in the educational leadership doctoral program has provided the groundwork for a strong organization and management training. My area of concentration is in educational administration. The necessary course work and experiences such as the Evaluation Leadership Institute have provided a strong base of organization and management. In addition to knowledge, my experience as a counselor certainly requires both organization and management expertise. Currently, I am working in a school with nearly 1200 students and approximately 150 staff. I am one of three counselors; this requires both organization and management!

\section{Scientifically Based Research}

The training as a trainer in the Life Skills Program (a scientifically based research program) has increased my understanding of the importance of such programs. During this training we used and advocated information and programs endorsed by the CDC. Programs that are based on scientifically based research are proven effective $\sim$ an ESSENTIAL ELEMENT in prevention!

I served as the coordinator for the research conducted at Elkins Middle School; we were selected as the site for the baseline data for the Life Skills Program.

\section{WVDE Staff Development Presenter}

I have conducted staff development for Upshur County Schools and Randolph County Schools. I am trained and certified as a National Trainer for the Ruby Payne 
Model "A Framework For Understanding Poverty." I have also trained staff members in the Life Skills Training and Asset Building Models.

\section{Presentation Skills}

My training, knowledge, experience and skill level provide the basis for positive presentation skills. My desire and love for working with those persons who are interested in working with children is the greatest asset that I hold. I truly enjoy presenting to adults $\sim$ especially educator! Working with a team of trainers over the past 5 years has enhanced my presentation skill level. The team approach is one that allows each member to receive honest feedback from other professionals.

\section{Instructional Strategies:}

My skill and instructional strategies were increased during my work as an elementary and middle school teacher. However, as a counselor, I am frequently going into the classroom to present information/programs or offer developmental guidance programs. These are experiences that continually strengthen my instructional strategies. My training as a trainer has also encouraged my instructional strategies and expertise when presenting to adult audiences.

\section{Leadership:}

Leadership is not just for administrators. Leadership is a competency in which you can learn to expand your perspectives, set a goal, understand human behavior and then take the initiative to get where you want to be. My work in the educational leadership doctoral program provides the knowledge base for good leadership decisions. My experience in the work place maintains my status as a person who is consulted in decision-making at the administrative level.

\section{A) TEACHER WORKSHOPS I HAVE CONDUCTED IN THE PAST THREE YEARS.}

$>$ A Framework for Understanding Poverty - Trained service personnel in the county in the Ruby Payne Model for understanding poverty - staff development. 10/18/02.

$>$ Life Skills Training - Training for Berkley County Schools- Donna Kuhn Coordinator.

$>$ Life Skills Training- Philadelphia School District teachers in the Life Skills Program.

$>$ WV University - Worked with a team of presenters. Taught a class using Ruby Payne's Model for Understanding Poverty. Class participants were Upshur County School Teachers. College Credit.

$>$ Raising Your Young Child in A Violent World- Hosted by the Family Involvement Team \& Stockert Youth- Presented to Parents of preschool children- Upshur County.

> WV Health Cadre- Presentation of Coordinated School Health Programs. Presented to various civic and school organizations. 
Tolerance Training-Staff development. Elkins Middle School. Worked with Judy Kramer, trained through the Dept O Justice.

> Responding to Domestic Violence-How to respond to children who are living with domestic violence, interventions, etc. Elkins Middle School Staff. Randolph County Staff Development.

$>$ Reporting Child Abuse/Neglect- The basics of reporting and intervention planning for children of abuse/neglect. Randolph Co./EMS Staff Development

TATU Training - Teens Against Tobacco Use - Trained over 50 teens in the TATU model. Worked with ALA and Greg Knight our Tobacco Specialist.

$>$ Peer Mediation- Trained nearly 100 Upshur County Elementary Students in the Peer Mediation Model. WVWC. Worked with teachers/counselors to implement.

Asset Development Training- Worked as a community specialist for the Stockert Youth Foundation in Buckhannon.

$>$ Family Support Groups-Worked through a grant and the Stockert Youth Foundation in Buckhannon. Offered weekly parent trainings - various weekly topics. March 29-May 17,2000.

> Family Wellness Program facilitate Family Wellness Sessions. Sponsored through FRN and Family Wellness Grant monies. 6 sessions over 3 months. March29-May 17, 2001.

$>$ Life Skills Training - WVDE trained teachers state wide in the Life Skills Program.

$>$ ACT STUDY/PRACTICE NIGHTS- Students from BUHS prepare for ACT.

$>$ SAT Training- Student Assistance Team Leader Training- Prepare agenda, train SAT Leaders from each elementary, middle and High school in our County. Trained with Renee Warner BUHS. 